\title{
Digital Media and Textuality
}
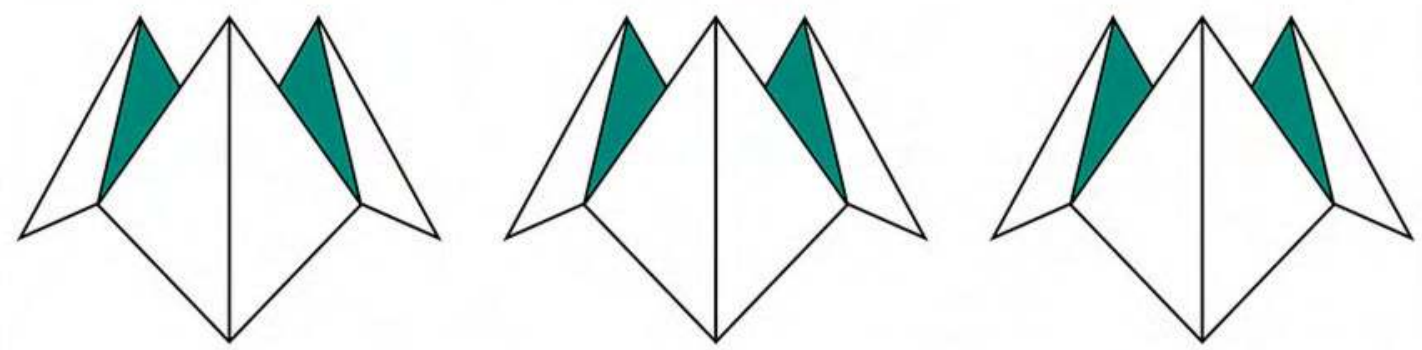

From Creation to Archiving 
Daniela Côrtes Maduro (ed.)

Digital Media and Textuality 
The series "Medienumbrüche / Media Upheavals" is edited by Peter Gendolla. 
Daniela Côrtes Maduro (ed.)

\section{Digital Media and Textuality}

From Creation to Archiving 
This book has been supported by the Institutional Strategy of the University of Bremen, funded by the German Excellence Initiative.

An electronic version of this book is freely available, thanks to the support of libraries working with Knowledge Unlatched. $\mathrm{KU}$ is a collaborative initiative designed to make high quality books Open Access for the public good. The Open Access ISBN for this book is 978-3-8394-4091-9. More information about the initiative and links to the Open Access version can be found at www.knowledgeunlatched.org.

\section{RII}

Bibliographic information published by the Deutsche Nationalbibliothek

The Deutsche Nationalbibliothek lists this publication in the Deutsche Nationalbibliografie; detailed bibliographic data are available in the Internet at http:// dnb.d-nb.de

\section{(c) $)(1)(\Theta$}

This work is licensed under the Creative Commons Attribution-NonCommercial-NoDerivatives 4.0 (BY-NC-ND) which means that the text may be used for non-commercial purposes, provided credit is given to the author. For details go to http://creativecommons. org/licenses/by-nc-nd/4.0/

To create an adaptation, translation, or derivative of the original work and for commercial use, further permission is required and can be obtained by contacting rights@transcriptpublishing.com

Creative Commons license terms for re-use do not apply to any content (such as graphs, figures, photos, excerpts, etc.) not original to the Open Access publication and further permission may be required from the rights holder. The obligation to research and clear permission lies solely with the party re-using the material.

\section{() 2017 transcript Verlag, Bielefeld}

Cover concept: Kordula Röckenhaus, Bielefeld

Cover illustration: Daniela Côrtes Maduro and João Rui: Cootie Catcher theme (2016)

Copy editing by Daniela Côrtes Maduro

Layout and Typeset by Daniela Côrtes Maduro

Printed by Majuskel Medienproduktion $\mathrm{GmbH}$, Wetzlar

Print-ISBN 978-3-8376-4091-5

PDF-ISBN 978-3-8394-4091-9

https://doi.org/10.14361/9783839440919

Printed on permanent acid-free text paper. 


\section{Contents}

Daniela Côrtes Maduro

Preface

\section{Part One: "Nothing Comes of Nothing"}

Dene Grigar

Rhapsodic Textualities.

Jörgen Schäfer

Passing the Calvino Test?

Writing Machines and Literary Ghosts.

\section{Part Two: Introspective Texts}

Otso Huopaniemi

Writing Through Contemporary Self-Translation

A Constructive Technogenetic Intervention

Sandy Baldwin and Gabriel Tremblay-Gaudette

Pwning Gamers, One Text at a Time

\section{Part Three: Where is Narrative?}

Carlos Reis

Character: A Concept That Does Not Stand Still 75

María Goicoechea de Jorge

Shelley Jackson's Grotesque Corpus

Notes on my body-a Wunderkammer. .87

Daniela Côrtes Maduro

Choice and Disbelief: Revisiting Immersion and Interactivity 107 


\section{Part Four: Teaching the Digital}

María Mencía

Creative Process: Interweaving Methods, Content and Technology .... 133

Mia Zamora

Distilling the Elements of "Networked Narratives" with Digital

Alchemy 151

\section{Part Five: Trans-Multi-Inter-Meta (The Medium)}

Anna Nacher

The Creative Process as a "Dance of Agency"

Shelley Jackson's Snow: Performing Literary Text with Elements

María Teresa Vilariño Picos

Narrative Across Media: Trans-Stories In-Betweeness 187

\section{Part Six: Tracking and Preserving Texts}

Devon Schiller

Face, a Keyword Story

The Archiving Vocabulary for Facial Expression in the German Imaginary

from Printed Text to Digital Image.

Daniela Côrtes Maduro

Curating "Shapeshifting Texts".

Frieder Nake

\section{Postscript}

Loosely Connected to What It's Coming After

Contributors 


\section{Preface}

Despite the fact that the concept of "text" is unstable and in constant shift, texts have not been able to surpass their root meaning. As we know, the term "text" is linked with the word "to weave" (Ong 13). Whether inscribed on paper or displayed in computer screens, texts have remained as fabrics comprised of a set of symbols or formulas, as well as intricate combinations of elements. Even though they are believed to be mostly comprised of words, images and graphic elements are often used as the interweaving thread holding texts together. Digital media seem to reinforce this idea, and to demonstrate that texts are not anchored in verbal language.

Since the introduction of computers, we have watched texts being turned into superimposed windows; into chunks of verbal and graphic material; footnotes interconnected by links (Landow 3); audio and video files; strings of letters that become images, or messages popping up on the screen of our mobile devices. We knew already that texts could be read, performed or listened to. However, digital media have provided alternative forms of contact between text and user, as well as further ways to combine semiotic modes. The act of reading is no longer exclusively related to the process of decoding letters or interpreting static images, but it is also linked with an invitation (or challenge) to assemble, play, activate, download or install. Besides scrolling up and down and zooming in or out, a reader can experience a text by moving across a room, touching a screen or speaking into a microphone. Sounds and gestures initiated by the reader can morph into words, letters or pictures displayed on a wall or a computer screen. In fact, digital texts need the cooperation of several languages (such as machine or assembly languages) in order to be understood by a human. The underlying code allows a text to generate itself and to shapeshift right before our very eyes. Thus, digital texts do not merely remain at the surface: they exist elsewhere, in our devices, or spread across the web. Locating the text—or bringing it to the surface—has become an intrinsic part of the reading act.

Digital media also allow readers to share their texts instantaneously. From self-generated poetry to beguiling bots, digital media have allowed the creation of additional ways to defy the role of the author. In so doing, they pose new challenges concerning publication, copyright, archive and access to information.

The implications of all these changes are analyzed in the essays included in this collection. Thus, the reader of this anthology may find unexpected connections between apparently disparate topics. Comprised of six parts, this book aims to offer the reader a broad perspective over the relationship between text and digital media, from creation to archiving of digital texts. The 
first part, "Nothing Comes of Nothing" presents an essay written by Dene Grigar, where a link between electronic literature and oral tradition is emphasized. In the same part, we can read Jörgen Schäfer's text whose title, as the reader may notice, is based on Italo Calvino's stimulating essay and Alan Turing's influential test. While reading this first part, we are reminded that electronic literature is not born ex nibilo (Hayles 60). In fact, electronic literature continues a dialog established long before digital computer was created.

The second part, "Introspective Texts," is focused on the way texts can be self-reflexive and mirror the process of their own creation or reading (Portela 25). The essay shared by Otso Huopaniemi explores a link between machine translation and self-translation. In the same part, Sandy Baldwin and Gabriel Tremblay-Gaudette underline a connection between poetry and video games by analyzing a performance which turns a game into an introspection about literature.

In the third part ("Where is Narrative?"), the reader will find essays about the way digital media can be used to tell a story or build a narrative. The essay written by Carlos Reis is focused on the survival of characters in (digital and print) fictional worlds. María Goicoechea De Jorge describes Shelley Jackson's work, my body - $a$ Wunderkammer, as an exploration of the grotesque. In an essay about choice and disbelief in digital fiction, the reader is invited to revisit the debate around the concepts of immersion and interactivity, as suggested by Marie-Laure Ryan.

The reader will also find a part focused on digital literacy and the teaching of electronic literature. In "Teaching the Digital," María Mencía argues for the benefits of adopting a practice-based research inside the classroom. In the same part, Mia Zamora offers us the opportunity to know Networked Narratives, both a course and a project designed to promote digital literacy.

The third part, "Trans-Multi-Inter-Meta (The Medium)," aims to describe the role of the medium in the production, transmission and comprehension of texts, as well as to evaluate the conditions of media interaction, convergence, and divergence. Anna Nacher analyses materiality by focusing on the intermedial component of Shelley Jackson's work, Snow (2014-). In this part, María Teresa Vilariño Picos shares her reading of several transmedia stories.

The final part, "Tracking and Preserving Texts," presents essays concerned with the process of gathering and archiving texts. In this part, the reader will have the opportunity to know Devon Schiller's research about vocabulary for describing facial expressions. An account of my experience as the curator of the exhibition "Shapeshifting Texts" is also shared with the reader.

This collection culminates with an enticing and thought-provoking postscript written by the pioneering artist and professor, Frieder Nake. 
I would like to thank the authors whose dedication has made this book possible: Sandy Baldwin, Dene Grigar, Otso Huopaniemi, María Goicoechea De Jorge, Anna Nacher, Frieder Nake, Maria Mencía, María Teresa Vilariño Picos, Carlos Reis, Jörgen Schäfer, Devon Schiller, Gabriel Tremblay-Gaudette and Mia Zamora. I would also like to thank the members of the "International Conference on Digital Media and Textuality" (ICDMT) scientific committee, and the following scholars: Joshua Enslen, Monika Górska-Olesińska, Davin Heckman, Angelica Huízar, John Mock, Søren Pold and Manuel Portela.

The "International Conference on Digital Media and Textuality" (ICDMT) was supported by the University of Bremen and by the Excellence Initiative. I am truly grateful to this institution for all the support provided.

My sincere thanks to Jörgen Schäfer and Peter Gendolla for including this book in the Media Upheavals series.

To João Rui, and to my parents, thank you.

Bremen, August 2017

Daniela Côrtes Maduro

\section{Works Cited}

Hayles, N. Katherine. Electronic Literature: New Horizons for the Literary. Notre Dame: University of Notre Dame, 2008.

Landow, George P. Hypertext 3.0: Critical Theory and New Media in an Era of Globalization. Baltimore, MD: John Hopkins University Press, 2006.

Ong, Walter. Literacy and Orality. New York: Routledge, 1982.

Portela, Manuel. Scripting Reading Motions: the Codex and the Computer as Selfreflexive Machines. Cambridge, MA: MIT Press, 2013. 



\section{Part One: \\ "Nothing Comes of Nothing"}





\section{Dene Grigar}

\section{Rhapsodic Textualities}

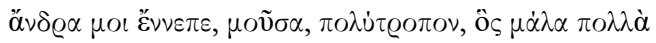

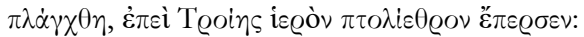

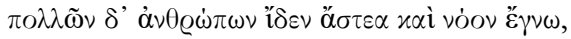

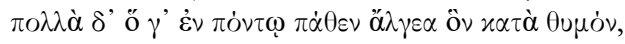

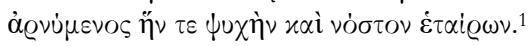

Homer, Odyssey

I am buried here. You can resurrect me, but only piecemeal. If you want to see the whole, you will have to sew me together yourself. Here Lies a Head, Trunk, Arms (Right and Left), and Legs (Right and left) as well as divers Organs appropriately Disposed. May they Rest in Piece.

Shelley Jackson, Patchwork Girl

In Writing Machines (2002), N. Katherine Hayles argues for electronic textuality, a condition of text that includes "signifying components" such as "sound, animation, motion, video, kinesthetic involvements, and software functionality" (20). Calling her approach to analyzing non-print texts "media-specific analysis" (29-31), she broadens the scope of literary criticism to attend to interaction common in hypertextual works where the user-audience experiences a text by kinesthetically combining and recombining lexias of text made possible through computer programming language and code. Such recombinatory structuring, according to Bill Seamen, allows a type of poetics where each "media-element ... convey[s] its own field of meaning" and the user-audience "becomes dynamically involved in the construction of meaning" (Seamen, "Recombinant" 157-158). I refer to this recombinatory quality of text as rhapsodic textuality.

While Hayles and Seamen theorize specifically about digital texts, we see this mechanism at work in ancient, epic literature where units of texts and whole episodes are believed to have been stitched together in performance by singers, known in the $5^{\text {th }}$ and $4^{\text {th }}$ centuries BCE, as rhapsodes. Derived from the Greek word rhapsodein ( $\dot{\rho} \alpha \psi \omega \delta \varepsilon \tilde{i} v)$, meaning "to sew songs together," rhapsody today implies a musical improvisation, one relayed episodically yet maintaining narrative integrity for the audience.

I argue in this essay that Shelley Jackson's Patchwork Girl (1995) is, like Homeric epic poetry, rhapsodic and that this quality of textuality constitutes the work's poetics. Scholars and critics have long identified Patchwork Girl as 
one of the major works of electronic literature. In "Electronic Literature: What Is It?" (2016) Hayles herself hailed it as "important and impressive" and called it "a culminating work for the classical period [of hypertext literature]" (200). Along with Michael Joyce's afternoon: a story (1987), it has long ranked high in the pantheon of electronic literature, which, to date, constitute the only works of the forty-three published by Eastgate Systems, Inc. on diskette or CD-ROM that have been migrated to a format accessible by contemporary computers. It is precisely because Patchwork Girl stitches together bits of texts, assembled and re-assembled during a reading or performance, with potentially many possible tellings _ each resulting in, while not a "textual whole" (Eskelinen 70), certainly a coherent experience for the user-audience-that the work has achieved its recognition as an important literary work. That it uses the metaphor of stitching the body of the Frankenstein monster for the sewing together of its many lexias of the hypertext only adds to the playful orchestration of the work.

My notion of rhapsodic textuality aligns with Daniela Côrtes Maduro's notion of "shapeshifting" - that is, the ability for literature to "self-renew" by "chang[ing] its form" — and to her argument that shapeshifting can be found in oral, print and electronic literature. ${ }^{2}$ I suggest that the potential to shapeshift is a feature of rhapsodic textuality.

In regards to Homer's rhapsodies, the work we know as the Odyssey, for example, was sewn together, according to Milman Parry, "by many [people] over many generations" (li) from several sources over time. References to the Trojan War can be loosely dated to $1250 \mathrm{BCE}$, while episodes focusing on Odysseus's journey, books 9-12, where he encounters the monsters Cyclops, Sirens, and Charybdos and Scylla are believed to be derived from very ancient folk tales that pre-date the war by hundreds of years. John Finley argues that such compositions arise from legends of heroes that "passed from generation to generation but [were] freshly used and slightly changed by each age and singer [enabling] singers to compose complete verses as they went along" (5).

It is believed that the work was performed in its totality from memory, beginning $566 \mathrm{BCE}$ at the Panathenae festival held in celebration of Athena's birthday during last $1 / 2$ of July and first $1 / 2$ of August, which was the first month of the Athenian year. The length of the epic-12,110 lines-however, required several performers in succession to present it at the event. Because of the amount of time it took to perform the work, it is believed that it was more often presented at other events by performers who recited their favorite episodes or targeted specific parts of the story to a particular audience (Doherty). Odysseus and Penelope's reunion where she tricks him into revealing himself as her husband is believed to have played well to an audience containing women. His defeat of the dangerous suitors at the end of the story may have been recited when the theme called for an example of heroism and male virility. And the 
loss of his men on the sea following their devouring the Sun God Helios' sacred cattle may have taught the ethical lesson about human folly and hubris against the gods. Performers of the Odyssey were believed to be adept enough to shift through the narrative from episode to episode, by word or phrase, based on the audience's reaction, stitching a performance together on the fly. Performed in this way, the Odyssey contains the potential for multilinear storytelling, though it was indeed assembled in the form that we have to today as one continuous written story with a beginning, middle, and end, long after it had been an oral experience. But as an oral epic, more often than not, it was recited in bits and pieces in a way that defies the notion of this very unilinear structure. Key to rhapsodic textuality is this very quality to relay a coherent and satisfying user-audience experience whether the story is relayed in parts or assembled as a whole, over time.

Patchwork Girl was published in 1995 by Eastgate Systems, Inc. on diskette and re-released on CD-ROM in 2000 and most recently, in 2014, on a USB stick. It was produced with the company's own proprietary software, Storyspace, a hypertext authoring system used by artists in the early 1990s to early 2000s. For authors wanting to experiment with writing for the electronic medium, Storyspace provides affordances like hyperlinking between textual units and opening up the text to multimedia reading paths. As a Storyspace hypertext, Patchwork Girl utilizes the structure of nodes and links to tell the story of the female monster created by Mary Shelley whose body is stitched together from body parts of other women. In total, Patchwork Girl contains 323 lexias, 462 links, and 45,000 words.

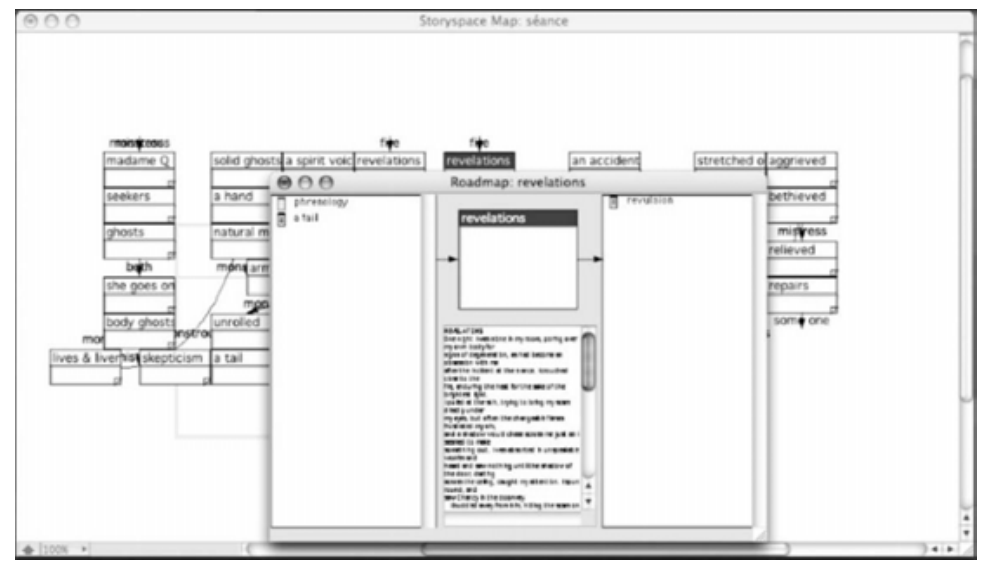

Fig. 1. Nodes and links found in Shelley Jackson's Patchwork Girl. 
Drawn from both Mary Shelley's Frankenstein, first published in 1818, and L. Frank Baum's The Patchwork Girl of Oz (1913), the story has been read as a commentary on feminist issues relating to authorial voice, women's body, society role and expectations, and image of self as other (Odin 58).

The narrative is organized into five threads: a graveyard, a journal, a quilt, a story, and broken accents. No particular order is required for moving through the hypertext. We can click on any of the threads to experience the work. Clicking on "graveyard" in the list takes us to the graveyard node where we can see more nodes nested inside. Clicking on the body of the node, we encounter the line: "I am buried here. You can resurrect me, but only piecemeal. If you want to see the whole, you will have to sew me together yourself." Clicking on the text gives us:

\author{
Here Lies a Head, \\ Trunk, Arms (Right \\ and Left), and Legs \\ (Right and Left) \\ as well as divers \\ Organs appropriately \\ Disposed.
}

May they Rest in Piece.

The work continues through this pattern of clicking on words and following links. As mentioned previously, no set path is laid out for the user-audience. We experience the work as bits and pieces not unlike the Patchwork Girl herself.

In the fall 2014, Stuart Mouthrop and I videotaped Shelley Jackson performing a Traversal of Patchwork Girl as part of the Pathfinders project, funded by the National Endowment of the Humanities. A Traversal is "audio and video recording of demonstrations performed on historically appropriate platforms" (Moulthrop and Grigar 5). In this regard, Jackson performed the work using the 2000 CD-ROM version of the work on a "graphite" Power Mac G4 Tower that had been released by the Apple Corporation in 2001, certainly the computer her audience may have used upon the release of this particular version. Traversal videos were edited into four clips ("Unweaving the Poetic Narrative," "Confronting the Monster," "Stitched Remix," and "Parallel Patches") and, along with other media, such as images and sound files, were made available in an open-source, multimedia environment built on the Scalar platform. The advantage of producing videotaped Traversals is obvious: they provide documentation of the work, particularly the interactive and hypertextual ele- 
ments that cannot be captured in a still image. Unlike Homeric epics where we have to rely on textual scholars from the $18^{\text {th }}$ century onward to figure out how the work was constructed and performed, video documentation of Shelley Jackson's Traversal means generations after ours can hear directly from Jackson how she conceptualized her work.

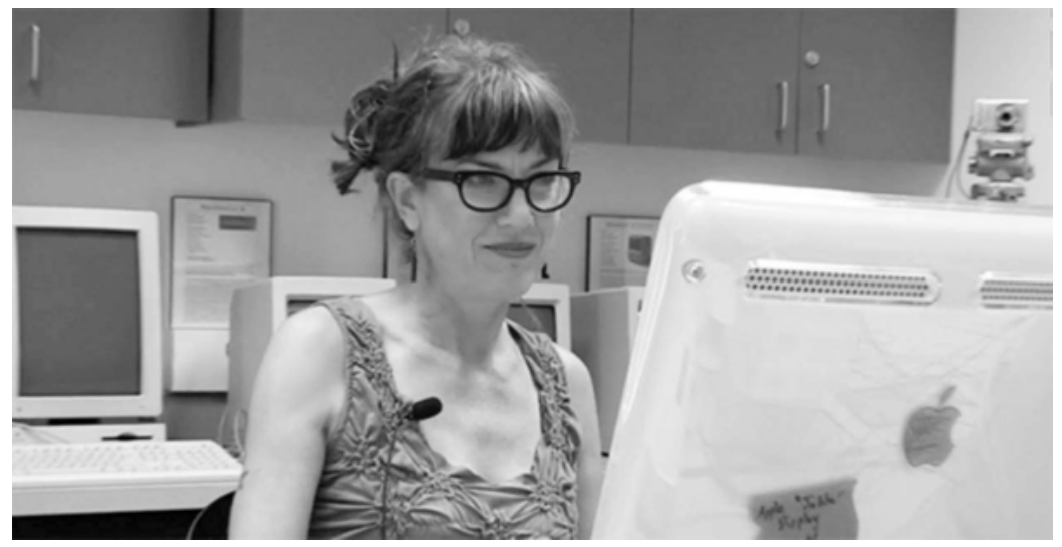

Fig. 2. Shelley Jackson at her Traversal.

For example, in the Traversal entitled "Confronting the Monster," Jackson talks us through her process of navigating through the text. She tells us that she decides to jump from the word “journal” to Mary Shelley's "account"-which is actually authored by Jackson—where Mary confronts her own monster. Once Jackson reads this piece of the story, or lexia, she is faced with a decision. She can hit the return key and move to a lexia that follows or she can choose among two phrases, "one written" and "one sewn," that are linked with other words in other lexias. These, she tells us, represent the "parallel paths" that she developed throughout the work. The parallel paths in this case relates to the body in the sense of "a body of text" and a literal body that must be sewn together. "Writing becomes," Jackson says, "like stitches, and stiches become like writing," and it is up to the reader to decide which direction to go. Like a rhapsode reciting a favorite episode for an audience, Jackson does the same for us by taking us through segments of the story she wished to highlight.

But the stitching to which she refers reflects not just the techne of sewing but also design of the fabric itself. Like the Odyssey that was stitched from tales well known by his audience, Jackson, as mentioned previously, stitches her own text from two with which we are familiar: Mary Shelley's $19^{\text {th }}$ century novel Frankenstein: or The Modern Prometheus and Frank L. Baum's The Patchwork Girl of $\mathrm{O}$. The genesis of Mary Shelley's story most of us are acquainted with: 
during the summer of 1816 Mary Shelley, her husband Percy Bysshe Shelley, Lord Byron, and others vacationed together at Lake Geneva. In the evenings, the group recounted "Old German ghost stories" to one another. On a dare, they all tried their hand at creating their own frightening tale. Mary Shelley's idea came to her one evening in a dream about a "hideous phantasm" (Shelley 9). So well conceived was hers that she was encouraged to finish it as a novel, which she did. However, it is important to note that the ghost tales from which her story was woven were themselves sewn together out of German folklore tradition that developed over centuries and reflected many cultural influences that were remixed and emerged influential to German nationalism. They were themselves already stitched together over time and then re-stitched by Mary Shelley into Frankenstein. A century later, Baum stitched his own tale out of Mary Shelley's, giving us his patchwork girl, which Shelley Jackson then borrows for in her novel.

Midway through this clip, Jackson tells us that she is clicking through a section that is "quite linear" so that she can get to the place in the story where Mary Shelley makes love to her monster. Jackson then tell us that she plans to "jump back" to the original overview where she can access the lexia relating to the "Graveyard." Storyspace hypertexts often made it possible to hit the return key and move along a predetermined path, riding, as Michael Joyce calls in his preface to afternoon: a story, "a wave of returns." Just as likely, one would spend time selecting a direction to go when encountering choices, as Jackson does when she encounters multiple paths to follow. Thus, within these hypertexts was the potential for many ways of reading and performing the work. The proverbial Borgesian forking path that Jackson confronts has the potential of revealing the composition of both the Monster's body and the body of the hypertext. Likewise, we find a similar forking path construction throughout the Odyssey. Homer's frequent use of the Greek conjunction, $\mu \varepsilon \nu \delta \varepsilon$ [on the one hand and on the other] signifies the mindful deliberations Odysseus often made when faced with a choice. A simple word search of the epic turns up well over 500 uses of this conjunction. George E. Dimrock argues that Homer used this construction as a way to maintain unity while at the same time to include "probability in his plot" (22). It's worth noting that Jay David Bolter, who along with Michael Joyce created Storyspace, was trained in the Classics and so may have very well have been familiar with the use of this Greek conjunction to denote choice.

The video clip continues approximately for a minute after the previous one with Jackson explaining the way she had constructed the lexias pertaining to the various body parts that comprise the Monster. She brings up the head of the Monster and shows us that she can "move" the lexia containing the head around and so reconstruct the body visually. Audiences listening to rhapsodes 
singing the Odyssey or Iliad would have been able to compose and recompose text by interiorizing it in the mind (Ong 9), much as Jackson reconfigured it kinesthetically on the screen.

Homer's epics were composed in a very consistent dactylic hexameter and with formulaic expressions. It is believed that this compositional approach is common to oral, epic poetry (Ong 21) and is built out of the affordances and constraints of the oral medium. Extrapolating from contemporary Hungarian heroic epic poetry, the great Homeric scholar Parry was able to verify this practice. In the same token, the distinctive feature of Jackson's work is due to the economy enforced on it by electronic methods of composition. This includes both the affordances of the medium and the software: the instantiation of ideas through visual, kinetic, and kinesthetic modalities as well as into Storyspace hypertextual nodes and paths.

Rhapsodic textuality - the quality of being stitched together from prescribed bits of texts, assembled (and re-assembled) during a performance, into a coherent experience, from potentially many possible tellings - is a quality associated with but not limited to hypertext literature like Jackson's and has at its core a long tradition of fluid and audience-centered poetics distinct from print texts. While Walter Ong maintained that "the epic in effect is dead" and "Kazantzakis' continuation of the Odyssey is an alien literary form" (Ong 159), I suggest that Jackson's Patchwork Girl is, like Homeric ancient narrative, rhapsodic, and offers us a new way to describe epic reading experiences in the $21^{\text {st }}$ century. Like the Patchwork Girl herself, it is alive in rhapsodic textuality.

\section{Notes}

1 Translation by Robert Fagles, 1996. "Sing to me of the man, Muse, the man of twists and turns/ driven time and again off course, once he had plundered/ the hallowed heights of Troy./ Many cities of men he saw and learned their minds,/ Many pains he suffered, heartsick on the open sea,/ Fighting to save his life and bring his comrades home."

2 More information available at <https://shapeshiftingtexts.wordpress.co$\mathrm{m} />$. 


\section{Works Cited}

Dimock, George E. The Unity of the Odyssey. Amherst, MA: University of Massachusetts Press, 1990.

Doherty, Lillian. “The Performance of Homeric Epic.” Didaskalia. n.d. < http://www.didaskalia.net/issues/vol3no3/doherty.html>.

Eskelinen, Markku. "Cybertext Poetics." Game Studies, vol. 1, no. 1 (2001). 6 Aug. 2017 <http://www.gamestudies.org/0101/eskelinen/>.

Fagles, Robert, translator. The Odyssey. By Homer. New York: Penguin Press, 1996.

Finley, John. Four Stages of Greek Thought. Stanford, CA: Stanford UP, 1966.

Grigar, Dene and Stuart Moulthrop. Pathfinders: Documenting the Experience of Early Digital Literature. LA, CA: Scalar, 2015.

Hayles, N. Katherine. "Electronic Literature: What Is It?” Doing Digital Humanities, edited by Constance Crompton, Richard J. Lane, and Ray Siemens. London and New York: Routledge University Press, 2016, pp. 197-226.

-Writing Machines. Cambridge, MA: The MIT Press, 2002.

Jackson, Shelley. Patchwork Girl. Watertown, MA: Eastgate Systems, Inc. 1995.

Joyce, Michael. "Preface." afternoon: a story. Watertown, MA: Eastgate Systems, Inc., 1990.

Moulthrop, Stuart and Dene Grigar. Traversals: The Use of Preservation for Early Electronic Writing. Cambridge, MA: The MIT Press, 2017.

Odin, Jaishree. Hypertext and the Female Imaginary. Minneapolis, MN: University of Minnesota Press, 2010.

Ong, Walter. Literacy and Orality. New York: Routledge, 1982.

Parry, Adam. The Making of Homeric Verse: Collected Papers of Milman Parry. Edited by Adam Parry. New York and Oxford: Oxford University Press, 1987.

Seamen, Bill. "Recombinant Poetics." Media Poetry, edited by Eduardo Kac. Bristol: Intellect Press, 2007, pp. 157-174.

Shelley, Mary. Frankenstein, or the Modern Prometheus [1831]. London: Penguin, 1994. 


\section{Jörgen Schäfer}

\section{Passing the Calvino Test?}

\section{Writing Machines and Literary Ghosts}

Le langage articulé n'appartient qu'à l'homme, d'accord. Mais accomplit-il ce miracle, au moyen d'un nombre fini de règles, d'engendrer un nombre infini d'énoncés? Et peut-on en tirer argument en faveur de la place unique occupée par l'homme dans la création? C. Lévi-Strauss and D. Eribon, De près et de loin (1988)

Half a century ago, in 1967, the novelist Italo Calvino delivered his famous lecture "Cybernetics and Ghosts" at various Italian universities. In an inspiring manner, he raised the question whether a computer will ever be able to replace a human poet. He asked whether or not a computer could possibly establish the interplay of linguistic signs, literary conventions, anthropological constants, social roles, and technical media from which literary texts have always emerged throughout history. From the very beginning, Calvino reminds his audience of a primal scene of all literature: a storyteller can use a limited amount of words to tell a potentially unlimited number of stories by selecting and arranging certain words, he puts "the possibilities implied in his own language" into a specific form, "by combining and changing the permutations of the figures and the actions, and of the objects on which these actions could be brought to bear" (Calvino 4). Influenced by Claude Lévi-Strauss' structuralist anthropology, one of the most prominent theories of the mid-1960s, Calvino concludes that the basic narrative operations may not differ much between folks or cultures, "but what can be constructed on the basis of these elementary processes can present unlimited combinations, permutations, and transformations" (6).

It is precisely this dialectic relation between the invariance of patterns or forms and the variation of a limited number of elements that makes Calvino regard computers (at that time large mainframes only) as "electronic brains ... capable of providing us with a convincing theoretical model for the most complex processes of our memory, our mental associations, our imagination, our conscience" (8). Of course, such an analogy between a human brain and a computer is not convincing for us today, neither from the point of view of neurosciences, nor from computer sciences and even less so when Calvino also compares the human brain to a chessboard "with hundreds of billions of pieces" (8). However, if we adopt the view of cybernetic epistemology, Calvino's 
approach of reflecting on similarities between nervous systems, computers and social systems is still a far-reaching conception.

Calvino's answer to his opening question whether a poet can be replaced by a computer is ambivalent. On the one hand, in a perfectly materialist manner, he argues that a poet has always been a writing machine insofar as he combines letters according to defined rules and historically rooted conventions. Consequently, a technical machine should also just as well be able to do this combinatorial work-but in a faster and more efficient way. On the other hand, Calvino doubts that any text produced by such a machine would be distinguished by those specific qualities of fiction, poetry and drama, which scholars so far have analyzed as their "literariness." In order to decide this question, Calvino proposed a thought experiment following the famous "Turing test." The mathematician Alan Turing introduced this test in 1950 to evaluate whether machines can think: a computer would have passed the test and thus had to be regarded as intelligent if a human evaluator was not able to reliably tell the difference between text messages delivered by a computer and those from a human being (cf. Turing). By analogy with this test arrangement, Calvino raises the even more speculative question whether or not a "writing machine" may be developed "that would bring to the page all those things that we are accustomed to consider as the most jealously guarded attributes of our psychological life, of our daily experience, our unpredictable changes of mood and inner elations, despairs and moments of illumination" (Calvino 12).

In this essay, I would like to follow the paths laid out by Calvino by exploring the relationship between language, media, and literary form. To this end, I will look into the history of combinatory literature, particularly of the Baroque period in Germany, and analyze its relations to both the history of ideas and the history of media technologies. Further, I will confront these historical examples of mechanical, as well as computer-aided text-producing machines, with Calvino's claim that works written by a "true literature machine" would have to be accepted by human readers as "literature." Calvino_—and this, I think, is the continuing provocation of his essay-asks for the specific features of "literary" texts, which allow readers to differentiate between "literature" and other forms of linguistic expression.

\section{Reflecting on Language: Rule-based Poetics and Literary Machines}

Calvino was a member of the international, though predominantly French, Oulipo group - the acronym is an abbreviation of Ouvroir de la littérature potentielle [Workshop of Potential Literature]—whose members kept with the long 
tradition of combinatory literature. Jacques Roubaud, for example, even argued that a writer, instead of producing closed works, should only provide "constraints" (contraintes) — or rather algorithmic rules—-to free the potentiality of literature:

The Oulipo is potential literature because the givens of a structure are those of all the virtualities of free objects, if they exist, of all the virtualities of the texts that realize it, necessarily multiple; the unicity of the Oulipian text actualizing a constraint. . . . being then envisaged only on the condition that this texts contain all the possibilities of the constraint - texts and virtual, potential readings: multiplicity again but, unlike that which traditionally results from the multiplication of examples, implicit and, at the outside, imaginary multiplicity . . . exhausted by the very gesture that announces or writes the structure. (Roubaud 95)

However, the Oulipo members have not only been developing their own "constraints," but also investigated and reinvigorated historic examples from the Ancient world, the Middle Ages and the Baroque era, which they ironically qualified as "plagiarism by anticipation" (Le Lionnais 31). By referring to these long-known rule-based procedures, they argued that "inspiration," in general, is a limited and overrated resource. From the Jewish Kabbalah to Ramon Lull's Ars magna generalis ultima (1305-1308), from Athanasius Kircher's famous Ars magna sciendi (1669) and Gottfried Wilhelm Leibniz's Dissertatio de arte combinatoria (1666) to Raymond Queneau's Cent mille milliards de poèmes (1961), and finally to the latest computer-based text generators, there have been lots of examples that can be traced back to only a few fundamental features, but also seem to have guided Calvino's conception of the "literature machine." First, there is a limited stock of signs from which an abundance of texts can be generated by using algorithmic procedures. Second, such text generation requires that the processes of word and sentence formation have to be reproduced in a sort of micro-grammar (cf. Cramer), and finally, it is to be expected that the result of this processing reveals a hidden meaning, something that could neither be predicted by the "author," nor by the "reader."

In German literature, for example, Baroque writers in the $17^{\text {th }}$ century did not consider the successful work of art as an achievement of creative genius but rather adopted and varied poetic methods and procedures. Georg Philipp Harsdörffer, for example, in his Poetischer Trichter (1647-1653) claimed that "[e]ven though quite a few persons are born to create respectable art/ this art is not born with them; it has to be learned/ as everything that humans want to know" (2). ${ }^{1}$ In addition, these poets also sought to enhance the poetic potential of the German language. Linguistic historiography has identified three ap- 
proaches of Baroque linguists for explaining the motivation of linguistic signs. ${ }^{2}$ Justus Georg Schottelius, who was noted for his linguistic patriotism, published a variety of influential studies on German language and literature such as Teutsche Sprachkunst (1641), Teutsche Vers- oder Reim-Kunst (1645) and, above all, Ausfübrliche Arbeit Von der Teutschen Haubt Sprache (1663) that were based on the idea of an "ideal German" preceding any specific language use and directly expressing the true being of things. Unlike these linguistic patriots, the theosophist Jakob Böhme held a mystical view of language and claimed that there is a God-given proto-language. According to Böhme, God in a very literal sense had created things by naming them. Hence Böhme regarded any linguistic activity of human beings only as a reconstruction of intrinsic properties of things (cf. Hundt 49). On the other hand, the linguistic universalism represented by Gottfried Wilhelm Leibniz and others is different from both aforementioned attitudes. Leibniz considered the whole world a closed system, an order of things that can be algorithmically produced and varied from a pre-existing and limited set of elements. The "universalists" were searching for the common grammatical structures of all languages, and beyond this, they were even trying to create an artificial and universal language. All these Baroque linguists and poets, however, have in common that they expected to draw conclusions about bidden organizational and creative principles either from analyzing the rules of word and sentence formation or from implementing mechanical principles into their poetic production.

In his Ausfübrliche Arbeit Von der Teutschen Haubt Sprache (1663), Schottelius claims that any language can be traced back to a limited number of stem words, "which moisten the whole tree of language like succulent roots/ so that its little shoots, its branches and venous twigs can spread assuredly and orderly in their unfathomable variety" (Schottelius 50). ${ }^{3}$ Of course, these stem words do not suffice to name things precisely. According to Schottelius, the complex structure of a language is dependent of varying combinations of words from basic elements. Word stems, word-forming and inflectional morphemes can be combined quite flexibly to create new words exceeding the habitual language use. As the linguistic historian Andreas Gardt argues, words cannot be simply considered a semantic "sum" of its constituents but "rather a set of an atomlike combination of single units" (Gardt 206).

The anagram is certainly the simplest and best-known example of such a literary genre: it is a word game that is based on rearranging the letters of a word or a phrase. At first, the connection between a signifier and a signified is dissolved, then the signifiers are rearranged, and only finally semantics comes into play because signifieds (and referents) need to be found for the newly established strings of signs. These strings are the "variable product of the combinative function — and not as a preliminary absolute, ne varietur" (Starobinski 
8). The anagram seems to have its origin in magical thinking. For example, the name anagrams of the Greek poet and grammarian Lycophron expressed the characters of persons that made them ideal for panegyric but also for polemical writing. In Jewish mysticism, the anagram was also used as a method of combinatory literature. Here is Claude Lévi-Strauss:

If such anagrams represent a particular application of a device which is both archaic and fundamental, it could conceivably have been perpetuated not by conscious observation of rules, but through unconscious conformity with a poetic structure that was perceived intuitively through experience of previous models evolved in the same conditions. After all, the objection that I come up against, on the part of conservative thinkers who refuse to accept that poetic inspiration depends on the play of a combinatory system, itself has its roots in a very old mysticism which, since the earliest times, may have consistently relegated the true mechanisms of aesthetic creation to the unconscious. (The Naked Man 651; emphasis added)

\section{Combinatory Machines and Text Generators}

This conjunction of the unconscious and the notion of "mechanisms of aesthetic creation" is important for the understanding of Baroque literature. In German Baroque, anagrams were popular as a creativity-stimulating parlor game at first, before they were eventually incorporated into literary texts. For Harsdörffer, the anagram or Letterkeer [letter twist] was a technique of poetic invention because it "can move letters and bring forth a different view" (Poetischer Trichter 17). ${ }^{4}$ As he was convinced that poetic writing could be learned, he gave detailed instructions for producing a well-done anagram: it had to be written in German and was not allowed to contain any Latin words. This was a common concern of all Baroque poets including Martin Opitz who cited the anagram as evidence for the equality of the German language with Latin and other European languages. Furthermore, the anagram had to be formed numerically correct, i.e. no letters were to be omitted and it was to generate semantically meaningful verses (cf. Harsdörffer, Poetischer Trichter 18). These principles allowed for designing mechanical devices, and this also was reflected in many poetic treatises of that time. ${ }^{5}$

The rather simple principle of generating an abundance of signs from a limited stock also is the basic idea of more advanced mechanical devices, which have been constructed in the course of the last centuries to facilitate literary production by combining words or attributes. The prototype of such a logical machine was the Ars magna devised by the Catalan monk Ramon Lull. 
Lull's machine consists of a stack of three concentric disks mounted on an axis where they are able to rotate independently. The disks were progressively larger from top to bottom. Nine fundamental terms, the so-called principia absoluta comprising the main topics of scholastic philosophy, were related to the letters from A to $\mathrm{K}$. By rotating the disks, a large number of random statements were to be generated that could not have been predicted in advance. The Ars magna sciendi, Athanasius Kircher's adaptation and elaboration of Lull's Ars magna, illustrates a common tendency of the Baroque era. In addition to books, alternative Aufschreibesysteme (Friedrich Kittler) were developed, which stored traditional knowledge and generated new knowledge at the same time. However, neither the storing nor the production of texts were ascribed to an author and the texts were not written or printed in syntagmatic chains but machines were designed that generated texts from a "database" by using combinatorial procedures.

This refers back to my considerations of linguistic theories from the Baroque era. Harsdörffer implemented methods of generating stem words and word formation rules in his Fünffacher Denckring der Teutschen Sprache (1651). He claimed that his machine was able to mechanically reproduce all possibilities of German without having to compile voluminous dictionaries. The Denckring consists of five rotating disks that the user has to cut out from the book at first: "This leaflet has to be cut out, parted into five disks and fastened onto five equal leafs of paper so that each disk can be turned around separately and when this has happened one has to glue that five-fold leaf back in" (Hundt 283). ${ }^{6}$

On the inner disk, there are 49 prefixes followed by 60 initial letters, 12 medial and 120 final letters as well as 24 suffixes. Leibniz calculated that Harsdörffer's Denckring makes possible 97,209,600 combinations. Further, he recommended applying the ideas of ars combinatoria to all sciences ("alle scientien"). In 1671, he even declared that he wanted to demonstrate that "all composite notions in the whole world are reduced to a few simple ones as their Alphabet; and by the combination of such an alphabet a way is made of finding, in time, by an ordered method, all things with their theorems and whatever is possible to investigate concerning them" (qtd. in Russell 283). Harsdörffer did not only use his Denckering for representing all possibilities of word formation but he also considered it a useful tool of literary writing:

This word-generating procedure then is completely accurate in creating a complete German Dictionary and we retain our opinion that all these composite words should be allowed as good German, especially in poems, even though they might not be used otherwise. (Deliciae mathematicae et physicae 518) ${ }^{7}$ 
This is Harsdörffer's solution of the problem of the non-semantic "blind" words. He thus resolves the problem that his machine inevitably generates words that make no sense in the German language by declaring the outcome of his Dencking to be the proper language. One could argue that this reveals the poetic potential of the machine; it becomes a generator of poetic invention or a mobile rhyming dictionary "for inventing rhymes by looking for the rhyming syllables on the third or fourth disk and then turning the second disk to add the rhyming letters" (Harsdörffer, Deliciae mathematicae et physicae 518). ${ }^{8}$

At a first glance it seems to be a huge step from the Baroque use of rather simple mechanical devices to the use of ever more advanced electronic computers. This step was already taken in the neo-avant-garde movements of around 1960, for example by the Oulipo's "Centre Pompidou Experiment" (1961, cf. Fournel) or, in Germany, by the "Stuttgarter Gruppe," where the mathematician and software engineer Theo Lutz produced his famous Stochastische Texte [Stochastic Texts] (1959) on the ZUSE Z 22 mainframe of the university's computer center. For the "Stuttgarter Gruppe," these first pioneering experiments seemed the "incunables of 'artificial poetry," as Reinhard Döhl recalls (cf. Döhl). According to Max Bense, the spiritus rector of the group, such computer-generated "artificial poetry" demonstrated, in the context of Concrete Poetry, that a poem had to be a reality in itself rather than an individual's statement about a pre-existent world, as is the case in "natural poetry":

By natural poetry, a sort of poetry is understood that . . requires a personal poetic consciousness; it requires a consciousness that possesses encounters, experiences, feelings, memories, thoughts, imaginations, etc.; in short, a pre-existent world and the ability to express it. . . - Contrary to this, artificial poetry is a sort of poetry that does not possess - if it has been created for example by a machine — any personal poetic consciousness with encounters, experiences, feelings, memories, thoughts, imaginations, etc., in other words, where no preexistent world exists and in which writing is no longer an ontological continuation by which the world-aspect of the words could be related to a subject. Thus, neither a lyrical ego nor a fictitious epic world can be meaningfully set apart from the linguistic specification of this poetry. Therefore, while for natural poetry an intentional beginning of the process of words is characteristic, only a material origin can exist for artificial poetry. ("Über natürliche und künstliche Poesie" 143) 9

As "pure" and technological literature, "artificial poetry" was supposed to be liberated from the burden of metaphysical, hermeneutical or ideological traditions. Instead, the avant-garde artists of the computer age were called on to assign the authorship to a machine and, in the end, to pure mathematics. ${ }^{10}$ At 
first view, Bense's manifesto reads like the perfect technological ideology of the early 1960s, neglecting everything that has made literature-and poetry in particular-meaningful to human beings. However, Bense was well aware that the computers of his time could come nowhere near to generating the "absolute" poetry, that they would in no way be able to write their code themselves, but would remain limited to combining human and machine writing: "Of course, the differences mentioned above in the first place are valid only idealtypically. Probably only the approximations are really existent" (Einfübrung in die informationstheoretische Ästhetik 144). ${ }^{11}$

\section{Inside the Language Vacuum: Myth and Literature}

The idea to generate literary texts on or with computers was soon taken up by other computer centers and individual artists during the 1960s, and it has been one of the main strands of so-called "electronic literature" ever since, culminating in more recent poetry generators by Nick Montfort, Scott Rettberg and others, as well as in more complex art systems such as John Cayley's and Daniel Howe's The Readers Project. All these attempts to replace or to expand "natural" by "artificial poetry" and to transcend traditional cultural conventions and institutionalized divisions of art and society have clearly placed electronic literature in the tradition of $20^{\text {th }}$ century avant-garde movements. Yet, in order to be recognized as "literature," these mechanically produced or computer-generated texts would still have to pass the "Calvino Test." The benchmark for this thought experiment is very high. Calvino argues that avant-garde writers by then had only used computers to produce disorder instead of using them to produce "classicist" texts, against which computers then, in a second step, would be able to react autonomously by establishing a new and true avant-garde. In other words, a literary computer would have to be more than just an advanced tool at the disposal of an avant-garde artist. Instead, it would have to be able to initiate the revolt against the classical form itself:

The true literature machine will be one that itself feels the need to produce disorder, as a reaction against its preceding production of order: a machine that will produce avant-garde work to free its circuits when they are choked by too long a production of classicism. In fact, given that developments in cybernetics lean toward machines capable of learning, of changing their own programs, of developing their own sensibilities and their own needs, nothing prevents us from foreseeing a literature machine that at a certain point feels unsatisfied with its own traditionalism and starts to propose new ways of writing, turning its own codes completely upside down. To gratify critics who look for 
similarities between things literary and things historical, sociological, or economic, the machine could correlate its own changes of style to the variations in certain statistical indices of production, or income, or military expenditure, or the distribution of decision-making powers. That indeed will be the literature that corresponds perfectly to a theoretical hypothesis: it will, at last, be the literature. (Calvino 13)

This utopian (or rather dystopian?) vision serves as a corrective against the "author function" that—at around the same time, although with a different focus-had also been famously attacked by Michel Foucault and Roland Barthes. Instead of incorporating the intentions of an author in the interpretation of texts, as had been traditionally practiced in literary criticism, the literary scholar of the future would "give place to a more thoughtful person, a person who will know that the author is a machine, and will know how this machine works" (Calvino 16). On the one hand, this "more thoughtful person" would have to know very well "that literature is entirely involved with language" (18); on the other hand, however, he would also have to realize that "literariness" can never be the result of algorithmic production only, be the sentences syntactically correct or not. Although, for Calvino, literature is "a combinatorial game that pursues the possibilities implicit in its own material, independent of the personality of the poet" (22), it also, seemingly paradoxically, is a mode "to escape from the confines of language" (18; emphasis added) in order to express the inexpressible. This transgression is not determined; it can by no means be formalized but rather emerges as an unpredictable outcome of the combination of elements. The literary qualities of this combinatory game only become apparent if the reader

at a certain point is invested with an unexpected meaning, a meaning that is not patent on the linguistic plane on which we were working but has slipped in from another level, activating something that on that second lev$\mathrm{el}$ is of great concern to the author or his society. The literature machine can perform all the permutations possible on a given material, but the poetic result will be the particular effect of one of these permutations on a man endowed with a consciousness and an unconscious, that is, an empirical and historical man. It will be the shock that occurs only if the writing machine is surrounded by the hidden ghosts of the individual and of his society. (22; emphasis added)

The "other level" mentioned by Calvino is myth, the "buried part" of every story, which has been repressed from consciousness, but where, nonetheless, those "ghosts" are thought to be hidden that only literature can bring to the fore. 
Myth is nourished by silence as well as by words. A silent myth makes its presence felt in secular narrative and everyday words; it is a language vacuum that draws words up into its vortex and bestows a form on fable. ... Literature follows paths that flank and cross the barriers of prohibition, that lead to saying what could not be said, to an invention that is always a reinvention of words and stories that have been banished from the individual or collective memory. (19; emphasis added)

This reminds of all the efforts from Lull to Harsdörffer to reveal something hidden behind the mere combination of letters, something that may be brought to the fore by unfolding the potentiality of language. However, this does not yet answer the question of how specific qualities of literary texts can be described. Calvino seems to have this in mind when he reflects on "the relationship between combinatorial play and the unconscious in artistic activity" (20). His definition of myth as a "language vacuum" may be surprising, since without any doubt literary texts consist of nothing other than inscription.

"Cybernetics and Ghosts" was certainly inspired by the works of Claude Lévi-Strauss with whom he was in touch since he had moved to Paris in 1967, at the heyday of Structuralism when Lévi-Strauss' seminal books Antbropologie structurale [Structural Anthropology] (1958), and La pensée sawvage [The Savage Mind] (1962) had a strong impact on intellectual debates and when he was in the midst of working on his four-volume opus magnum Mythologiques (1964-1971). Lévi-Strauss's structural anthropology aims at discovering deep structures that exist in all cultures and determine all forms of cultural expression, including literature. In myths, he argues, anthropologists can discover "the complete range of unconscious possibilities" that are to be expressed, for example, in artworks according to rule-based combinatorics. The number of possible combinations, however, according to Lévi-Strauss, is not unlimited (Structural Anthropology 23).

To be more precise, myths are linguistic constructions-but of a specific kind. They are "both the same thing as language, and also something different from it" (209). To understand this difference, Saussure's famous distinction between the language-system (langue) and the meaningful speech acts (parole) is to be complemented by a third level: the "mythic language" that consists of different elements, the so-called "mythemes" (209). Mythic language is thought to be an underlying permanent structure, a "specific pattern [which] is timeless," as "it explains the present and the past as well as the future." By exploring the grammar of mythic language, Lévi-Strauss believes to identify objective structures of the human unconscious, and as he claims "to show, not how men think in myths, but how myths operate in men's minds without their being aware of the fact" (The Raw and the Cooked 12; emphasis added). As "second-order codes," 
myths both determine and limit the possibilities of free expression of human beings (using the "first-order code" of human language):

$[1] \mathrm{f}$ it were possible to prove in this instance, too, that the apparent arbitrariness of the mind, its supposedly spontaneous flow of inspiration, and its seemingly uncontrolled inventiveness imply the existence of laws operating at a deeper level, we would inevitably be forced to conclude that when the mind is left to commune with itself and no longer has to come to terms with objects, it is in a sense reduced to imitating itself as object; and that since the laws governing its operations are not fundamentally different from those it exhibits in its other functions, it shows itself to be of the nature of a thing among things. The argument need not be carried to this point, since it is enough to establish the conviction that if the human mind appears determined even in the realm of mythology, a fortiori it must also be determined in all of its spheres of activity. (10; emphasis added)

This is a far-reaching assumption, since for Lévi-Strauss these "basic and universal laws" operating at a deeper level define an "inventory of mental patterns" (10), ${ }^{12}$ which, as a whole, afford a general set of possibilities of human thinking and expression. This corresponds to Calvino's claim that such mythic structures are still determining artistic creativity today; in other words, that they constrain and frame the products of human imagination, which otherwise would be amorphous. If this is the case, established literary genres and formal conventions can be traced back to very basic cultural patterns, even to anthropological dispositions at last (cf. Eibl). It is not by coincidence that none other than Johann Wolfgang Goethe claimed that all literary genres ("Dichtarten") can be reduced to three "pure natural forms of poetry": "the clearly telling, the enthusiastically excited and the personally acting: Epic, Lyric und Drama" (Goethe 187). ${ }^{13}$ The idea is that such generic structures are based on deeply rooted mental representations from which lots of various literary forms have developed subsequently. These forms, of course, can be regarded as reactions to fundamental cognitive and social problems of humankind-as had been myths, cultic rituals, songs and prayers before. Every literary text, in LéviStrauss' understanding thus is a singular event that is based on an underlying structure: "events in this sense are only one mode of the contingent whose integration (perceived as necessary) into a structure gives rise to the aesthetic notion" (The Savage Mind 27).

Of course, this integration into given structures is also subject to media technologies. It makes a difference whether a story is told by a storyteller or a poem is performed by a reciter-or if the text is silently read from a book or even from a computer screen. And it makes an even larger difference when 
aesthetic practices are carried over to software systems so that stories and poems, performances and games are always and inevitably co-produced in a more or less autonomous way by networked computation and under the influence of "Big Software" corporations (Cayley 17).

The programmable and networked computer is adding something that has not been available in books and other print media. It is certainly true that, as Katherine Hayles puts it, "electronic text is more processual than print, it is performative by its very nature." But I am inclined to doubt that electronic text, as Hayles continues, is "independent of whatever imaginations and processes the user brings to it, and regardless of variations between editions and copies" (Hayles 101). When the "work" itself is a processing entity, "the computer is also a writer, and the software programs it runs to produce the text as process and display also have complex and multiple authorship (not to mention the authoring done by hardware engineers in configuring the logic gates that create the bit stream)" (Hayles 105). One may regard this quite explicitly as a turn against any notion of "creativity," at least if creativity is only considered an activity of a particularly gifted person. Instead, according to ActorNetwork Theory, "creativity" is either distributed between various human beings or between human and non-human actors, and it can be distributed across time and space (cf. Schäfer). In this process, something effectively happens or emerges "for another first next time" (Harold Garfinkel): "an 'event' occurs which has a positivity of its own that cannot be limited to its origins and determinants, no more than to its effect" (Hennion and Grenier 346).

But still, it is important not to forget Calvino's statement that even such peripheral "events" can only be regarded as "literature" if the reading of such a text-as-process is in a dialogue with previous experiences of reading literature. In order to experience a piece of electronic literature as literature, the reader has to simultaneously correlate the output of the computer system with his imagination, which is inevitably rooted in traditional notions of fiction, poetry or drama that - to rephrase Lévi-Strauss—operate in his mind without him being aware of the fact. This still is the case even if a current reading comes into conflict with the reader's horizon of experience. Consequently, Calvino in defining "literariness" insists on the existence of the "ghostlike" imprint of symbolic processes. To enable the rise of the aesthetic notion, the capability of computers to generate and to form syntactically correct sentences is not enough. As Peter Gendolla argues:

... it rather is crucial that the paradigmatic fields generated by them, or better, that the horizons of association producing the 'ghostlike' possibilities or variants of contextualization that suddenly emerge in the interfaces between the encoding by machines and the decoding by 
humans, are poetically 'correct'. Aesthetic or literary demands are only fulfilled through a double reflection: by opening up both intertextual and intermedial realms of allusion, by simultaneously combining imaginary and physical-medial elements of man and machine. (171)

\section{$4 \quad$ The Readers Project}

The Readers Project (2013) by John Cayley and Daniel Howe is a project whose various installations and performances comment on and play with these issues. The project consists of a collection of "art systems" that relate to writing and to reading, to human readers' encounters with literary language. However, it is essential that the "readers" that the title of the project refers to are not—or at least not only—human beings who are reading a literary text. Instead, they are software agents that traverse a projected page following different behavior patterns. Here, for example, is the artists' description of the so-called "Unconstrained Perigram Reader":

Having read a word, this reader also looks around at its typographic neighbors. Whereas the Perigram Reader is only interested in its 'easterly' neighbors, this reader will consider whether any adjacent word, even the preceding word, would form a perigram. If it finds such a phrase, the reader may read in the direction of the viable word. This reader wanders and may be momentarily caught in eddies and loops. It is also, however, weighted to proceed slowly through the text. Visually, it 'haloes' the words at the center of its attention. (Cayley and Howe $)^{14}$

The output of the "readings" of this (or any other) "reader" is represented on different displays within the artwork, which means that the whole of the work as it can be experienced by a human reader consists of an arrangement of various screens, depending on the particular setting of the installation. Scott Rettberg, as an example, gives an instructive report from an exhibition in Dundee in which already the use of the past tense indicates that this is only one particular staging of the project:

The human reader ... experienced the work on a wall-mounted screen. The operations of the reading agents were represented in two different ways - by a highlighted portion of the text that represented the reader's attention, and through an iPad tethered to the main display that represented the program's focus by showing the individual word that had drawn the program's focus at the given time. The human reader's experience of the work is not limited to the operations 
of the agents, but also reading the texts the system moves through, in this case 'misSpeltLandings' and 'poeticCaption'-both of which are also meditations on the process of reading in typographic space. $(3)^{15}$

Rettberg's report illustrates that, on the one hand, the human readers are confronted with a fixed narrative text that is and remains one component of the work, but, on the other hand, also with constantly changing instantiations of additional poetic texts that are generated during the reading process. This reading process, at the same time, turns out to be also a writing process. The textual events are emergent phenomena of co-dependent agencies of human and non-human actors. The Readers Project thus, in addition to the conventional reading of a story, also raises the awareness for the simultaneity of program and process, of pre-scripted procedures and the performance, or more generally for the interactive nature of meaning-making "between several media within one work" (Ricardo 2). Here, subjectivity does not only refer to the "experiences" of the human readers, but also to that of the machines, which recursively observe their own operations. This is why for Francisco Ricardo, The Readers Project is one of the seminal works which demonstrate that "the procedural, not the structural or medium-specific, has become the new foundation of this [what he calls the 'engagement'] aesthetic.... Thus we can see ... both a dispersal and a unification of time and space, of creation and reception, of event and of place" (111).

This becomes even clearer in How It Is in Common Tongues (2012), another derivative of The Readers Project. Here, Cayley and Howe entangle the novel written by Samuel Beckett, How It Is (1961), as a source text and use the Google search engine for finding the largest phrases from How It Is in what they call the "Commons of language"- the Internet. These readings generate found phrases that are then indexed and footnoted with URLs discovered via Google. In addition — and this is a crucial point—-the resulting text was printed and published in a print-on-demand book. Thus Beckett's text in The Readers Project's adaptation "is made entirely of the words of others yet is also utterly mediated by Google's search engine algorithm" (Emerson 184) and recaptured by The Readers Project. The resulting book is a material manifestation of a stitched-together text, the fragments of which were co-authored by thousands of human contributors and compiled by a hidden search algorithm. As bound book it re-enters the traditional literary system of book culture and thus reflects the ramifications of a communications system in which "online" and "offline" are continuously entwined.

The text can be read again in the same manner as Beckett's novel, since the corpus text appears to be exactly the same and additionally, the print-like act of reading is supplemented by a different kind of attention that is directed 
at the activities of the software "readers." Therefore, Manuel Portela convincingly described the reading experience of the Readers Project as "meta-reading":

Since the readings of the machine are offered as writing to human readers, the writing of reading and the reading as writing contained in The Readers Project turn readers into metareaders who are forced to read their own act of reading the program reading. . . . Automated generative writing is presented as an act of reading that rewrites the text and makes it available for literary reading. (346; emphasis added)

I completely agree with Portela's analysis-but still: What is literary reading in this instance, and how does it relate to "meta-reading"? Do both acts of reading depend on different forms of reflexivity? Following reader-response theorist Wolfgang Iser, communication in literature is

a process set in motion and regulated . . . by a mutually restrictive and magnifying interaction between the explicit and the implicit, between revelation and concealment. What is concealed spurs the reader into action, but this action is also controlled by what is revealed; the explicit in its turn is transformed when the implicit has been brought to light. (Iser 168)

It is evident that this classical conception of an act of literary reading is derived from the reading of a printed text. For centuries, the combination of natural language, script, paper and print technologies provided the dominant media of written communication. Literature, then, has always been-and, as I insist, will have to be in future-the medium of aesthetic reflection of such communication. In such a meta- or "inter-discourse" (that can be distinguished from but also incorporates elements of scientific, religious, philosophical or any other discourse) reflexivity is not a definiens, but an interpretament of art. Its point of reference is the self-perception and self-reflection of the reader whose experiences, however, depend on the engagement with the work of art and the interpretation of the author's intentions (cf. Hilmer 245). If "meaning" always is a result of such reflexivity, then, in my understanding, literature can be described as a specific form of the use of language that activates a surplus of the possibilities of language_or, in Calvino's terms, that releases the hidden ghosts of literature. Hence, we have to deal with the paradox that even though language can say more than one can assert, it can at the same time also say nothing without asserting anything. Literary texts, then, mediate the assertive statements of a "sense of reality" with the "sense of possibility" of language.

In a piece like The Readers Project as well as in its derivatives it can in no way be unambiguously differentiated who or what is "reading" whom or what. It is 
precisely this automation of the mutual observation of human and non-human actors that is made available to literary aesthesis as a distinct and reflexive perception of perception. Thus, literature maintains its function of creating an aesthetic distance - that is to say, a deliberate disruption or defamiliarization (to use the classical Formalist term) of (at least partially) automated social and technical interactions.

In addition to the reading of a linear poetic text, The Readers Project demonstrates that now far more complex media-technological and social conditions have to be reflected as well. This piece therefore clearly shows that, in current media dispositives, technical "disruptions" also participate in the constitution of meaning - something that only can be taken into account in reflexive acts of meta-reading. One might conclude that by realizing this, The Readers Project is the closest any piece of electronic literature has come to meeting Calvino's requirements of the "true literature machine." It arguably is not a coincidence that Nigel Thrift coined the term "technological unconscious" to describe the influence of technical devices on the historical occurrences of the unconscious (cf. Thrift). However, it is still an open question to what extent the latest computer-based and networked media technologies will have a profound effect on the way in which writers and readers produce and experience literary artifacts. As has been shown, both Lévi-Strauss and Calvino insisted that any sort of aesthetic experience is based upon an unconscious conformity with given poetic structures that have had a lasting influence on literary communication to date. Although Calvino's "true literature machine" has never been nor will probably ever be realized in the future, it will remain one of the main focuses of electronic literature to reflect upon the mutual impact of the unconscious poetic structures from ancient times and the manifestations of the "technological unconscious" in environments of the latest networked computer architectures.

\section{Notes}

1 All translations from previously untranslated German sources were done by Brigitte Pichon and Dorian Rudnytsky. Original text: "Ob nun wol etliche zu wolermeldter Kunst geboren / so ist doch die Kunst nicht mit ihnen geboren; sondern muß erlernet werden / wie alles / was wir Menschen wissen wollen" (Harsdörffer 2).

2 In the following, I mainly draw upon the books of Andreas Gardt, Stefan Rieger and Markus Hundt.

3 Original text: "welche als stets saftvolle Wurtzelen den gantzen Sprachbaum durchfeuchten / dessen Spröslein / Ast- und Aderreiche Zweige in 
schönester Reinligkeit / steter Gewisheit und unergründender Mannigfaltigkeit / reumiglich und hoch ausbreiten lassen" (Schottelius 50).

4 Original text: "so kann man die Buchstaben versetzen und eine andere Meinung heraus bringen" (Poetischer Trichter 17).

5 Philipp von Zesen, for example, in his Helikon gave recommendations to facilitate writing anagrams by using cardboard letters: "So that the poet, who wants to imitate this, does not have to think so much about the spelling and interpretation of the letters and names, I advise him to cut out all letters from card-games. He should take as many as are in the word, lay them down and invert them until one or several meaningful words have been created from the first, which he can use for his creation. Or, in order not to have to cut up so many card-games, and so that the godless people can keep their bible as a whole, I should like to advise him that he write down a letter on one card-game only, or on something else, and then mix them up and change them around." Original text: "Damit aber auch der dichterische künstler / so dieses nachkünsteln wil / nicht so viel kopfbrechens / mit verschreib- und ausleschung der buchstaben und nahmen / haben dürfte / so geb' ich ihm den raht / dass er ihm alle buchstaben aus karten oder spiel-blättern schneide / und dan ihrer so viel nehme als im nahmen begriffen seind / selbige verlege und wider lege / so lange / bis eines oder etliche worte aus dem nahmen zusamengebracht hat / die einen guten und folkomnen sin haben / und die er zu seiner erfindung brauchen kan. Oder / damit er nicht so viel schneidens mit den spiel-blättern bedürfe / und die Gottlosen ihre Bibel auch gantz behalten / so wil ich ihm den raht geben / dass er nuhr auf ein karten- oder spiel-blat / oder auf sonst etwas einen buchstaben schreibe / und sie also gantz verlege / und ümwechsele" (Zesen 174).

6 Original text: "Dieses Blätlein muß heraus geschnidten / in fünff Ringe zertheilet / und auf fünff gleich-grosse Scheiben von Papyr / also aufeinander gehefftet werden / daß man jeden Ring absonderlich umbdrehen kan / wann solchs geschehen / muß man dises fünfffache Blat wider hinein pappen" (Hundt 283).

7 Original text: "Ist also dieses eine unfehlbare Richtigkeit / ein vollständiges Teutsches Wörterbuch zu verfassen / und beharren wir in der Meinung / daß alle solchen zusammen gesetzte Wörter / welche ihre Deutung würcken für gut Teutsch zulässig / sonderlich in den Gedichten / ob sie gleich sonsten nicht gebräuchlich" (Harsdörffer, Deliciae mathematicae et Physicae 518). 
8 Original text: "Erfindung der Reimwörter / wann man die Reimsilben auf dem dritten und vierten Ring suchet / und die Reimbuchstaben auf dem zweyten Ring darzu drehet" (Harsdörffer, Deliciae mathematicae et physicae 518). Text generators based on rotating disks, however, are no peculiarity of the Baroque era but there also have been some interesting examples in recent times, e.g. in the Fluxus movement. André Thomkins produced his polyglot machine dogmat-mot (1965), which allows the user to produce "mobile dogmas." This machine consists of ten hexagonal cards, each with 12 words that are common in each of the three languages German, English and French (there are 48 German-French, 60 German-English and 12 German-French-English words). The hexagons pivot on a plane and form phrases in three directions on the hexagonal roof. They can even be arranged differently on the ten slots, so that the number of combinations can further increase. Ferdinand Kriwet wrote many of his texts on disks, among them are three-disk-texts whose disks overlap and thus make combinations of elements possible. Dieter Roth produced so-called "Leserollen” (reading rolls) - paper webs with abstract ornamental patternsfor the "Apparat zum Simultanlesen" [apparatus for simultaneous reading]. This machine was invented by his fellow-artists Daniel Spoerri and Jean Tinguely and consists of a rotating rod driven by an engine.

9 Original text: "Unter der natürlichen Poesie wird hier die Art von Poesie verstanden, die . . . ein personales poetisches Bewußtsein . . zur Voraussetzung hat; ein Bewußtsein, das Erlebnisse, Erfahrungen, Gefühle, Erinnerungen, Gedanken, Vorstellungen einer Einbildungskraft etc., kurz, eine präexistente Welt besitzt und ihr sprachlichen Ausdruck zu verleihen vermag. . . . Unter der künstlichen Poesie hingegen wird hier eine Art von Poesie verstanden, in der es, sofern sie z. B. maschinell hervorgebracht wurde, kein personales poetisches Bewußtsein mit seinen Erfahrungen, Erlebnissen, Gefühlen, Erinnerungen, Gedanken, Vorstellungen einer Einbildungskraft etc., also keine präexistente Welt gibt, und in der das Schreiben keine ontologische Fortsetzung mehr ist, durch die der Weltaspekt der Worte auf ein Ich bezogen werden könnte. Infolgedessen ist auch aus der sprachlichen Fixierung dieser Poesie weder ein lyrisches Ich noch eine fiktive epische Welt sinnvoll abhebbar. Während also für die natürliche Poesie ein intentionaler Anfang des Wortprozesses charakteristisch ist, kann es für die künstliche Poesie nur einen materialen Ursprung geben" (Bense, "Über natürliche und künstliche Poesie" 143).

10 Cf. Max Bense, Einführung in die informationstheoretische Ästhetik. Grundlegung und Anwendung in der Texttheorie: "The analytical description of texts via mathematical means of a statistical or topological kind from the beginning 
suggested reversing the procedures of separation into the technical procedures of synthetically structuring the texts. The idea became more obvious when it became possible to use information-processing computers with their ability to program saving, selection, classification, repetition and connection of entered data. . . With this, the idea of an artificial poetry entered the experimental literature of the avant-garde, which now could be defined as synthetic or even technologic poetry." Original text: "Die analytische Beschreibung von Texten mit mathematischen Mitteln statistischer und topologischer Art legte von Anfang an den Gedanken nahe, die exakten Verfahren der Zerlegung in technische Verfahren eines synthetischen Aufbaus der Texte umzukehren. Verstärkt wurde der Gedanke, als es möglich wurde, datenverarbeitende Rechenanlagen mit ihrer Fähigkeit zur programmierbaren Speicherung, Selektierung, Sortierung, Repetierung und Verknüpfung von eingegebenen Daten heranzuziehen. . . . Damit drang die Idee einer künstlichen Poesie in die experimentelle Literatur der Avantgarde ein, die zugleich als synthetische oder sogar als technologische Poesie definiert werden konnte" (Bense, Einführung in die informationstheoretische Ästhetik 109).

11 Original text: "Selbstverständlich gelten die angeführten Differenzen in erster Linie nur idealtypisch. Wirklich existent sind jedoch wahrscheinlich nur die Annäherungen" (Bense, Einführung in die informationstheoretische Ästhetik 144).

12 This approach, however, has not been without controversy. Karlheinz Stierle, for example, raised the objection that structural anthropology was not able to explain the relationship between the deep mythical structure and the specific form of any of its literary adaptations. Cf. Karlheinz Stierle: "Mythos als 'bricolage' und zwei Endstufen des Prometheusmythos." Terror und Spiel. Probleme der Mythenrezeption, edited by Manfred Fuhrmann. Munich 1971, pp. 455-472, p. 456.

13 Original text: "Es giebt nur drey ächte Naturformen der Poesie: die klar erzählende, die enthusiastisch aufgeregte und die persönlich handelnde: Epos, Lyrik und Drama" (Goethe 187). In German, the term "Gattung” denotes a group of objects that have distinguishing or typical features in common; it has deeper structural connotations than the similar but more flexible English term "genre."

14 Cf. <http://thereadersproject.org/readers.html>.

15 misSpeltLandings and poetic Caption are texts from John Cayley. 


\section{Works Cited}

Bense, Max. "Über natürliche und künstliche Poesie." Theorie der Texte: Eine Einführung in neuere Auffassungen und Methoden. Cologne: Kiepenheuer \& Witsch, 1962, pp. 143-147.

- Einführung in die informationstheoretische Ästhetik. Grundlegung und Anwendung in der Texttheorie. Reinbek: Rowohlt Verlag 1969.

Calvino, Italo. "Cybernetics and Ghosts" [1967]. The Uses of Literature, translated by Patrick Creagh. New York: Harcourt Brace Jovanovich, 1986, pp. 327.

Cayley, John. "Terms of Reference and Vectoralist Transgressions. Situating Certain Literary Transactions over Networked Services." Amodern 2. Oct. 2013. 3 July $2017<$ http://amodern.net/article/terms-of-reference-vectoralist-transgressions $/>$.

Cayley, John, and Daniel C. Howe. The Readers Project. 2013. 3 July 2017 <http://thereadersproject.org/readers.html\#PerigramReader>.

Cramer, Florian. "Combinatory Poetry and Literature in the Internet." 2000. 3 July 2017 <http://cramer.pleintekst.nl/essays/combinatory_poetry_permutations/combinatory_poetry_-_permutations.tex $>$.

Döhl, Reinhard. "Vom Computertext zur Netzkunst. Vom Bleisatz zum Hypertext.” 16 Apr. 2000. 3 July 2017 <https://www.netzliteratur.net/computertext_netzkunst.htm>.

Eibl, Karl. Die Entstehung der Poesie. Frankfurt am Main: Insel Verlag, 1995.

Emerson, Lori. Reading Writing Interfaces: From the Digital to the Bookbound. Minneapolis, MN: University of Minnesota Press, 2014.

Fournel, Paul. "Computer and Writer: The Centre Pompidou Experiment." Oulipo: A Primer of Potential Literature, translated and edited by Warren Motte. Lincoln, NE: University of Nebraska Press, 1986, pp. 140-142.

Gardt, Andreas. Sprachreflexion in Barock und Frühaufklärung: Entwürfe von Böhme bis Leibniz: Berlin: W. de Gruyter, 1994.

Gendolla, Peter. "Artificial Poetry: On Aesthetic Perception in ComputerAided Literature." Literary Art in Digital Performance: Case Studies in New Media Art and Criticism, edited by Francisco J. Ricardo. New York: Continuum, 2009, pp. 167-175.

Goethe, Johann Wolfgang. "Noten und Abhandlungen." Werke: Hamburger Ausgabe, Band 6: Gedichte und Epen II, edited by Erich Trunz. Munich: C.H. Beck, 1981, pp. 187-189. 
Harsdörffer, Georg Philipp. Deliciae mathematicae et physicae. Der mathematischen und philosophischen Erquickstunden zweyter Theil [1651]. Frankfurt am Main: Keip, 1990.

. Poetischer Trichter, vol. II [1647-1653]. Darmstadt: Wissenschaftliche Buchgesellschaft, 1969.

Hayles, N. Katherine. My Mother Was a Computer: Digital Subjects and Literary Texts. Chicago: University of Chicago Press, 2005.

Hennion, Antoine, and Line Grenier. "Sociology of Art: New Stakes in a PostCritical Time." The International Handbook of Sociology, edited by Stella R. Quah et al. London: Sage, 2000, pp. 341-355.

Hilmer, Brigitte. "Kunst als reflexive Form und als reflektierende Bewegung." Zeitschrift für Ästhetik und allgemeine Kunstwissenschaft, vol. 55, no. 2 (2010): pp. 235-246.

Hundt, Markus. "Spracharbeit" im 17. Jahrbundert: Studien zu Georg Philipp Harsdörffer, Justus Georg Schottelius und Christian Gueintr. Berlin: W. de Gruyter, 2000.

Iser, Wolfgang. The Act of Reading: A Theory of Aesthetic Response. Baltimore, MD: The Johns Hopkins University Press, 1978.

Le Lionnais, François. "Second Manifesto." Oulipo: A Primer of Potential Literature, translated and edited by Warren Motte. Lincoln, NE: University of Nebraska Press, 1986, pp. 29-31.

Lévi-Strauss, Claude. Structural Anthropology [1958]. Translated by Claire Jacobson and Brooke Grundfest Schoepf. New York: Basic Books, 1963.

- The Naked Man: Mythologiques, Volume 4 [1971]. Translated by John and Doreen Weightman. Chicago: University of Chicago Press, 1981.

—. The Savage Mind [1962]. Chicago: University of Chicago Press, 1966.

The Raw and the Cooked: Mythologiques, Volume 1 [1964]. Translated by John and Doreen Weightman. Chicago: University of Chicago Press, 1969.

Portela, Manuel. Scripting Reading Motions: The Codex and the Computer as SelfReflexive Machines. Cambridge, MA: The MIT Press, 2013.

Rettberg, Scott. "Visions of Reading." Vagant 2. 2011. 3 July 2017 < http://elmcip.net/sites/default/files/files/attachments/criticalwriting/visions_of_ reading.pdf $>$.

Ricardo, Francisco J. The Engagement Aesthetic: Experiencing New Media Art Through Critique. New York: Continuum, 2013. 
Rieger, Stefan. Speichern/Merken: Die künstlichen Intelligenzen des Barock. Munich: W. Fink Verlag, 1997.

Roubaud, Jacques. "Mathematics in the Method of Raymond Queneau." $O u$ lipo: A Primer of Potential Literature, translated and edited by Warren Motte. Lincoln, NE: University of Nebraska Press, 1986, pp. 79-96.

Russell, Bertrand. A Critical Exposition of the Philosopby of Leibniz. Nottingham: Spokesman, 2008.

Schäfer, Jörgen. "Reassembling the Literary: Toward a Theoretical Framework for Literary Communication in Computer-Based Media." Beyond the Screen: Transformations of Literary Structures, Interfaces and Genres, edited by Jörgen Schäfer and Peter Gendolla. Bielefeld: [transcript] Verlag, 2010, pp. 25-70.

Schottelius, Justus Georg. Ausführliche Arbeit Von der Teutschen Haubt Sprache [1663]. Tübingen: Niemeyer, 1967.

Starobinski, Jean. Words upon Words: The Anagrams of Ferdinand de Saussure. Translated by Olivia Emmet. New Haven, CT: Yale University Press, 1979.

Thrift, Nigel. "Remembering the technological unconscious by foregrounding knowledges of position." Environment and Planning D, 22, no. 4 (2004): pp. 175-190.

Turing, Alan. "Computing Machinery and Intelligence." Mind 59, no. 236 (1950): pp. 433-460.

Zesen, Philipp von. Sämtliche Werke, vol. X/1: Hoch-Deutscher Helikon [1656]. Edited by Ferdinand van Ingen, Ulrich Maché and Volker Meid. Berlin, New York: de Gruyter, 1977. 
Part Two:

Introspective Texts 



\section{Otso Huopaniemi}

\section{Writing Through Contemporary Self-Translation}

\section{A Constructive Technogenetic Intervention}

This article is a theoretical sketch or note on the relationship between human and machine as regards writing and translation of one's own texts, or "selftranslation." I propose expanding or modifying the concept of self-translation to include translation that incorporates digital media, more specifically machine translation, into the process. Furthermore, I claim that self-translation of this kind is, in fact, self-reflexive writing that constitutes a "constructive technogenetic intervention," a concept discussed by N. Katherine Hayles. In addition to Hayles, this brief piece responds to Rainier Grutman's observations on the field of self-translation and is to be read as an extension or adaptation of Grutman's ideas. To complement more traditional forms of self-translation, I suggest considering the writing practice described in this article as their contemporary counterpart.

\section{Double Writing Process}

After writing in one language, which may or may not be their native tongue, the self-translator ${ }^{1}$ is compelled-for artistic, political, economic, or personal reasons - to translate what they have written into another language. This may happen immediately or only after a gap in time, even after the text in the first language has been published and perhaps translated by someone else. Assuming for the current purposes that the self-translator does not wait for the first text to be published-and thus fixed-but rather translates an unfinished work-in-progress, it is conceivable that they would return to the first text and rework it based on their fresh translation. Also, having rewritten the first text, they are likely to return again to the translation and alter it based on the changes they have made in the first language. As this reciprocal dynamic between the two texts continues and intensifies, instead of an original text and its selftranslation, what emerge are two parallel texts of comparable status authored by the same individual in two different languages. Thus, the process of translation becomes, in effect, a "double writing process" (Grutman 259).

Consider then what happens when a third language is introduced to break or bridge the linguistic binary of the self-translator. Although, as Eva Gentes has pointed out, trilingual writing formations and publications open up many 
fascinating possibilities (278), what I am referring to here is not (another) natural language, but rather a language of another kind: the programming language of the machine translator. ${ }^{2}$ For in this instance, rather than "manually" translate their text, the self-translator has a machine translation program translate it first. Utilizing it to varying degrees, they then take the machine translation and treat it as a found text, using it for the purposes of their own translation. More concretely, they write over parts of what the computer has translated, while also including words, phrases, or larger portions of text that the computer has suggested, some of which would otherwise not have found their way into the text. Thus, a digital agent in the form of machine translation software is introduced and incorporated into the writing through self-translation process. More importantly, a close causal relationship between the self-translator and the digital media emerges in which the human writer can be seen to write with and against the intelligent (i.e. capable of learning) machine.

To distinguish it from more traditional forms of self-translation, which date back to at least the Middle Ages (Hokenson and Munson 17-77), but have only recently received proper attention in translation studies (Grutman 257), this algorithmically aided_or, more correctly, mediated-form of selftranslation could be called contemporary self-translation. In fact, unless the contemporary self-translator anachronistically refuses to use common digital technologies (and thus, to follow the logic of the argument, ceases to be a contemporary self-translator), their text is very likely to be algorithmically mediated in one way or another, even if they are not explicitly using machine translation or other forms of natural language processing. ${ }^{3}$ As Frederik Kaplan has argued, Internet search engines along with their autocomplete functions (which correct misspelled words, in addition to suggesting statistically probable searches) push natural languages in more algorithm-friendly and economically viable directions, striving to shape and exploit the words we enter into seemingly innocuous text-entry fields (Kaplan 57-62). Thus, contemporaneity is, in this instance, both an advantage and a burden — an advantage in that, as I claim, algorithmic processes can enrich and invigorate self-reflexive writing processes; a burden in that these same processes are made possible by corporate players whose interest in language is capitalistic.

\section{Technogenesis and the Question of Progress}

However, here I would like to follow another line of thought. Such is the interdependent relationship of the human writer and the digital media in contemporary self-translation that my proposition is to view this practice as an example of "technogenetic intervention" (83), a term N. Katherine Hayles takes up 
in the context of the digital humanities in How We Think: Digital Media and Contemporary Technogenesis (2012). Building on, among others, Bernard Stiegler's (1998) work on the relationship of technics and the human, by "technogenesis," Hayles refers to the co-evolution of humans and technologies and their reciprocal influence on each other's development (10). Hayles writes of "contemporary technogenesis" as distinct from the co-evolution of humans and non-digital tools, e.g. the writing tools used by practitioners of traditional selftranslation (18). In contemporary self-translation, digital media and their users together form "complex adaptive systems" (18) in which technologies are continually changing while also changing those entwined with them. Clearly, the biological meaning of adaptation, becoming better suited for one's environment, is key to Hayles's hypothesis. In contemporary technogenesis, adaptation involves compatibilities (and/or incompatibilities) between "organisms and their environments, recognizing that both sides of the engagement (humans and technologies) are undergoing coordinated transformations" (81).

Why should contemporary self-translation be approached in terms of technogenetic intervention? What distinguishes it from the countless other algorithmic adaptations that make up the media ecologies of the $21^{\text {st }}$ century? First, it centrally involves language, an embodied medium of human thought (Dove 372). Second, because it involves language, it is at the core of the challenges digital media pose to human cognition_challenges impacting, for example, human attention, which is becoming a scarce resource (Lanham xi). For Hayles, the main question is, "how digital media can be used to intervene constructively in our present situation" characterized by widespread uncertainty as to where our deepening engagement with digital technology will ultimately lead (83). The "technogenetic spiral" (or the accelerating interlacing of humans and technologies) both enables and requires constructive interventions (83). As it does not, in principle, entail progress - a point that Stiegler $(95)^{4}$ also stresses - the potential for both desirable and undesirable change remains on individual, societal, and global levels, a fact that is made dramatically apparent by changes in reading and writing practices.

Reading practices evolving in response to the prevalence of contemporary digital media — a topic that Hayles discusses in detail—can be seen as adaptations or "strategic responses to information-intensive environments" (61). On the one hand, they allow us to function in our media environments by increasing our capacity to absorb different types of information quickly. On the other hand, they can be seen to constitute a deterioration of concentrated reading practices that have been at the heart of contemporary literary studies and, more generally, at the core of what has traditionally been considered good reading. Thus, hyperreading (i.e. digital reading) highlights the ambiguities of technogenesis, an evolutionary process that always implies complex negotiat- 
ions and tensions between the interests of corporations, individuals, and other actors.

\section{Room with Mirrored Walls}

Within the field I come from, artistic research (an inter-, trans-, or postdisciplinary domain in which research is carried out in and through art work) there is an ongoing debate on the role and status of writing as a part of research. ${ }^{5}$ Simply put, the debate stems from the question, why must artistic research follow other fields in presenting its research processes and outcomes in the form of (discursive) writing, if the actual research happens in the artworks themselves. My claim that methods such as those practiced by the contemporary self-translator are examples of constructive technogenetic interventionsanalogous to the ones Hayles makes reference to in the context of the humanities (83) — should be understood in this context. However, in this particular article, I am less concerned with what impact, if any, the idea of the artistic researcher as self-translator has on the field. Rather, my question is how to actually verify that technogenesis is taking place and that there is something to intervene in. In other words, how to show that human writers (no matter what their field or genre) and their digital technologies are actually bringing about profound embodied changes in each other.

The rapid rate at which digital media evolve, for its part, is plain to seeand machine translation is no exception in this regard. It might not have lived up to the expectations of Warren Weaver's "Tower of Anti-Babel"-which was, as Hayles also points out, paradoxically a basement that allowed individuals trapped in their towers to descend to a common cellar and communicate with each other (Weaver 11; Hayles 162)—, but machine translation continues to evolve as its developers adopt and implement new approaches. ${ }^{6}$ Despite (or, indeed, due to) accelerated technological development, detecting technogenetic changes is no easy feat, for as Hayles writes, "the instruments by which one might attempt to measure these changes are themselves part of the technical environment and so are also involved in dynamic transformations" (81). Discerning the changes on the human side of the technogenetic equation is particularly difficult here, as that would require monitoring and interpreting the bodily changes occurring as one writes. How has, for instance, the contemporary self-translator evolved in relation to their traditional counterpart? More to the point, how does the contemporary self-translator continue to evolve as a writer through the use of machine translation and other digital media?

Rather than try to show what kind of embodied changes contemporary

self-translation entails, I will here take the somewhat more modest route of 
proposing how the inclusion of digital media in the self-translation process transforms the practice on a more general level. In order to do that, I will first take a closer look at self-translation per se. As we have seen, self-translation is a highly particular form of translation and one very close to writing-so close, in fact, that their difference may be negligible. Certainly, in light of the contemporary discussion of self-translation in translation studies, the differences between writing and translating seem so fluid that it is tempting to ask whether all translation is, in fact, (re)writing, and all writing (a form of) translation (Bassnett 289). The term "self-translation" refers to both the process and its outcome, as Rainier Grutman points out (257). What differentiates a selftranslator such as the one I described above from bilingual and polyglot writers who switch from one language to another on an everyday basis? In Grutman's view, the key difference is in the degree of consciousness: selftranslators are not only fluent in two or more languages; they make a conscious decision to write in more than one language (Grutman 257). Crossing over from one language to another is thus not (only) dictated by practical reasons, but rather the result of a strategic choice, which highlights the significance of translation as something other than the mere transfer of text (and meaning) from one language to another (the machine translator could be seen to attempt just this).

For the self-translator - and now I speak from the standpoint of my own self-translation practice-, self-translation is a means of thinking, a method of carrying out (or, at the very least, intensifying) artistic and intellectual inquiry and creation. The act of translating into another language constructs a selfreflexive space, akin to a rehearsal room with mirrored walls, in which the parallel texts reflect back on each other, "cross-fertilizing each other," as Grutman writes (257). They enable a cross-linguistic examination of one's thoughts and thought processes that would, if one were to write in just one language, be missing or externally imposed (by supervisors, examiners, or editors). Through the foreignization of one's own text a perhaps paradoxical domestication, a recapturing or extension of one's thoughts, occurs. ${ }^{7}$ In this regard, self-translation is not only a means of thinking, but also a strategy for gaining textual efficacy: the twofold writing process stretches the limits of the writing and the writer, in the best case scenario resulting in not only increased textual density and precision, but in deeper, more comprehensive knowledge. For writerresearchers in particular, this motivation is strong enough to compel us to repeatedly partake in an activity that some regard as absurd (why would anyone, after all, want to go to the trouble of writing their text twice), and that (according to even the most prominent self-translators of the $20^{\text {th }}$ century such as Samuel Beckett or Vladimir Nabokov) requires overcoming a strong feeling of disgust (Grutman 257). 


\section{Self-Translation as Extension}

What, then, does machine translation have to offer this self-reflexive process? In the part of his essay on self-translation entitled "Textual relations," Rainier Grutman attends to two topics germane to this discussion: self-translation as extension and the question of authority (258). How do self-translations compare to translations made by others? Do they have distinct features? In this connection, Grutman refers to Jacqueline Risset's essay Joyce Translates Joyce (1984), which deals with James Joyce's "Italianizations" of his own unfinished text fragments from what was to become Finnegans Wake (Grutman 258-259). In Risset's view, conventional translations (of Joyce) tend to be "hypothetical equivalents of the original text" compromised by their "fidelity and uninventiveness"; Joyce's own versions of the texts, in contrast, constitute "a kind of extension, a new stage, a more daring variation on the text in progress" (Risset according to Grutman 258-259; emphasis added).

My wish is not to further reinforce the dichotomy between self-translation and translation performed by others. Instead, I would like to point out that, in the case of writing through translation (i.e. clearly writing parallel, distinct texts rather than adhering to the structure and logic of the original and its translation), a translation made by someone else, no matter how interesting, would be unworkable, as it would not contribute to the writing process itself. Why? Simply because it would not be produced by the same hands, as it were, as the original-it would not afford the writer the same practical, embodied information as the self-translation. It would rather be a finished product in itself, unmovable, insoluble, even if unprotected by copyright. Risset's idea of selftranslation as an "extension, a new stage" is, however, useful in another way. It aptly describes how self-translation works: the writing emerges only after it has been extended by self-translation, only after a new stage has been set up for it. Without this extension, this new stage, we would remain at the monolingual starting point of the process. In contemporary self-translation, machine translation plays a key role in the creation of this stage, as it functions as the machinic other-or co-foreignizer — against whose algorithmic proposals the selftranslator weighs their choice of words. Certainly, not all of Google Translate's suggestions, for instance, constitute "more daring variations on the text in progress," but given machine translation's current capabilities and its potential for further development, it is already capable of carrying out this role and likely to be even more so in the future. If the contemporary self-translator adapts to the machine translator by resisting and exploiting it, the machine translator is, in the logic of the technogenetic spiral, sure to change in ways that make it more and more usable for this purpose-until a tectonic shift in the technological landscape reconfigures this bind, or makes it obsolete altogether. 


\section{Authorial Control}

I conclude by touching on the question of authorship from another direction. With regards to the authority of the self-translator, Grutman alludes to how the relationship between author and translator is conventionally perceived (259). Customarily, authors have control over their work and translators are expected to adhere to their intentions. Therefore, Joyce's by all accounts inventive re-writings of his own texts gain prestige simply because they are the work of the author himself. Even venerable translations made by skilled translators pale in comparison. The self-translator is free to make radical changes to the target text (and, for that matter, to the source text too), changes that would be considered questionable, to say the very least, had they been made by another translator, as Menakhem Perry points out (Perry according to Grutman 259). Grutman cites several other authors that concur. The "writer-translator," as Brian Fitch calls the self-translator, is widely seen to be best positioned to grasp the intentions of the original author, to possess "intimate knowledge" (Cohn) unavailable to "any ordinary translator," leading to this "unusual degree of acceptance [of the author as self-translator]," as Grutman describes it (Cohn and Fitch according to Grutman 259).

For its part, the machine translator has no intimate knowledge of any particular text. Moreover, it is not programmed to search for the intentions of any particular author. Instead, its algorithms approach the translation of any given text as a mathematical task, in which words and phrases from the source language are paired with their most probable equivalents in the target language. Rather than reason for consternation, for the contemporary self-translator accustomed to the affordances and limitations of the media, the seemingly narrow approach of the digital agent becomes a tool to work with. Not only does it deviate from how the context-conscious self-translator would initially translate their text, presenting them with options that may lead to further changes (surely also improvements) later in the writing process, the digital agent is free of the human problems that both privileged and unprivileged translators, with their concern for (or disregard of) the author's perceived intention, present. Bypassing and deconstructing authorial power regimes, the machine translator works according to a technical scheme, according to code that can be understood despite the "black box" nature of commercial algorithms (cf. Pasquale 2015)—making it a transgressive, adaptive media in the act of writing one's text and reworking one's thoughts anew. 


\section{Notes}

1 This article stems from my artistic doctoral research Algorithmic Adaptations, which I am currently completing at the Performing Arts Research Center, Theater Academy, University of the Arts Helsinki. In my research, I focus on contemporary (i.e. digitally mediated) self-translation as an auto-reflexive practice. By self-translation, I understand the translation of one's own writing into another language or other languages. The argument I make in this article and in my research is that the introduction of digital media significantly changes the self-translation process by opening it up to the influence of technology and even to digital co-authorship.

2 By machine translation, I refer to algorithmically governed translation carried out by computer programs that utilize natural language databases. Machine translation plays a key role in the artistic practice upon which my artistic research is based. Having first become a central element of my performance practice-for example, in the love.abz performance series (20112015) and Mind Machine (2017)_, it has subsequently also become a crucial medium in the writing of the written part of the research. In addition, conceptually it figures prominently in the central claims of the research.

3 Christopher Manning states that natural language processing (NLP) or computational linguistics "is a field at the intersection of computer science, artificial intelligence, and linguistics." Its goal is "for [the] computer to process or 'understand' natural language in order to perform tasks that are useful," such as translation (Lecture 1, YouTube).

4 Stiegler writes, "If technology, which for a long time has been synonymous with progress, is no longer necessarily perceived as such, or rather, if it is no longer obvious that progress is tantamount to benefit for the human race, a feeling found deep in the multifarious reactions of resistance to development, can it still be affirmed that technoscience submits theory to useful finalities - usefulness still being understood as usefulness-for-humanity?" (95).

5 In 2016, the Society for Artistic Research (SAR) organized an international conference, the topic of which was writing in artistic research. The description of the conference on its website provides an overview of the debate on writing in artistic research: "The relationship between artistic practice and writing in the context of research is a challenging and much debated topic, both in and outside of art degree programs. Often the relationship is felt to be one of friction, opposition or paradox. Writing gives an explicit verbal account of the implicit knowledge and understanding embodied in artistic practices and products while at the same time art may 
escape or go beyond what can be expressed by words and resist (academic) conventions of accountability." Writing as Practice, SAR20 available at $<$ https://www.sarconference2016.net/rc/index.html)>.

6 Recently, neural machine translation (NMT), which utilizes artificial neural networks developed in artificial intelligence research, has emerged as a "new paradigm in the machine translation field" (Castilho et al. 109). Manning has described NMT as "the approach of modeling the entire machine translation process via one big artificial neural network" (Lecture 10, YouTube).

7 I borrow the dichotomy foreignization/domestication from Lawrence Venuti, for whom they represent opposite translations strategies, the former having the potential to "restrain the ethnocentric violence of translation ... [as] a strategic cultural intervention in the current state of world affairs, pitched against the hegemonic English language nations and the unequal cultural exchanges in which they engage their global others" (qtd. in Kearns 285).

\section{Works Cited}

Bassnett, Susan. "Rejoinder." Orbis Litterarum, vol. 68, no. 3 (2013): pp. 282-289.

Castilho, Sheila et. al. "Is Neural Machine Translation the New State of the Art?." The Prague Bulletin of Mathematical Linguistics, vol. 108 (2017): pp. 109-120.

Dove, Guy. "Thinking in Words: Language as an Embodied Medium of Thought." Topics in Cognitive Science, 6 (2014): pp. 371-389.

Gentes, Eva. "Potentials and Pitfalls of Publishing Self-Translations as Bilingual Editions.” Orbis Litterarum, vol. 68, no. 3 (2013): pp. 266-281.

Grutman, Rainier. "Self-translation." Routledge Encyclopedia of Translation Studies, edited by Mona Baker and Gabriela Saldanha. New York: Routledge, 2011, pp. 257-260.

Hayles, N. Katherine. How We Think: Digital Media and Contemporary Technogenesis. Chicago: The University of Chicago Press, 2012.

Hokenson, Jan Welsh and Munson, Marcella. The Bilingual Text: History and Theory of Literary Self-Translation. Manchester, UK and Kinderhook, NY, USA: St. Jerome Publishing, 2007. 
Kearns, John. "Strategies." Routledge Encyclopedia of Translation Studies, edited by Mona Baker and Gabriela Saldanha. New York: Routledge, 2011, pp. 282-285.

Lanham, Richard. The Economics of Attention: Style and Substance in the Age of Information. Chicago: University of Chicago Press, 2006.

Manning, Christopher. "Lecture 1: Natural Language Processing with Deep Learning." YouTube, uploaded by Stanford University School of Engineering. 3 Apr. 2017. 20 June 2017 <https://www.youtube.com/watch?v=OQQ-W_63UgQ>.

. "Lecture 10: Neural Machine Translation and Models with Attention." YouTube, uploaded by Stanford University School of Engineering. 3 Apr. 2017. 20 June 2017 <https://www.youtube.com/watch?v=IxQtK2S-jWWM>.

Pasquale, Frank. The Black Box Society: The Secret Algorithms That Control Money and Information. Cambridge, MA: Harvard University Press, 2015.

Stiegler, Bernard. Technics and Time, 1: The Fault of Epimetheus. Translated by Richard Beardsworth and George Collins. Stanford: Stanford University Press, 1998.

Weaver, Warren. "Translation." Machine translation of languages: fourteen essays [1949], edited by W. N. Locke and A. D. Booth. Cambridge, MA: The MIT Press, 1955, pp. 15-23. 


\section{Sandy Baldwin and Gabriel Tremblay-Gaudette}

\section{Pwning Gamers, One Text at a Time}

In leetspeak and gamer cultures, to "pwn" means to own or to conquer. Pwning is "for the win," but what would it mean to think of a performative pwning, even a textual pwning? The ludo-semiotics of "transwriting" considers how textual performance re-sets and re-cites codes and actions. In this essay, the authors describe Poems You Should Know, a transwriting performance with famous literary texts in an online multiplayer video game (Counter-Strike: Global Offensive). This performance pwns the game as a critical, artistic intervention. If pwning means owning, then the performance becomes a question of who owns what? Who owns the game? Who owns the texts? Who owns the right to play the game? Who determines winning the game and under what conditions? Injection of literary language in the game displaces or irritates gameplay, but also adds a layer of constraint to the horizon of action of gameplay. The text may vanish or it may inform the game and lead to new possibilities for performers and players alike.

\section{Poems You Should Know}

What can poems do and what can video games do? What can poems do to videogames and what can videogames do to poems? Can we sort out what takes place and the proper action? To play, to perform, to troll, to pwn?

In the performance Poems You Should Know, these questions collapse into each other, interrupt each other, but are not resolved. In Poems You Should Know, the users named "Poems you should know"' and "You should know poems"' wander through the game Counter-Strike: Global Offensive (CS:GO). These two play the game but do something else as well: they type and speak poetry. Violence is all around: the CS:GO players are engaged with disarming bombs, freeing hostages, but mainly killing each other. The other players have names like "Sergeant Slaughter" and "suckmybullets." It's a serious arms race out there: you need to up your guns over and over, you need to make sure you've got the most powerful weapon. Otherwise you're shot dead and your corpse will be littering the map, your gaze lingering over the action as a kind of departed spirit.

The two players, "Poems you should know" and "You should know poems," run, shoot, duck and reload, they engage in the game. While player "Poems you should know" pastes poems into the text chat channel, "You should 
know poems" reads the poems aloud into the voice channel. Players can see these poems in their chat and hear them being read aloud. The poems go on and on, filling the time of the game, clogging the channels. The other players ignore the poems, treating them as noise unrelated to the game. They continue killing. Or they furiously reply and engage with the texts, they attack and take on the voices that bring poetry into the game. They treat the poems as weapons and as part of the world of CS:GO.

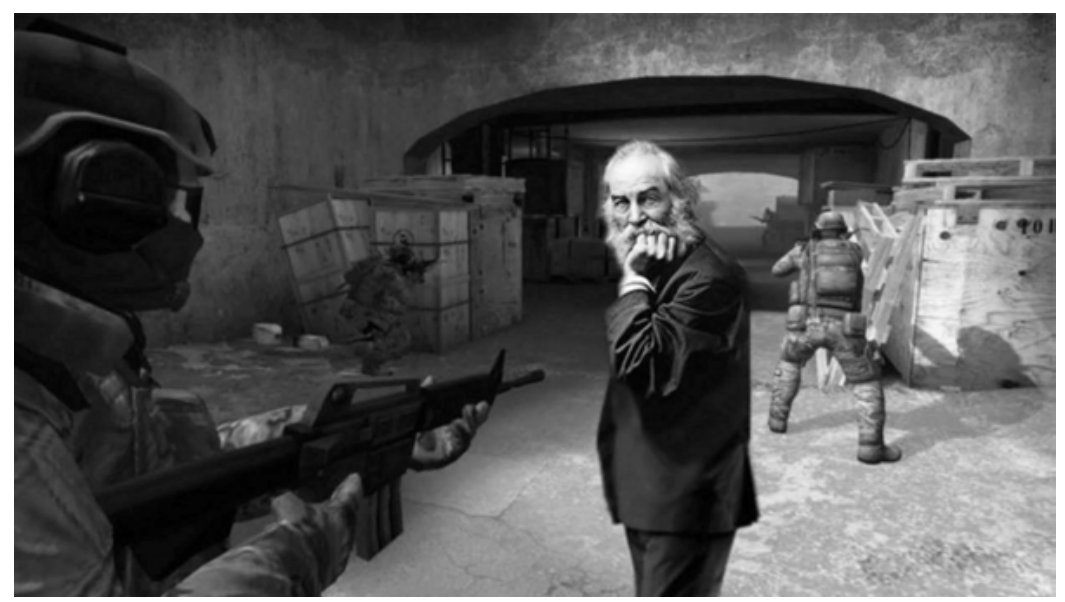

Fig. 1. Promotional material used to advertise an upcoming performance of Poems You Should Know. Picture credits: Ellie Stringer.

Of course, this is not how CS:GO should be played. But, actually, how should it be played? How do we understand the response to this performance? What is and is not a performance? Is the performance a reading of the poems by players "Poems you should know" and "You should know poems"? What is and is not a reading? Is the performance a transwriting practice? Or is the entire "performance" somewhere else, outside literary and textual practice, in the space of internet culture? Is this a form of trolling?

Poems You Should Know is difficult to place within literary practice in digital media. Is it "electronic literature" as defined and promulgated by groups such as the Electronic Literature Organization?" "Electronic literature" is clearly a field with a range of means of production, a canon of historical artists, and a set of criteria for inclusion. None of these apply to Poems You Should Know. The performative aspects of the work already make it difficult to characterize as electronic literature, a concept that may include generative text but always indicates a defined work and author. What can be considered as the work and author in this case? 
Poems You Should Know may use language and poetry but rather than think of it in terms of electronic literature, we are inspired by and draw on performance art, on agitprop theater that occupies spaces through guerilla action, and on the Augusto Boal's "theater of the oppressed." In this work, Boal tores down the stage's "fourth wall" to foster critical thinking and turn the spectator into the "spect-actor," who both witnesses and acts as part of the play. ${ }^{4}$

One way to explore these questions is to ask what poems are involved, and in what way do they interrupt the game? Perhaps the poems' themes can be taken as commentary on CS:GO. John Donne's "Death, Be Not Proud" (1633) seems to resonate with the violence of the game. Walt Whitman's "I Hear America Singing," (1860) with its passionate invocation of the bodies and Americans and the caring intermingling of all the peoples of the country, seems to contrast to the stark roles and divided teams of Counter-Strike. There are no terrorists and violence in Whitman but, if there were, it seems he would sing of them as well. And then there's Edward Lear: "O pussy, my pussy" reads the "The Owl and the Pussycat" (1871). The coy, wink-wink-nudgenudge of the children's poem is out of place in the military world of CS:GO but perhaps utterly appropriate in the space of the game. There are no "pussies" in the toxic-masculinity-soaked soldierly violence of Counter-Strike. The poems are oblique and at an angle to the game, trollish interruptions of the regular business of killing, and yet resonant to the proceedings.

William Wordsworth's "Daffodils" $(1807)^{5}$ is perhaps the best-known poem in the English language and elicits the most response from the other players. The famous refrain that "I wandered lonely as a cloud" itself floats and even condenses cloud-like on top of the game's combat and across its beautiful maps, the line floating up in the text chat, the words sounding across the chat channel. "Daffodils," a classic that invokes high school encounters with poetry and sets code of learning and culture against the space of leisure, is used within world of combat in the game. Perhaps Wordsworth's romantic poem can be itself considered as a passing cloud through the space of play. In short, not a utopic or atopic critique of the game, but a heterotopic occupation by another space.

Poems You Should Know is a performance of counter striking imperatives, of interfering demands on what matters in the world. The poems mobilized in the performance disrupt the game without being weapons themselves. While not instrumentalized for killing, the poems announce contemplation, introspection, and love. You Should Know: the title insists that CS:GO become about knowledge and not action. The interruption disturbs the players' assurance of the separation of playing from knowing, of killing from reading. Are the performers playing and the players performing? What is play or performance? Sure, there is a lot of critical discussion of play and performance, but does anyone know 
for sure? In the visual space of the game, the performers are poor players, inept terrorists or counter-terrorists. It is in the chat, both voice and text, where the interferences manifests. Chat channels are both peripheral to the game and vital to the play. If the violence takes place in the visual space of the game, the text chat is where negotiation and confirmation occurs, where players interacts to reinforce and comment on the game play, where teams coordinate, and where poems are posted in the course of Poems You Should Know. Text chat intermingles player commentary with the textual detritus of the game, player comments intersperse with commands and data.

Counter-Strike: Global Offensive is perhaps the most popular first person shooter in the history of video games. It famously originates in a mod of the game Half-Life but does not take place in that world's Black Mesa of anomalous materials and mutant monsters. In Counter-Strike players join one of two teams: terrorists engaged in acts of violence, including planting bombs and taking hostages; or teams of counter-terrorists engaged in foiling and killing the terrorists. Each team of five race the clock to defuse the bomb or kill all of the other side. Anyone who has played remembers the final announcement that "Terrorists Win" or "Counter-Terrorists Win." CS:GO is a game world of perpetual violence. We write "world" carefully: this is a beautiful world of nature and culture, fields and buildings, light and sound, tiny details and vast maps. In all this, the only goal is death and survival. Kill the other team, remain alive. You may defuse the bomb or rescue the hostages, and you will slaughter your opponents along the way, and stand alive over their bodies. The dead linger in the game, watching the living continue to play. To live is to play, to die is to observe. The games are brief and intense. They repeat endlessly.

$C S: G O$ is governed by an imperative: to be a terrorist, to be a counterterrorist. It is a space of strict legal and moral directives. You must act as your team is directed. Your acts are firm and without any option. The consequences are clear and time is ticking away. No other actions exist. The space of the vast and beautiful map is channeled by and towards this imperative: I play and follow paths because they lead me to the terrorist or because they allow me to protect my hostages. This is a world given over to the imperative of being a terrorist or counter-terrorist and winning the challenge in the brief time offered. How do poems interfere with these directives?

Poetry also comes with imperatives. Arthur Sze, Chancellor of the American Academy of Poets, is quoted on the front page of the Academy's web site: "Poetry matters more than ever before, because we are more challenged than ever before." Challenged how, you ask? The American Academy of Poets site offers poems for a time of war, of disaster, of political turmoil. Poetry matters for an era of Trump, climate change, and ISIS. Poetry is set against these challenges. To matter and materialize and face the challenge. But how? Sze conti- 
nues: "Poetry is the essential language that, endlessly branching, enables us to live deeply and envision what matters most." 7 This more enigmatic: how does endless branching lead to a deeper life? In what way does poetry endlessly branch? How does branching lead to envisioning what matters most? Since it is put as a matter of what matters, and since the previous sentence asserted that poetry matters more than ever before, does poetry lead us to envision more poetry as what matters most?

The Academy of American Poets website includes a page of "Poems Everyone Should Know." "This is a very assertive title: not just good to know or worth reading but everyone should know. The website connects this imperative to only two poems: Dylan Thomas' "Do not go gentle into that good night" and Walt Whitman's "I Sing the Body Electric.” Only two poems! When poetry matters it seems unfortunate that there are so few that we should know but it makes these two all the more important. After all, the site is authoritative and deeply tied to the institution of American poetry. It is this site that represents the American poetry establishment with its poets laureate and grand MFA programs. But why these poems? Sure, Thomas and Whitman are great, but only these two? There is no explanation: why should we know them? The imperative is powerful: everyone should know them.

The imperative of "poems you should know" repeats an order, a sentence passed on everyone, passed from academic institutions that tie knowledge of poetry to citizenship, literacy, and ultimately to subjectivity. Why should you know these poems? The poetic logic runs the opposite way: you should know poetry and that's all there is to say. And this is the performative power-and, as we show later, pwning power-of poetry.

The Times of London goes much further, offering "30 great poems everyone should know."' In this case, we are at least told that the poems are great, which gives some justification for why we should know them. At the same time, it is a far greater task to know 30 poems. The list of 30 ranges widely, and includes works by Emily Dickinson and Maya Angelou, diversifying the authors from the Academy of American Poets' dead white guys.

You should: the imperative comes from within, from what drives us to read a poem or play a game of CS:GO. You should: the imperative comes from without, from the text of a poem that matters or from the ticking clock of a bomb in a game of CS:GO. You should: the imperative comes from the poem, perhaps it is the poem. Is it the same imperative that leads us to play and kill in the world of CS:GO?

You should read: the imperative is textual, performative in relation and through poems. Let us be perfectly clear: "Poems you should know" is a powerful individual claim, an interruption of subjectivity by an aggressive text, one that branches — perhaps in the player's minds? — and one that forces atten- 
tion on itself. This is no small claim. And "poems everyone should know" goes beyond, raising the ante to a wider society: the burden is not simply on me, the player or gamer, not simply that I should know, not simply that I should stop and read these two poems — again, why these two? - but that everyone should. Such an imperative means that I should stop you and force some Whitman and Thomas on you. That "should" is an imperative to us all, and to me, an imperative to be an interpersonal force: I should (and I will) make you read "The Owl and the Pussycat" and all the other twenty-nine great poems.

The two performers "Poems you should know" and "You should know poems" act as they do because of poems that everyone should know. The two performers are killed and silenced by the other players. Or they are ignored and the poetry scrolls indifferently in the chat. Or they are cursed at, told to fuck off and shut up by other players, told to stop distracting from the game. They are dismissed as trolls. Or these trolls interrupt and occupy the game. What takes place in the performance? A suspension of imperatives: the imperative of a world, a textual world or the game world of CS:GO, is put to rest. The call of a world that situates and directs actions is dissolved or suspended in the trollish performance.

\section{$2 \quad$ Transwriting}

What are the textual and semiotic practices involved in Poems You Should Know? How far do these practices explain the performance? Poems You Should Know is a literary performance within a video game space. It is not a straightforward literary-work-to-videogame adaptation, as are Charlie Hoey and Pete Smith's Great Gatsby or Vector Belly's Waiting for Godot videogames; the dynamic, ephemeral, and real-time aspects of Poems You Should Know pose an additional set of constraints and opportunities.

In order to think through the conceptual, aesthetic and performative dimensions of our work, we can evoke the concept of "transécriture," which can be translated to transwriting. It was introduced at a Cerisy Conference of 1990, titled La transécriture: pour une théorie de l'adaptation. Surprisingly, the conference proceedings of this event does not offer an explicit definition of this concept. We will thus provide our own: transwriting refers to the process by which the transposition of some original material in a new, foreign media, addresses the boundaries between the different media and aesthetic expressions in order to shed light on them rather than trying to conceal them.

The need for a neologism, "transwriting," in order to address the ingenious, surprising and disruptive aspects of certain media transposition found its origins in the impulse to turn away from considerations of fidelity in the adap- 
tation to instead pay attention to the poetics and technicalities of the transfer operations (Gaudreault and Groensteen 5-6). Thus, transwriting exceeds the strict and conventional adaptation, in which the transposition process aims to minimize the friction between media and tends to focus its energies on making sure that the narrative material from the original work emerged as unscathed as possible in the adapted version. Rather, it problematizes the passage between media by foregrounding the aesthetic specificities and possibilities inherent to the media in the upstream and downstream positions of the adaptation process. Thinking about adaptation through the lens of transwriting allows us to address in turn the mobilization of semiotic codes, media properties, and the technical means of the "arrival" media.

\subsection{Media and Technical Means}

Take the case of Poems You Should Know from a transwriting perspective: there is little friction in terms of media transfer from the selected poems (texts) to the videogame environment. Most videogames can easily display text, and aside from gameplay information provided in the HUD of the player, the firstperson-shooter genre has a history of integrating text into the action, or rather, between actions, as was the case for the numerous war-themed quotes displayed on the "kill screens" of many titles of the Call of Duty (CoD) franchise. In the case of $C S$ : $G O$, several means of communication between players (allies and foes alike) are built in the game mechanics; indeed, communication is essential to teamwork and thus indispensable for any competitive-level play, and taunting your opponent is inherent to the gaming culture. Thus, not only does the presence of text is not entirely foreign to the game screen, a precedent was set by the practice of the reflexive quotes inserted between attempts in the CoD shooters.

If media transfer presented little transwriting issue, on the other hand, the transposition of textual units from its original state-poems written centuries and decades ago, available online- to the video game space involved some keyboard acrobatics. Indeed, in terms of technological means and constraints, inserting the text within the game proved to be a challenging exercise. Early attempts to rely on printed versions of the poems to manually type each line in the text chat box proved to be too cumbersome, and the back-and-forth between a Web browser and the video game wasn't fluid. In order to circumvent this problem, the selected poems were copy-pasted from the Web pages on which they were reproduced in a Notepad file for easier retrieval. Then, some poems had to be slightly edited to break down the lines in smaller chunks, since CS: GO only allows for chat messages of a maximum of 126 characters. 
During the performances, player "Poems you should know" shifts quickly between each software, selecting and copying each line of the poems in Notepad by a click-and-drag selection and a CTRL $+\mathrm{C}$ command, before returning to CS:GO, type "T" to open the text chat window, and paste the poem line using the CTRL+V shortcut. When the line appears inside the game in the bottom left corner of the player's HUD, player "You should know poems" activates his microphone and recites the displayed line. The process is repeated over and over again; in our experience, a regular game of CS:GO lasting on average five minutes, if everything goes without a hitch, we manage to perform one poem per game. As such, the temporality of the game and the performed poem are roughly synchronized. The game CS:GO is the poem and the poem is the game.

The reading and performance of the poems rely on a complex technical and textual operation, where this complexity forms the operations of moving the poem into the world of CS:GO. The quick and precise manipulations required by the "Poems you should know" player adds a daunting degree of difficulty to the game experience; while he is switching back and forth between software and pasting the poem lines in the text chat, his avatar is immobilized in the game (in CS:GO, as in many first-person-shooter games, player movement is controlled via the familiar WASD axis). However, a certain level of movement and action within the normal parameters of CS:GO is required in order to avoid being votekicked out of the game. In addition to this, since the poem lines need to be displayed in the text chat in order for "You should know poems" to read them aloud, a certain cadence of action within and outside of the game is to be maintained in order to achieve a satisfactory public reading of the poems. As for the player "You should know poems," his ingame performance challenge consists of keeping his composure while declaim the poem in the middle of a virtual warzone, ignoring objections (humorous and vilifying alike) hurled at him by fellow teammates all the while doing his best to play the game in a conventional manner.

\section{Engagement with the Audience(s)}

The technical constraints were not limited to mere text insertion. In order to complete our performances, we had to insert and read in full the four selected poems; any partial rendering of the poems would have been considered unsatisfying at the very least. However, with this criteria in mind, we had to take into consideration that our immediate audience would not be passively facing the stage; on the contrary, members of the audience were in a sense fully armed and had the capacity to fire back and even to kick us out of the virtual theater. 
In Dead in Iraq (2011), the artist Joseph DeLappe performed a similar artistic intervention in a multiplayer FPS game. DeLappe would log in a game by himself and stand still, refusing to engage in the perpetual videoludic slaughter. Instead, he would type the names of American soldiers killed in Iraq into the chat channel. The performance became a virtual memorial to the dead in Iraq, except for the fact that the other players could silence DeLappe by shooting down his avatar, forcing him to login and begin over and over again. The performance of freedom (2010) by the artists Franco and Eva Mattes also refuses to engage in the current death match between players, but rather than opting for a subversive message of remembrance and stakes-measuring, they opted for a more direct approach: they ask "please don't shoot me" and state "I'm an artist," "I'm making an art performance." Their immobilism coupled with direct addressing of the other players is transgressive and, in a sense confrontational; their in-game audience responds in kind by shooting the player repeatedly. The work is more confrontational and more self-consciously "art" for that reason.

What do Dead in Iraq (2011) and freedom (2010) achieve? From a strictly ludic perspective, they could be seen as flawed, even foul: however legitimate the questions raised by DeLappe and the Mattes' may be, the engagement with their immediate audience hinged on their refusal to play the game. Perhaps DeLappe is more transgressive in his passivity. His passive resistance amounted to more than mere immobilism; it also constituted a sabotage of the ludic activity, a bursting of the Magic Circle. His performance (and the Mattes'), was, from the start, aimed at an audience of subsequent viewers of the recorded play sessions; the unwilling participants of his play sessions became cannon fodder for his artistic goals.

We considered these questions of engagement while planning our own performance. As we discovered by in our previous performances of Beckett Spams Counterstrike, it is compulsory to engage with our audience by moving around and firing shots, for two intertwined reasons. First off, by committing to the game space we are investing with our literary performances; we are not simply invading it and imposing our own agenda, we are offering the players a rendering of a play or an in-situ poetry reading for their entertainment. Secondly, and rather importantly as well, we need to be active within the game in order to avoid being votekicked. ${ }^{10}$ In short, an acquiescence to the requirements and imperatives of the game world.

If we were to make our fellow players "unwilling participants" in our performance, we thought that at the very least we should attempt to act as "willing participants" of their game. We soon realized that in practice, such an oppositional description of our roles and stances would blur: engagement pulls us into the practice of playing the game but it also emerges from the text itself. In 
truth, similar performances such as Dead in Iraq involve playing as well: in every case, the text's performance meets playing the game.

\section{Communication Breakdown and Common Tongues}

While we managed to establish and maintain communication with the immediate audience of our performance in order to reach the end of our games - and poems, there was also the issue of how this communication would be received. We recognized that it could be perceived as a form of disruption, obstruction, and sabotage of the match, there was also the distinct possibility that the audience would be too busy shooting at each other to pay attention to us. In other terms, our artistic intervention could be perceived as "mere" trolling.

\subsection{Trolling}

Self-proclaimed trolls will explain their antisocial behavior by stating that they are doing it "for the lulz": an ever-shifting end, equal parts sardonic and nihilistic. Judith Donath "characterizes trolling as a malicious and deliberately destructive lie [which in turn] incite paranoia, and paranoia sours the communal spirit that yearns to express itself online" (Phillips 16).

Are we trolls in this way? We are nothing but forthright. Our avatar names state our intent; we do what we say and we say what we do. Are we trolls if we do and act so honestly? Has the trolling behavior so infected online communication and sociability that every free gesture towards strangers is to be met with suspicion and hostility?

On trolling, Whitney Phillips argues that the "troll's behaviors provide an implicit, and sometimes outright explicit, critique of existing media and cultural systems" (7). What if our usage of the text and voice chat functionalities of CS: $G O$ was meant as a critique? If there's no reason why we can't mix a little pleasure with business, why can't we sprinkle some poetry in a multiplayer video game match? Yes, we are clogging the communication channels but so are many other trollish players vociferating their specific taunts after triumphs or grief after failure, or their general racism, sexism and/or homophobia-at least we are elevating the debate! Trolling is exclusionary, spoken from a position of power. Our gesture is inclusive: after all, we were told that everyone should know these poems. We are just passing them along.

The troll is noise in the channel. The troll lives under the bridge. What channel and what bridge? The bridge is the space of communication. The bridge is the channel famously seen in the Shannon-Weaver model where the 
task of communication in the presence of noise is to encode and transport information across the bridge that hangs between communicative subjects. The troll is not exactly a parasite in Michel Serres' sense (2007). The parasite both shares and takes, attaches and destroys. By contrast, the troll is an intruder, lurking under the bridge, suddenly looming and horrible. The troll does not share or attach, but nor does the troll take and destroy. The parasite is with us, the troll is below us. The parasite inhabits the contracts and documents we operate with and through, its agenda becoming one with ours. The troll defaces the same texts that the parasite inhabits, all the while asserting an altogether different agenda. The imperative to act and follow enforced by game worlds and textual worlds is destroyed by the troll. What remains?

\subsection{Pwning}

Is Poems You Should Know trolling? The jury is still out. But there is another aspect to consider; how are we addressing the players on another level through the way we engage in the virtual gunfight? After all, we are not "just" playing, we are artificially creating a challenge through an additional set of constraints, which happens to take the form of poetry reading. Such a departure from the traditional gameplay has been described by Felan Parker as expansive gameplay, defined as "involv[ing] players dictating additional or alternative rules from completely within the confines of the existing game rules [that is, the affordances and constraints], using the game in a very different manner" (3). In our case, the surface of the game is extended to another software, as it involves gathering extraneous material, though this eventually came to be perceived as intrinsically part of the game.

Play a videogame long enough, and you start thinking of other player's avatars as terrorists or counter-terrorists forever entangled in an endless battle, or even as highly-detailed body-shaped pixels. They become mere targets, objectives in a game structure, not as much emptied of their meaning as narrowed down to their essential importance as no more than surfaces to aim at in the confines of the game paradigm. In Poems You Should Know, this process of desemiotization, this erosion of the signs through a combination of familiarization and utilitarianism is eventually transferred to the poems themselves, which become weaponized as tools for pwning.

The player "Poems you should know" came to consider his selecting, dragging and copying of the poem lines as an additional gaming action; in fact, "using one's mouse to aim at objects and perform an operation on the target" describes adequately both the actions of retrieving the poem lines and of shooting at opponents in CS: GO. Reading, writing, targeting, shooting. Each 
line of the text is inserted in sequence and within a reasonable delay from one to the next; reaching the end of the poem without having been kicked out of the game by allies or opponents becomes the all-encompassing objective of both the play and the performance.

Furthermore, if the textual component of the poems became an extension of the game, a quantity to be transferred in the chat window in order to achieve a specific goal of the game, then, in a sense, the poems did become a part of the game, as much as the maps of the space or the array of weapons and accessories one needs to buy before every round of CS:GO begins. The poem was part of the play, was played, while it was performed. When the last line of a poem is read aloud by "You should know poems," it doesn't matter who-between the terrorists and the counter-terrorists-is ultimately declared the winner. In the advanced version of the game we establish, "poetry wins." Literary pwning occurs. The performance overtakes the game. The expected "terrorists win" or "counter-terrorists" win is a sad echo after the lines of Wordsworth's "Daffodils."

The slang term "Pwning" has yet to achieve the official recognition bestowed by its inclusion in the prestigious pages of the OED or the MerriamWebster. As it is, we can find a definition in the "urban dictionary" as: "A corruption of the word 'Owned.' This originated in an online game called W arcraft, where a map designer misspelled 'owned.' When the computer beat a player, it was supposed to say, so-and-so 'has been owned.' Instead, it said, soand-so 'has been pwned.' It basically means 'to own' or to be dominated by an opponent or situation, especially by some god-like or computer-like force" (2017). Additionally, Wikipedia explains that "[i]n script kiddie jargon, pwn means to compromise or control" (2017). What constitutes a "pwning" is eminently subjective; it is up to the players to determine if and when pwning has occurred and by which standards. "Pwning" is a malleable signifier.

When we manage to "achieve" our goal (complete our performance?), we are satisfied. We have triumphed against the odds; facing skilled enemies, outgunned, burdened with the responsibility or transmitting poetry to fellow players, encumbered by this task to the point of being paralyzed by it most of the time, still, we succeed, the poems are read, the poems are now known. We pwned players. But that's not all: we also managed to engage some of the players and, instead of lambasting, we were greeted with polite questions, laughter, even enthusiasm, from times to times. During one performance, a player reciprocated by spontaneously reciting Lewis Carroll's "Jabberwocky" from memory.

Still, that's not all; from time to time, one of the performers actually hit someone with a bullet. It was mostly blind luck, but nonetheless, how about that! During a performance on November 30, 2016, player "Poems you should 
know" paused his shuffling between Notepad and CS:GO long enough to aim his weapon at an unsuspecting opponent and down him with a "headshot." This rare occurrence elicited an uproar from nearly every other player. Participants of the game were by this point well aware of our peculiar approach to the game and were both impressed that one of us could manage to contribute to the fight while busy copy-pasting lines from Whitman and delighted to taunt the slain player. This opponent who fell victim to "Poems you should know" had been completely pwned by poetry.

Back to the question: what should you do in CS:GO? To be a terrorist or counter-terrorist is no small matter in contemporary society. The idea that "poems matter more than ever" seems little consolation. Both Counter-Strike: Global Offensive and Poems You Should Know carry out a sentence and seek to pwn the space of the game. They are counterstriking imperatives in Counter-Strike. "I pwn you" does not just mean I win but that I dominate entirely, utterly, without limit. I "own” you, yes. But it is more this, and the slippage from own to pwn, the typographical force, the phonetic shift, and the lingual transformation from owning to the pursed lips of pwning: all this invokes a dimension of ownership and domination that the words ownership and domination do not capture.

Poems You Should Know proposes that pwning is the imperative of poetry. The occupation of a game of CS:GO by Wordsworth's "Daffodils" is the ultimate pwnage.

\section{Notes}

1 Gabriel Tremblay-Gaudette was behind that moniker for the series of performances.

2 Sandy Baldwin was behind that moniker for the series of performances.

3 This definition can be found at <http://eliterature.org/what-is-e-lit/>.

4 Cf. Frasca, Gonzalo. "Videogames of the Oppressed: Critical Thinking, Education, Tolerance, and Other Trivial Issues," in First Person. New Media as Story, Performance, and Game, edited by Noah Wardrip-Fruin and Pat Harrigan, Cambridge, MA: The MIT Press, 85-94, p. 88.

5 We cite "Daffodils" from < https://www.poets.org/poetsorg/poem/daffodils $>$. This poem is in the public domain.

6 Cf. Academy of Poets web site <https://www.poets.org/>.

7 Cf. Academy of Poets web site <https://www.poets.org/>. 
8 Cf. page <https://www.poets.org/poetsorg/anthology/poems-everyoneshould-know $>$.

9 Cf. article <https://www.thetimes.co.uk/article/30-great-poems-everyone-should-know-732g9fc5l>.

10 At any time during a match, a player on any team can initiate whenever she wishes a "votekick" which, as its name suggests, allows players to kick a target out of a room via voting. On CS: GO's Wiki page, the following official reasons are listed as motives for a votekick: "Illegal programs/ Cheating Racism/ Inappropriate words/ Player harassment AFK (away from keyboard) Bugs/ Poor sportsmanship/ Others." Initiating a votekick is extremely simple—one only needs to hit the Caps Lock key and select a player - and the decision is made by pressing a single key.

\section{Works Cited}

Baldwin, Sandy, and Yvonne Hammond, Katie Hubbard, Kwabena OpokuAgyemang, Gabriel Tremblay-Gaudette, Philip Zapkin. "Beckett spams Counter-Strike.” Sens-Public. \#6. 2016. 24 Aug. 2017 <http://www.senspublic.org/article1205.html>.

DeLappe, Joseph. “dead-in-iraq.” delappe.net. 2011. 24 Aug. $2017<$ http://www.delappe.net/project/dead-in-iraq/>.

Donne, John. "Holy Sonnets: Death, Be Not Proud" [1633]. Poetry Foundation. 2017. 24 Aug. 2017 <https://www.poetryfoundation.org/poems-and-poets/poems/detail/44107>.

Lear, Edward. "The Owl and the Pussy-Cat" [1871]. Poetry Foundation. 2017. 24 Aug. 2017 <https://www.poetryfoundation.org/poems-and-poets/poems/detail/43188>.

Mattes, Franco, and Eva Mattes. "Freedom." 0100101110101101.org. 2010. 24 Aug. 2017 <http://0100101110101101.org/freedom/>.

Parker, Felan. "The Significance of Jeep Tag: On Player-Imposed Rules in Video Games.” Loading..., vol. 2, no. 3 (2008). 24 Aug. 2017 <http://journals.sfu.ca/loading/index.php/loading/article/viewArticle/44>.

Phillips, Whitney. This Is Why We Can't Have Nice Things. Mapping the Relationship between Online Trolling and Mainstream Culture. Cambridge, MA: The MIT Press, 2015.

"Pwn." Wikipedia, the free encyclopedia. 2017. 24 Aug. 2017 < https://en.wikipedia.org/wiki/Pwn>. 
"Pwning." Urban Dictionary. 2017. 24 Aug. 2017 <http://www.urbandictionary.com/define.php?term $=$ pwn $>$.

Serres, Michel. The Parasite. Minneapolis, MN: University of Minnesota Press, 2007.

Whitman, Walt. "I Hear America Singing" [1860]. Poetry Foundation. 2017. 24 Aug. 2017 <https://www.poetryfoundation.org/poems-and-poets/poems/detail/46480>.

Wordsworth, William. "I Wandered Lonely as a Cloud" [1807]. Poetry Foundation. 2017. 24 Aug. 2017 <https://www.poetryfoundation.org/poems/45521/i-wandered-lonely-as-a-cloud $>$. 

Part Three:

Where is Narrative? 



\section{Carlos Reis}

\section{Character: A Concept That Does Not Stand Still}

1. In a text published in 1976, Amélie Rorty wrote: "The concept of a person is not a concept that stands still, hospitably awaiting an analysis of its necessary and sufficient conditions" (Rorty 301). I quote these words from the "literary postscript" of the volume The Identities of Persons (1991), edited by Rorty, in order to point out their interest for a field of study which, at first sight, would seem to have only tenuous connections with theory of character. The field in question is that which deals with philosophy of mind, emotion work, and the mind-body relationship.

However, it was that brief reference to the concept of character as a dynamic entity that served as the starting point for Rita Felski in her introduction to issue no. 42 of the journal New Literary History (2011): "Riffing off an observation by Amélie Rorty, we could say that the concept of character is not a concept that stands still" (Felski V). The context in which Felski's words appear should be taken into account. This was the introduction to a special issue of New Literary History devoted entirely to the question of character. That introduction confirms the theoretical and epistemological "resurrection" of an area of study that was apparently exhausted, namely that of character: "In the last decade, however, we have seen the sudden revitalization of a once moribund field" (Felski V). Finally, the parallel between the person (in Rorty) and the fictional character (according to Felski) enables two distinct trajectories: one leading from person to character, and the other going in the opposite direction, from character to person. In short: "People inside and outside works of art” (Felski VI). Or in other words: characters don't stand still.

I am not going to follow here the route proposed by that important issue of New Literary History. I would, however, like to stress its significance in the light of how narrative studies have developed in the last twenty years. What is more, there is no analysis in it that comes at all close to what is important right now: understanding the extent to which digital technologies and networking have resulted in the reconfiguration of a category — character - which had for centuries been content to stay put in the place that had been allocated to it by narrative. It is also important to observe that reconfiguration with the proper historical perspective, so as to identify some precursors or (if I may put it like this) "founding characters."

The final words of Felski's text seem promising in the sense that they announce something new: "No doubt, a certain conception of what constitutes character — an idea of unified, unchanging, intrinsic, or impermeable person- 
hood-is no longer sustainable on theoretical or historical grounds" (Felski IX). For me, that implicit promise of a new world in which character has to be reanimated raises a challenge, one with both a theoretical dimension and an analytic potential; and I shall respond to it in function of a major personal research project whose beginning I can locate but whose end is not in sight. ${ }^{1}$ From this project, I will develop certain emblematic texts and several suggestions of analysis. What I read into this research project is a specific route: from a conception of character as a static narrative element, I arrive at its "reconstruction" as a dynamic, unstable, even evanescent category. In short, as I suggest in my title (directly imported from Felski and indirectly from Amélie Rorty), character is "a concept that does not stand still."

2. In 1874, the great Portuguese novelist Eça de Queiroz published his first consistent and ambitious tale involving the conditioning of character and the narrative work that this entails. It is a short story of some considerable length, entitled, in its English translation, "The Idiosyncrasies of a Young Blonde Woman" (2009), a title which already tells us something, for, as suggested here, the story centers upon a character that is unusual, or rather, somewhat strange. In a second-hand account, because it is told by someone that heard it and reproduces what he was told, we hear about an unfortunate amorous incident in which a young man, honest and hardworking, falls in love with a "blonde woman," who turns out to be a kleptomaniac. The story, as we might expect, does not end well, and Macário, the protagonist, realizing his fiancée's predilection for stealing, decides to expel her from his life: “'Go!' And moving closer to her he said: 'You're a thief!'” (Queiroz 138).

Everything in the short story rings true if we take into account the aesthetic and ethical framework of realism that the young Eça had begun to adopt as his literary project: the characters are clear-cut and their values well defined, determining behaviors and producing consequences that cannot be avoided. As if wishing to underline the principle of how character is stable and predictable, Eça offers a description, right at the beginning, which, for me, is exemplary. The narrator, having arrived at a small provincial hotel and climbed to his room, sees what is described in the text as follows:

Room number 3 was at the far end of the corridor. Outside the doors on either side the travelers had placed their shoes to be cleaned: there were heavy riding boots all covered in mud, complete with spurs and chains; the white shoes of a hunter; the tall, red boots of a landowner; the high boots of a priest, with their silk tassels; the battered calfleather ankle boots of a student; and, outside one of the doors, number 15, a pair of women's boots, tiny and slender, with beside them 
the even tinier lace-up boots of a child, all scuffed and worn, the unlaced legs of the kid boots flopped over to one side. Everyone was asleep. (Queiroz 120)

There are two discursive procedures combined here, pointing in a clear direction. First: the way the guests' shoes and boots are described in itself reveals a great deal about the social, cultural and professional aspects of these characters, who are fixed in stable roles. In some cases, these roles are very close to what we call social types: a priest, a student, a hunter, a landowner, etc. Second: they are objects of a certain nature which, through a process of metonymy, announce the characters that are associated with them. In short: tell me what kind of shoes you wear and I will tell you who you are-to the extent that we don't need to actually see them. We let them sleep in peace, because the principle of predictability has been confirmed, establishing a security regulation that protects the reader against surprises and the effort of unpredictable reading. In other words: the conventional realist character does not stray beyond the framework of behaviors attributed to it for the comfort of a reader that is passive and perhaps even a little lazy.

3. Curiously, the figure that I have called (in a deliberately reductive manner) the realist character may actually be considered a regressive feature. To prove this, I shall compare it with narrative and fictional antecedents which, earlier in the $19^{\text {th }}$ century, had proposed a dynamic, and to all effects more modern concept of character. Here, I am referring to certain key aesthetic and philosophical concepts deriving directly from the Romantic worldview, according to which textual practices and the figuration of characters were governed by the values of instability and change.

The aesthetic of the fragment, understood as "the Romantic genre par excellence" according to Lacoue-Labarthe and Nancy, already foreshadows a freeing-up of language that the digital tools and electronic composition would later make fully effective. The Romantic fragment brings with it "the relative unfinishing," "the variety and mixture of objects that could be treated by a single collection of parts." Thus, "the unity of the whole" comes to be "constituted somehow outside the work, in the subject that is revealed in it or in the judgement that enables its maxims" (Lacoue-Labarthe and Nancy 58).

The Romantic character is similarly configured. In its nature, its social and moral attitudes, its reactions to life and to other men, it is a sign of permanent instability. The portrait that is drawn of it, or which one might hope to draw of it, has difficulty in defining the features of a character affected by change and unpredictability. It is the super-energy of the Romantic hero that precludes an image reduced to stable characteristics. 
Almeida Garrett, the most important writer of Portuguese Romanticism, seems determined to portray a character that is inconstant and voluble, something that is frequent in figurations of European Romanticism. It is a kind of impossible project, as we see in Chapter 20 of Travels in My Homeland (1987), Garrett's masterpiece novel, a hybrid account, which combines elements of travel writing, the novella, the fragment and the essay. It is in that chapter that the impossible portrait of the hero is spelled out, dispersed between commentaries, advances, withdrawals and interpellations to the reader:

His eyes, which were grey and not very large, but extremely bright and lively, displayed the talent, the volubility, perhaps the thoughtlessness, but also the upright simplicity of a frank, loyal and generous character, quick to anger and quick to forgive, incapable of taking offence lightly, but unable to forget a real insult. . . . When he was silent and serious, his countenance could be said to be hard, but the slightest excitement, the merest smile, made it cheerful and sunny, because volubility and seriousness were the twin poles of that unusual, not easily understood character. (Garrett 116)

Volubility and bipolarity, are two terms which, explicitly or implicitly, appear in this figuration, which is condemned to be a failed attempt. In the case of Eça's short story, the characters were recognizable only by their shoes, and nothing more was necessary for them to be identified and remain static, as suited the realist doctrine. In Garrett's text, the character in constant movement means that stabilization is not an option, which opens up the way to a dynamic condition, long before the tools were available that today give full meaning to that potential.

4. I know well that, in Garrett's character, the tendency for change and bipolar oscillation has its roots, as I have already observed, in a worldview which makes that tendency necessary and justified. In other words: I am aware that mutability is not yet a property established by tools such as those that the digital world makes available, within a framework of technical references that Garrett, of course, did not know. And the reader, despite being often interpellated by the narrator, continues passive as regards the development of the story and characters. However, none of this prevented Garrett from conceiving a text in which I have long been able to read the assumption of a hypertextual logic inscribed into the genetic code of Travels in My Homeland. I recall what I defined in a 1999 essay as "the hypertextual suggestions of the Travels" (Reis, "As Viagens como hipertexto" 123), ${ }^{2}$ founded on principles which we recognize in hypertextuality per se: the principle of interactivity, translated into a conception of the reader as an entity that is challenged to react, albeit rhetorically, to the text; 
the principle of openness, which implies a text constructed as a syntagm of fluid syntax, permitting advances and withdrawals, and differentiated reading pathways; the principle of plurality, through the use of various genres and narrative levels, without any kind of fixed or rigid compartmentalization; the principle of fragmentation of the text into autonomous units, which the reader works to interrelate; the principle of simultaneity of times and spaces summoned for a reception in which the past and the present co-exist; the principle of playful activation, through the cultivation of an attitude that vacillates between entertainment and knowledge, risk and security, certainty and uncertainty, the fictional and the real.

Much of this is in Travels in My Homeland and its characters, particularly in that protagonist of the unstable portrait (if we can phrase it this way) of whom I have already spoken. And obviously, before Garrett was Laurence Sterne, expressly mentioned in the prologue and text of Travels in My Homeland; and after both of them came the great Brazilian novelist, Machado de Assis, an admirer and confessed follower of the author of The Life And Opinions of Tristram Shandy (1759) and also of Almeida Garrett.

I shall give just one example, taken from The Posthumous Memoirs of Brás Cubas, the most "Sternian” of Machado's stories, published in 1881, almost 40 years after Travels in My Homeland. I shall again focus on character and its movements to reaffirm that dynamic condition which, long before the digital era, cultivated a figuration in constant mutation. In Chapter 90, in virtual dialogue with the son that is about to be born, Brás Cubas anticipates a future which involves the many facets and diverse conditions of that much-longed for son. The narrator says:

The best thing was that we would both converse, the embryo and I, talking about present and future things. The rascal loved me, he was a funny little rogue, giving me little pats on the face with his chubby little hands or then sketching out the shape of a lawyer's robe, because he was going to be a lawyer and he would make a speech in the chamber of deputies. And his father would listen to him from a box, his eyes gleaming with tears. (Assis 135)

He continues his voyage in time in which the character (who is practically virtual, still an embryo) is one and is many, simultaneously concentrated, multiple and radically subjective:

From lawyer he would go back to school again, tiny slate and books under his arm, or then he would drop into his cradle and stand up again as a man. I sought in vain to fix the spirit in one age, one appearance. That embryo had my eyes, all of my forms and gestures. He 
suckled, he wrote, he waltzed, he was interminable in the limits of a quarter hour-baby and deputy, schoolboy and dandy. (Assis 135)

5. How can we pass from $19^{\text {th }}$ century narrative to the mutations and developments brought by digital media and technologies? The response that I shall try to give to this question does not have the form of a temporal or conceptual rupture. Or rather, it does not cancel a certain narrative tradition and enunciation of the account/story. It is understood as a precursor of narrative experiences that the digital era has made viable: videogames and narrative in its digital format and electronic environment.

As regards videogames, particularly those that manifest a certain narrative impulse, their association with the logic of the fictional story as such is justified in function of the various features that they have in common: the advance of the story or game along a time line; uncertainty as regards its outcome; the use of simulation procedures with the "voluntary suspension of disbelief" and also the representation of figures — avatars or characters - that perform the action and display what appear to be human traits. The specificity of videogames is defined in the following observation: "The only feature that objectively and absolutely defines video games is their dependency on the computer as a material support" (Ryan 181). From there, Marie-Laure Ryan adds: "But if there is a general tendency that distinguishes them from other formalized games (sports and board games in particular), it is their preference for organizing play as a manipulation of concrete objects in a concrete setting - in a fictional world rather than on a mere playfield" (182).

The figuration of characters in videogames takes on a special significance in this context. I am referring to those games in which the character plays an important role: he or she is, in the language of videogames, a "playable character," that is, a figure whose actions are decided by the player and not by the internal rules of the game. The process of identification between player and character, typical of this kind of game, occurs in a framework of effective interactivity, which is non-existent in the reading of the conventional novel. But that does not completely detach the relationship of the player with the "playable character" from that other more diffuse interaction provoked by the novel, when a reader projects onto his or her own behavior something that he or she has read, or believes he or she has read, in the fictional character. The psychological and cultural condition that we call Bovarism, as a character-effect (cf. Jouve 132) is a pertinent example of this, though by no means the only one.

This implies that the narrative universe of videogames, on the side of both authorship and interactive reception, certainly owes something to a persistent narrative memory which cannot be expunged. On the contrary, it is reflected in the construction of narrative videogames and their characters. I believe 
(though I cannot prove this here) that the behaviors and trajectories that the player attributes to the characters, and the outcomes that result from this, is an extension of the narrative experience of motives, stereotypes and human development that has such a broad tradition in Western culture and its stories. Another approach, which would lead me to make value judgements that I cannot do at present, would be to compare the literary character in its sophisticated complexity with the simplified schematization of the "playable character." Instead, I prefer to emphasize the following point: that certain literary characters — such as those in Garrett and Machado de Assis that I have called unstable and mutable - prefigure what digital technology allows us to do with other characters in a mediatic context that favors limitless interactivity.

In any case, whether we are concerned with the time of the $19^{\text {th }}$ century novel or the digital era, narrative was and continues to be a demanding and fascinating meaning-making machine. In all cases, it is important to note that the digital narrative, enunciated in the electronic environment, has overcome certain principles and routines that were (and still are) dominant in verbal narrative, in general terms. First: textuality no longer obeys a linear and unidirectional logic. Second: authorship is no longer univocal, but instead has been opened up to collaborative composition involving multiple voices. Third: the narrative composition is made up not only of words but also of images, sounds, graphics, etc. Fourth: the text is open to reading trajectories that do not obey a rigid syntax but construct meanings through interactivity.

6. When a constraint-free textuality is elaborated in the framework of narrative texts, certain categories inherited from a long literary past become the object of radical revision. The character and its figuration is one domain in which that revision becomes inevitable, and may enable the establishment of a direct relationship between it and two concepts that I consider to be complementary: the concept of transmedia fictionality and the concept of emergent narrative.

Transmedia narrative "releases" fictional worlds from the restricted scope of literary narratives: "By now fictionality has become an important notion not only in literary theory but also in other disciplines, such as film studies, theater studies, computer games studies, and more generally the philosophy of art" (Zipfel 103). From here it is a short step to two correlated notions: the transmedia character and the "multimodal novel." As regards the second, I follow Wolfgang Hallet, who, without speaking expressly of digital narrative, says "since the 1990s an ever-growing number of novels have not merely consisted of verbal text," aggregating into the narrative discourse (itself a renewed concept) components such as "typed, handwritten, or electronic letters; film scripts; websites; pieces of academic writing; and many other generic forms" 
(151). All this ends up transforming the reading process into an act of multiliteracy.

The characterization of emergent narrative is deduced from the primordial concept of emergence, diffused through various disciplinary contexts (cf. Walsh 73). Proposed by Tinsley Galyean over two decades ago (cf. Galyean), the expression emergent narrative brings to narrative studies the possibility of analyzing stories that have effectively emerged out of pre-narrative situations (such as a basic plot structure); from these pre-narrative situations, collaborative and interactive reading trajectories open out, generating a narrative which thus passes from the virtual to the active plane.

Narrativity is thus understood as a property that is as yet unverified in terms of verbal textuality but has instead an anthropological dimension. For this, Monika Fludernik argues "that narrativity is a function of narrative texts and centres on experientiality of an anthropomorphic nature" (Fludernik 26). If we accept this post-narratological definition of narrativity, we can also accept that "narrative is emergent, since it has emerged from human life experience. If 'life' seems too grandiose a concept to fit into a VE [virtual environment], there are smaller-scale examples in which explicit narrative structure is absent but narrative frequently emerges through interaction" (Aylett 84).

From here we drift to "smaller-scale examples" such as videogames and associate them both with real games in which they are often inspired, and with characters, also emergent, that are manifested in them. Ruth Aylett gives the example of football, as a team game in which we observe the emergence of narrative motivated by the behavior of certain appealing characters. The example suits me for two reasons: one, because a considerable number of videogames reproduce (using digital tools in an electronic environment) lively football matches, which are often more exciting than those we see live or on TV; second, because from football and its media treatment (and indeed, its representation in videogames) characters emerge with an impressive presence not only on the field but also off it. I realized this when I analyzed the media figurations and images of Cristiano Ronaldo and Lionel Messi; they are an actualization (a narrative actualization, obviously) on the sporting level of the ancestral motif of the brothers in arms (cf. Reis, Pessoas de Livro 171-172). Returning to Aylett's text: “it's easy to understand which of the two characters corresponds to the description of the 'talented but petulant player who retaliates when fouled"” (Aylett 84).

7. I will not hide my difficulty (and it is certainly not mine alone) in fully apprehending character as an element renewed by narrative in digital support. I have at least two explanations for this. First: we are dealing with technologies in rapid change, not always, I suppose, motivated by effective needs of perfect- 
ing the available tools. Economic interests which, in the world of computer sciences, intervene in research and development (R\&D), create expectations that are often artificial and superfluous; false needs, in short, at least for the current user. The industry that generates those expectations responds to them with new products, rendering obsolete operating systems and programs, which become literally unusable. And thus, whoever today wants to "read" the founding works published by Eastgate Systems Inc. in Storyspace software, such as afternoon, a story (1987), by Michael Joyce, Victory Garden (1992), created by Stuart Moulthrop or Patchwork Girl (1995), by Shelley Jackson, has extreme difficulty in accessing the versions originally produced in that software.

In addition to that (second explanation), the cognitive attitudes demanded by electronic literature - by its narratives or proto-narratives, by the lines of action proposed, the characters that emerge from them, those attitudes derive from a communicational paradigm that is not established. Or from a multiliteracy to which I have to adapt. I move through Michael Joyce's Twelve Blue (1996) or Anne-Cécile Brandenbourger's Apparitions inquiétantes (1998) and I situate myself in a context of interaction that dissolves and disperses the fictional character which, for me, was a stable and sometimes friendly figure. It's not easy to erase from our own cognitive routines a reading tradition which, particularly since the $18^{\text {th }}$ century, has installed in our imaginary the faces and attributes of Robinson Crusoe, Tom Jones, Oliver Twist, Julien Sorel, Emma Bovary, Anna Karenina and Don Fermín de Pas, the Magistrate who, in a provincial Spanish city, seduced the beautiful Ana Ozores, who was also called "la Regenta." The same character, or perhaps already another that I still recognize when I pass by the Cathedral in Oviedo and come across her life-size statue, as flagrant evidence of the survival of a fictional figure.

After these and other characters, modernist and postmodernist literature, from Mallarmé to Jorge Luis Borges, passing through Fernando Pessoa (or Bernardo Soares), James Joyce, Kafka, Raymond Queneau and Julio Cortázar, gradually announced, as yet without suitable digital tools, the communicational paradigm of electronic literature. And already before these, writers of the $19^{\text {th }}$ century (I recall Almeida Garrett and Machado de Assis) sketched characters in whom we read a certain impulse to free themselves from narrative constrictions which do not threaten their congenital instability. That instability, in complicity with digital narrative in its different manifestations, is deepened in texts and proto-texts in which narrativity remains active or latent. As someone said: before the digital narrative and its evanescent characters, we could read Bernardo Soares's Book of Disquiet (first published in 1982), fragments of Finnegans Wake (1939) or Rayuela (1963) by Cortázar. In all of them there emerge (invariably in a diffuse form) figures that reject the consistent character constructed by the $19^{\text {th }}$ century novel: or, in an expression that evidently has pa- 
ternity, all are assimilated to the "man without qualities" of a time of sick dispersion and ontological crisis without solution. Some of this was suggested by Bernardo Soares, when one day, in Lisbon, on the bank of the River Tagus, he hesitated between the inertia of tranquility and the instability of what he could not attain. Or rather: between being a stable figure or giving in to the temptation of disquiet, which makes him an impossible character in various titles. A character that "does not stand still":

Sometimes, lost in vain meditation, I stand for hours in Terreiro do Paço, by the river. My own impatience tries again and again to tear me away from that quiet state, but inertia holds me fast. Gripped by a physical torpor, which resembles sensuality only to the extent that the whispering of the wind resembles human voices, I meditate on the eternal insatiability of my vague desires and on the perennial instability of my impossible longings. What afflicts me most is a sickness which is really only my capacity for suffering. I lack something I do not want and suffer because this is not true suffering. (Pessoa 93)

\section{Notes}

1 Project Figures of Fiction: < https:// figurasdaficcao.wordpress.com/>. A dictionary about Portuguese characters (<http://dp.uc.pt/apresentacao/dicionario-de-personagens-da-ficcao-portuguesa $>$ ) and an annual colloquium (please visit <https://figurasdaficcao.wordpress.com/2017/07/18/5o-coloquio-internacional-figuras-da-ficcao/ $>$ ) are being organized under this project.

2 All translations were done by Karen Bennet.

\section{Works Cited}

Assis, Machado de. Posthumous Memoirs de Brás Cubas. Translated by Gregory Rabassa. New York and Oxford: Oxford University Press, 1999.

Aylett, Ruth. "Narrative in Virtual Environments. Towards Emergent Narrative." Proceedings of AAAI Symposium on Narrative Intelligence. Menlo Park, CA: The AAAI Press, 1999, pp. 83-86.

Felsky, Rita. "Introduction." New Literary History, vol. 42, no. 2, Spring 2011, pp. v-ix. JSTOR, 9 Sept. 2017 <https://www.jstor.org/stable/i2301253$8>$.

Fludernik, Monika. Towards a 'Natural' Narratology. London: Routledge, 1996. 
Galynean, Tinsley. Narrative Guidance of Interactivity. Cambridge, MA: The MIT Press, 1995.

Garret, Almeida. Travels in My Homeland. Translated by John M. Parker. London: Peter Owen Publishers, 1987.

Hallet, Wolfgang. "The Rise of the Multimodal Novel: Generic Change and Its Narratologic Implications." Storyworlds Across Media. Toward a MediaConscious Narratology, edited by Marie-Laure Ryan and Jan-Noël Thon. Lincoln and London: University of Nebraska Press, 2014, pp. 151-172.

Jouve, Vincent. L'effet-personnage dans le roman. Paris: P.U.F, 2008.

Lacoue-Labarthe, Philippe, and Jean-Luc Nancy. L'Absolu littéraire. Théorie de la littérature du romantisme allemand. Paris: Seuil, 1978.

Pessoa, Fernando. The Book of Disquiet. Translated by Margaret Jull Costa. London: Serpent's Tail, 1991.

Queiroz, Eça de. "The Idiosyncrasies of a Young Blonde Woman." The Mandarin and Other Stories, translated by Margaret Jull Costa. Sawtry: Dedalus, 2009.

Reis, Carlos. “As Viagens como hipertexto: hipóteses de trabalho.” Leituras, Revista da Biblioteca Nacional, 4 (1999): pp. 115-123.

. Pessoas de Livro. Estudos sobre a Personagem. 2nd ed. Coimbra: Imprensa da Universidade de Coimbra, 2016.

Rorty, Amélie Oksenberg, editor. The Identities of Persons. Berkeley, Los Angeles and London: University of California Press, 1991.

Ryan, Marie-Laure. Avatars of Story. Minneapolis, MN: University of Minnesota Press, 2006.

Walsh, Richard. "Emergent Narrative in Interactive Media." Narrative, vol. 19, no. 1, Jan. 2011, pp. 72-85. Project Muse, 9 Sept. $2017<$ https://muse.jhu.edu/article/413054>.

Zipfel, Frank. "Fiction across Media: Toward a Transmedial Concept of Fictionality." Storyworlds Across Media. Toward a Media-Conscious Narratology, edited by Marie-Laure Ryan and Jan-Noël Thon. Lincoln and London: University of Nebraska Press, 2014, pp. 103-125. 



\title{
María Goicoechea de Jorge
}

\section{Shelley Jackson's Grotesque Corpus}

\author{
Notes on my body — a Wunderkammer
}

For no one has thus far determined the power of the body.

Benedicto Spinoza, Ethics

\section{Introduction: Shelley Jackson's Grotesque Corpus}

The body - that place from which the concept of self emanates, the locus where the subject conflates with the socio-cultural regulations that provide its frame-is for Shelley Jackson the fundamental canvas on which to display her work. The different metaphors of the body present in her pieces share a common aspect: the author is not concerned with beautiful bodies, but rather with deformed, hybrid, tragicomic, grotesque ones. These bodies deviate from the established beauty canon in the same way that the hypertexts used to contain them overflow the limits of a conventional reading economy. The reader generates her own grotesque feeling when faced with a textual framework that devours her without rhyme or reason, without revealing its confines, its routes, and where she must advance half-blindly, groping in the dark the interior of a fragmented and intertwined textual body, at once vital and morbid. Jackson colonizes hypertext as a feminine writing space, warning beforehand of its ugliness, transforming ugliness in an aesthetic manifesto, a vindication of the grotesque at the hands of the author. Shelley Jackson makes use of the disfigured body to pose a critical stance regarding the social regulations that constrain, not only the feminine body, but also the corpus of her creations.

As we will see, Patchwork Girl (1995) and my body —a Wunderkammer (1997) are two variations on the same theme, the history of the body as a space in which the subject is progressively constructed and acquires its identity traits. ${ }^{1}$ The mind-body relation does not emerge from an ontological integrity, but in the immanent and recursive parceling, fragmentation, and reconstruction of the whole, the subject, by a reflexive and creative self through a variety of metaphors. These metaphors allude to the mechanisms by which the notion of the subject is reconstructed: acts of fictional creation like reading and writing. In the case of Patchwork Girl, sewing, as an eminently feminine activity, becomes a synonym for female writing and the reading mode recommended by the hyper- 
text ("I am buried here. You can resurrect me, but only piecemeal. If you want to see the whole, you will have to sew me together yourself').

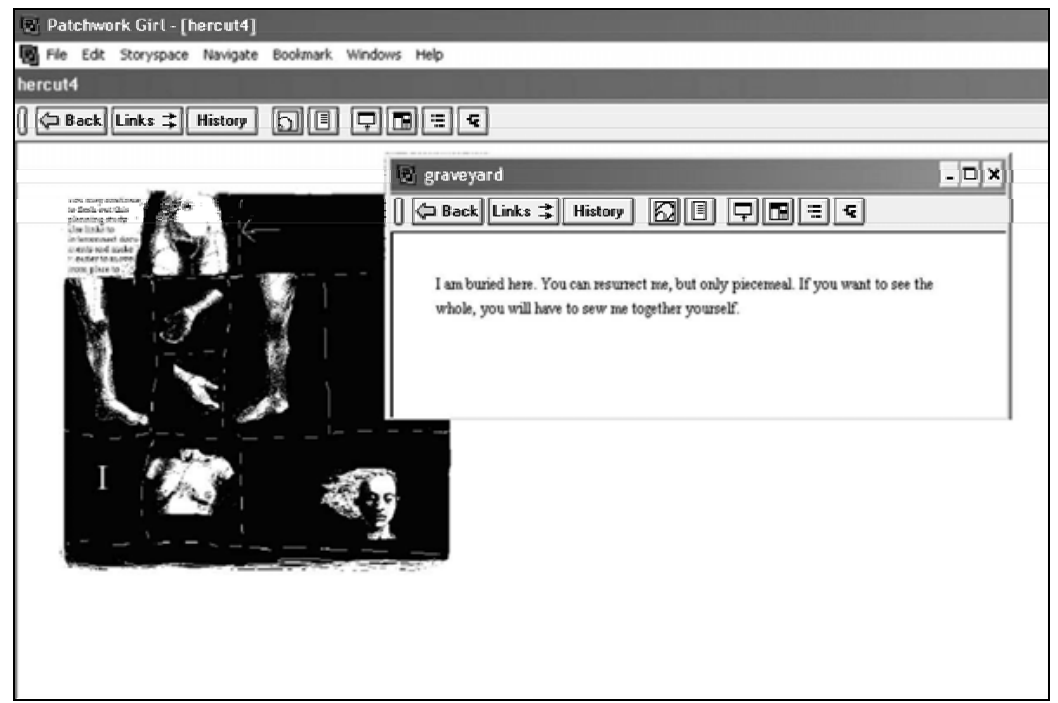

Fig. 1. First and second lexias of the "Graveyard" section of Patchwork Girl.

In my body-a Wunderkammer, the cabinet of wonders is the metaphor around which the textual fragments as well as the reader disposition are articulated- the body exhibits itself with the promise of surprising visitors with the revelation of some deformity, anomaly or grotesque eccentricity.

The exhibition of grotesque bodies is a recurrent theme in Jackson's work, both digital and in print. We can read, for example, her first print collection The Melancholy of Anatomy (2002), where, as Lance Olsen has observed, "the engaging and the invigorating discover their source in the contaminated, the infected, the mongrel, the ill-defined, the unhygienic, the grotesque, the interstitial," Jackson's corpus affirms the freakish, Lance states, because for her the freaks are the real survivors in "evolutionary, gender, and narratological terms" (4). I believe we should pay closer attention to the mechanisms by which Shelley Jackson makes use of the aesthetic quality of the grotesque to construct her corpus, both fictional body and artifact; at the same time a strategy to reflect on the connection body/self and a critical stance regarding the expressive possibilities of hypertext as a medium. Or, we should rather say, the grotesque is in Shelley Jackson a mode of figuration used to explore the limits of any form of writing to apprehend the self. As we read in Patchwork Girl: "You could say that all bodies are written bodies, all lives pieces of writing" ("all written"). 
The grotesque style shares with the monster of Patchwork Girl a subterranean origin. From the Italian word grottesco ("of a cave"), the grotesque emerged during the Renaissance as an imitation of an Ancient Roman decorative style rediscovered when Nero's unfinished palace Domus Aurea was excavated. As the distorted mirror image of Neoclassical values, the grotesque was characterized by excess, extravagance, lack of symmetry and proportion, by reflections of organic excrescence growth in arabesques and contorted shapes that yielded strange, hybrid bodies. The grotesque glance implies therefore a particular deformation of reality that produces in the viewer a complex reaction of disgust and empathy, a tragicomic relief that allows society to integrate that which is unexplainable, unclassifiable, mysterious and absurd.

As Rémi Astruc (2010) contends, the grotesque — which profusely emerges in times of change and transformation-provides a form of expression to a primeval and universal experience of alterity and change, prior to any attempt at conceptualization, either in philosophical or aesthetic terms. It emerges from a sensation of curious surprise towards the world on the part of the subject (3), who tries to apprehend the unknown through the anthropological operators of the grotesque aesthetics: reduplication, hybridity and metamorphosis. And we should not lose sight, Astruc reminds us, of the first anthropological operator from which all human experience is constructed: the body.

In his article "The Grotesque Body: Overflow and Signification" (2008), Barrios discusses the body as a socio-semiotic construction regulated from highly coercive control dispositifs and the grotesque as a subversive reaction to them. The grotesque body functions as a social destabilizer of the control apparatus. Appropriating the Cynical attitude, the grotesque also identifies the body — with its porous skin, its orifices, and the immediacy of its scatological functions — as the locus of resistance against the idealized and strategic discourses of Greek philosophy (6). In its aesthetic sense, Barrios argues: "the grotesque is fundamentally defined by the overtaking of identity, which implies an opposition in principle with the beauty canon as that which basically defines the status of the body in Western culture" (16). ${ }^{2}$

If as Astruc and Barrios argue, the grotesque responds to a universal, anthropological need, an artist might reach its potentialities without too much philosophical scaffolding. Nevertheless, I would rather think it is the liminal status of the grotesque as an aesthetic category, especially in literary theory, which makes it an appealing mode of expression for such a meta-reflexive author as Shelley Jackson. A deceptive or even anti-cognitive concept, ${ }^{3}$ it provides a space of expression where other more regimented categories, such as the absurd, the ludicrous or the macabre, might fail. Moreover, the grotesque is always playing at overflowing the limits, but as it goes, it is always referenc- 
ing those boundaries it continuously trespasses, the boundaries of what is considered proper, pertinent, respectful, and decorous.

I would like to posit that analyzing Shelley Jackson's corpus under the light of the grotesque as aesthetic category provides us with yet another tool to understand her work across different media, and it is especially relevant in her approach of hypertext. Shelley Jackson writes in "Stitch Bitch" (Boundary Play Section):

But hypertext in particular is a kind of amphibious vehicle, good for negotiating unsteady ground, poised on its multiple limbs where the book clogs up and stops; it keeps in motion. Conventional texts, on the other hand are in search of a place of rest; when they have found it, they stop." Similarly, the mind, reading, wants to make sense, and once it has done so it considers its work done, so if you want to keep the mind from stopping there, you must always provide slightly more indicators than the mind can make use of. There must be an excess, a remainder. Or an undecidable oscillation between possibilities. I am interested in writing that verges on nonsense, where nonsense is not the absence of sense, but the superfluity of it. ${ }^{4}$

The "absence of sense" could be associated with the absurd, the excess is undoubtedly the territory of the grotesque. As the quote implies, it is both a mode of writing and a mode of reception, the excess produces indeterminacy, ambiguity and ever-receding horizons of expectations that do not allow the reader to rest and find an assimilable signified. However, as I will try to show, Shelley Jackson's hypertexts vary in their degree of experimentation with both the medium and the construction of a narrative voice or authorial identity with which the reader can establish a dialogue, and in this manner, reduce the text's otherness.

While in my body the author apparently reveals her most intimate secrets with resolute ease, exhibiting herself in an explicit autobiography, in her previous work the reader ends up discovering the author's self-portrait hidden behind layers and layers of a complex hypertextual framework. The reader of Patchwork Girl progressively draws a sketch of the authorial persona (a vigorous, androgynous, young woman), after running through the profiles of different fictional characters that will end up converging, in a time journey, in her figure: the feminine monster created by Mary Shelley herself and Frank Baum's patchwork doll are Shelley Jackson's alter egos. The first owners of the body parts that will constitute the monster also leave an imprint of their personalities and vivid memories in this pain-body, this conglomerate of stories that will form the communal female body. Each micro-story deposits tragicomic sedi- 
ment in the reader, black humor becoming the subversive tool through which tragedy can be assimilated.

The Headstone that gives entrance to the Graveyard section reads thus: "Here Lies a Head/, Trunk, Arms (Right/ and Left), and Legs/ (Right and Left)/ as well as divers/ Organs appropriately/ Disposed/ May they rest in Piece." The irony of this "appropriate" epitaph cannot be missed, but neither can the connotations to violent forms of death involving amputation, dismemberment, organ dispersion. The links that lead to these body parts confirm this: the skull is shattered like an ancient vase, its remembrances ignite in the reader images of witchcraft accusations by an angry mob ("Sometimes when it's quiet I hear in my ears the roaring of a crowd"), the right hand belongs to "Dominique, ambidextrous pickpocket," who lost it to "punitive justice but later extracted a silk purse from the judge with her left," the lungs to Thomasina, who run in the high Alps with the goats until her father sold her to a passerby, who "took her to polish his silver in a wood-paneled home in the valley, where she found a certain pleasure in scaling the steep roof on dark nights until a loose shingle brought about her first fall ever, and her last," or the stomach, which belonged to "Bella, an oblate simpleton. She was never dyspeptic, though she ate everything. . . . When a ne'er-do-well by his fellow revelers at the tavern, was found crushed by an enormous weight, the townspeople tried Bella for murder. Bella, uninterested, nibbled on figs."

Like a Bosch' tableau, the collection of lexias in this section paints an irreverent mosaic of misfortune and nonchalant subversion. In his review of the work, George Landow remarked the distinctive voice with which Shelley Jackson endows each tale, "thereby creating a narrative of Bakhtinian multivocality while simultaneously presenting a composite image of women's lives at the turn of the century" (1). The grotesque is regenerated by Jackson through her carnivalesque inversion of reality and its hierarchies, producing a fantasy of interlocking body parts, recollections and emotions of a female collective that converge in the figure of the new monster, itself the fragile embodiment of contrastive elements, the horrific and the ludicrous.

Paradoxically, as Katherine Hayles has noted in her famous study of Patchwork Girl, "the text not only normalizes the subject-as-assemblage but also presents the subject-as-unity as a grotesque impossibility" (29). She alludes as an example to the passage when the narrator satirizes the unified subject and the medieval theologians' dilemma regarding the resurrection of amputees who have had their limbs eaten by other creatures. The bizarre scenario depicted in this section (body of text/resurrection/remade), with diverse limbs being regurgitated from the animals' flesh, in fact serves to destabilize the notion of the Cartesian subject by showing the shortcomings of our use of logic in domains that elude our understanding. By exposing the grotesque product of lo- 
gic in philosophical constructs of the past, Jackson invites us to reflect upon contemporary notions of the self which are equally preposterous.

To contribute to this erosion of the Cartesian subject, Jackson offers in Patchwork Girl a collage of discourses in which the literary history of the texts of the body comes together with her personal story, fictionalizing in a grotesque manner the way in which the collective memory is incarnated in an individual female subject. The opposite movement is patent in the case of my body, in which the body, whose diagram is the center of the hypertext structure, is a universe where the microhistory (the author autobiography) becomes macrohistory. This movement is based on the mimetic nature of the reading experience, as the author writes her inventory of body memories, she is urging us to participate in a meticulous exploration of our own bodies, using her model to find coincidences and points of suture.

As readers, we undertake the exploration of a literary anatomy in which each section of the body is the entry point to an associative chain of memories linked to that zone. These memories reverberate in our mind as we proceed with the reading, producing friction with other zones and other bodies. The body is lived as a primeval and universal experience, connecting us more than our anatomic differences separate us. As we can gather from their reading, both works reflect upon the relation between body and identity, upon the mystery entailed in the unfolding of our being inside a space we cannot thoroughly apprehend, whose in-depth knowledge is elusive. The body is, simultaneously, the Other, the undiscovered territory, which provokes curiosity, and the territory of being, of our very identity. To tackle this paradox, Jackson resorts to analogies with thinking modes of the past, with obsolete technologies, and subverts them to transform them in literary exercises that can reveal to us new ways of looking at our relationship with the body. For instance, Patchwork Girls section entitled "Broken Accents" (fig. 2) is inspired by phrenology to offer a graphic medium in which to interweave fragments, quotes, scattered thoughts; Jacques Derrida's texts get interlaced with those by Donna Haraway, Hélène Cixous, Deleuze and Guattari, Lyotard or Lucrece.

This is the most metareferential section of all, since in it the author describes her understanding of hypertextual writing and reflects upon the relation among the mechanisms and resources of memory, the eternal present of the thinker, the text fragmentation and the whole. Hypertext is presented by Jackson as a framework that allows her to reconstruct in a more reliable manner than paper her own mental rhizomes, at the same time that it becomes an overwhelming and unmanageable monster even for its author, who gropes her way through her writing. 


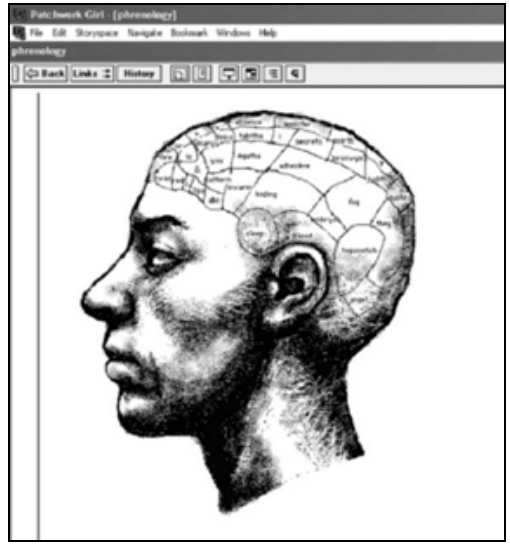

Fig. 2. Entry frame for the "Broken Accents" section of Patchwork Girl.

If the monstrous body of the patchwork girl is formed by a conglomerate of limbs and organs of diverse origins, the text in which it lives as a fictional entity is also a composite work made of multifarious elements, both originally created and appropriated, fiction and metafiction, remediated print assembled as a hypertext and newborn digital lexias that read linearly (Journal). As the narrator notes, membrum or "limb" also signified "clause" (body of text/typographical), which propitiated the analogy used by ancient Rhetoricians regarding a well-written text, which should not look like a disproportioned, grotesque body.

Throughout the work, this grotesque characteristic is often associated with the deviant feminine writing the hypertext represents. However, despite the defense of the author in "Stitch Bitch" of hypertext's superior flexibility to capture our train of thought, "a mesh of relationships," without clogging, and to take the reader beyond the comforts of certainty, Patchwork Girl does not actually support a binary opposition between print and hypertext, as Paul Hackman has observed (96). It is still a work heavily indebted to print modes of reading. In his article, “I Am a Double Agent': Shelley Jackson's Patchwork Girl and the Persistence of Print in the Age of Hypertext" (2011), Hackman's insightful reading exposes the interaction between print and hypertext, rather than the celebration of one at the expense of the other, as one the most important contributions of the work. As the narrator expresses in Hackman's selected lexia: "I have a letch for sequence, don't doubt it. I am not the agent of absolute multiplicity any more than I am some redoubtable whole. I am a double agent, messing up both territories" ("double agent" / Body of text). It is my contention that this "productive multiplicity" at the borders is exactly what the grotesque celebrates, not only the monstrous deformity of hypertext associated by Jackson to the feminine and its deviance from canonic notions of beauty, 
but the unsettling of both categories, print and hypertext, through their intermingling. As Hackman concludes: "Patchwork Girl therefore references both print and hypertext in order to question how our world and sense of self are structured by both the illusion of wholeness and the impossibility of complete fragmentation" (105) or, as the narrator herself remarks: "What holds me together is what marks my dispersal. I am most myself in the gaps between my parts" (body of text/dispersed). This statement would also fit like a glove in Jackson's hypertext for the web, my body-a Wunderkammer. In this case, we confront an apparently simpler work, less indebted to print, which makes it, paradoxically, a more conventional hypertext. However, its labyrinthine structure and complex lexia connections bring forth with brilliant execution the enigma of human identity and its relation with corporeality.

If phrenology tried to establish the foundation for a relation between brain and mind by parceling out brain areas and associating them to an emotion or type of thought, the cabinet of wonders becomes at the hands of Shelley Jackson a metaphor through which to explore the relationship between the set of body parts and the sense of wholeness associated with one's identity. The body as microcosms is a vision that finds its way back to the Renaissance, a moment in which the body is perceived as a miniature world that reflects God's creation in every detail. The analogy with the cabinet of wonders carries us back to a phenomenon prior to the Enlightenment, to a way of exploring the world free from the cataloguing craze of the $19^{\text {th }}$ century. As the author herself states in this work: "But you don't approach a cabinet of wonders with an inventory in hand. You open drawers at random." Thus, this analogy is applied not only to the introspective work carried out by the author, but it also turns out to be a guideline for the reader-visitor, who must adopt a certain attitude in order to explore the work.

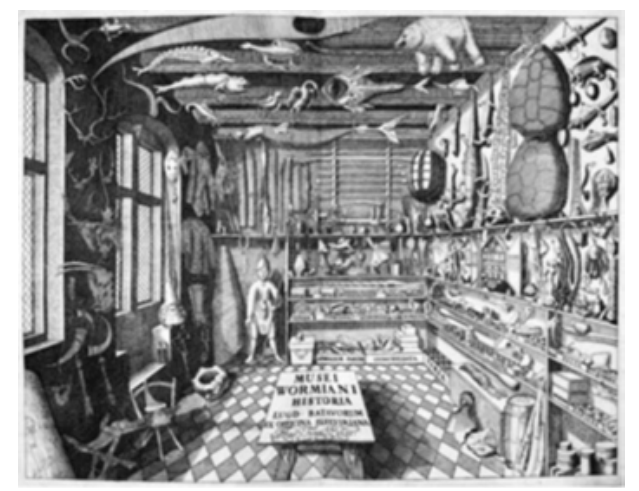

Fig. 3. The frontispiece of the book Musei Wormiani Historia, catalogue of the cabinet of curiosities of the Danish physician and collector Olw Worm, 1588-1655. 
Geographical and spatial metaphors have been used recursively in the history of art to allude to and describe the body. However, I am interested here in exploring the effects that the use of these analogies produces in these particular works. With phrenology, Jackson had recurred to an obsolete science, a mode of cataloguing the spaces of the mind characteristic of the $19^{\text {th }}$ century to illustrate the prejudices that each period projects upon its way of ordering the world, the bodies and the minds. With the cabinet of wonders, the approximation towards the body promises to unveil something shocking, exotic, out of the ordinary, belonging to the world of the unwonted, even the mythical. The work alludes, in a premeditated manner or not, to one of the predominant phenomena of cyberspace: the exhibition of intimacy as a narcissistic pose around which cybernauts articulate their social roles between voyeurs and exhibitionists. The reader is supposedly endowed with a curious zeal and made nearly a voyeur in this exploration of the exposed body's intimacies, which is performed without leaving a trail, in search of a rarity, an astonishing surprise that would bring forth exclamation.

Nevertheless, Jackson goes on to subvert the reception pattern expected of wonder cabinets, provoking in the reader contradictory sensations of a sort, the minor affects (using Sianne Ngai's terminology) one so often encounters in relation to the cultural products of our contemporary societies. Unlike Romanticism's sublime ideal, or the shock of the grotesque, these are low-intensity sensations; they produce tenderness, laughter sometimes, uneasiness at the lack of decorum, a certain interest, and empathy. As Ngai explores in her work Our Aesthetic Categories: Zany, Cute, Interesting (2012), these apparently trivial aesthetic categories have become central in our culture. These sensations produce in the spectator ambivalent, nearly contradictory, feelings of low intensity, so diffuse as to avoid a cathartic reaction. The cute versus the beautiful, irritation versus downright rejection, the interesting versus that which is transformative. Ngai places Jackson's work in the category of the comedian in the commedia dell'arte, a category that has to do with performativity, with action, with doing too many things at the same time and experiencing information overload (7-8). These characteristics, which inscribe Jackson's corpus in the aesthetics of its time, can also offer us, as we will see next, a particular vision regarding the renewal of the grotesque in the digital creations of the $21^{\text {st }}$ century.

\section{My Body - a Wunderkammer}

Jackson's piece is a hypertext with the body as the narrative's map, a historical map of sedimented memories (scars, tattoos, life fragments associated and evoked by the curious and thorough observation of body parts, fragmented in 
different territories). This canvas-body, map-body, is a bidimensional diagram which has, nevertheless, many layers: it becomes an index of the various lexias or textual fragments, the origin and destination to which the reader always returns - it is thus the entry to the body's interior, which in its turn, is formed by the intertwined nodes, some textual intestines that curl and heap up in an aleatory fashion. The body image is that which is external, the surface; and the text and its meanders offer us a journey through an interior space in intimate symbiosis with the surface, but with multiple levels and internal pathways.

If we inspect the HTML code of the body diagram page, we can read the list of tagged lexias, but we do not gain access to the third underlying layer, which would show all the hidden lexias, as in the complete graphical representation of the work offered by the different maps of Patchwork Girl in Storyspace. We can observe here that the hypertext is formed by the lexias linked to the body part labels and some others, which are distributed inside other lexias and which compose alternative reading routes (for instance, the lexias "theories," “migraines," “cabinet," or “other bodies").

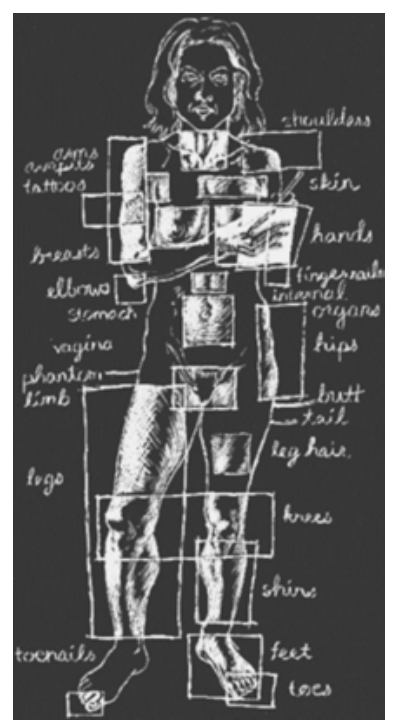

Fig. 4. Main page of my body —a Wunderkammer (1997).

As it becomes apparent, the "Wunderkammer" hides surprises, not everything is labelled out, and there is space for the discovery of something unexpected. There is, for example, even a phantom limb, which is indicated in the diagram but its tag leads nowhere. We will actually find the "phantom limb" lexia in the tagged lexia "arms," if we click in the area "I roller skate." The phantom limb is an imaginative device conceived by the child to explain her clumsiness. And 
there are moments when the highlighted word again leads you nowhere, as in one of the few instances in which the narrator addresses the reader directly in the lexia "tie in products": "This is a work in progress. If you would like to sponsor further study of your favorite body part or you are a collector, please email me care of Alt-X," and the word "collector" does not activate any window. As in these cases, Jackson's rhetoric of links is rich and playful with the reader's expectations: sometimes the relation between lexias has overt narrative coherence, at other times it seems purely coincidental, since the same word appears in each lexia. There are frequent loops, for instance, the lexia "skin" is connected to the uncharted lexia "theories," which in turn has "skin" as a hot word that leads you back to the "skin" lexia.

These multiple levels and internal pathways are created by the intertwining of highlighted words that provide internal routes from one lexia to another, introducing different themes and trails of association that function independently of the route provided by the body diagram. Important themes are often hidden in deeper layers. For example, "other bodies" (connected to the lexia "skin" by the highlighted phrase "I swam in the neighborhood swim team") is one of the few links in which the narrator directs her attention to other bodies, which she finds despicable, pretentious and unhealthy, and expresses the frictions implicit in exchanging gazes: "It was difficult to negotiate the field of crossed gazes between my towel and the pool."

There is only one body area which is free of its corresponding tags in the diagram, the head, although it also contains hyperlinks to the elements that compose it (brain, eyebrows, eyes, nose, lips, ears). In this case, the territorialization of the body seems to imply a deterritorialization of the face, following Deleuze and Guattari's metaphor in A Thousand Plateaus (1972), a sort of invitation to exchange roles. The author's image looks straight ahead, pen and paper in her hands, ready to draw whatever she sees, also transforming the reader/viewer in object of scrutiny, returning our gaze. The possibility of this change of perspective, which is made patent in the lexia "other bodies," reminds the reader that the body we scrutinize as tourists has eyes through which to judge us in return.

This monochromatic diagram over slate is remediated in pixels that shine on the screen. In it, the game proposed to the reader is not based exclusively on the exhibitionist revelation of intimate memories, but rather in a mirror game that invites us to establish similarities with our own recollections of the body. Soon, however, we will discover that the apparent autobiographical tone of many paragraphs should not deceive us: the authorial persona recreated in my body shares with the patchwork monster some freakish characteristics, the narration often jumps to magic realism, grotesque irreverence, turns a defamil- 
iarizing glance at the body as a veritable cabinet of wonders that verges on the fantastic.

The textual monstrosity, however, is not as apparent as in Patchwork Girl, which was a far more complex work to execute. Nevertheless, the exploration of my body is neither easy nor straightforward. As we have seen, it has hidden passages and chambers, the narrative coherence between the parts is not made explicit and you have to traverse it as a labyrinth, undoing your steps, going in circles, groping your way blindly through this textual body's interior. As in her previous work, the connection between body and text, self and writing, is also established. In the lexia "vagina," through sensual and indecorous provocation, literature is incarnated in the most literal sense, ${ }^{5}$ as Susana Pajares Tosca has also noted:

It wasn't a big leap from eating books to sticking them up me, a page at a time. Fine literature in my vagina, pulp fiction up my ass, that was my instinctive decision, that is at first, before I began to question whether the distinction was really so clear. I sat through English class with Chaucer and Boccaccio here, S. E. Hinton there. One day, when I fished out the slippery wad, laid it on my desk and teased its folds open with a pen, I noticed that some of the words seemed changed. I took the stinking page to the library and confirmed my discovery in the echoing stacks. My vagina had rewritten Joyce. It was then I knew I was going to be a writer. I also found, and would like to share with other women, that a dictionary in a pocket edition, if well worn, can be rolled up and used as a tampon in case of need. ("vagina")

As we can see, it is a matter of giving voice, of exhibiting that which is socially inexpressible in the screen space — a place which is a cabinet of wonders of its own right, at once public and private. The back and forth movements promoted by the hypertextual reading draws in the mind of the reader a map of the territory, and an arboreal and rhizomatic image that progressively grows and interlaces with one self's childhood and adolescence memories.

my body is the representation of the interior of an imagined, mythical, surrealist body, and the hypertextual writing is the method to approach its knowledge. The drawing of the body is the replica, a scale model over which one can project the spaces of remembrance and imagination, a spatial metaphor that allows the author to classify the snippets of memory, imagined as texts with diverse origin and materiality (pages from journals and notebooks, school reports with pictures and diagrams, drawings, labelled biological specimens or broken vials) which comprise a single corpus. Overriding the knowledge of an interior filled with entrails appears the empty space of the imagined body ("While I know that the inside of my body is a dense press of lubricated 
meats / I can't help seeing it as hollow space, like the inside ${ }^{6}$ of a trunk") inside which lexias are organized, not as an exercise of textualizing the body, but rather as a form of handing a corporeal nature to the text. The shapeless mass of the hypertext transmutes into the ideal canvas in which to sieve the memories and overflow the forms of this grotesque body/corpus. The medium is the meat, and reading becomes peristalsis, in Terry Harpold's words: “The docuverse could be shaped like your own intestines, and reading an act of dissection turned inside out, the text traversed convulsively by the contractions and dilations of the boundaries of what you used to think of as a book" (1).

The hypertextual reading can be seen as an act of digestion of a text that advances in peristaltic and involuntary throbs, jumping from frame to frame, reluctantly facing a structure that challenges the reader's orientation skills. It is not in vain that the reading mode prescribed by the author is that of touching, groping one's way towards the inside. In the lexia that carries the piece's title, "cabinet of wonders," the author gives us the key to access her work, which also serves as guideline to make the most of this internal journey travelled by all:

As a matter of fact, I am making a replica of this text: a huge wooden chest in the shape of my body, with innumerable drawers in which I will store my findings. Some of the drawers will be large and capacious, some smaller than matchboxes. Some will be disguised, some will be booby-trapped. I will hide secret buttons, levers and locks in my carved folds and crevices. You will have to feel your way in. ("Cabinet of Wonders")

As she did in Patchwork Girl, warning the reader that she would have to sew the pieces herself, in my body, the reader must dig through her senses and feelings in this other body that it is not her own, but with which she cannot help but to feel at least a connection. The most apparently trivial details are told in a string of thoughts evoked by the meticulous exploration of the map of the body. One of the points of suture with the reader's own memories is the banality of some memories interlaced with moments of tenderness, rebelliousness or alienation that we have all associated with those recollected fragments (an apparent incongruity of memory, a system breakdown: Why do we remember this and not that? What is hidden behind that sketch?).

The workings of memory, fastened to body reactions, both physical (such as pain or cold) and psychological (such as feelings of inadequacy or embarrassment) direct us to the body as the anthropological operator, primeval and universal, from which all sense of identity is built. In my body, the memories associated with the body are focused on childhood and adolescence, a stage where one is not totally aware of the social restrictions regarding the body and 
where its limits are explored. The body is a cabinet of wonders for the subject herself, who must rummage through it until she finds her talent, that which makes her unique.

From the reading emerges the presence of the little author in the making, an image of infancy that deviates, however, from the category of "cute" associated with childhood; Shelley Jackson's remembrances are not tailored to transform powerlessness in aesthetic experience, neither do they provoke a sentimental attitude towards that which is diminutive or weak. The intimate selfportrait offered by the narrative voice is that of a person that stands out from the crowd, an androgynous girl, vital, strong, and carefree. But she is someone who, at the same time, searches for her space among the other bodies. In the link "other bodies," the narrator shows her concern with beauty, with leaving a mark in others: "My own body was, I felt, invisible. . . . It didn't register, I was like a stick figure, of which you don't ask, is it well-drawn, is it beautiful? My body was the engine that propelled a pair of eyes through the world." If the author has ever felt invisible, subject rather than object of the gaze, a voyeur rather than an exhibitionist, the work my body inverts the terms, transforming herself into an object of scrutiny. Exhibiting her rarity, the author places herself as the central piece of a cabinet of wonders, a piece that provokes attraction and repulsion in equal measure, since she feels half-boy, half-girl, a kind of monster, a hermaphrodite, a candidate to represent the third sex. Nevertheless, as the patchwork girl of her previous work also claimed, that which is monstrous can also be beautiful, since it is unique.

Drawing as a way to explore the human anatomy is one of the recurrent themes in this piece. As we can see in her silhouette (fig. 4), her body is both object of analysis as well as subject who draws and analyses what she sees. One of the leitmotivs that provide a sense of coherence to the textual fragments is the progressive learning of drawing techniques that will allow her to capture with pen and paper the contours and shapes of different parts of the body. The little Shelley Jackson, this artist girl, tries to approach her object as it really is, escaping artistic or cultural stereotypes. The art of sketching is presented as an antidote against prejudices, criticisms, against hegemonic doctrines of beauty. On the one hand, the body's observation, the intense gaze over the object and its transposition to the canvas, becomes a nearly erotic relation: "At one time or another, learning to draw, I have been obsessed with every part of the human body. . . . Could I mistake this doting attention for disinterested curiosity? Drawing is almost sex." In this line, the tattoos are treated as relevant authorial elements, traces left on purpose over the canvas of the body, which are not born of accident nor trauma, but of the subject's decision, and which allow other bodies to read and approach her person. The action of tattooing oneself promotes a new instance of re(signification), of reterritorialization, of those 
body parts or aspects that are affected by the social construction of the body. In the same way, the piercings, another type of voluntary transformation of the body, manifest the wish to exert a transgression of the beauty canon in defense of an exercise of singularity that does not flinch at embracing the "grotesque" character of the said transgressions. The body of Jackson, with its multifarious tattoos and perforations, metamorphoses itself, as modelling clay at the hands of its owner, in the grotesque corpus of the hypertext. In fact, the interconnection between body and text manifests itself again in the commitment to writing and the discipline it entails as a relation of voluntary servitude: the ring that decorates her navel is used to chain the writer to her desk, so that she does not get up every five minutes to clip her "toenails or refill the ice trays." And she adds: "The weight of the links— - it is not a heavy chain — is enough to make me aware of my bondage, and strangely, this is a relief; it stops me from wondering where else I might want to be" ("Stomach").

The central diagram foregrounds the isolation of the author's body, privileging the moment of writing, of creation, as an intimate and solitary action; the textual nodes, on the contrary, demonstrate her interconnection with other bodies, other eyes. In words of the Spanish writer Rosa Montero, "writing sews you up, unites you to the world." "The same can be said of reading as an action that connects you to the vital fluid and sews you up inside. In particular, hypertext is a dialogical genre in which each link interpellates us and compels us to establish a point of suture that would maintain the structure on its feet; the scaffolding that works as point of reference is found as much in the authorial personality that provides coherence to the disperse fragments as in the identity structure of the reader himself. In each act of meaning negotiation, the narcissism of the reader is united with the narcissism of the author.

The proposal of Shelley Jackson invites the reader to accompany her in her chaotic reordering of the body's reminiscences, a decontextualization (inside the hypertext) of its original context. But, what is the effect produced by this successive disordering and reordering of memories associated to different body parts? The territories of memory and body are drawn and blurred, they overlap and overflow, they merge in new associations, exerting through the hypertext's grotesque corpus a destabilizing and liberating function. Above all, it implies a negotiation between the macrocosms (the society, the world) and a microcosms (the body, the cabinet of curiosities); a negotiation between the linearity of discourse and its dispersion and fragmentation in the hypertext, which makes explicit the coercive pressures that regulate the social construction of the body.

In its aesthetic sense, the grotesque is fundamentally defined by the surpassing of identity, which implies a clash in principle with the beauty canon, as the body statute in Western culture is mainly defined by it (Barrios 16). In this 
sense, the form and content of my body make a well-oiled gear. Both the hypertext and the image of the grotesque body have blurred boundaries, diluted semiotic frontiers, each hypertext lexia is the fragment of a conversation whose meaning is marked, accidentally, by the order it occupies in our own reading, by its contingency relations with other fragments; despite the finite number of links that the piece contains, this becomes endless by virtue of the quantity of possible combinations. We could say that the hypertext, as the grotesque body alluded to in Cristóbal Pera's essay, "is a body never finished, never completed, always under construction" $(37)^{9}$, a feature that the narrative voice also attributes to my body in the lexia "tie in products." This incessant action is what, according to Sianne Ngai, characterizes the aesthetic category of "zany," the sign of our times, in which the frontiers between play and work are dissolved, and the gender roles come together with those of social class to draw a stressed and surpassed feminine role. However, in this piece, the feminine subject does not drown in a sea of demands, as it is evident in other digital literature works created by women as is the case of Pieces of Herself (2003-2005) by Juliet Davis, or Fitting the Pattern (2008) by Christine Wilks. On the contrary, the dialogism of the hypertext is used to show, in a subversive manner and in connivance with the reader, the matrix of social conflict that underlies every aesthetic judgement, in relation to the body and to the text itself. The author's personality, which the reader progressively constructs out of the textual tangle of my body, possesses a contagious rebelliousness and force.

As in a curiosity cabinet, where knowledge emerges not from the objects themselves but from the relations that they keep among them, in the hypertext the recognition of an authorial voice emerges from the personality that is gathered from all the fragments that form the work, and from their relation with adjacent works by the same author. After reading the contents of the different drawers of memory, an image is formed that gives coherence to all of them, a new layer in which the reader reconstructs the type of personality that complements and confirms the authorial persona of Patchwork Girl, a subjectivity preoccupied with similar concerns regarding the power of the body to contain a fragmented yet enduring self, and the power of writing to express the experience of living in/through its contingent nature.

Acting as one of the central nodes of the work we find one of the longer lexias, it is entitled "Theories" and one can arrive to it from different paths. In it, an apparently trivial anecdote is again remembered: the narrator relates the recollection of a sudden reality jolt, the split of a branch while she was climbing up a tree as a child and which could have ended in a fatal accident. This seemingly trivial occurrence hides one of the work's epiphanies: the awakening of maturity, the acknowledgement of being limited, alike others, and not a magical child chosen by the forces of nature to be something more than hu- 
man. Life - the narrative voice concludes—-is still wonderful, but now one has to be careful since one will not be granted special rights, her fantasy of belonging and mystic union with the physical world has vanished.

Shelley Jackson's piece brings us back to that childhood moment in which the world, and the body in particular, is a box full of surprises, where everything is possible, and therefore, we must try hard to find the possibilities, the talents we have in store without knowing. At some point, this full confidence in our own potential, and thus in the capacity of our own body, breaks and in its place appear the vulnerability, the complex, the inadequacy feeling, which the main character of my body manages to eschew.

Jackson's work transpires defiance and assertiveness. Just one melancholic moment can be singled out when the narrator asserts that, as time passes, our body acquires the characteristics of inanimate objects, until it becomes one. As in a cabinet of wonders, in my body the objects of nature (the body), intermingle with the human-made artifacts (the texts) and the myths (the imaginary connection that binds them together). However, in this chaotic skein of memories, each lexia does not produce the same sense of wonder and surprise than a true collection object; the curiosity it provokes is ambiguous, at once narcissistic and generous. It becomes interesting by the pure fact of being a lexia in the hypertext, by being singled out by the author as a photographer capable of isolating and making meaningful any instance that is framed by her camera.

We can assert, nevertheless, that the objectification, the parceling out of the feminine body at the hands of the female writer acquires a tone of vindication. A wunderkammer, the cabinet of wonders, exhibited, open to scientific exploration and curious tourism, shows us the body of woman as an undiscovered territory, yet to be known, both in the physiological plane and in the psychological. The body revealed by Shelley Jackson is certainly a curiosity because of its androgyny, but its reading sparks the recognition that such sexual ambiguity is part of all of us in some way. The myth that the author toils to deconstruct is that of a sexual polarity totally univocal and defined. The deconstruction carried out by Jackson of each memory associated with the body in fragments of text, territorializing and deterritorializing the global image of the body, and the recollection of the stark contrast between lived experience of the body and the social restrictions imposed on each little parcel of it, produces a defamiliarization effect that brings to the surface the subtle confinement to which the feminine body is subjected from infancy.

Finally, the most attractive feature of the authorial personality constructed by Shelley Jackson is that she manages to write about her insecurities in carefree, vital, and beautiful language, transmitting the pride inherent in being oneself. She is weak and strong, vulnerable and resilient, sensitive and unbreakable. We could say that she revisits the grotesque as yet another non-cathartic, 
minor affect, as she does not really fit into any of the aesthetic categories to which Sianne Ngai refers. She is not "cute," maybe a little "zany" and definitively interesting, but not in the sense of "merely interesting," since she manages to involve us in an intimate way in her own memories. She exhibits herself without shame and demonstrates that the authorial character can become even more elusive and mysterious the more we learn about it: behind the grotesque exhibition of her most private memories lies another layer, that of the real person, which continues to be unfathomable.

Our platonic heritage has excised us, our consciences, from our own bodies in the same way that classical normativity and aesthetics have alienated our experience of reality, which often shows its ugly teeth, from an idealized representation of the world. Yet, Shelley Jackson invites us to reduce the distance between bodies and expand our knowledge towards this primeval mystery that separates self from other, consciousness and materiality, text and body, through the grotesque mode, which becomes, in her hands, a way to approach the incongruous elements that compose our identity and its relation with the body in a continuous play with the reader's expectations. The grotesque emerges then, not as a shocking spectacle, but at the interstices between Jackson's memories of the discovery of her body' potentialities and shortcomings and our own. By mixing triviality with transcendence, irreverence with devotion, by resorting to a humorous, surreal distance to assimilate our ambivalent emotions towards our own body and that of others, Jackson leads us through her particular cabinet of wonders, at once peculiar and strangely familiar, suggesting that only a grotesque text can hold the disproportioned, the unclassifiable, the non-canonical and even the tragic in its bosom without losing its integrity.

Through these notes I have tried to tentatively play with Scott Rettberg's suggestion that hypertexts can be seen as simultaneously belonging to many sets, and that "theory, like literature, does not ultimately operate a world in which each passing phase obviates the other" (1). In this case, I believe that Shelley Jackson's corpus should definitely be counted inside the renewal of the Grotesque at the turn of the $21^{\text {st }}$ century, adding to this ancient style the bizarre, hybrid bodies of our technological age.

\section{Notes}

1 Parts of this text were published in the journal Tropelias: Revista de Teoria de la Literatura y Literatura Comparada. The text, written in Spanish, can be found at <https://papiro.unizar.es/ojs/index.php/tropelias/article/view$/ 1156 / 1019>$. 
2 All translations were done by the author. Original text: "En su sentido estético, lo grotesco se define fundamentalmente por el sobrepasamiento de la identidad, lo que supone una contraposición de principio con el canon de lo bello como aquello que define fundamentalmente el estatuto del cuerpo en la cultura occidental" (Barrios 16).

3 Astruc contends that the danger of the established orders perceived in the grotesque had to do with the surprising anti-cognitive properties that are still today attributed to it: "because it resists interpretation, the grotesque always appears as a domain where it is expressed a certain type of irrationality, or at least, of the unintelligible" (Astruc 3).

4 Cf. <http://web.mit.edu/m-i-t/articles/jackson.html>.

5 Cf. <http://pendientedemigracion.ucm.es/info/especulo/hipertul/wunderkammer.html>.

6 Cf. <http://www.altx.com/thebody/organs_internal.html>.

7 Cf. <http://www.altx.com/thebody/butt.html>.

8 Original text: "Escribir te cose, te une al mundo" (Montero).

9 In the original: "es un cuerpo nunca acabado, nunca completado, siempre en proceso de construcción” (37).

\section{Works Cited}

Astruc, Rémi. "Le renouveau du grotesque. Introduction de l'ouvrage publié chez classiques Garnier en 2010.” 2010. 9 Feb. 2017 < https://www.academia.edu/15714899/Le_Renouveau_du_grotesque $>$.

Barrios, J. L. “El cuerpo grotesco: desbordamiento y significación.” Jornadas de Cuerpo y Cultura de la UNLP, 15-17 May 2008. La Plata. 9 Feb. 2017 <www.memoria.fahce.unlp.edu.ar/trab_eventos/ev.695/ev.695.pdf>.

Carriedo López, Lourdes. "Pervivencia y renovación de lo grotesco en la narrativa del siglo XX.” Cédille. Revista de estudios franceses, 7 (2011). 9 Feb. 2017 $<$ http:// cedille.webs.ull.es/7/19carriedo.pdf $>$.

Davis, Juliet. "Pieces of Herself” [2003-2005]. Electronic Literature Collection, vol. 2, edited by Laura Borràs, Talan Memmott, Rita Raley and Brian Kim Stefans, 2011. 9 Feb. 2017 <http://collection.eliterature.org/2/works/davis_pieces_of_herself.html>.

Hackman, Paul. “I Am a Double Agent': Shelley Jackson's Patchwork Girl and the Persistence of Print in the Age of Hypertext." Contemporary Literature, 52.1, Spring 2011, pp. 84-107. 
Harpold, Terence. "The Grotesque Corpus.” Perforations 3, vol. 2, no. 3 (1992). 9 Feb. 2017 <http://www.pd.org/topos/perforations/perf3/grotesque_corpus.html>.

Hayles, N. Katherine. "Flickering Connectivities in Shelley Jackson's Patchwork Girl: The Importance of Media Specific Analysis." Postmodern Culture, 10.2. (2000). 9 Feb. 2017 <http://pmc.iath.virginia.edu/text-only/issue.100/10.2 hayles.txt $>$.

Jackson, Shelley. Patchwork Girl. Watertown, MA: Eastgate Systems, Inc. 1995.

my body-a Wunderkammer [1997]. Electronic Literature Collection, vol. 1, edited by N. Katherine Hayles, Nick Montfort, Scott Rettberg and Stephanie Strickland, 2006. 9 Feb. 2017 <http://collection.eliterature.org/1/works/jackson_my_body_a_wunderkammer.html>.

. "Stitch Bitch: The Patchwork Girl." MIT. 1998. 9 Feb. 2017 <http://web.mit.edu/m-i-t/articles/index_jackson.html>.

The Melancholy of Anatomy. New York: Anchor Books, 2002.

Landow, George. "Stitching Together Narrative, Sexuality, Self: Shelley Jackson's Patchwork Girl." Electronic Book Review, 1 Sept. 1996. 9 Feb. 2017 <http://www.electronicbookreview.com/thread/writingpostfeminism/piecemeal $>$.

Montero, Rosa. "Nena, esto es de lo más normal." El País Semanal, 28 Sept., (2014). 9 Feb. 2017 <http://elpais.com/elpais/2014/09/25/eps/1411663777_303887.html>.

Ngai, Sianne. Our Aesthetic Categories: Zany, Cute, Interesting. Cambridge, MA: Harvard University Press, 2012.

Olsen, Lance. "Embodying the World." Electronic Book Review, 2 May (2002). 9 Feb. 2017 < http://www.electronicbookreview.com/thread/writingpostfeminism/foetalfiction $>$.

Pera, Cristóbal. Pensar desde el cuerpo. Ensayo sobre la corporeidad humana. Madrid: Triacastela, 2006.

Rettberg, Scott. "The Pleasure (and Pain) of Link Poetics." Electronic Book Review, 1 Jan. 2002. 9 Feb. 2017 <http://www.electronicbookreview.com/thread/electropoetics/pragmatic $>$.

Spinoza, Benedicto. Ethics. Translated by G. H. R. Parkinson. London: Everyman Classics, 1989.

Tosca, Susana Pajares. "my body-a Wunderkammer." Hipertulia. 9 Feb. $2017<$ http://pendientedemigracion.ucm.es/info/especulo/hipertul/wunderkammer.html>. 


\section{Daniela Côrtes Maduro}

\section{Choice and Disbelief: Revisiting Immersion and Interac- tivity}

The interplay between immersion and interactivity was widely discussed by Marie-Laure Ryan at the beginning of the $21^{\text {st }}$ century. Since then, even though these terms have been studied by several scholars - Grau, Ryan, Zimmerman, Calleja, to name but a few - they have been considered imprecise or too broad, and a shadow of doubt has been cast upon their value as theoretical tools. Nevertheless, both of them continue to represent the kind of contact established between reader and device(s). Companies such as Sony (more precisely, the Immersive Technology Group and Sony Interactive Entertainment) have been using these words to describe the kind of contact established between users and devices. Similarly, although these terms have been turned into advertising buzzwords, ${ }^{1}$ scholars continue to use them to describe exchanges between computers and users. For instance, the following adjectives are used to describe the New Media Writing Prize: "Innovative, Interactive, Immersive." 2

Many authors, some of them cited in this essay, have already created comprehensive lists of levels and types of interactivity and immersion. However, because "immersion" and "interactivity" are so deeply ingrained in the discourse devoted to human-machine relationship, I would prefer to describe the different appropriations of these terms and the multiple contexts in which they appear. Hence, the way "immersion" and "interactivity" have been used in texts dedicated to electronic literature will be, as far as the space allows, examined in this essay. ${ }^{3}$ I believe that by focusing on these features, we are given the opportunity to address both content and form of digital texts. Moreover, because the analysis of "immersion" and "interactivity" demands the contribution of knowledge gathered by different disciplines, it allows us to establish a link with electronic literature's antecedents, as well as seemingly opposing fields of research.

\section{Immersion vs. Interactivity}

By the end of the nineties, Ryan stated that immersion "was either ignored or dismissed as the holdover of a now-discredited aesthetics of illusion." As for interactivity, Ryan considered it "the triumph of postmodernism's aesthetic ideals of a creative reader, an open text, and a ludic relation to language" (Ryan, 
"Immersion vs. Interactivity" 111). Interactivity was used to offer freedom of choice and the opportunity of co-authoring the text, even though, as it is known, readers were not allowed to make any changes to the text's structure and design. As for immersion, this concept was related to the feeling of losing oneself in the story or as the result of a reading experience based on a "willing suspension of disbelief," as suggested by Samuel Taylor Coleridge, and thus, constrained by authorial intention. Therefore, interactivity was largely regarded as an antidote for reader's immersion in the text. Since narrative was often related to coherence and linearity, the fragmented and combinatory nature of these works seemed to foster a "clash between ergodic and narrative layers" (Eskelinen 104) of a text. Yet, the expansion of the World Wide Web and the emergence of new software and mobile devices suggested new reading and writing experiences. Emergent technology added multiple ways to tell a story or create a narrative. As computers could now provide an environment where different types of media were able to thrive and prosper, age-old or additional debates began to (re)surface. Immersion-interactivity theory demanded an inclusive perspective: one that could address the multimodality of electronic literature. ${ }^{4}$

In an effort to accommodate several "climatic changes" (2), Ryan has recently reformulated her book, Narrative as Virtual Reality: Immersion and Interactivity in Literature and Electronic Media (2001). This essay also argues for the need to revisit Ryan's thesis, especially at a time when augmented reality, tracking or locative devices are increasingly being applied to create further reading experiences. In line with Ryan, I will demonstrate how both immersion and interactivity can be regarded as interdependent. To accomplish this task, I will gather the invaluable knowledge produced by several theorists and create a link between perspectives often regarded as essentially incompatible. Besides focusing on text behavior (or on what the text can do), this essay will describe texts as matrixes of possible worlds and as fertile grounds where meaning can be disseminated. In so doing, I will argue for the need to consider "interactivity" as an expressive feature which allows (rather than forestalls) reader's immersion in the text. In this essay, interactivity will represent the contact established between reader and text and the kind of negotiations taking place while (or after) reading a text. As for the term "immersion," it will be used to represent not only the reader's suspended disbelief, but also the cognitive processes (and level of attention and concentration) which allow us to keep contact with a fictional world and to understand a text. 


\section{Background Process}

Works created with Storyspace software such as Michael Joyce's afternoon: a story (1989) are often cited to pinpoint the beginning of electronic literature. In fact, according to Judy Malloy, Storyspace was "one of the first authoring tools to be written specifically for writers of new media literature" (35). ${ }^{5}$ However, if we consider the use of computers as tools for literary creation as a point of departure, literary experiments with computers can, for instance, be backtracked to Alan Turing's and Christopher Strachey's love-letters generator. Storyspace was launched by Eastgate Systems Inc. in 1987.

Interactive fictions represent other important antecedent. According to Nick Montfort, interactive fictions "have clearly influenced software engineering, interface design, online communities such as MUDs and MOOs, and other forms of digital and nondigital media" (Montfort 2). Montfort adds that they have also influenced the "style of at least one important work of hypertext fiction, Stuart Moulthrop's Victory Garden" (226). Hypertext fictions written in Storyspace and interactive fictions were predominantly verbal. However, as mentioned above, following the expansion of the WWW, digital texts became multimodal artifacts encompassing different semiotic languages. Readers of digital works could now find multiple figurative dimensions (Zuern) that were unavailable to readers of earlier hyperfictions. ${ }^{6}$ Works such as Brian Kim Stefans' Dream Life of Letters (2000), where letters are turned into dynamic shapes, or Ingrid Ankerson's Cruising (2001), a cinematic flash poem which "is an excited oral recitation of a teenager's favorite pastime," demonstrated that a text, besides literary, poetic or narrative, could also be defined as responsive or animated. A vast array of texts produced with new software, and read or experienced through new devices demanded the knowledge and critical tools gathered by different research areas, from computer science to film studies. These texts also challenged the notion of a literary text as exclusively verbal, and undermined any hierarchical relations between word and image. Nevertheless, as we know, long before the emergence of electronic literature, a cleancut separation between word and image had already been compromised. From medieval manuscripts, William Blake's illuminated printing, to concrete poetry, the kind of contact between letter and image was already one of fusion, rather than division. With electronic literature, we witnessed an extension of this practice under which mechanisms and surfaces of inscription continue to be thoroughly reworked in order to convey stories and ideas.

As Ryan explained, because it was often coupled with the need to assemble the text or respond to multiple challenges, interactivity was believed to hinder reader's immersion in the story. ${ }^{7}$ The kind of vagrant ${ }^{8}$ or participatory reading often related to the presence of interactivity was believed to settle the 
disruption of the narrative's thread. However, we know that a narrative can no longer be described as a plot clearly divided into beginning, middle and end. Long before electronic literature was named as such, a line of modernist and postmodernist texts had already dismantled this idea. ${ }^{9}$ Furthermore, I would like to emphasize that a text can be comprised of a disrupted or hindered narrative, and thus, the reader (or interactivity) cannot be held responsible for the text's dismemberment. The text's fragmentation is not urged by the reader's "participatory role" or by the reader's choices.

The idea that interactivity and immersion are incompatible features of a text is deeply connected with the assumption that "interactivity" (or, in its fundamental sense, the need to activate or assemble the text) is at the basis of the text's disruption because the reader is asked to split the attention between the manipulation of the text and the reading of the suggested narrative path(s). The belief that this feature promotes textual fragmentation (and consequently, a disrupted reading) stems from the fact that interactivity is often regarded as a result of reader's intervention, and not as the result of a set of decisions made by the author. Any failed attempt to see the text as a whole or to follow the narrative's thread is creatively and intentionally planned by the author (or designer). Moreover, as we shall see further on, a text can be comprised of narrative elements, for instance, characters, events or narrator(s) that may provide clues to the presence of a narrative.

Another trend that seemed to foster the antagonism between immersion and interactivity was matching interactivity with physicality. As for the concept of immersion, it was often related to cognitivity, as well as passivity and submission to authorial intention. In "Peeling the Onion," an essay published in 2005, Marie-Laure Ryan identified four layers of interactivity and four modes of participation. Ryan linked level two of interactivity to hypertexts and to the possibility of choosing between "several pre-defined stories." In level three of interactivity, "the system grants him some freedom of action, but the purpose of the user's agency is to progress along a fixed storyline, and the system remains in firm control of the narrative trajectory" (Ryan, "Peeling the Onion"). Adventure games, shooters and mystery-solving games represented this level of interactivity. The activities executed by the reader (who, in the third level of interactivity, becomes a "player") were described as follows: "the actions available to him are not merely abstract ways to see more of the text, but represent a physical engagement of the avatar with the surrounding world, such as moving, jumping, building, shooting, killing, picking up objects and looking around" (Ryan, "Peeling the Onion"). In this description, Ryan conveys the idea that interactivity increases as soon as the text begins to resemble a game or as soon as the reader is asked to perform (although simulated) physically demanding activities. By contrast, the consultation of external documents 
is matched with interactivity level one. The focus on physicality seems to be directly related to the special attention given to embodiment in theoretical and literary works created between the end of the $20^{\text {th }}$ century and the first decade of the $21^{\text {st }}$ century. For instance, the activity of sewing or assembling lexias, was thoroughly explored by rhizomatic works such as Shelley Jackson's Patchwork Girl (1995), where the reader would have to sew body parts together to read the text. It was also later explored by Fitting the Pattern (2008), where the reader is provided with sewing patterns and "is the tailor who must bring it all together to complete the pattern and make the narrative cohere" (ELO Collection 2008). The primacy given to reading as a bodily or manual experience was partly promoted by the need to demonstrate that electronic literature, inscribed in the dematerialized world of cyberspace, offered an embodied experience of the text. Some of these texts were also deeply influenced by feminist theory as envisaged by Donna Haraway, and sought to undermine the mind-body dualism by focusing on embodiment. However, reading has always been a physical activity, whether we are touching the pages of a book or reading from a computer screen. Considering a digital text "immaterial" meant to ignore a set of practices inscribed in the physical world and overlooking the role of the medium in the production of meaning. What is more, materiality is not merely a characteristic of the observable and tangible, but is also represented by the way ideas and stories are conveyed and perceived while making use of medium's affordances. The acknowledgement that something like "material metaphors" may exist indicates that a shift in the study of materiality took place. According to Hayles these metaphors "control, direct, and amplify this traffic between the physical actions the work calls forth and structures, and the imaginative world the artifact creates with all its verbal, visual, acoustic, kinesthetic, and functional properties" (48). In this description, Hayles points out that the text mechanics and any semiotic systems involved work conjointly (as intrinsic and equal parts of the text) to create an "imaginative world."

The focus on physicality ${ }^{10}$ was also motivated by the belief that an increased sense of interactivity (often by allowing the reader to use his hands to assemble or customize the text) would transfer more power from the author to the reader, as envisaged by postmodernist and poststructuralist theory. ${ }^{11}$ Whereas interactivity may no longer be linked with the attempt to free the reader from the author's control, it certainly remains focused on creating innovative reading experiences which allow the implication of readers in the construction of the text. ${ }^{12}$ Thus, experimentation with the medium is still a central feature of electronic literature, and technology continues to be used to convey ideas or to tell stories in an unprecedented way.

Aarseth once claimed that " $[\mathrm{t}] \mathrm{o}$ declare a system interactive is to endorse it with a magic power" (48). Because electronic literature depends on software 
and technological advancements, a tendency to conflate interactivity and technology's marvelous potential to create alternative reading experiences still lingers. In so doing, focus is placed on what a text can do and on the way software is used to create the element of surprise. Nevertheless, as it will be demonstrated, "interactivity" might have a specific role other than involving the reader in the dismantlement/assemblage of the text. Instead of focusing exclusively on a text's mechanism and considering a digital text as a toolbox, we could perhaps benefit from considering a text as multilayered and analyze how its mechanism is built to convey meaning. This essay can be considered as a preliminary gesture, and an invitation, to rethink the way we study interactive or ergodic texts. By departing from "immersion and interactivity debate" -and thus, by bringing together the knowledge gathered by disciplines such as narratology, cognitive sciences, literary theory, media studies and game studies - I aim to demonstrate the importance of including interpretation of content and expressive features in the analysis of digital texts.

The notion of a text as strictly verbal, the idea of narrative as circumscribed by closure or by a linear plot, as well as the notion of interactivity as dependent on physicality, are at the basis of the dichotomy between immersion and interactivity. We will now focus our attention on another widely propagated idea: the belief that interactivity grants the reader a reading experience in a collaborative mode.

\section{The Illusion of Choice}

In the intro to the game The Stanley Parable (2013), the reader faces a first challenge: "the story doesn't matter, it might not even be a game, and if you ever actually do have a choice, well let me know how you did it." During this game, the reader is often reminded (parables serve a didactic purpose) that there is no freedom of choice. Every time readers try to disobey, they are redirected to an initial stage of the game and their possibilities of action are frequently taken away. While the game loads, the reader can read the following sentence "The end is never the end is never..." This parable is not a game of action but a game that challenges the limits of fiction or the notion of narrative logic, coherence and closure. Because it is comprised of events, characters and a narrator, The Stanley Parable can be considered as a narrative. ${ }^{13}$ Nonetheless, this parable is a narrative based on the challenge of its own foundations. To Markku Eskelinen, hypertextual fiction and some postmodernist fiction are "potentially narrative" (Eskelinen 104). To Gordon Calleja, during a game, there seems to exist an "experiential narrative" (Calleja 116), or a narrative shaped by the mind of the reader. Instead of an antinarrative or a sabotaged and reluctant narrative, 
Aarseth has identified the existence of a "game of narration" (Aarseth 94). These scholars acknowledge the presence of an underlying or imminent narrative. The Stanley Parable seems to play the game of narration, as described by Aarseth, in order to produce what I have described elsewhere as a "projected narrative,"14 or a narrative that repeatedly undermines and postpones the production of a story and, in that process, lays bare the foundations of a narrative.

The distinction between "story" and "narrative" has fueled many debates within the field of narratology (Eskelinen 277), partly because these terms have often been used interchangeably. Because of its metafictional tone and self-reflexive stance, The Stanley Parable might offer us a blueprint for narrative. The Stanley Parable allows us to consider "story" as the content of a building named "narrative." Except that, in The Stanley Parable, the building was evacuated, and the reader will only be able to find empty corridors leading to dead ends. The Stanley Parable also allows us to understand that the reading of a narrative is not delayed or prevented by interactivity, but by the author's and programmers' decisions. The inability to follow the thread of a story-or to know a story at all-is part of the expressivity of this game, and it is not a consequence of the reader's ergodic effort to traverse the text. This parable encourages the reader to participate, but continuously usurps the reader's freedom of choice. Both the illusion of participation and the illusion of choice are explored by this interactive fiction. ${ }^{15}$

The Stanley Parable enacts a metalepsis and invites the reader to participate imaginatively in the construction of the story. However, as Janet Murray once claimed, "interactors can only act within the possibilities that have been established by the writing and programming" (152). Similarly, Astrid Ensslin noted that the "users respond to the textual tools and structures created by an author, rather than creating their own narratives independently" (14). These scholars, distanced by thirteen years, seem to conclude the obvious, but the participatory role of the reader in the construction of the story is often treated as irrefutably connected to interactivity. Instead of pursuing this perspective, I would like to underline that readers are only allowed to revisit or reconstruct the story or proceed according to the author's or programmer's plan. Certainly, what the reader does after the contact with the story (for instance, literary analysis, appropriation, fan fiction, retelling or synopsis), escapes the author's control and broadens the scope of a work. In that case, a distinction between two conditions of a text needs to be made: the text as it is being read (or the text during a reading session), and the text presented as a singular artifact available online or stored in a device (the text between reading sessions). The first cannot be altered or reformulated; the second can be easily manipulated, suffer endless alterations and give rise to entire different objects. Yet, texts such as Ian Hatcher's Opening Sources (2008) which has been changed by readers since its publi- 
cation, were created to resemble authoring tools. The surface of this text shapeshifts permanently but its principle remains the same: the reader is expected to replace sentences and change the surface of the text collaboratively. ${ }^{16}$ Here, the kind of interactivity described by Zimmerman, even though exclusively related to "linear" texts (or, as stated by Zimmerman, "linear media"), may be useful. Zimmerman has identified a "meta-interactivity" which he defined as follows: "This is interaction outside the experience of a single text. The clearest examples come from fan culture, in which readers appropriate, deconstruct, and reconstruct linear media, participating in and propagating massive communal narrative worlds" (Zimmerman). By identifying this kind of meta-interactivity, Zimmerman acknowledges that this feature is not exclusively related to a set of actions performed by the reader while in contact with a text. In fact, interactivity can exist outside (and posteriorly to) the reading of a text. In Opening Sources, because the reader is given the chance to contribute with words, meta-interactivity becomes the text's central theme. Opening Sources, as the title indicates, is open to manipulation and the reader is invited to "Change (...) to: (...)." The sentences inserted by the reader are used to collaboratively accumulate changes, causing the text to shapeshift between reading sessions, but adding nothing to its structure or foundations. In Opening Sources, meta-interactivity is, in its turn, used to explore themes such as authorship and access to information in a digital age. It also allows us to identify a link between Opening Sources and experimental texts (or antecedents) which depend on collaborative work and make use of techniques such as the cadavre exquis or the cut-up.

Interactivity is often depicted as a set of new textual responses that offer readers the chance to become co-authors. The word "participatory" is frequently used in conjunction with "interactive." However, this word seems to communicate, without any possible refutation-especially in electronic literature, where interactivity was once used to undermine the author's power- that the reader can co-create or generate a text while reading it. ${ }^{17}$ In this regard, I would like to stress that this participatory role attributed to the reader is not an inherent characteristic of interactivity but an illusion promoted by the text, and thus, one of its expressive features.

Ryan linked the fourth level of interactivity to the construction of stories in real-time but adds that these stories do not yet exist. Therefore, in Narrative as Virtual Reality (2001), Ryan does not aim to address the expressive or figurative potential of virtual reality, but to use this technology as both a critical tool and a space of reflection. Ryan's work is a groundbreaking analysis of an emergent technology. It also represents an attempt to include narratology in the study of digital texts. Therefore, it may be regarded as an effort to grasp virtual reality's potential as a technology and an artistic or literary tool. In Ryan's text, 
this technology is used to imagine what would happen if readers could penetrate a virtual world which is being built by them in real-time. In so doing, the "reader" becomes the "user" to avoid the read-it-while-you-write-it paradox. If we consider interactivity as an expressive feature or as a trope and metaphor, this paradox is replaced by an aesthetic experience. Our attention becomes focused on the message, on the layers of meaning, and not exclusively on the behavior of the text. By focusing on content I do not aim to argue that text's behavior (Aarseth) should be excluded from the analysis of a text. What I intend to demonstrate ${ }^{18}$ is that there is a tendency to consider interactivity as a byproduct rather than a specific expressive feature. If our focus remains on the kind of actions a work might allow us to perform (or what the work can do), the singularity of interactive works run the risk of being ignored. Furthermore, the actions the reader is allowed to perform or the text's behavior are assumed as the work's defining characteristics. In order to analyze an interactive text, the way media affordances are used to convey meaning also needs to be contemplated. Works such as Young Hae Chang Heavy Industries' Nippon (2003), whose reproduction cannot be paused, rendering the text (almost) illegible, help us realize that just because a text is dynamic it does not mean that it is interactive. By the same token, Jason Nelson's Game, game, game and again game (2007), which cultivates the "illusion of clean lines and definitive choice" (Jason 2007) allows us to conclude that, just because the text is interactive, it does not mean that readers will be endowed with the power of choice.

\section{$4 \quad$ Gamers Love Stories Too}

Ryan once claimed that most gamers are not interested in the story and that they usually play "for the adrenaline rush of competition and for the thrill of beating the game." Moreover, "as long as they get stunning graphics and their dose of fast action, they are satisfied with the same old storyline clothed in different themes and visual motifs" (Ryan, "Peeling the Onion"). However, according to Gordon Calleja, the story may play a central role in games: "The promise of an interesting scripted narrative can attract players to the game in and of itself. This attraction can vary from the general appeal of a particular setting and genre to a specific expectation of an intriguing story that players can participate in" (Calleja 131). Calleja makes an interesting distinction between scripted narrative ("pre-scripted story events written into the game") and alterbiography ("the story generated by the individual player as she takes action in the game"). The relationship between both is described as follows: 
If the alterbiography ... meshes well with the scripted narrative, players will tend to care enough about the game world, its events, and its inhabitants to want to return to the game in order to find out more about them and to see where the scripted narrative will lead. (131)

The distinction suggested by Gordon Calleja allows us to identify what keeps a player concentrated on (or attached to) the game during and between sessions. However, the story cannot be "generated" by the readers' actions, nor can readers participate in the story being told. The story was fully (and not partly) pre-determined by the authors (or a team of designers and programmers). All that is left to do is to explore the game's surface, its multiple endings and, if any exists, try to reconstruct the story. Players can, of course, subvert or fight against rules and predetermined endings. However, any insurgency will always be tamed by game's architecture and programming.

In The Stanley Parable, the voice resembles a narrator from a novel. The personal dilemmas introduced by the narrator of this parable (he often loses track of the story and he frequently restarts the game to deal with conflicting episodes) set a metafictional tone. Some gamers have indicated the use of literary language $\mathrm{e}^{19}$ as one of the most appreciated features of this game. If we visit forums or read reviews about this parable, it becomes clear that players are not attracted to The Stanley Parable due to the promise of (inter)action, but because of the way this parable is conveyed to the reader/listener. ${ }^{20}$ For instance, in the Hardcoregamer webpage the following comment can be found: "The writing is smart and the narration is excellent, so much so that I usually found myself stopping any time the narrator had something to say just to make sure I didn't miss anything." According to this player, The Stanley Parable is a game with "limited interactivity" (interactivity is again linked with the opportunity for action) and its value is "in discovery and experimentation." 21 Another player claims the following:

... it's exciting to play again and again, because the choices you make can take you down such wildly different paths, and because the narrator's commentary is so smartly written and its delivery so hilarious that finding ways to trigger new bits of it is as rewarding as discovering a secret area containing precious treasures in a great adventure game. ${ }^{22}$

For a game with basic set of actions, The Stanley Parable was extremely well received by the gaming community, which means that gamers might be not only interested in the story, opportunity of action or collaboration, but also in theoretical riddles ${ }^{23}$ or intellectual challenges suggested by the designers or authors of this game. In this case—and also in the case of games that include a wide 
range of actions or demand the execution of multiple and simultaneous tasks - immersion can represent the level of concentration and the degree of attention dedicated to a text. ${ }^{24}$ Therefore, besides succumbing to the lure of fiction, a reader may be immersed in a text in order to maintain contact with a fictional world or to respond efficiently to challenges posed by the text. Ryan reminded us of the "complex mental activity that goes into the production of a vivid mental picture of a textual world." Because "language does not offer input to the senses, all sensory data must be simulated by the imagination" (Ryan, Narrative as Virtual Reality 11). I would like to take this idea one step further. Although seen as a passive and acritical activity, ${ }^{25}$ immersion entails several cognitive processes, such as decoding, interpreting, speculating, reviewing and creating mental images, which are represented by an imaginative effort invested while reading a text. All of these allow the reader's immersion which, in its turn, simultaneously fosters and is dependent on interactivity. Here, interactivity is not only represented by the actions performed by the reader, but by exchanges between reader and text taking place at the cognitive level. In the next section of this essay, I will describe how imaginative and ergodic efforts cooperate so that readers can experience and understand a text.

\section{$5 \quad$ Imaginative and Ergodic Effort}

\subsection{Ergodic Effort}

Espen Aarseth has produced a model which helps us to describe the relationship between user and text. Even though the concept of "interactivity" was undermined by Espen Aarseth, I believe that it is possible to find an interesting dynamic between "interactivity" and the "ergodic effort" described by this scholar. Before describing this dynamic, I would like to focus attention on the concept of cognitive interactivity. At the basis of the ergodic work done by the reader which is here represented by the configurative, explorative, textonic user functions, there is a cognitive work which enables the reader to understand the text. The idea that interactivity can be related not only to a participatory role in the construction of the text or to physical agency, but also to the cognitive work done by the reader, might bring immersion and interactivity closer together and may help us analyze interactive texts in their full dimensions.

Besides displaying a narrative or presenting the possibility of interaction, a text can also be considered as the matrix of possible worlds. These can only be accessed through a cognitive interactivity which was once described by Eric Zimmerman as a set of "psychological, emotional, hermeneutic, semiotic, reader- 
response ... kind of interactions that a participant can have with the so-called 'content' of a text' (Zimmerman). Here, I have adopted this concept to represent the cognitive work performed by the reader and the interpretation of the texts mechanics and the "content of a text." I believe that interpretation is the origin and product of the reader's user functions because, in order to perform an action, the reader needs to understand what is asked of him. The reader is urged to interpret the result of his actions so that he can improve his skills, create a strategy and react to the text in an informed and efficient way. Similarly, the reader is asked to gather information and configure the text so that he can interpret it. For this reason, I argue that the interpretative function which, according to Aarseth, "is present in all texts" (64), should not be placed side by side with other user functions but as follows:

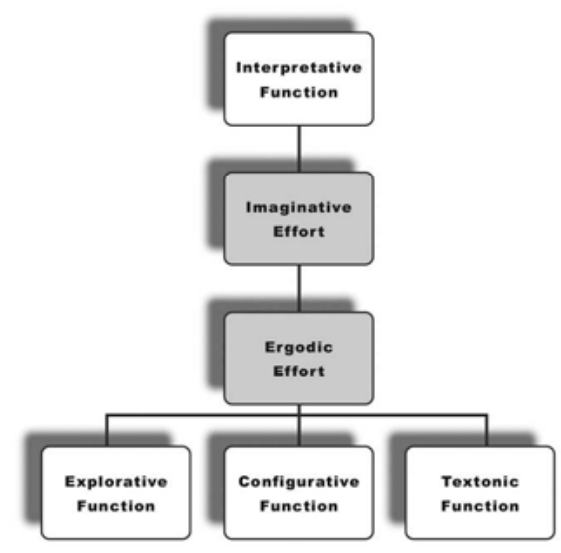

Fig.1. Imaginative and ergodic effort: user functions interplay.

This graph does not represent a hierarchical model and it merely aims to demonstrate that user functions are interdependent. In fact, an analysis of a digital text can begin by selecting any element of this graph. Because it is dependent on the interpretation of data and the ergodic effort invested by readers, cognitive interactivity enacts a fusion between all of the mental and physical activities performed during reading. This kind of interactivity also enables us to see immersion (usually linked to cognitive processes) and interactivity (usually linked to physical activities) as cooperating features.

I believe that Aarseth's model is open-ended, and thus, allows the critic and researcher, albeit within certain limits, to expand the range of each function. Aarseth is interested in the text's mechanics and he believes that a cybertext is "a mechanical device for the production and consumption of verbal 
signs" (21), but digital texts are not exclusively verbal artifacts. The reader may be asked to activate the interpretative function to understand icons, pictures or moving images or, as claimed by Hayles, "material metaphors." Aarseth's explorative function is focused on the selection of paths, which indicates that, when he envisioned this model, Aarseth was thinking about multilinear and hypertextual works. When analyzing ergodic texts that make no use of rhizomatic paths, this function could refer to the exploration of the text's surface or its expressive features. It can also be related to the exploration of a game's different spaces or sceneries.

By expanding Aarseth's model, I wish to bring expressive and mechanical features together and to build a bridge between multiple fields which allow us to address interactive texts. These texts demand close collaboration among disciplines such as game studies, narratology, literary theory, media studies or aesthetics. In order to analyze these texts, critics need to adopt multiple approaches, some of them considered as incompatible. By bringing imagination and ergodicity together, interactive texts become more than a set of textual responses, paths or tools made available to the reader. Interactive texts can be considered as irregular fields where meaning emerges according to different processes and, as such, demands multiple procedures to be grasped. Thus, only by applying the invaluable knowledge gathered by different disciplines and by creating an open and productive dialogue between them, will it be possible to successfully address interactive texts.

According to Aarseth, the configurative function is analogous to the selection or creation of textons. Yet, it can also be associated to the way the reader organizes and displays information in order to read and interpret the text. Readers can configure the text but cannot co-create it: they can only reconstruct it imaginatively. Because readers cannot add something to the structure of a text-in Opening Sources, for instance, readers are allowed to accumulate changes, and thus, contribute for the proliferation of meaning, but cannot change the text's mechanics—, the textonic function would have to be excluded from this reading of Aarseth's model. However, textons exist in a (what if) potential state. Readers do not know what shape textons will assume. Textons offer keys to possible worlds and the reader needs to perform a textonic function to be able to explore those spaces. In other words, the reader needs to create a "strategy" so that textons are turned into scriptons. Let us take the example of the work The Intruder (1999) by Natalie Bookchin. ${ }^{26}$ This work is comprised of a set of games such as Space Invaders or Pong. In one of the games, the reader is urged to collect several objects to keep the narration flowing (or to play the "game of narration," as suggested by Aarseth). The textonic function is, in this case, activated by the need to turn the objects into a sequence of narration. Only after understanding how this is done, and only after designing a strategy 
that enables the reader to transform the textons into scriptons (or performing a textonic function), will the reader be able to access the story and interpret it. Nevertheless, during the reading of the story, the user needs to permanently adopt the interpretative function to formulate or improve a strategy. This function enables readers, not only to understand the figurative strategies of the text but also to understand the result of their actions in order to continue reading. The interpretative function becomes an invaluable tool to understand and interact with the text.

\subsection{Imaginative Effort}

Schäfer and Gendolla have claimed that gamers only unravel the mystery in detective stories if they respond successfully to the challenges of the game. To fulfil that goal, they need to resort to imagination:

In games and net literature, the mystery is unraveled if and only if the readers/players' actions, which have been inspired by their imaginative analysis in the course of the reception, turn out to be in accordance with pre-scripted solutions that have been programmed by the game designers and implemented into the rules and computer operations. (Schäfer and Gendolla 98; emphasis added)

In order to read a text that asks the reader to sew a corpse, to grab objects, and follow a trail of clues, the reader needs to invest what I consider to be an imaginative effort. According to Zumthor, imagination is a "poetic" faculty that departs from "a deeply concrete apprehension," but needs to be supported by a "reconfiguration of the perceived elements" or "perception and imaginary reconstruction" (Zumthor 196-197). Imagination is not a mental process disconnected from reality. In fact, it is used to apprehend or understand the world. However, this faculty cannot be equated with the possibility to participate in the construction of the text. Imagination is based on a subsequent process in which the creative work done by the writer, programmer or designer is appropriated and reconstructed. In stories or games, the reader needs to follow the rules created by authors. This means that increased interactivity by means of an expanded range of actions, does not necessarily offer an increased amount of power or freedom of choice to the reader. ${ }^{27}$ As the guard fields used in hyperfictions or the scheduled actions in online works allow us to conclude, there are multiple and powerful ways to circumscribe the reader's movement across the text. If readers, gamers or users feel that they are participating in the construction of the story or assisting the author(s) in generating it, this happens because an imaginative effort is being exerted, not because the story is being 
built or generated on the go. The ability to co-create a text or the opportunity to participate in its construction is the product of reader's imaginative effort. The text may be gradually presented to the reader as a consequence of reader's actions, but both the text and the story existed previously to the process of reading or playing. "Meta-interactivity" allow readers to tell stories based on their playing experience or game session, and even to create versions of games. Yet, while in touch with the game, the user's range of actions, as well as the text's properties, are limited to those planned by the creator(s) of the game.

In The Intruder, readers need to suspend or suppress disbelief so that they can beat the enemy, take a walk on the fictional world or trade objects for a piece of narration. At a certain point, the reader is asked to shoot an opponent. The Intruder is based on a short story written by Jorge Luis Borges, in which two brothers share a woman. The competition between these two characters (or between the reader and the computer) is illustrated by the back and forth movement of the feminine figure between the two shooters. The reader's desire to win the game or listen to the story—which can be compared to the reader's voracity, or struggle to reach closure-puts the female character in danger. Details such as these enable us to see that interactivity (or the possibility of interaction) has its own meaning and that this feature is, in fact, dependent on the interpretative function. I would like to emphasize that this function is not only hermeneutical, but is also applied to explore and configure the text, and thus, to understand it.

To perform a function, the reader of an ergodic text needs to invest an imaginative effort, which means that the reader has to formulate strategies, focus and manage attention, as well as "fill in the gaps" (Iser). ${ }^{28}$ In this sense, imaginative effort not only allows readers to impersonate a character, but to speculate about future outcomes and to adjust to unpredictability or fragmentation. Without the contribution of an imaginative effort, the reading of an ergodic text would be limited to the reader's manipulation of what is presented on screen (or other kind of surfaces). Fictional worlds would crumble and poems would be emptied of their metaphors, since the reader or player would be prevented from getting in touch with them. Ultimately, the reader or player would be incapable of understanding the text. The sense of participation and agency is an illusion sustained by the text and, without an imaginative effort, the reading of an ergodic work would not be possible.

Therefore, suspension of disbelief does not correspond to a passive role played by the reader but becomes the matrix of cognitive interactivity. This feature is linked to the imaginative effort applied by readers, which is vital to understand the text. The reader's ability to suspend disbelief is instrumental and decisive to read and operate a text. As for immersion in the fictional world (which is related to the reader's suspension of disbelief), it is dependent on the 
ergodic effort invested by the reader to maintain the contact with the text. Therefore, as hinted before, immersion is not only related to the possibility of permeating a fictional world, but also to the level of attention invested (namely required by userfunctions) to maintain contact with a text.

A digital text is not a mere set of opportunities for interaction. What is more, the reader's expectations are not always fulfilled. In fact, they can be severely thwarted. At a certain stage of The Intruder, the reader is asked to fall down bottomless pits in order to win an excerpt of the narrative. In a sense, readers need to fail, so that they can continue listening to the story being told. Aarseth once described the situation of the cybertext's reader as unstable: "The cybertext puts its would-be reader at risk: the risk of rejection" (Aarseth 4). This sentence is particularly interesting because Aarseth acknowledges that the text can exist in a potential state ("would-be reader") and that, although ergodic, the text is not designed to bend to reader's will. Moreover, it can offer resistance and keep the reader immersed in a quest for meaning. To Aarseth, the creation of an "individual outcome" may be illusory. I would add that it is dependent on reader's imaginative effort.

\section{Conclusion}

The inclusion of an imaginative effort enables us to overcome the paradox "writing a story while reading it" and-by recognizing that the reader's participatory role is the result of imaginative reconstruction and, simultaneously, part of interactive text's expressivity — to back claims such as "the text is generated by the reader."

To conclude, I would like to present one last example. While interacting with a statue in a gallery in Emily Short's Galatea (2000), the reader is invited to imagine that an actual conversation is taking place. Galatea is based on ELIZA (1966), a chatterbot created by Joseph Weizenbaum. ${ }^{29}$ If we ask the right questions (or insert the correct commands), Galatea will reply. Once readers enter the interactive fiction/the gallery, a narrator intervenes and "an interactive conversation with Pygmalion's statue" (Short; emphasis added) is initiated:

You come around a corner, away from the noise of the opening. There is only one exhibit. She stands in the spotlight, with her back to you: a sweep of pale hair on paler skin, a column of emerald silk that ends in a pool at her feet. She might be the model in a perfume ad; the trophy wife at a formal gathering; one of the guests at this very opening, standing on an empty pedestal in some ironic act of artistic deconstruction. You hesitate, about to turn away. Her hand balls into a fist. "They told me you were coming. ${ }^{30}$ 
Galatea demonstrates that, if an imaginative effort is not invested and if disbelief ${ }^{31}$ is not suspended, actions such as "talk[ing] about objects present in the room," as suggested by Emily Short, are deemed impossible and Galatea's fictional world becomes inaccessible.

In a computer game, the player needs to suspend his disbelief and apply an imaginative effort in order to jump off a cliff. When the player or the reader are welcomed as characters in a fictional world, they are invited to imagine that their actions have consequences in an alternate world, or else the interaction with other characters is impracticable. Nevertheless, interactivity is not a mere way to offer the reader a chance to manipulate the text, nor a manifestation of technological prowess. Interactivity strongly contributes to the production of meaning, and thus, it is not a tool to co-create the text or to unravel a narrative. This feature of digital texts was once used to transfer the authorial power to the reader. However, as emphasized in this essay, this was an illusion (the illusion of choice) sustained by interactive texts. Even though all has been preprogrammed, readers of an ergodic work need to imagine that they have a participatory role in the construction of the text to keep the story or narrative unfolding. Therefore, suspension of disbelief cannot be confused with a passive or distracted reception of a work of art (Benjamin). To feel immersed (or concentrated) in a text and to inhabit its textual world, readers need to activate their imagination.

Since imaginative effort also involves speculation to predict the next step or formulate a strategy, it is also needed to understand and maintain the contact (or any kind of interaction) with a text. The same holds true for print novels, interactive fictions, games or virtual reality. Thus, immersion in a virtual world is allowed not only by the technological resources being used, but also by the imaginative effort invested by the reader.

As stated before, immersion is also linked with the degree of attention demanded by riddles and intellectual challenges suggested by texts such as The Stanley Parable (2013) or The Intruder (1999). During reading, different user functions are required to assemble and understand the text. Because interactivity is linked not only with physical actions, but also with cognitive tasks performed by the reader, interactivity is enabled simultaneously through the affordances of the medium, the text's properties or expressive features, as well as reader's immersion in the text.

By taking into account an imaginative effort, the conflict between narrative and ergodic layers of a text (Eskelinen) can be brought to an end. Interactivity is seen as an aesthetic feature of the work. Consequently, it can be considered as part of the text's expressiveness, and not as a tool to dismantle the text's stability, interrupt the narrative arc or to defy the author's ruling. 
Interactivity is often related to physicality, to the reader's participatory role and to the amount of textual responses displayed by a work. These perspectives turn the text into a set of challenges and magical tricks and the reader into a paths' selector and a shuffler of possible outcomes. In order to operate and understand these textual machines, the user must activate an interpretative function which is both the origin and result of the textonic, explorative and configurative user functions (Aarseth). Cognitive processes and physical actions are thus interconnected through joint imaginative and ergodic efforts. As demonstrated, both cooperate in handling the resistance, multimodality and aesthetic richness of digital texts.

\section{Notes}

1 The tendency to consider "interactivity" as a self-explanatory word has been criticized by Aarseth: "This trajectory is typical of industrial terms appropriated by analysts of technoculture (a more recent example is the ubiquitous "virtual") and shows how commercial rhetoric is accepted uncritically by academics with little concern for precise definitions or implicit ideologies" (48).

2 Cf. <http://newmediawritingprize.co.uk/>. In NMWP webpage is stated that: "Interactivity is a key element of new-media storytelling" $<$ http://newmediawritingprize.co.uk/the-prizes/>.

3 This essay is based on the doctoral research developed at the University of Coimbra (Portugal), as part of the Doctoral Programme in Materialities of Literature (2010-2014). All translations were done by the author.

4 I have claimed elsewhere that the immersion and interactivity debate, because it demands the participation of several disciplines and a multiperspectival view, allows us to depict the emergence and development of this field.

5 In fact, Judy Malloy is the author of Uncle Roger, a pioneering work published serially in 1986, and as an interactive hyperfiction in 1987. Malloy is also the developer of the authoring software BASIC Narrabase (1986). The history of Uncle Roger is available at <http://scalar.usc.edu/works/pathfinders/history-of-judy-malloys-uncle-roger $>$.

6 In her reformulation of Narrative as Virtual Reality, Ryan mentions the "loss of the prominence of hypertext" and states that "hypertext is no longer perceived as the narrative use of digital technology but only as one of many possible such uses" (2). 
7 In Narrative as Virtual Reality, Ryan claims that "narrative coherence is maintained at the cost of interactivity" (256). Ryan also notices an "antiimmersive effect of interactivity" (280).

8 I have described this kind of reading in the $\mathrm{PhD}$ dissertation Imersão e Interactividade na Ficção Digital [Immersion and Interactivity in Digital Fiction] (2014). The adjective "deambulatória" [vagrant] was used to describe the aimless and random, even frustrating, reading promoted by multilinear and open-ended texts.

9 Espen Aarseth has associated "interactivity" to a "new technology" which has overshadowed pre-existent ones: "This word [interactivity] has long been associated with the use of computers that accept user input while a program is running, as opposed to 'batch' computers, which process only preloaded data without interruption." According to Aarseth, "interactive thus came to signify a modern, radically improved technology, usually in relation to an older one" (48). Jessica Pressman has described the existence of a digital modernism or a "strategy of renovating modernist aesthetic practices, principles, and texts into new media" (2). According to Pressman, writers exploring digital modernism refashion tradition in such a way that "simple designations of 'new" become difficult to employ (96). Similarly, I believe that interactivity represents expectations and techniques common to several art and literary forms. For this reason, even though the link with computer science is undeniable, it is difficult to consider interactivity as the result of technological innovation or as truly "new."

10 A link between physicality and interactivity continues to be explored by several authors. For instance, while describing interactive metalepsis, Ensslin claimed the following: "It involves mostly digital and interactive media that require the user's physical interaction with its hardware and software" (1).

11 Here I would like to refer to the texts written by Roland Barthes, "La mort de l'auteur" (1967), and Michel Foucault's "Qu'est-ce qu'un auteur?" (1969).

12 In Narrative as Virtual Reality, Ryan claims that hypertext authors have exacerbated some features of postmodernist theory: "hypertext authors conceived the strange new gift of interactivity as a way to free the novel, even more radically than postmodern works of the print variety had done" (264-265).

13 In fact, this work is often described as an interactive fiction. Cf. <https://en.wikipedia.org/wiki/The_Stanley_Parable>. See also the following re- 
view <http://www.telegraph.co.uk/technology/video-games/video-game-reviews/10443454/The-Stanley-Parable-review.html>.

14 Cf. "Entre textões e escritões: a narrativa projectada" [Between textons and scriptons: the projected narrative], in Narrativa e Media: géneros, figuras e contextos (2017). Available at: <https://doi.org/10.14195/978-989-26-1324-6>.

15 According to Emily Short, some interactive fictions "sharply constrain player agency and make that constraint an important part of the message of the story" (Short 290). For instance, Short claims that interactive fictions such as Adam Cadre's Photopia (1998) make "a 'win' state impossible," and "reproduces the denial, bargaining, and acceptance of grieving as experienced through the player's attempts to replay the work for a better ending and the inevitable failure of those attempts" (290). As in The Stanley Parable, interactivity strongly contributes to the expression of an idea, and thus, cannot be exclusively considered as a tool to co-create a narrative.

16 This text can be read at <http://openingsources.com/ $>$.

17 This ambition has been present throughout the history of electronic literature and is often related to the project of achieving an authentic and unmediated experience or reaching the transparency of the medium. As we know, this same desire can be identified in art and literature in general.

18 In Narrative as Virtual Reality 2 (2015), Ryan also identifies a change of perspective and considers that "[i]n the heyday of structuralism and deconstruction, it became heretical even to mention the phenomenon of emotional response" (107) and now "it is acceptable again to talk about content, mimesis, reference, emotional involvement with characters, and immersion in fictional worlds" (2).

19 Here I relate literary language to the use of third person singular, extensive descriptions of events, the careful choice of vocabulary and the use of a formal register.

20 Graphics are not a strong feature of The Stanley Parable. In fact, they are rudimentary and monotonous, and work as a discouraging element.

21 This review is available at <http://www.hardcoregamer.com/2013/10/1$7 /$ review-the-stanley-parable/58895/>.

22 This review is available at <http://www.gamespot.com/reviews/the-stanley-parable-review/1900-6415481/>. Adventure games such as Zork (1977) emerged during the seventies and are often considered as antecedents of electronic literature (Cf. Montfort). 
23 While describing the literary riddles suggested by the Latin poet Symphosius and The Exeter Book, Nick Montfort claimed that: "[b]y presenting a metaphorical system that the listener or reader must inhabit and figure out in order to fully experience, and in order to answer correctly, the riddle offers its way of thinking and engages its audience as no other work of literature does." According to Montfort, "interactive fiction is related to the riddle because the interactor is "also an writer." Nevertheless, as Montfort points out, even though "useful," the interactor's contributions basically consist of commands such as "go north, jump off the roof, or eat a peach" (Montfort 4).

24 Different types of attention are demanded during the reading of an interactive text. This subject has been explored in Imersão e interactividade na ficção digital [Immersion and Interactivity in Digital Fiction] (2014).

25 Ryan believes that: "The self-explanatory character of the concept is easily interpreted as evidence that immersion promotes a passive attitude in the reader, similar to the entrapment of tourists in the self enclosed virtual realities of theme parks or vacation resorts" (Ryan, Narrative as Virtual Reality 11).

26 Some documentation about this work can be found at the author's page <https://bookchin.net/projects/the-intruder/>.

27 For instance, in 2003, Nick Montfort hoped that interactive fictions could "provide even more appealing possibilities for the interactor" and that technology could allow the production of "works of greater power" (5).

28 In fact, Wolfgang Iser considers that the act of reading can convey the impression that the reader was given a participatory role or that it has been welcomed to a fictional world: "The dynamic interaction between text and reader has the character of an event, which helps to create the impression that we are involved in something real" (Iser 67).

29 This chatterbot emulates the behavior of a Rogerian psychiatrist. In an ACM communication, Weizenbaum explained the reason for using a therapy session as a model: "ELIZA performs best when its human correspondent is initially instructed to 'talk' to it, via the typewriter of course, just as one would to a psychiatrist. This mode of conversation was chosen because the psychiatric interview is one of the few examples of categorized dyadic natural language communication in which one of the participating pair is free to assume the pose of knowing almost nothing of the real world. If, for example, one were to tell a psychiatrist 'I went for a long boat ride' and he responded 'Tell me about boats,' one would not assume that he knew nothing about boats, but that he had some purpose in so di- 
recting the subsequent conversation. It is important to note that this assumption is one made by the speaker. Whether it is realistic or not is an altogether separate question" (Weizenbaum 42).

30 Cf. <http://collection.eliterature.org/1/works/short_galatea.html>.

31 In Narrative as Virtual Reality (2001) Ryan mentions the existence of a "ELIZA effect" which is equated to "the user's willingness to suspend disbelief in the humanity of the computer." The conversation with ELIZA can lead to illogical replies and to episodes of "graceful degradation" (314). For Ryan, "[i]t did not matter that ELIZA did not understand a conversation. . . . To the user willing to play a game of make-believe with the computer, ELIZA was the perfect prop" (313). Yet, in the case of Galatea, readers are also invited to reconstruct what is being described (readers can "move" across a room), and thus, to invest an imaginative effort. Jonathan Lessard considers ELIZA an example of procedural literature. For Lessard, "[ $\mathrm{t}]$ he main interest of procedural objects is their ability to generate varying content in response to changes in input and setting." However, "[t]he complexity of even the simplest human interactions makes interesting procedural texts very difficult to design" (407-408).

\section{Works Cited}

Aarseth, Espen. Cybertext: Perspectives on Ergodic Literature. Baltimore, MD: The Johns Hopkins University Press, 1997.

Benjamin, Walter. Das Kunstwerk im Zeitalter seiner technischen Reproduqierbarkeit. Frankfurt am Main: Suhrkamp Verlag, 2003.

Bookchin, Natalie. The Intruder. 1999. 6 Aug. 2017 <http://bookchin.net/projects/the-intruder/ $>$.

Coleridge, Samuel Taylor. Biographia Literaria. Edited by James Engel, and W. Jackson Bate. Princeton, NJ: Princeton University Press, 1983.

Ensslin, Astrid. "Diegetic Exposure and Cybernetic Performance: Towards Interactional Metalepsis." 2011. 6 Aug. 2017 <http://www.academia.edu/1157402/Diegetic_Exposure_and_Cybernetic_Performance_Towards_I nteractional_Metalepsis>.

Eskelinen, Markku. Cybertext Poetics: The Critical Landscape of New Media Literary Theory. New York: Continuum, 2012.

Grau, Oliver. Virtual Art: From Illusion to Immersion. Cambridge, MA: The MIT Press, 2003. 
Hatcher, Ian. Opening Sources. 2008. 6 Aug. 2017 <http://openingsources.co$\mathrm{m} />$.

Hayles, N. Katherine. Writing Machines. Cambridge, MA: The MIT Press, 2002.

Iser, Wolfgang. The Act of Reading: a Theory of Aesthetic Response. Baltimore, MD: The Johns Hopkins University Press, 1980.

Jackson, Shelley. Patchwork Girl. Watertown, MA: Eastgate Systems, Inc. 1995.

Lessard, Jonathan. "Procedural." The Johns Hopkins Guide to Digital Media, edited by Marie-Laure Ryan, Lori Emerson, and Benjamin J. Robertson. Baltimore, MD: The Johns Hopkins University Press, 2014, pp. 407-408.

Maduro, Daniela Côrtes. Imersão e interactividade na ficção digital. Coimbra: University of Coimbra, PhD dissertation, 2014.

Malloy, Judy. "Authoring Systems." The Johns Hopkins Guide to Digital Media, edited by Marie-Laure Ryan, Lori Emerson, and Benjamin J. Robertson. Baltimore, MD: The Johns Hopkins University Press, 2014, pp. 32-37.

Montfort, Nick. Twisty Little Passages: An Approach to Interactive Fiction. Cambridge, MA: The MIT Press, 2005.

Murray, Janet H. Hamlet on the Holodeck: The Future of Narrative in Cyberspace. Cambridge, MA: The MIT Press, 1980.

Nelson, Jason. "Game, game, game and again game" [2007]. Electronic Literature Collection, vol. 2, edited by Laura Borràs, Talan Memmott, Rita Raley and Brian Kim Stefans, 2011. 6 Aug. 2017 <http://collection.eliterature.org/2/works/nelson_game.html>.

Pressman, Jessica. Digital Modernism. Making It New in New Media. Oxford and New York: Oxford University Press, 2014.

Ryan, Marie-Laure. "Immersion vs. Interactivity: Virtual Reality and Literary Theory," SubStance, 28.2 (1999). 6 Aug. 2017 <https://muse.jhu.edu/login?auth=0\&type $=$ summary\&url=/journals $/$ substance $/$ v028/28.2ryan.html \#FOOT1>.

. Narrative as Virtual Reality: Immersion and Interactivity in Literature and Digital Media. Baltimore, MD: The Johns Hopkins University Press, 2001.

" "Peeling the Onion: Layers of Interactivity in Digital Narrative Texts." 2005. 8 Aug. 2017 <http://www.marilaur.info/onion.htm>.

- Narrative as Virtual Reality 2: Immersion and Interactivity in Literature and Digital Media. Baltimore, MD: The Johns Hopkins University Press, 2015.

Schäfer, Jörgen, and Peter Gendolla. "Reading (in) the Net." Reading Moving Letters. Digital Literature in Research and Teaching, edited by Roberto 
Simanowski, Jörgen Schäfer and Peter Gendolla. Bielefeld: [transcript] Verlag, 2010.

Short, Emily. "Galatea" [2000]. Electronic Literature Collection, vol. 1, edited by N. Katherine Hayles, Nick Montfort, Scott Rettberg and Stephanie Strickland, 2006. 6 Aug. 2017 <http://collection.eliterature.org/1/works/short_ galatea.html>.

—_. "Interactive fiction." The Johns Hopkins Guide to Digital Media, edited by Marie-Laure Ryan, Lori Emerson, and Benjamin J. Robertson. Baltimore, MD: The Johns Hopkins University Press, 2014, pp. 289-292.

Weizenbaum, Joseph. "ELIZA: A Computer Program For the Study of Natural Language Communication Between Man And Machine." Communications of the ACM, vol. 1, no. 9, Jan. (1966): pp. 36-45.

Wreden, Davey e William Pugh. The Stanley Parable. 2013. 6 Aug. $2017<$ http://www.stanleyparable.com/>.

Young Hae Chang Heavy Industries. Nippon. 2003. 6 Aug. 2017 <http://www.yhchang.com/NIPPON.html>.

Zimmerman, Eric. "Narrative, Interactivity, Play, and Games." Electronic Book Review. 7 Apr. 2004. 6 Aug. 2017 <http://www.electronicbookreview.co$\mathrm{m} /$ thread/firstperson/ludican-do $>$.

Zumthor, Paul. Performance, Recepşão e Leitura. São Paulo: Cosac Naify, 2007. 
Part Four:

Teaching the Digital 



\section{María Mencía}

\section{Creative Process: Interweaving Methods, Content and Technology}

\section{Introduction}

This article has developed from a keynote presentation I gave about researchled teaching in the panel of "Teaching the Digital" at the International Conference on Digital Media and Textuality ${ }^{1}$ hosted at Bremen University by Daniela Côrtes Maduro. It delves into teaching creative practice as research in a module titled Creative Digital Environments where students learn by doing and enquiring through practice-based research. It outlines the content of the module and focuses on one of the sessions where we discuss the integration of methods, content and technology in the production of practice through the analysis of works representative of this approach. It also comments on the merits of two different methods of module delivery.

I designed the module specifically for undergraduate students in their final year as part of a Media and Communications undergraduate program at Kingston University. It is a research-led module that engages students with a diversity of digital creativity in hybrid fields of electronic literature (e-lit), e-poetry and media arts and it could also be a relevant module in Art, Digital Cultures and Digital Humanities programs. The aim is to train students to be individual researchers by producing a practice-based research project, articulating goals, research enquires, as well as show them how to disseminate their outcomes. The Creativity and Cognition Studios at the University of Technology, Sydney, gives a definition of practice-based research with which I concur:

Practice-based Research is a form of research that aims to advance knowledge partly by means of practice. The type of research is an original investigation undertaken in order to gain knowledge and understanding. It includes the invention of ideas, images, performances and artefacts including design, where these lead to new or substantially improved insights. ${ }^{2}$

The content of the module reviews pioneering works of media art and their historical influences; change and hybridity in electronic literature (e-lit); interweaving methods, content and technology in the production of creative practice; integration of theory and practice in practice-based research; culture remix and digital creations; creative programming and collaboration; concepts of ap- 
propriation, authorship, publishing and dissemination, and with this, the Creative Commons. Finally, it addresses media archaeology and methods to archive and preserve digital media works. As a consequence of the process of production of creative work, students also become aware of the nature of interdisciplinarity in practice-based research and the possibilities of collaboration. These are all current and relevant topics in e-literature and the wider fields of digital culture, humanities and media arts, which students need to be familiar with and to critically analyze in today's digital media society.

Students are able to explore the creative potential of digital technologies through their own practice-based research; that is, questioning through practice, as well as through the critical analysis of works created by practitioners/theorists using digital technologies. I emphasize both practice and theory because one of the aims is to encourage students to think critically about the production of their own practice and see practice as a way of enquiry and means to explore and discuss theoretical concepts. They are used to doing this through more traditional academic forms like essays but, in this module, students are able to interrogate what is traditionally understood as "academic work" and use practice-based research methodologies to push the boundaries of research practices in the humanities. Why should we still use the medium of print when we use digital technologies in every aspect of our lives? Nowadays, there are a whole set of tools, many of them open source, offering a range of writing, editing and publishing platforms which students can explore to break away from traditional ways of writing and thinking. In addition, exploring through making born-digital texts helps the student to compare the relationship of "conventional" academic research with practice-based research. Also, students as digital readers seem to relate more and more to the use of digital technologies to express themselves: writing poetry, designing websites, webbased works and videos in order to study humanistic concerns, bring up social and political issues, write personal stories and more. Electronic literature gives students this possibility. They can examine exciting and innovative ways of creating multimodal writing using image, sound, text, coding; addressing the role of the author/reader/writer/artist/scholar and using open-source software. Electronic literature provides media literacy beyond the regular use of emails or visiting websites which can enhance students understanding of contemporary mediated society. As Roberto Simanowski notes:

Such literacy not only consists of the ability to read, write, navigate, alter, download and ideally program web documents. . . . It also includes the ability to identify with the cursor, the avatar and with virtual space, to travel in spatially and temporally compressed units without physical motion, to carry our real-time activities, and to undertake 
associative selection, sampling and reconfiguration resembling DJ and VJ culture. (231)

Furthermore, drawing from my experience as a practice-based researcher and a lecturer, I believe using practice-based methodologies to make cultural artifacts enhances students' understanding of concepts pertinent to digital media practice, social and cultural aspects of digital culture raised by these theories. In many art and design programs, students choose a topic and develop it through the final year as a practice-based model, informed by related theories often focusing on personal experience, practice and motivation so the learner is at center stage. In this module, students have a first opportunity to create practice as research within a field of study but the topics are wide enough to allow students to bring their own interests to bear, to extend and expand what is provided in the module. From my observations in teaching and learning approaches, I have noticed that when students are able to reference their own interests, it engages and enhances their learning experience.

\section{Outline of the Module}

The following are stages of the course in order of appearance.

\section{New Media: Origins}

This session maps out general themes, issues and topics to be explored over the next eleven weeks, and for this purpose, we start questioning how previous art influenced pioneering work in digital culture/media arts. That is, how avant-garde and dada influenced net.art, ASCI art; how concrete poetry, visual poetry influenced e-poetry; where do new media come from; what interdisciplinary landscape is new media rooted in; what are the historical, theoretical, technological contexts. Through exploring these topics, we encounter methods and approaches used by different movements to produce creative practice, which encourage students to think and reflect about their own creative process and approaches.

\section{Change and Hybridity in Electronic Literature}

This lecture introduces students to new forms of writing where art, literature, and new technologies meet to produce multimodal textualities (image-soundtext) in electronic literature. We study the process of refashioning media discussed by J. D. Bolter and R. Grusin in their seminal work Remediation: Understanding New Media (1998) through the exploration of examples of different media (paintings, websites, VR, film, games) but particularly in connection to 
works of electronic literature. Notions explored cover: digital born (Hayles), immediacy, hypermediacy, text, engagement and experience of the work, as well as digital environments (web, virtual realities, augmented realities, apps) and the e-lit genres that generate from the use of these different technologies.

\section{Creative Process: Interweaving Methods, Content and Technology}

Following on from the previous session, in this lecture we explore the ideas and processes employed in the creative processes of different artists, including my own research practice in Multimodal Textualities, with a focus on how to integrate content and form. This method is used to discuss with students the processes used by different practitioners, to compare them and to bounce ideas off each other. I will expand on this session further in the paper by exploring exemplary creative practice.

\section{Culture Remix-Digital Creations: Remix Creativity Ro/Rw Culture}

The next three sessions address methods of remix culture. Lawrence Lessig writes about Remix creativity "remix is an essential act of Read Write (RW) creativity" (56). In this lecture, through Lawrence Lessig's contrast of "readwrite" (RW) and "read-only" (RO) cultures, we explore the paradigm shift that occurs in fundamental models of writing and creative practices. Since online technologies have facilitated and increased the production of creative and collaborative practices, it addresses the potential of the Internet as a creative palette (Andrejevic 127). Notions addressed: creativity, participation, user, producer, consumer, author, Creative Commons, new media literacies, practice and theory.

\section{Culture Remix-Digital Creations: Appropriation-Uncreative Writing} This session focuses on the chapter "Why appropriation?" written by Kenneth Goldsmith in his book Uncreative Writing (109-124). It reflects on the approaches/methods Goldsmith discusses in the production of re-appropriating texts, raising questions on authorship, authorial curatorial decisions, process, style, design, creative/uncreative, reading experience, dissemination, distribution and the electronic medium. "All of the decisions we make while performing our remixes are part of what Duchamp calls The Creative Act" (Amerika).

\section{Culture Remix-Digital Creations. From Dada to Java: Collaborative Practice}

The title is taken from a short documentary featuring Nick Montfort, Darius Kazemi, Stephen McGregor, Paul Kneale, George Buckenham and Sandy Baldwin and it is the basis for this session. It was made at QMUL as part of the Digital Arts Documentary group. ${ }^{3}$ The introduction of free software has 
created an Open Culture of sharing and DIY where anybody can be creative from their own home, or what Conrad Bodman calls "home-brew culture"(14). We will explore creative code, repurpose and remix as writing experiments for creative collaborative practice in humanities research.

A case study appropriating and remixing code, engaging in collaboration during the period of a week and exhibited as a site-specific installation, is the UpsideDown Chandelier. This is the outcome from a research project I led in Košice, Slovakia, as part of the Code Interactive \#2 seminar workshop. It is a collaboration between artists, scholars and critics of e-lit, Christine Wilks, Jeneen Naji, Zuzana Husárová and myself. The project was developed as part of the exhibition I co-curated with Husárová, Repurposing in Electronic Literature at the new media DIG gallery, in response to the notion of repurposing. The site-specific installation references events relating to the history of Košice and its tobacco factory from 1851, which employed mostly women workers. In our research we found out that the women workers donated a candle chandelier to St. Elizabeth's Cathedral when it was being renovated (Kolcun). The chandelier itself was repurposed twice-from the original candles to gas lighting and with the advent of electricity, was turned upside down. In the installation, images of the chandelier from the cathedral are randomly generated and projected onto a screen in a flux of forms. The code was repurposed from a generative work Wilks and Randy Adams remixed called Notes Noir, included in the collection of digital media works titled, $\mathrm{R} 3 / \backslash \backslash 1 \times \backslash / \mathrm{ORX}$ (remixworx), a project initiated by Adams in 2006 and in which Wilks was one of the main collaborators. Simultaneously, the words connected with this story appear projected on the walls of the room, and phonetic sounds from Slovak, Hungarian and German languages are generatively re-mixed to create the multilingual soundscape of languages that were once spoken in the very same place by women workers. The factory room was transformed to become an immersive, contemplative and reflective space with a sense of historical reminiscence reflected on the walls, floor and windows.

\section{Methods (Theory-Practice) in Practice-Based Research}

After reflecting on the making process and the interconnection of content, method and technology, the next stage is to put into practice the process of thinking through the production of practice. Borgdorff writes: "we should not say: 'here is a theory that sheds light on artistic practice,' but 'here is art that invites us to think"' (96). Students reflect on the theories covered in previous sessions - remediation, remixing, appropriation and coding - as methodologies to produce their creative practice and invite the reader to think. 


\section{Digital Humanities: "Data Visualisation Poetics"}

What are the digital humanities? (Berry). Here, we focus on visualization in the $\mathrm{DH}$ as research methodology for data analysis and as a medium for creative practice. What is the difference between tools and medium? How can we use open data as raw material for creative practice? The notions explored in this stage are: visualization as translation, as universal language; interdisciplinarity in collaborative practices; "visualisation poetics." Case study: Gateway to the World by María Mencía. ${ }^{4}$

\section{Digital Humanities: Personal/Historical Research}

The lecture brings up different case studies which are addressing issues of cultural heritage, migration heritages and historical memory through user generated content, online communities and ways of archiving content creatively. One of the case studies: The Poem that Crossed the Atlantic by María Mencía where personal and historical events come together in a poetic sea of interlaced stories. ${ }^{5}$

10. Media Archaeology and the Migration of Forms in E-Lit

Technology is constantly evolving. How do we preserve early e-lit works? The addressed issues here are archiving, recovering and migration of media forms which Grigar and Moulthrop study in their recent publication: Traversals: The Use of Preservation for Early Electronic Writing (2017).

As a sample, I would like to add detailed information about the third session, "Creative Process: Interweaving Methods, Content and Technology." Creative practice in the hybrid and interdisciplinary field of electronic literature engages in a rich diversity of processes and methodologies. Practitioners stretch the possibilities of emerging technologies to create new literary artistic forms. Only the few examples selected already include multimodal, interactive, generative narratives, Augmented-Reality (AR) poetry, app novellas to address key concepts and concerns characteristic of electronic literature with the reader as the center of attention.

The following selected works are those I have discussed with students in my classes because they are representative examples where content, form and interactive elements are interlaced. Thus, when I talk about content in these works, I refer to the fusion of the concept, narrative theme or poetics with the interactive elements, which I see as an integral part of the content and vital in generating meaning-production while engaging the reader in the exploration of the work. Readers are invited to unravel the story and the different layers of meaning by taking active part and interacting with the piece. This reading requires a lot of dedication and "prying," digging in, unraveling. ${ }^{6}$ These works cannot be 
read through the lenses of traditional print literature, they are not about transferring from print to new media but about what that medium offers, about how the new writing tools create new ways of expression where there is space for the integration not only of film, text, augmented reality, photography in multimodal textualities, but the text is also traversed through clicking, pitching, stretching, caressing.

\subsection{Examples of Practice}

Fitting the Pattern (2008) published in the second volume of Electronic Literature Collection (2011) ${ }^{7}$ is an early work by Christine Wilks created with Adobe Flash, which she describes as an interactive, animated memoir where she explores aspects of her relationship with her dressmaker mother. Wilks has carefully thought about reflecting this personal story of her mother in the design of her work, by using sewing and cutting techniques in her digital visual and sound design, to fuse the narrative story and the form of the work. In her words:

The design of the user-interface repurposes sewing patterns and their instructional symbols to fuse the interactive process into the narrative world. The familiar mouse pointer is restyled as a series of digital dressmaking tools so the reader becomes actively involved in cutting through memories, pinning down facts, stitching fabrications, unpicking the past. (37)

Thus, the reader is invited to stitch this nonlinear narrative together, "the memoirs," and fit them into a pattern with the different dressmaking tools such as pins, needles and scissors presented as mouse pointers in the dressmaking pattern interface-becoming in this way, the maker of the story or as she says: "the tailor who brings it all together to make the pattern fit the cloth of the narrative coherence" (37). In the Electronic Literature Collection, she writes:

Life's mysteries are rarely uncovered by a logical, linear process of deduction. You arrive at answers, ideas, suspicions, intuitions, haphazardly in fragments. Over time you build the picture, piece by piece, shuffling and rearranging, until you start to see a pattern emerging. ${ }^{8}$

She has used this formative process of arriving at an answer, building a picture in time as the structure of the work by replicating the creative process of her dressmaker mother as her own new media form with sewing patterns embed- 
ded in the text. Thus, the work integrates beautifully its short texts, design methods, form with the interactive elements to construct the narrative and to experience the work.

Connected Memories (2009) is an interactive work that I started researching and designing for a presentation at the panel in Interactive Storytelling and Memory Building in Post-conflict Society for the International Symposium of Electronic Arts (ISEA), celebrated in Belfast in 2009. Since then, it has been exhibited in the USA, Germany, Slovakia and Portugal; performed in Austria and Norway, and published in the Anthology of European Electronic Literature (2012). ${ }^{9}$ In the technical side of the project, I collaborated with José Carlos Silvestre using the open source programming language Processing. Connected Memories is a fluid interactive poetic generative narrative without a focused point, beginning or end, as opposed to systems founded upon ideas of center, margin, hierarchy and linearity. It consists of a series of interviews conducted with refugees living in London and it works as a digital platform to archive, interconnect, share and perform these stories. ${ }^{10}$

When I considered the aesthetics and poetics to integrate content and form, I designed the work so the readers would need to interact with the piece by clicking on the common keywords that link these real stories (color-activated hyperlinked words) with the aim of generating the fractured realities and the formations of connected memories. The chosen words are those that repeat themselves in the different narrations and highlight the key issues stemming from the interviews. The extracts are taken from a database and linked as in a hypertextual narrative. Based on the participants desire to keep memories alive or their preference to forget them and put them aside, the extracts in Connected Memories come and go as if forgotten, but can reappear, to be connected again to another extract. In Repurposing in Electronic Literature, I have stated the following:

It was my intention to blend two meanings together; one the literal part of the work, the narrative as a fundamental of human communication the reading of legible extracts. The other, the textual narratives in the form of generative visual poems, where simultaneously the eye and the brain are functioning to reveal the semantic meaning, as well as the visual abstraction of the text. As the participant explores and experiences the work by connecting the narratives appearing on the screen, the fortuitous position of extracts produces new relationships, and in the process, a constant current of meanings, connections and narratives; shifting from the semantic linguistic meaning to the visual, from the literal, the legible, the transparent to the abstract memory; and simultaneously creating a poetic space of readable and visual textualities, connecting memories, blending them and making them dis- 
appear in turn to make the other memories appear. (Mencía, "Connected Memories" 34)

Visual and semantic meaning meet to invite the reader to "look at the text" (the surface, the materiality of the text), and to "look through the text" (the semantic meaning of language). This notion is an underlying principle in my creative practice including this work. The role of the reader/viewer is essential to generate the text and thus, for the text to exist.

Between Page and Screen (2012), by Amaranth Borsuk and Brad Bouse, is an influential work of electronic literature, produced in Adobe Flash. It has been exhibited internationally and most recently published in the Electronic Literature Collection, Vol. 3 (2016). ${ }^{11}$ Borsuk explains that her work is at the intersection of print and digital media and she is questioning the place of books in an era where we are reading more and more on screens. According to Borsuk, Between Page and Screen: "merges the book art and e-poetry traditions, trespassing the boundary between print and digital, old and new media" (165).

These are issues clearly addressed in this work where content and form are perfectly integrated, interconnecting print and the screen through the augmented space and the interaction of the reader. In the works' official website the authors state:

The pages of this artist's book contain no text—only abstract geometric patterns and a web address leading to this site, where the book may be read using any browser and a webcam. The poems that appear, a series of letters written by two lovers struggling to map the boundaries of their relationship, do not exist on either page or screen, but in the augmented space between them opened up by the reader. ${ }^{12}$

The space between the book and the screen, as the title indicates, where the geometric patterns fuse with digital technology to create augmented reality poems that generate a dialogue between the page and the screen, is in itself facilitated by the reader's interaction, interrogating in this way the role of the reader. The text materializes visually in the augmented space to conceptualize N. Katherine Hayles' suggestion, quoted by Borsuk:

... that scholars of electronic literature have much to learn from those in print history, who have long known that "literature was never only words, never merely immaterial verbal constructions. Literary texts, like us, have bodies, an actuality necessitating that their materialities and meanings are deeply interwoven into each other. (165) 
Borsuk and Brad Bouse have considered all the issues addressed: the book, the digital, the reader, the materiality of the text in their design and interaction with the work; this is what makes this work so successful: the content and form are perfectly interlaced. As Borsuk claims: "literature can never be read separately from the form of its reception" (167).

Another compelling work is Weareangry.net (2015), ${ }^{13}$ an interactive issuebased multimodal narrative produced by Digital Fables, a multimedia production house led by Lyndee Prickitt. I came across this piece when I was acting as one of the jurors for the New Media Writing Prize (NMWP) 2015, celebrated yearly at Bournemouth University in the United Kingdom. The work was not only the runner-up of this award but was also nominated for the Webby awards, and it was one of the winners of the digital book awards. In the "about" page we find Prickitt "is an American woman who has lived in India for 'over' nine years. As a woman, a mother of a daughter and a multimedia journalist, the message of Weareangry.net is as important as the medium, digital fiction."14

The artist uses a journalistic approach where she mixes reality and fiction to create awareness about gang rape in New Delhi. The journalistic method is exemplified in the design style through video dramatizations, factual snippets, photos, vox pops, audio and hypertext notes. The story is interlaced with the style and presented online as a website for better dissemination. The reader is given two options: to read it in a remediated online book or to experience the work through its interactive multimedia textualities. As the artist writes in her introductory page to the website: "This is a free to view digital short story-a piece of multimedia fiction including photos, videos, audio and artwork, but is also bolstered by real reports, statistics and editorials. It can simply be read or you can experience a new wave in digital storytelling." 15 In her submission to the NMWP she wrote:

Weareangry.net is a born-digital short story that captures the swell of anger over India's rape crisis. At its heart is a short written narrative from the point of view of a rape victim—a viewpoint woefully undervalued in patriarchal India. The fictional narrative is intermingled with different perspectives of a society grappling over the treatment of its women. It includes video dramatizations (like the "CCTV video" of the victim's abduction), audio montages, vox pops, music, artwork, thought bubbles and hypertext footnotes (from definitions of Hindi swearwords to fact boxes about actual reported rapes referred to by the characters). As a piece of issue based fiction it is also-crucially-reinforced by real information, from curated editorials to interactive statistics. 
This project uses technology in an exemplary way to present and narrate a strong and poignant issue on rape and misogynistic societies. It makes excellent use of digital media with multimodal options for optimal user experience. It is engaging, accessible, easy to navigate, innovative in its way of presenting the subject matter, has easy interaction and, as an online born-digital short story, can reach a wide audience.

Lastly, the most current piece is PRY (2015) produced by the art collective and studio Tender Claws (TC) funded by Danny Cannizzaro and Samantha Gorman, which has been the recipient of many awards. It is an app novella that re-imagines the form of the eBook. On the app Store website where the app can be downloaded, the reader is invited to: "Pry open a troubled mind and hold its thoughts in your hands. It tells us James returned from the first Gulf War six years ago and invites us to explore James' mind as his vision fails and his past collides with his present."16

Tender Claws use born-digital approaches specific to the use of the touch screen to explore the narrative and get into the mind of the protagonist experiencing it as a first person digital novella. The work stretches and explores the possibilities this platform offers as an e-book but, in contrast to the e-book, interactivity is part of the story. In order to discover detailed information and conflicting storylines, at the deepest level, the page itself rips apart with a fragment to show a video. Obsessive thought is represented as an infinite field of text that can be scrolled in any direction. The many layers of the characters consciousness are represented through text interaction, film, words and images. It engages the reader in an experience, not only with the text but also with the process of reading, putting the reader in the mind of the author as well as the main character. Interactive elements are there to serve the story, for instance: prying James' eyes to get into his mind, "tactile caressing" or use of fingers over braille symbols to help James read, and many other touch screen gestures, as noted by TC, based on experience with interaction design, such as expand, touch, crunch, unfold, tear and reveal what readers can use to unravel the different layers of meaning. The story was produced to be read in a touchable device like this app, so that every element of design was considered as part of the story.

Tender Claws notes how different mediums are used to relate to different parts of the story and they use them seamlessly; text is used to immerse the reader into James' internal world, as well as floating text, animations and video flashbacks; while video is used to reflect what is going on in the external world and the protagonist's everyday experience. "Language seems to hold a privileged position when it comes to thought. We liked the idea of readers hearing their own internal reading voice, just as James would hear an internal voice of his thoughts." 17 They make use of many metaphors such as the interface of 
each chapter being designed to evoke the associative and slippery aspects of thought and memory. Overall, to pry (or to dig into James' story) is a process of discovery.

This influential work shows a way forward in digital writing. The integration of film, text and interactivity is outstanding, making it a great example to study for its interweaving of the story and interactivity, its explorative reading methods and its use of technology to create the overall content.

These are only a handful of examples I draw upon in my classes but in the process of interweaving ideas and form, we engage with creative methodologies, programming languages and publishing platforms which generate enough curiosity in students to start questioning the interconnection of their own ideas with technology and initiate the process of research, pre-production and production of their work.

\section{Approaches to Teaching the Module}

In my teaching, I have used two different approaches to deliver this module. From top-bottom, where I had to lecture and run seminars every week for a semester, and as a research-led Special Studies module running through two semesters with classes every other week. In the latter, the lecturer acts as a facilitator helping students with their individual research projects. In both cases, students are expected to carry out independent study consisting of either practical work with a written reflective element or an essay. In both cases, the written element varies in length, depending on whether it is covering one or two semesters.

The Special Studies model releases the lecturer from having to present a lecture every week and students become independent researchers over the period of an academic year. The classes run every other week so students have time to read the allocated reading material and come to the class prepared to lead and present the specific topics the lecturer has outlined in the first two or three sessions. These usually establish the field of study and might cover main concepts and theories, research processes and methodologies, context, relationship of theory and practice in the production of practice-based research. Students can access all the material from our virtual learning environment to structure their learning and it is up to them how much reading they want to do, how many of the topics they want to explore and whether they wish to write a research paper or produce a practical piece.

Running the module as a rich content module provides all the material and lectures in the style of top-bottom, my aim being to keep students on their toes even if I was the one doing all the talking to start with. I had to be careful not 
to let them be passive listeners and had to find ways of involving them in a kind of "community discussion and participation" within this top-bottom model where the lecturer is supposed to be the supreme source of knowledge. I was interested in unsettling them so they could find ways to understand the reasons why they were unsettled or even confused. As Richard Sennet writes: "The good teacher imparts a satisfying explanation, the great teacher... unsettles, bequeaths disquiet, invites argument" (6).

I used a kind of bombardment method of introducing ideas through the presentation of many different examples including the ones discussed in this paper. This was in itself a learning experience for me as I had to review the work of many of my peers; their research interests, processes, the different ways we all deal with the relationship between content, medium, form, aesthetics and production of work, and how these could help students with their own projects. We looked at many examples with strong social and political issues because the group attending the class was interested in issue-led work. The group of students was representative of Kingston University, a really diverse group, as most of them were going through real life struggles which I am glad to say, were all reflected in their creative projects.

My intention throughout the presentation of ideas, and introduction to creative projects, was to bring out their personal experiences so they got engaged in learning and, most importantly, exploring these experiences through their projects in a contextualized contemporary field of art, literature and new technologies. My projects tend to have this personal touch as well as exploring current social issues through the production of electronic literature works. I am involved in many international groups, so students can see there is a context for my work and, consequently, theirs. Brown et al. argue in their paper "Situated Cognition and the Culture of Learning" (1989), that understanding the culture of the community and how this community sees the world, is done through their tools and their beliefs. They state:

Unfortunately, students are too often asked to use the tools of a discipline without being able to adopt its culture. To learn to use tools as practitioners use them, a student, like an apprentice, must enter that community and its culture. Thus, in a significant way, learning is, we believe, a process of enculturation. (33)

Therefore introducing the context and the culture of the field of research was an important task. Undoubtedly, learning from professionals and their cultural research world, presents a great opportunity for students to better understand that world, and to see the relevance and impact their own work can have in the outside world. 
It was exciting to see them involved in the class discussions. The rhythm was much faster than that seen on Special Studies; students had to read every week and did not have a week in-between classes. At the same time, this was challenging because from week five they also had to start thinking about the production of their own project or written assignment. For those carrying out practice (which was most of them) meant deciding which technology they were going to use. In some cases, they had to learn new software and even collaborate with programmers they found outside university.

From their mid-year feedback questionnaire and discussions in the class, we as a group decided that I would carry on delivering lectures until week nine and, from that point, they would concentrate on their projects. After that, we could look further at some of the main features of communities of discovery interested in collective learning, discussed by Coffield and Williamson in their chapter From Exam Factories to Communities of Discovery: The Democratic Route (2012), where "[e]ducators and learners are not 'providers and consumers but partners in learning" and "[l] earning will be mainly collaborative, based on dialogue" (49). I was gratified to learn that most students commented positively on the creative freedom experienced, and the enjoyment of being able to work on their own project instead of a predetermined one.

In conclusion, these are two very different approaches to teaching and learning, and both present different challenges for students and the lecturer. My thoughts, through discussions with students in both modules, is to merge both styles and have the module running for the whole academic year. I have written this paper because I am eager to share this module with other colleagues working in higher education so we can collaborate on further similar projects. Ironically, I cannot share this essay online for a period of time, due to legal publishing constraints, but it can be shared in academic contexts and I look forward to exchanging constructive ideas.

\section{Notes}

1 Cf. E-Lit Practice and Pedagogy: Interweaving Methods, Content and Technology $<$ https://digmediatextuality.wordpress.com/conference-schedule/ $>$.

2 The Creativity and Cognition Studios (CCS) at the University of Technology Sydney is an internationally recognized multidisciplinary environment for the advancement and understanding of practice in digital media and the arts. Cf. <https://www.creativityandcognition.com/research/practicebased-research/>. 
3 Cf. FROM DADA TO JAVA: conversations about generative poetry \& Twitter bots. <https://vimeo.com/164973724>.

4 Cf. María Mencía, Gateway to the World (2017) < http://mariamencia.com/pages/gatewaytotheworld.html>.

5 Cf. Mencía María, The Poem that Crossed the Atlantic (2017). Please visit: $<$ http://winnipeg.mariamencia.com/?lang=es $>$.

6 Cf. Espen Aarseth's definition of ergodic as "a non-trivial effort" in Cybertexts: A Theory of Ergodic Literature (1997). Baltimore, MD: The Johns Hopkins University Press.

7 Cf. <http://collection.eliterature.org/2/works/wilks_fittingthepattern.ht$\mathrm{ml}>$.

8 Christine Wilks, ELC, volume 2 <http://collection.eliterature.org/2/works/wilks_fittingthepattern.html>.

9 Anthology of European Electronic Literature (2012), edited by Talan Memmott, Maria Engberg and David Prater. ELMCIP < http://anthology.elmcip.net/works.html>.

10 Cf. Mencía's website for Connected Memories <https://www.mariamencia.com/pages/connected_memories.html>.

11 Borsuk and Bouse <http://collection.eliterature.org/3/work.html?work=between-page-and-screen $>$.

12 Borsuk and Bouse, Between Page and Screen, official work website <http://www.betweenpageandscreen.com/about>.

13 Cf. Weareangry.net at <http://www.weareangry.net>.

14 Weareangry.net, "About" page < http://www.weareangry.net/mobile/pages.php?page $=23>$.

15 Lyndee Prickitt, introduction to Weareangry.net <http://www.weareangry.net>.

16 The app can be downloaded from Apple store <http://prynovella.com>.

17 Kevin Holmes' blog includes quote by Tender Claws <https://creators.vice.com/en_uk/article/go-inside-the-mind-of-a-gulf-war-vet-with-first-person-digital-novella-pry>.

\section{Works Cited}

Aarseth, Espen. Cybertexts: A Theory of Ergodic Literature. Baltimore, MD: The Johns Hopkins University Press, 1997. 
Adams, Randy, and Wilks Christine. R3/\/1x\//ORX. 2006-2014. 18 May 2017 < http://crissxross.net/remixworx/indexcxtrail.html>.

Amerika, Mark. Remixthebook. Minneapolis, MN: University of Minnesota Press, 2011.

Andrejevic, Mark. "Art in Cyberspace. The Digital Aesthetic." Web.Studies, edited by Ross Horsley and David Gauntlett. London: Arnold, 2004, pp. 127-136.

Berry, David M. Understanding Digital Humanities. London: Palgrave Macmillan, 2012.

Bodman, Conrad (co-curator). Digital Revolution Catalogue Exhibition, Barbican 2014, pp. 10-23.

Bolter, Jay David, and Richard Grusin. Remediation: Understanding New Media. Cambridge, MA: The MIT Press, 1999.

Borgdorff, Henk. "Artistic Research and Academia: an Uneasy Relationship." 96. 2008. 18 May 2017 <https://www.researchcatalogue.net/profile/show-work? work $=129283>$.

Borsuk, Amaranth. "Between Page and Screen." \#WomenTechLit, edited by María Mencía. Morgantown, WV: West Virginia University Press, 2017, pp. 165-175.

Borsuk, Amaranth, and Brad Bouse. "Between Page and Screen" [2012]. Electronic Literature Collection, vol. 3, edited by Stephanie Boluk, Leonardo Flores, Jacob Garbe and Anastasia Salter, 2016. 18 May 2017 <http://collection.eliterature.org/3/work.html?work=between-page-and-screen $>$.

—. Between Page and Screen. 2012. 18 May 2017 <http://www.betweenpageandscreen.com/about>.

Brown, John Seely et al. "Situated Cognition and the Culture of Learning." Educational Researcher, vol. 18, no. 1, Jan-Feb (1989): pp. 32-42.

Cannizzaro, Danny, and Samantha Gorman (Tender Claws). PRY. 2015. 18 May 2017 <http://samanthagorman.net/Pry>.

Hayles N. Katherine. "Electronic Literature, What is It?” Doing Digital Humanities: Practice, Training, Research, edited by Constance Crompton, Richard J. Lane and Ray Siemens. London and New York: Routledge, 2016, pp. 197-220.

Goldsmith, Kenneth. Uncreative Writing. New York: Columbia University Press, 2011.

Kolcun, Milan. "Dóm sv. Alžbety.” 2015. 18 May 2017 <http://kosice-city.sk/dom-sv-alzbety>. 
Lessig, Lawrence. Remix: Making Art and Commerce Thrive in the Hybrid Economy. London: Penguin Press, 2008.

Mencía, María. “Connected Memories.” 2011. 18 May 2017 <http:/ /www.mariamencia.com/pages/connected_memories.html>.

" "Connected Memories." Anthology of European Electronic Literature, ELMCIP, edited by Talan Memmott, María Engberg and David Prater, 2012. 18 May 2017 <http://anthology.elmcip.net/works.html>.

"UpsideDown Chandelier." Repurposing in Electronic Literature, edited by María Mencía and Zuzana Husárová. ENTER, dive buki, no. 16 (2015): pp. 78-81.

—. "Connected Memories." Repurposing in Electronic Literature, edited by María Mencía and Zuzana Husárová. ENTER, dive buki, no. 16 (2015): pp. 32-35.

Gateway to the World. 2017. 19 Apr. 2017 <http://mariamencia.com/pages/gatewaytotheworld.html>.

- The Poem that Crossed the Atlantic. 2017. 21 May $2017<$ http://winnipeg.mariamencia.com/?lang $=\mathrm{es}>$.

Montfort, Nick et al. From Dada to Java: Conversations About Generative Poetry and Twitter Bots. Vimeo, uploaded by Victor, 2016. 21 May 2017 <https://vimeo.com/164973724>.

Moulthrop, Stuart, and Dene Grigar, editors. Traversals: The Use of Preservation for Early Electronic Writing. Cambridge, MA: The MIT Press, 2017.

Prickitt, Lyndee. Weareangry.net. 2015. 18 May 2017 <http://www.weareangry.net>.

Sennett, Richard. The Craftsman. New Haven, CT: Yale University Press, 2008.

Simanowski, Roberto. “Teaching Digital Literature.” Reading Moving Letters, edited by Roberto Simanowski, et al. Bielefeld: [transcript] Verlag, 2010, pp. 231-248.

Wilks, Christine. "Fitting the Pattern" [2008]. Electronic Literature Collection, vol. 2, edited by Laura Borràs, Talan Memmott, Rita Raley and Brian Kim Stefans, 2011. 18 May 2017 <http://collection.eliterature.org/2/works/wilks_fittingthepattern.html $>$.

- "Fitting the Pattern." Repurposing in Electronic Literature, edited by María Mencía and Zuzana Husárová. ENTER, dive buki, no. 16 (2015): pp. $36-41$. 
María Mencía | Creative Process: Interweaving Methods, Content and Technology

Wilks, Christine, Jennen Naji, Zuzana Husárová and María Mencía. UpsideDown Chandelier. 2013. 18 May 2017 <https://www.mariamencia.com/pages/upsidedown.html>. 


\section{Mia Zamora}

\section{Distilling the Elements of "Networked Narratives" with Digital Alchemy}

\section{Introduction: The Backdrop to "Networked Narratives"}

In fall 2017, Michiko Kakutani of the New York Times quoted U.S. President Barack Obama as he reflected on his "Secret to Surviving the White House Years: Books": "At a time," Obama says, "when so much of our politics is trying to manage this clash of cultures brought about by globalization and technology and migration, the role of stories to unify - as opposed to divide, to engage rather than to marginalize-is more important than ever."1 Obama realizes that storytelling stands as a bridge that might span usual divides. He knows that the art of stories holds truths that remain "under the surface of what we argue about every day." However, in many ways, today's polarized online environment stands in direct contrast to this vision of empathy via stories that connect us. Digital networks have let people increasingly retreat to their own silos (talking only to like-minded people who amplify their certainties and biases).

The morning after the American presidential election of 2016, the words of American biochemist and writer Isaac Asimov captured my concern: "There is a cult of ignorance in the United States, and there always has been. The strain of anti-intellectualism has been a constant thread winding its way through our political and cultural life, nurtured by the false notion that democracy means that "my ignorance is just as good as your knowledge."'2 In the dawning of a new political reality and regime, educators have been forced to grapple with the effect of divisive digital networks and media disruption in classrooms and in everyday lives. In many ways, today's media culture is a culture where the nuanced realities and complexities of entire lives are reduced to fragmentary glimpses or soundbites. Social media seem to precipitate a kind of violence of self-assertion: a barrage of forcible framing of our identity for presentation and idealization. A notion of self-branding and the will to amplification is often understood as the primary currency of life online. But the affordances of the network can also be much more than a proverbial soapbox to shout from. How can we metamorphose from media consumers to media producers while embracing the digital mediascape in the context of learning, growth, community, and creativity? 
Whatever pedagogical pathways we might take towards such a transformation, exercising our creative imagination must play a role in getting us there. Our collective creative capacity in this cultural context of new digital tools and networks is an important consideration. Imagination is our own, personal, infinite playground (De Koven). And it is, by its very universality, a shared capacity. The developmental psychologist Lev Vygotsky has suggested that "the creative activity of the imagination depends directly on the richness and variety of a person's previous experiences because this experience provides the material from which the products of fantasy are constructed. The richer a person's experience, the richer the material his (or her) imagination has access to" (qtd. in Zamora, "The Importance of Imagination"). Our collective playground in which to imagine has become an increasingly vast and daunting place. The world is indeed at our fingertips. Networked knowledge and combinatorial creativity should be a cornerstone resource for nurturing our growing capacity to imagine together. In order for us to truly create and contribute to the world, we must be able to connect countless dots, to cross-pollinate ideas from a wealth of influences. We must be able to surf in the vast grab bag of different stories, and we must combine and recombine these pieces to build new castles. At this critical juncture in our cultural and political history, we should never underestimate the power of fiction to lead the way in our real lives. Make no mistake, stories are not just child's play. Stories give us starch up our spine, they point us to how we might do better, they give hope, they help us survive.

As a literature and writing professor with a strong commitment to the notion of digital citizenship, I have felt the urgency to face the negative effects of the digital mediascape head on, while opening up more nuanced (and empowered) conversations about what is possible when contributing and participating in digital networks. In the spring 2017, I co-designed and co-taught a course entitled "Networked Narratives"3 (better known as \#NetNarr). This article is a case study and reflective synthesis of "Networked Narratives" — an innovative pedagogical experiment in teaching digital literacies, digital writing, and electronic narrative in the age of amplification and post-truth politics.

\section{What is "Networked Narratives," also known as \#NetNarr?}

Instructional web designer and Professor Alan Levine ${ }^{4}$ and I partnered to devise an open emergent community of storytellers in spring 2017 . We embraced the notion of "digital alchemy" as we thoughtfully mixed together "elements" of media and storytelling. "Networked Narratives" is a networked "collaboratory" in digital storytelling, world-building and co-learning. The community has distributed its digital artifacts on many digital platforms on the open web. 
Diverse global participants in the open "Networked Narratives" course (\#NetNarr) inhabit personas, share and remix digital media, and explore the role of multiple identities in networked spaces. Taking a cue from the age of alchemy (often thought of as closeted pseudoscientists concocting formulas to make gold from common substances), \#NetNarr is an open online collaboration seeking narrative transformations while co-building a "mirrorworld" inspired by current \#netprov design conversations. "Networked Narratives" includes "virtual field trips," live video visits with international artists and scholars to explore the latest in digital storytelling, electronic literature, fan fiction, \#netprov, and game-based narratives. \#Netnarr participants developed creative skills via our "Daily Digital Alchemy" challenges and other media assignments, plus networked discussions via Twitter chats and the web annotation tool hypothes.is. With an eye towards the challenges of cultural translation and the constraints of narrative expectation bound to a local cultural lens, we consider the growth (and politics) of networks in an international context.

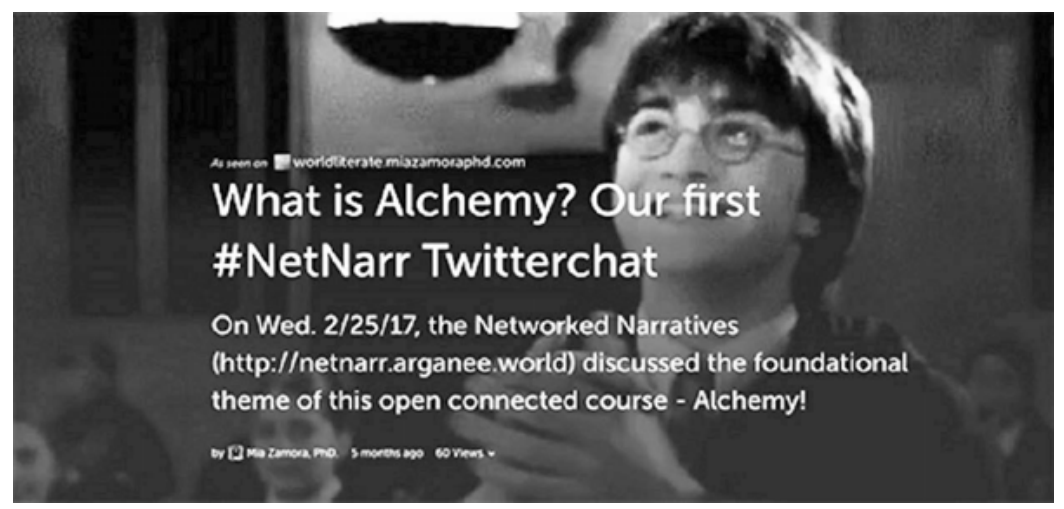

Fig. 1. Our first \#NetNarr

In a face-to-face context, this was a full class of undergraduate and graduate students at Kean University in NJ, USA who were taking this course for credit. ${ }^{5}$ But \#netnarr has also been an open online transnational network. This means that there were many participants with no formal institutional affiliation to Kean University (i.e. they were not taking the college course for academic credit). Still, these open participants were very much a part of the daily unfolding of the \#netnarr experience, and they were just as critical to the development and coherence of the \#netnarr community.

In short, \#NetNarr is many things: it is a hashtag, a course, a community, and an open experiment in "digital alchemy." It has also been an experiment in designing for narrative emergence with teaching itself as a narrative-based experience. I will share an account of our unique storytelling community as I 
consider the intersection of co-learning, networks, civic imagination, pedagogy, and digital writing/making. In addition, I will reflect on the role that "coimagineering" and ARG practices (alternative reality games) might play in addressing real world challenges.

\section{3 \#NetNarr: Designing for Emergence}

It is a surprising and often counterintuitive truth that good learning design must anticipate the unforeseen. When it comes to designing a dynamic learning environment, a professor should leave ample room in the course plan for what they cannot quite predict, with an eye towards responsive improvisation ( $\mathrm{Za}$ mora, "Networked Narrative: Designing for Emergence"). Said another way, the instructor cannot (and should not) know every outcome before they attempt to set a course for authentic learning. I have always made student agency, student choice, and student instinct a listening/actionable priority. But this step towards emergent learning as a course design principle is not an easy one. We have heard quite a bit about the limits of the "sage on the stage" approach and the dawning of new affordances in teaching with the "guide on the side" model. But it is risky for an educator to take on a true co-learning stance. It goes without saying that a changing relationship to authority and hierarchy in the classroom is no small feat. It can certainly induce anxiety for all involvedthe teacher must relinquish familiar control, the student must claim learning on terms that are not prescribed by anyone else. Unlearning traditional learning frameworks is not easy for all involved. It is a radical shift setting everyone a bit adrift on an unknown course. For there are always established ways of doing things that prescribe the kind of road you *must* or *should* embark on. Specific destinations are identified. God forbid the college class that does not have a clearly mapped out syllabus, and firmly asserted SLOs (student learning outcomes). Amidst this stricture, learning itself has often become a trafficridden highway of the well-trodden path. But what if all our learning pathways could be less discernible, and we allowed ourselves to "follow our noses" to where the magic seemed to manifest? What if learning environments were founded on the intuitive, and were more like "desire pathways" rather than traffic-ridden prescriptions (Bowles)? You could let your instinct determine your next act of creation, your next discovery, your next act of love. In education, to choose to veer "off-course" in designing a class is not for the faint of heart. It can be dangerous (Zamora, "Returning from \#Arganee").

But, this kind of paradigmatic sea change may also be a timely and much needed shift. It is the leveling effect when designing a co-learning environment that lends itself to preparing new learners to cope with the boundless and 
ubiquitous connectivity that technology has made possible. Anyone can claim a voice or develop a platform on the social web. Who do we choose to listen to? Who do we attempt to connect with, and for what reasons? And how do we develop trust and come to build our own unique learning networks? The current digital mediascape and the open social web can serve as the ultimate colearning environment. But there are many pitfalls that might prevent such a growth/learning oriented online experience. With this lens, a flexible colearning model for teaching a course on networks and digital storytelling was an intuitive fit from the onset. By incorporating open networked practices into our teaching, we set out to model connected and networked learning on the internet. But how did we build out a flexible and responsive model for open learning? When Alan Levine and I co-designed "Networked Narratives," we settled upon a notion of course "spine."

We have been shrouded in mystery. That's by design! But today we are releasing the Networked Narratives "spine" that defines the shape of the open course that starts the week of January 16, 2017. Typical courses will have a familiar syllabus or schedule, but as you will see unfolding soon, nothing about "Networked Narratives" will be typical. The idea of a spine is that it defines the structure and framework of a structure or even our own bodies, but is also flexible. ${ }^{6}$

The course "spine" was a procedural framework (a loose timeline with events and shared activities), but it also left room for responsive planning depending on how the learning unfolded. While our conversations developed (both in the classroom, and also in the open web), we negotiated a body of shared work which reflected creative and collaborative responses to our community's concerns and questions. The students who were registered for our face-to-face course were committed to be there for the entire length of "the spine," but the same activities were available to all open participants as well. The interaction between open web participants ${ }^{7}$ and face-to-face students was rich and instructive. We pushed back against the common incorporation of live video streams from a classroom or canned lectures "by professors sitting in front of bookshelves." Each month featured different interactivity and different modalities for our open discussions and networked events (i.e. live video studio visits, collaborative creative writing forums, live social annotation of webtext, and community Twitter chats). Threaded across the entire course experience were a series of media creation and story making assignments. In addition, there were regular daily doses of smaller creative challenges which we called "Daily Digital Alchemy" also known as \#dda on Twitter. Each \#netnarr week started with a blog post announcement of all \#netnarr activities and assignments for the 
week. The \#netnarr community played with new genres of narrative (i.e. generative poetry, hypertext fiction, \#netprov, etc). In this way, an online global community of artists, scholars, students, and educators emerged with the shared purpose of exploring new forms of storytelling in the digital age as they mixed and remixed multimodal media together.

\section{The Course "Spine"}

The typical spring semester runs from late January to early May, so we designed a flexible schedule which we considered a "course spine" for this length of time. In January, participants entered the world of Digital Alchemy. We asked all of our participants to think about the ancient practice of alchemy applied in the present with digital tools. Students began to personalize their own "digital toolboxes" with syndicated blog accounts (a.k.a. "Digital alchemy notebooks") and social media feeds as they explored many new digital applications. The tool setup for the course was presented as a "labyrinthus" that each participant must pass through in order to be acclimated to the open online environment.

Here you stand at a starting point for "Networked Narratives." Are you ready? While not a labyrinth per se, it has not strict walls nor a Minotaur, think of this as a guided path for setting up the first online tools you will use as part of this experience. Here you stand at a starting point for "Networked Narratives." First, let us say at this doorway (not a gate), that we force no one to use an online tool to which they might have an objection or a concern. We will provide alternative paths for each. There are always, always multiple options in "Networked Narratives." Are you ready to enter Labyrinthus? This may take 30 minutes to an hour to a lifetime. Most likely not the latter. ${ }^{8}$

By moving through a choose-your-own-adventure hypertext game with several rounds of choices, students and open participants were guided through the basics for building their own digital platforms (i.e. their own digital alchemy laboratories). They set up social media accounts, public annotation accounts, and syndicated blog accounts. In addition, we also devised a special process to address course assessment. Our in-class (credit-bearing) Kean University students were invited to co-design their own grade contract. Students were able to input some ideas regarding the terms of their own evaluation by considering what kind of effort, intensity of input, and learning outcomes might reflect each letter grade. This process certainly added some accountability to their own understanding of how they were to be evaluated. 


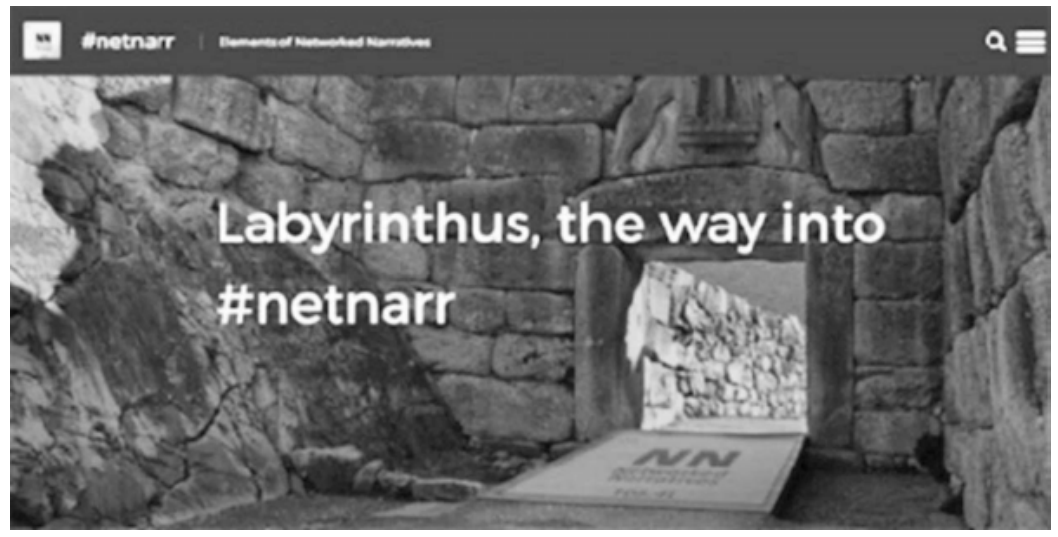

Fig. 2. Labyrinthus.

\section{$5 \quad$ Studio Visits}

\#NetNarr produced a series of "Studio Visits" which were co-streamed at the educational consortium "Educator Innovator" in order to reach a broad community of those interested in electronic literature, digital storytelling, digital writing, and transformative, collaborative learning. ${ }^{9}$ During these virtual studio visits we spoke with artists, researchers and practitioners, meeting them in their own unique work spaces in order to open up conversations about new media writing in the $21^{\text {st }}$ century (McIntyre, Visiting Digital Storytellers).

Our first stop was with Leonardo Flores, Professor of English and researcher of digital literature at University of Puerto Rico at Mayagüez. Flores is also the esteemed founder of I Love E-Poetry, a daily blog and resource dedicated to short-form scholarship on born-digital poetry and poetics. \#NetNarr students and a few open participants spoke with Flores about the development of Electronic Literature. As Flores put it, “[i]t's an experimental practice at this point, it hasn't become naturalized. But as it does, it starts to change mindsets, it starts to change how we even conceptualize the work." Our conversation covered questions including: What is electronic literature? Where can we discover it? What narrative genres have emerged based on the affordances of new media tools? What role might transmedia storytelling play in our school environments? We introduced the Electronic Literature Collection, while we also did some on-screen e-lit "walkthroughs" in order to share the power of this kind of art with a generalist audience. We discussed E-Poetry, interactive fiction, generative poetry and Twitter bots. The studio visit stop with Flores was then archived in YouTube and our course site, and the public conversation was extended through the open web annotation tool called hypothes.is. 


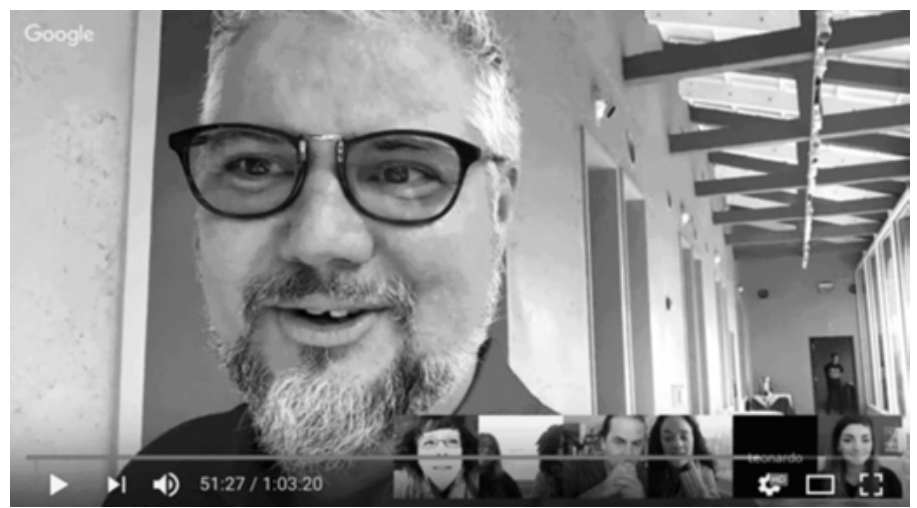

Fig. 3. Leonardo Flores studio visit. ${ }^{10}$

In our second studio visit, we checked in with educators and \#Netprov artists Mark Marino and Rob Wittig to discuss some of their guiding principles and past experiments, and explore the political and pedagogical implications of this new form of participatory art. \#Netprov—or "networked improvisation narrative"-is an online art form occupying the densely populated cultural space of social media. Netprov is networked improvised storytelling. Collaborative stories are playfully improvised in real time. How does networked media create new opportunities for improv, collaborative satire, and emergent storytelling? Blurring the boundaries of reality and fiction, we explored the question of what might be the inherent goals for this kind of storytelling work. By discussing the consequences of netprov as "hoax," we grappled with the implications of trust and security in online communities. Students in the conversation also explored the nature of performativity both in real time practice, and reflection afterward. We also considered how this social form of collaborative storytelling might be used pedagogically. As Marino and Wittig shared:

Netprov is, there's an impulse that lots and lots of people are having which is to make funny fake Twitter accounts, to fictionalize in small ways, and what we're doing in a lot of ways is to try to bring the whole bag of tricks, or as many tricks as we know, from the grand beautiful literary tradition, and bring those tricks into these new media. ${ }^{11}$

This studio visit included Wittig's students, \#NetNarr students, and open participants as well. 


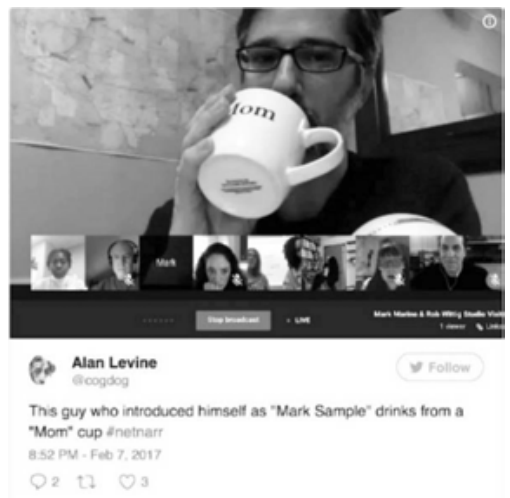

Fig. 4. Mark Marino studio visit. ${ }^{2}$

In our following studio visit we connected with Flourish Klink and Elizabeth Minkel to further explore the effect of networks on collaborative digital writing. Klink and Minkel are hosts of the "Fansplaining podcast" — a serialized conversation devoted to thinking further about participatory culture, networks, fan fiction. What is fanfiction, and what is it not? Why does fanfiction matter? And what makes it so important to the future of literature? How does fan fiction work? What does it mean to world build? How do practitioners of fan fiction engage their civic imagination? Together we explored how fan fiction (and it's communities of practice) have redefined the role of narrative in our society. Along the way, we considered new ways to think about "authorship." Klink and Minkel helped the growing \#NetNarr community explore the central role that community and reciprocity play in fanfiction, and their possible place as a bellwether for $21^{\text {st }}$ century transmedia culture.

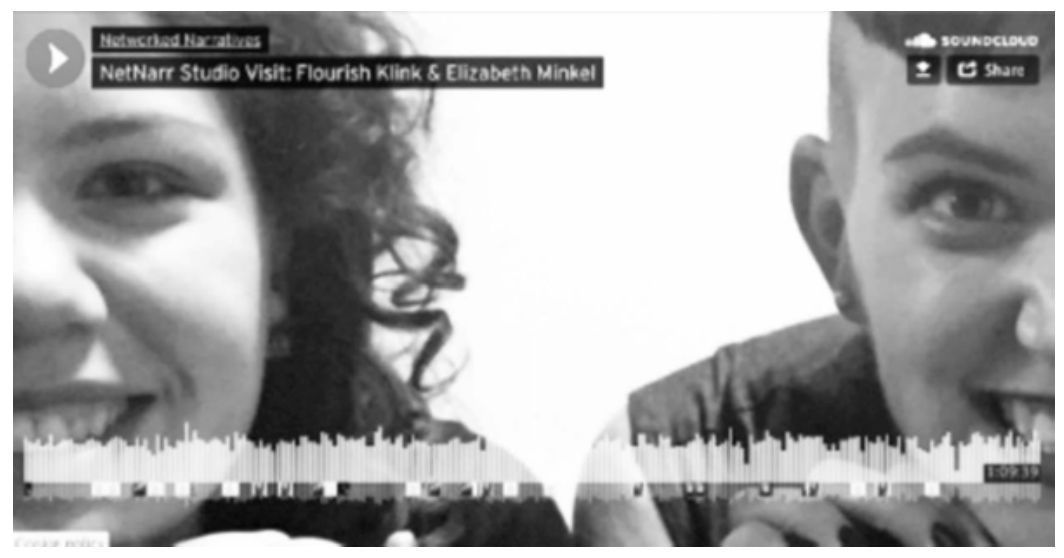

Fig. 5. Flourish Klink and Elizabeth Minkel. ${ }^{13}$ 
In our final \#NetNarr studio visit, we had the opportunity to visit the acclaimed critic and writer Howard Rheingold, as well as his designer and systems-thinker daughter Mamie Rheingold, to discuss digital citizenship and critical pedagogy, examining how new digital tools and contexts shape how educators and students think about civic participation. As Howard said, "[w] hether 20 people or 20.000 people listen to you, the important thing is agency and participation. You are not just one of the millions of people who are fed what a few people create for you. You are in some way a creator of culture. That does not always move the giant ship of state, sometimes it does." We discussed the network effect, mindfulness in the digital age, and the role that intuition plays in creative work and the importance of paying it heed in the digital age.

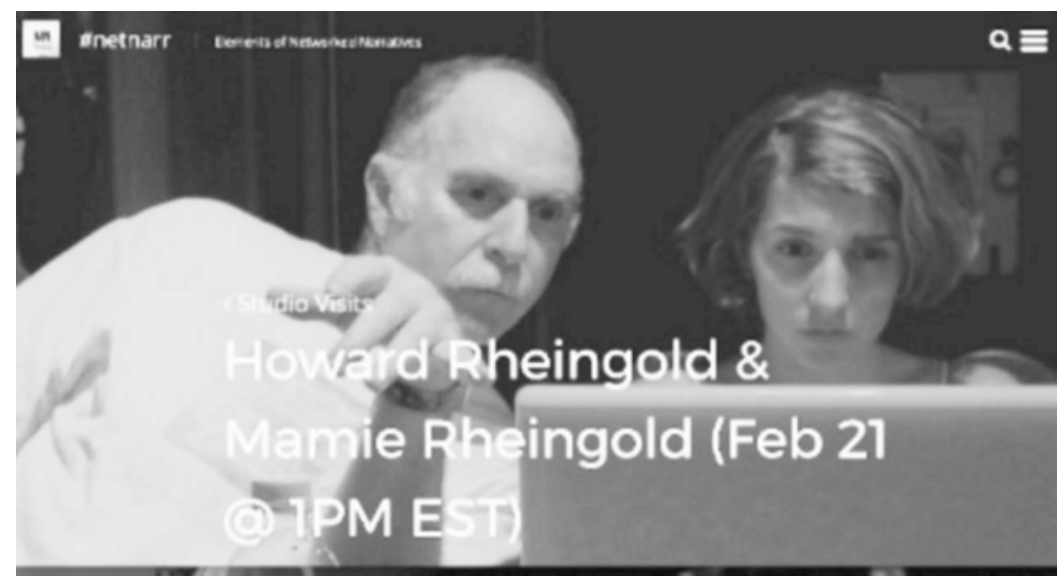

Fig. 6. Howard Rheingold and Mamie Rheingold. ${ }^{14}$

\section{Virtual Bus Tours: Expanding the Network}

Another important \#NetNarr event-series included our virtual "bus stops" that occurred throughout the month of March 2017. The \#NetNarr bus stops were about networked possibilities: exploring local worlds from a distance, while reaching across divides in order to understand different kinds of learners and make new connections.

We strived to sow the seeds for more meaningful connections across vast divides. We virtually visited different locales while engaging different cultural contexts. With these engagements, we sharpened our lens on what invisible expectations we might hold about different parts of the world. In the process, we strived to tell new stories and discover new perspectives. For each virtual bus stop, we designed a networked online activity in which "host" communi- 
ties from across the globe (Mexico, Vermont, Australia, Cairo) created unique digital artifacts to share with our \#NetNarr network. In turn, the \#NetNarr community responded and connected with questions, remixes, and further inquiry.

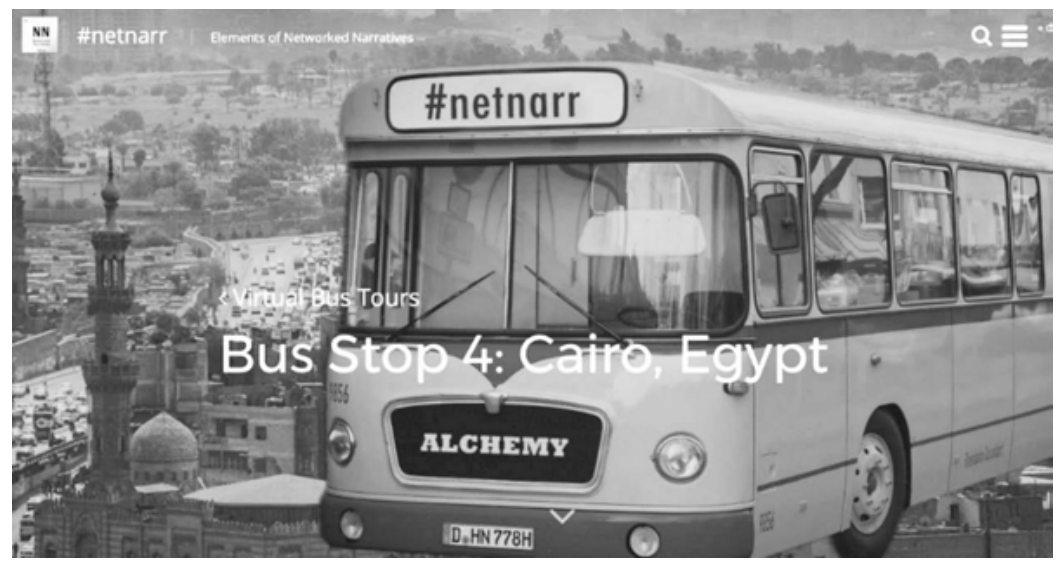

Fig. 7. Virtual Bus Tours. ${ }^{15}$

\section{7 \#Arganee (and Back Again)}

I know that teaching is in part performance. However, it is never an act of sincere generosity unless it is also real improvisation. A teacher who is also learning must always be on their toes, must always be open for what isn't planned. In \#NetNarr, our final act of collaboration was to co-create an alchemical world called \#Arganee — a mirror world to \#NetNarr. \#Arganee was our open gamespace for role-play, our own foray into an alchemical \#netprov. \#Arganee was our world-building space for our own alternative alchemical digital identities. There was something aspirational about being challenged to "breathe life" into one's own digital alchemist character. Alan and I also had alternative identities in \#Arganee also known as "Rebeg Maestro" and "M Prophetissima." These two sentient beings from another world were indeed a part of ourselves, special corners of our own imagination, but a more depthful understanding of their significance did not really arise until we let them live a little in/on the open web (Zamora, "Networked Narratives: Designing for Emergence"). 


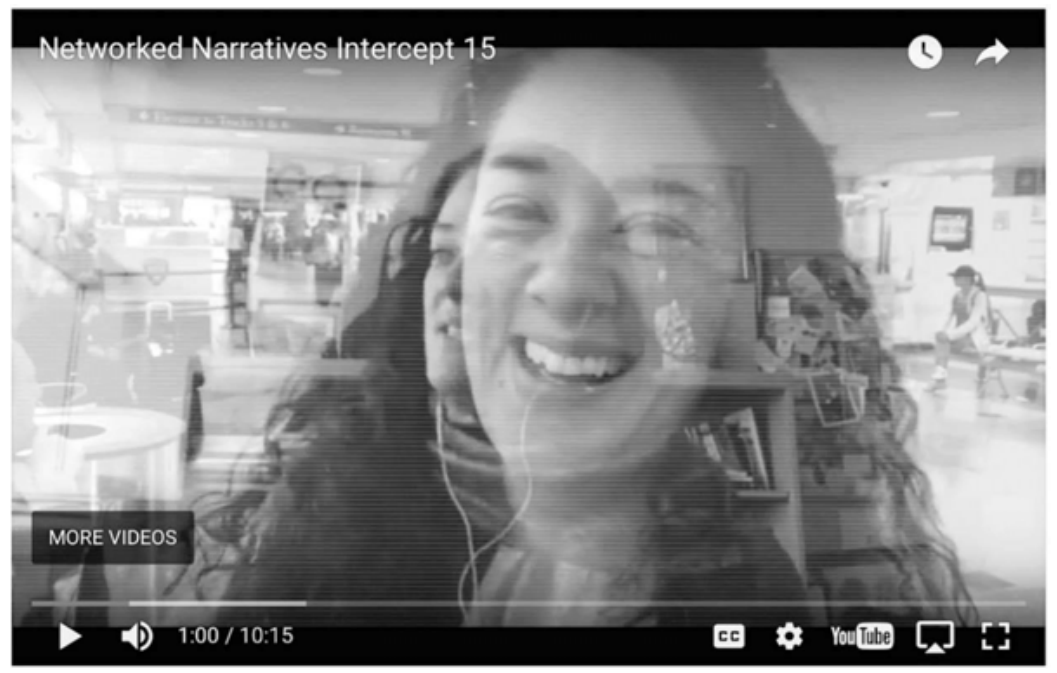

Fig. 8. NetNarrArganee.

Initially, we were wary of them, not trusting their hacking-meddling ways. They seemed to disrupt the \#NetNarr community, trolling our conversations and hacking and remixing our planning video chats. But eventually we realized their mission was more than simple disruption. Rebeg and M opened up a portal to learning that felt more vital and free. In other words, role-play and collective world-building transformed what we were learning about digital storytelling together. The magic of our collective imagination really started to pave new pathways to discovery, invention, and consideration of what it means to be a digital citizen. The mirror world of \#Arganee was born with this new crop of digital alchemists at the center of our growing community. Social media served as a platform for our exploration of novel perspectives, linguistic innovation, and new style and stance. A playful kind of schizophrenia-scape seemed to emerge. Our \#NetNarr participants were getting to know their own (self-created) \#Arganee alchemists. And Twitter really worked as an open space for creative imaginings in conversation. It certainly became the key locale for the convergence of different digital identities — both real and imagined. ${ }^{16}$

Since \#NetNarr's first iteration came to a close in spring 2017, I have been grateful for the trust, and for the unique contributions of each and every human (and \#arganee alchemist friend) who played with us along the way. As I marvel at the twisting road of our special journey, I realize just how chuck full the conversations have been. The "Networked Narratives" YouTube channel is certainly worth revisiting, if just to catch a glimpse of the places we have been. Imagine if we could actually aspire to build our very lives with a bit of magic, mirroring the alchemical \#NetNarr serendipity we experienced togeth- 
er? It would certainly require leaving room for the unknown. We would have to learn to trust our own instincts more. We would have to register "connection" as a prioritized value. Playfulness would also be a top priority. And it would necessarily require plenty of room for listening and tangents. As to the future, we now have a crew of "alchemist elders" (alumni per se) to call into action in our future offerings of \#NetNarr which will take the form of transnational collaboration in spring $2018 .{ }^{17}$

\section{Notes}

1 Cf. <https://www.nytimes.com/2017/01/16/books/obamas-secret-to-surviving-the-white-house-years-books.html>.

2 Cf. <http://aphelis.net/cult-ignorance-isaac-asimov-1980/>.

3 Cf. <http://netnarr.arganee.world>.

4 Further information on Alan Levine: <http://cog.dog/>.

5 Enrolled students took this course as an elective that contributed to their credit requirements for the BA in English or the MA in Writing Studies at Kean University.

6 Cf. <http://netnarr.arganee.world/the-spine/>.

7 \#Netnarr open participants are those who are not affiliated with Kean University or taking the course for academic credit, yet they are active participants in the learning community via the open web.

8 Cf. <http://netnarr.arganee.world/labyrinthus/>.

9 Educator Innovator supports educators in re-imagining learning on the ground through the Educator Innovator Fund, a micro-investment fund supporting practitioners working with youth and communities to move their practice toward Connected Learning and community engagement. Partners include: National Writing Project, MacArthur Foundation, Scholastic Art and Writing Awards, New York Times "The Learning Network," Smithsonian Center for Learning and Digital Access, Creative Commons or Mozilla Webmaker.

10 \#NetNarr studio visit with Leonardo Flores about electronic literature: $<$ http://netnarr.arganee.world/studio-visits/leonardo-flores/ $>$.

11 Cf. <http://educatorinnovator.org/visiting-digital-storytellers-with-the-alchemists-at-networked-narratives $/>$.

12 \#NetNarr studio visit with Mark Marino and Rob Wittig about \#netprov: $<$ http:// netnarr.arganee.world/studio-visits/mark-marino-rob-wittig/>. 
13 \#NetNarr studio visit with Flourish Klink and Elizabeth Minkel about fan fiction: <http://netnarr.arganee.world/studio-visits/flourish-klink-elizabeth-minkel/>.

14 NetNarr studio visit with Howard Rheingold and Mamie Rheingold about digital citizenship: < http:// netnarr.arganee.world/studio-visits/howard-rheingold-mamie-rheingold $/>$.

15 Cf. <http://netnarr.arganee.world/bus/plans/>.

16 Cf. <https://www.youtube.com/watch?v=Pr8F3Z-EDUc>.

17 Alan Levine and I will direct another iteration of \#NetNarr in spring 2018, co-located institutionally at Kean University in NJ and in University of Bergen, Norway (where I will be a visiting Fulbright scholar for AY 2017-2018). We will also have an expanded group of open web participants.

\section{Works Cited}

Asimov, Isaac. "A Cult of Ignorance." Aphelis. 1980. 13 Aug 2017 <http://aphelis.net/cult-ignorance-isaac-asimov-1980/>.

Bowles, Kate. "Chorus of Voices.” Music for Deck Chairs. 2 Aug. 2016. 13 Aug 2017 <http://musicfordeckchairs.com/blog/2016/08/02/chorus-of-voices $/>$.

De Koven, Bernard Louis. "The Infinite Playground.” Deepfun. 2016. 13 Aug 2017 < http://www.deepfun.com/the-infinite-playground/>.

Kakutani, Michiko. "Obama's Secret to Surviving the White House Years: Books.” New York Times. 2017. 19 Jan 2017 <https://www.nytimes.com/2017/01/16/books/obamas-secret-to-surviving-the-white-house-years-books.html>.

McIntyre, Tim. "Visiting Digital Storytellers with the Alchemy at Networked Narratives." Educator Innovator Blog. 5 June 2017. 15 Jan 2017 <https:/ / educatorinnovator.org/visiting-digital-storytellers-with-the-alchemists-at-networked-narratives $/>$.

Popova, Maria. "Networked Knowledge and Combinatorial Creativity." Brainpickings. 2011. 15 Jan 2017 <https://www.brainpickings.org/2011/08/01/ networked-knowledge-combinatorial-creativity/ $>$.

Zamora, Mia C. "The Importance of Imagination, Part 1.” DML Central: Digital Media and Learning: The Power of Participation. 17 Nov. 2016. 15 Jan 2017 $<$ https://dmlcentral.net/importance-imagination-part-1/>. 
Mia Zamora | Distilling the Elements of "Networked Narratives" with Digital Alchemy

- "Returning from \#Arganee." WorldLiterate. 8 May. 2017. 15 Jan 2017 $<$ http://worldliterate.miazamoraphd.com/uncategorized/returning-from$\operatorname{arganee} />$.

"Networked Narratives: Designing for Emergence." DML Central: Digital Media and Learning: The Power of Participation. 19 July (2017). 13 Aug 2017 < https://dmlcentral.net/networked-narratives-designing-for-emergence $/>$. 



\section{Part Five:}

Trans-Multi-Inter-Meta (The Medium) 



\title{
Anna Nacher
}

\section{The Creative Process as a "Dance of Agency"}

\author{
Shelley Jackson's Snow: Performing Literary Text with Elements
}

\begin{abstract}
Why did I want to write a story in snow? Because it's white like a page. ... Because I have a fascination with the relationship between words and space (a page is a space, but that often escapes our notice), with the idea of publishing a story on or over a landscape (here, on Brooklyn), so that all the complicated activity that goes on in that territory gets unpredictably mixed up with the story. Because I like the tension between the meaning of the word and its physical presence, which shows up all the better when it's both isolated, when you come across it in an unexpected place and don't know what it's trying to tell you. Because snow melts, and I have a fascination with the ephemeral. . . . Because it's already a writing medium: kids write their names in snow, so why not a story? Because it's fun to be outside in the bright sun and the cold wind making something beautiful.

Shelley Jackson, "Shelley Jackson Writes on Snow for a New Type of Story."
\end{abstract}

\section{Introduction}

Shelley Jackson's Snow (2014-) does not easily conform to established literary categories or interpretative strategies-words written in the snow are evanescent and fragile, vanishing as soon as the surface on which they are inscribed melts away. Yet, where the medium is fragile, the text becomes somewhat more solidified, with each semantic inscription recorded in photo streams that are available through the popular social media platforms Flicker and Instagram. In this way, according to Søren Pold and Christian Ulrik Andersen, Jackson's project is "not just a work in snow, but also a work that displays the frictions between the site-specific text and the distributed photos and text on social media" (Pold and Andersen 33). ${ }^{1}$ In 2014, the artist started writing a short story on snowy surfaces around her home in Brooklyn, documenting the project with her Flickr and Instagram profiles. This is, however, her second attempt at designing the story. In an interview for The Guardian, Jackson disclosed the fact 
that in 2010 she tried to perform the text on the snow for the first time but the endeavor proved to be more difficult and challenging than she had previously thought (Flood). As of March 2017, when this article was nearing completion, the story was almost halfway there (it allegedly has 802 words, and the Instagram stream currently has 386 posts). ${ }^{2}$ There are some minor differences between the two versions on Instagram and Flicker - the former is entitled Snow: $A$ story in progress, weather permitting, the latter just Snow: A story, weather permitting. The respective streams are also currently suspended at different points (they end up with different words).

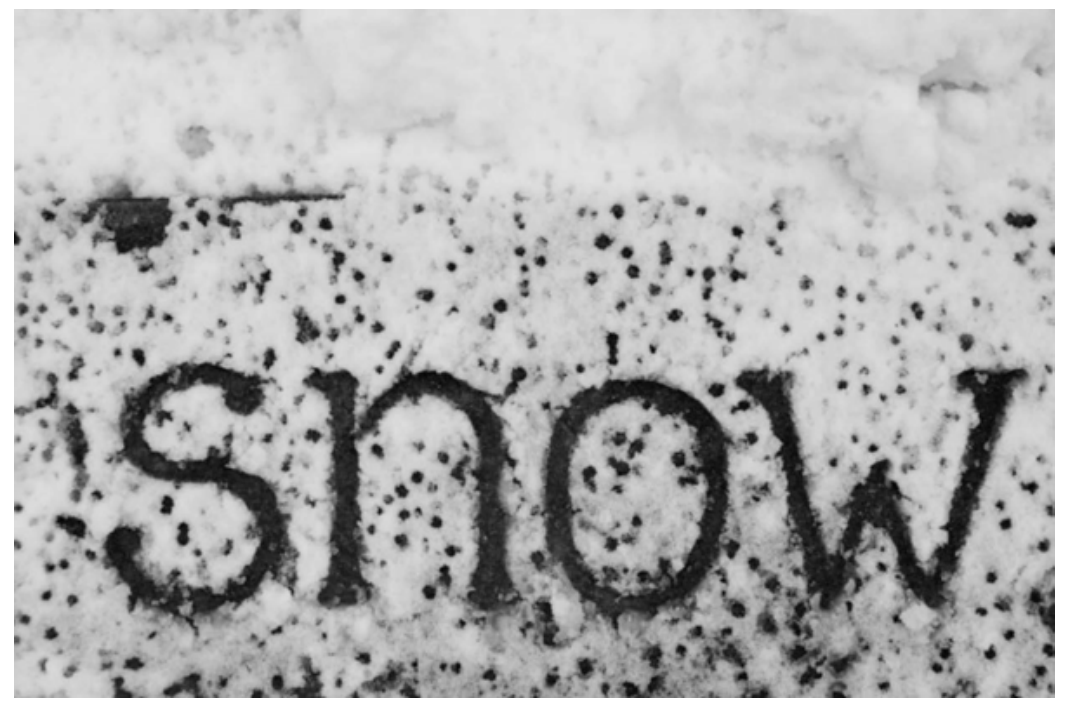

Fig. 1. Snow.

In my article, I would like to focus on the specific materiality of Snow. On the one hand, the work obviously references its unusual inscription surface, inspiring us to think in terms of the natural elements that have been repurposed for literary use. On the other hand, we are also confronted with a more sophisticated question: in the case of an artwork that develops by implementing the strategy of a network, how does the relationship between evaporating substance, photographic documentation and networked media play out in an aesthetic sense? According to Ryszard W. Kluszczyński, who has characterized the various strategies utilized by interactive art, such a strategy constitutes a significant part of contemporary media art and seems to be one of its most important features. Kluszczyński underlines the communitarian and social aspects of the proposed category (which seems to be lacking in the case of Snow) 
and basically understands it as a work of art placed in the public space. I nevertheless take advantage of his proposition, shifting the focus only slightly.

In my opinion, Snow embodies the strategy of a network when viewed through the lens of media hybridity. In this respect, it possesses features that Kluszczyński has outlined as important for such a strategy: "it binds various means of action, including of course, digital communication technologies" (Kluszczyński 22). I would argue, then, that the intermedial quality of Jackson's project should be accounted for, because the work's full meaning is located in the space between installments: the actual words written on snow that comprise the story, the Instagram stream, and the database of photographs on Flicker (also available to download as .zip files). In taking advantage of the tension between the evanescence of actual open-air performances, and the manner in which such performances are documented in various media, these practices follow the tradition of land art. The obvious points of reference in this context are Hamish Fulton, Richard Long, Nancy Holt or Robert Smithson and-in an especially significant way-Andy Goldsworthy.

\section{The Artistic Strategy of a Network}

Traditional interpretations of land art focus on connections between the artwork and the site of its location/performance, pointing to the indexicality of such work, its site-specificity, and its tendency to undermine discourses that present the art gallery as a "white cube." However, some contemporary examples of land art have been almost entirely appropriated as a kind of mainstream public art that is imbued with environmental sensibilities, the kind of work that is often supported by the various agencies dedicated to regional development, as illustrated by the French Portail du Land Art initiative. An example is Christo's latest large-scale installation The Floating Piers, which was carried out on Italy's Lake Iseo in 2016. The media reported that the artwork became the main tourist attraction (Morlin-Yron; "Italy: Christo 'walk on water' project opens on Lake Iseo"), and, indeed, the crowds it drew even caused some disturbances in local public transport (The Local).

The Floating Piers epitomizes the significant tendency to design and build monumental structures out in the wild. Gesturing towards the aesthetic practices of American artists who were known for making the landscape a theme of their art, Robert Smithson famously coined the idea of "earthworks" to distinguish such works from more traditional sculpture - an exhibition with the same title was organized in October 1968 at the Dwan Gallery in New York City (Lailach and Grosenick 8; Shapiro 4). Francesco Careri does however propose another way of categorizing works of land art. His proposal differen- 
tiates between projects that leave visible and solid traces on the sites where they were carried out, and (mostly walk-based) projects that are evanescent and ephemeral, evaporating as soon as the project is complete, with the only stable "site" of the artwork being its photo documentation (Careri 149). While the monumental works of Robert Smithson, James Turrell, and Christo and Jeanne-Claude are typical examples of the former, the works of Andy Goldsworthy, Hamish Fulton and Richard Long belong to the latter category.

Operating in this way, Richard Long performed a whole series of his Lines, works that left traces on the surface of the earth but that were, nevertheless, reversible, fading with passing time. He started with A Line Made by Walking in 1967, followed by A Line in Peru (1972), A Line in Ireland (1974), A Line in the Himalayas (1975), A Line in Australia (1977) and many other Lines around the globe. In the case of his most famous work, A Line Made by Walking, Long walked back and forth across the grass to produce a straight line. Because great technical care was taken to ensure that the line was really visible, the impression left was significantly magnified in the photographs taken, but it eventually vanished when the grass grew long enough to cover the traces.

Seen from such a perspective, land art seems to exploit strategies that are associated with a certain kind of conceptual art — art that aims to dematerialize the object that constitutes the work of art and to shift the focus towards accompanying documentation, be this video, text or photography. However, if we investigate the role of documentation in the aesthetic practices of land art, we discover that the manner in which most artists employ such documentation works a little differently. The aim, in fact, is not so much to get away from the object, but rather to dismantle the stable ontological grounds of the artwork as object. Such work is not, apparently, aimed at the dematerialization of the artwork but at materializing it in a different way: across a whole range of elements (some of them placed in the physical space, others embodied as the objects of media technologies), and between them. Accordingly, photography plays a different role than, for example, in the case of performance art, where photographs function as the record of a singular, ephemeral act.

What is probably the best-known work of land art, Smithson's Spiral Jetty (1970), illustrates such a strategy in a particularly remarkable way. Placed in complete wilderness at Utah's Great Salt Lake, the monumental rock spiral is rather difficult to access, requiring either a very detailed map or precise knowledge about the location. However, Gary Shapiro insightfully notices that the trouble with locating the Spiral Jetty is not confined to its geographical position. In fact, at least three elements of Smithson's project bear the same title: the rock spiral mound itself, a film made when the structure was built and a photo-essay published in Artforum in October 1972. Hence, Shapiro states: "I want to suggest as do multiple referents of the title Spiral Jetty, that there is no 
primary, authentic object (the spiral) to which the film and the essay are merely ancillary" (Shapiro 7).

The remark is valid for virtually every land art project; for the most part, the work's legacy lies in the series of photographs that are circulated, in art books, and in specially designed exhibitions or video clips, which are often combined with additional statements from the artist. Such an approach (which is precisely what I call the artistic strategy of the network), was present from the very beginning of the land art movement. According to Gilles Tiberghien, land art's founding gesture can be traced back to Tony Smith's journey along the New Jersey Turnpike, which he later described in an essay in a 1967 issue of Artforum. Instigated by Michael Fried in reaction to Smith's project, suffice to say that the article inspired one of the most famous debates of the $20^{\text {th }}$ century on the subject of modernist aesthetics. In this case, the whole artwork consisted of the ephemeral (but embodied and lived) experience of driving along a highway that was still to be completed, and the consecutive documentation of the journey, as published in Artforum.

Robert Smithson's projects such as Monuments of Passaic and Incidents of Mirror-Travel in Yucatan (1969) possess a very similar structure. The former revolves around an actual trip to the small New Jersey town of Passaic, and the work consists of photo documentation made with an Instamatic camera, a map, and an essay entitled "A Tour of the Monuments of Passaic," New Jersey, which was published in Artforum in 1967. The latter artwork follows the same logic by again creating a multimodal and multimedia network of various aesthetic objects - the artist performed a series of installations in Yucatan, placing mirrors in the wilderness, and the work was later presented as a series of photographs and yet another photo-essay by the artist himself, "Incidents of Mirror-Travel in Yucatan” (1969). Both works-if analyzed as multipart, networked phenomena-uncover slightly different interpretations of Smithson's works. Seen from this angle, he is an artist primarily interested in the transversality of the embodied visual experience.

With all that said, some obvious questions remain outstanding: Where is the actual location of meaning? Is it the "earthwork" itself, the structure or performance carried out on the ground at a specific physical site that lies beyond the walls of the art gallery? Or maybe it is the documentation that delivers the meaning? According to Miwon Kwon and Peter Kaiser, who prepared the significant land art retrospective at the Museum of Contemporary Art in Los Angeles in 2012, it is reductive to view the material that accompanies such works as mere documentation of the actual artwork:

Rather than being supplemental or secondary, then, the production, distribution and circulation of images and information about a work 


\begin{abstract}
"out there" is defining of that work's existence. This is not to say that mediation fully eclipses "the work" but rather that the identity or meaning of "the work" cannot be fully realized without it. This is a structural condition, a fundamental attribute of Land Art from the outset in the 60s. (Kaiser and Kwon 27)
\end{abstract}

Kaiser and Kwon second Shapiro's observation, quoted above, about Spiral Jetty: the production and circulation of imagery accompanying land art projects should be perceived as a meaningful component of the work, something that is always related to the other elements of the project. The strategy of the network does not, therefore, exclusively designate the artwork's intermedial quality; crucially, the distribution and circulation of elements, something that is often considered "additional" or "external," in fact constitutes the very structure of the work. In this respect, Shelley Jackson's Snow-considered as the actual performance on the snowy surface combined with two photographic collections that have different functionalities (Flicker and Instagram) - is significantly similar to the works just discussed. However, what seems particularly interesting in this case is the manner in which the aesthetic strategy of the network relates to the very materiality of Jackson's project.
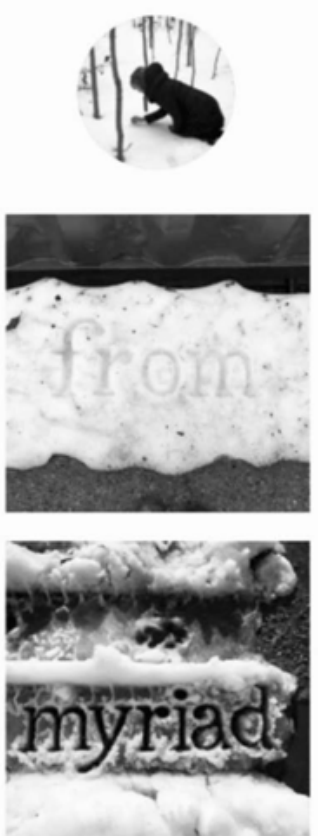

\section{snowshelleyjackson}

386 posts $\quad 2,652$ followers $\quad 0$ following

SNOW A story in progress, weather permitting. (Read in reverse order.)
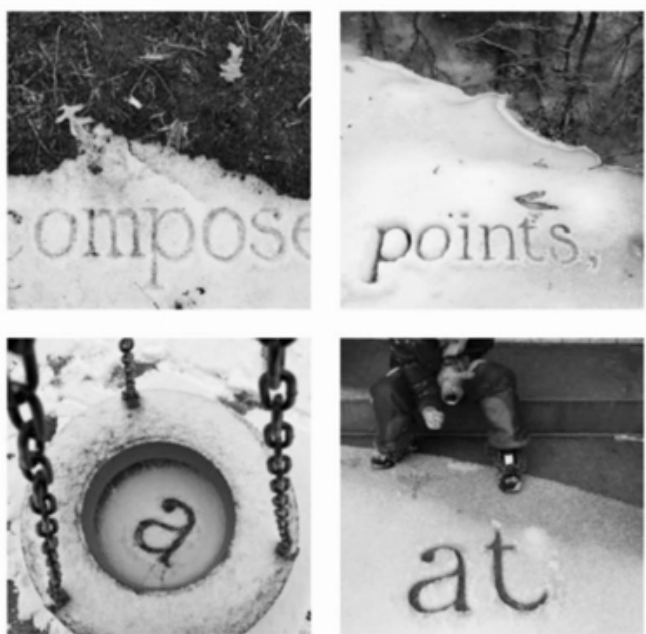

Fig.2.SNOW (@snowshelleyjackson). 


\section{Between Early Materiality and Ephemerality}

Looking closer at the possible affinities between Shelly Jackson's Snow and land art, Andy Goldsworthy's oeuvre seems especially appropriate as a point of reference, as both artists make a convincing attempt at striking a balance between ephemerality and specificity, between evanescence and earthiness. Jackson became inspired by Goldsworthy while working on her SKIN project (Walters), and the reasons for the affinity are apparent. Goldsworthy is known for creating artworks out of natural elements: the leaves and stalks of various plants, different types of mud, stones and rocks, ice and... snow. Often these elements are purposely left to decay, as passing time slowly but steadily changes their structure and appearance. Some of Goldsworthy's sculptures are sizeable structures, inspired by the traditional mounds or stonewalls of Scotland. These can be located at particular sites or stretch for many miles, intertwined, when necessary, with a highway (e.g. Contour 950 in Ohio, USA).

Goldsworthy's art circulates mostly in the form of photo albums and documentary movies, of which Rivers and Tides: Andy Goldsworthy Working with Time (2001)—directed by Thomas Riedelsheimer, with music composed by Fred Frith-is probably the best known. The documentary established Goldsworthy's reputation as an artist interested in uncovering the fragile temporalities that revolve around natural occurrences and non-human time scales. Owing to the passage of time and the course of natural processes (be it growing grass or the sea tide covering part of a sculpture), the "objecthood" of such work is often questioned. The cinematic medium, with its capacity to enable time-lapse sequences, does therefore seem particularly well suited to rendering the specific processuality of some of Goldsworthy's ephemeral, site-specific sculptures.

In fact, a significant tension between transience and permanence is hidden at the core of Goldsworthy's art. In the closing sequence of Rivers and Tides, we see the ultimate evanescent work of art: an artist is throwing powder snow in the sunny air, forming shaky, shimmering clouds whose transient quality becomes almost tangible. From almost the beginning of his career, snow as material has been present in Goldsworthy's practice-one of his early works, executed in Leeds, Yorkshire, is First Snowball (1977). Following on from this, different works making use of this element span his entire career. Looking only at the early period, these include Snow Jump (1977), Snowball made from last remaining patch of snow left in the shadow of a tall hedge (1979), Snowball in trees (1980), Snow compacted in to series of joining arches (1984), and Snow circles (1987). Capturing the process with film and photography remains necessary because, to some extent, this imbues the performance with a sense of "objecthood," becoming much more than mere representation or documentation. The information provided by Goldsworthy's digital archive supports this observation: 
It is well known that every ephemeral work that Goldsworthy has made is invariably photographed, always immediately following the making, and often in revisiting the work. He has described the process of photography as one that is "routine" and "demanding." Certainly, in terms of the setting up, timing, viewing, and awareness that it requires of Goldsworthy, the photographing process constitutes a performative corollary to the making of the sculpture. (Andy Goldsworthy Digital Catalogue)

By the way, the last photo uploaded to Jackson's Snow Flickr database, is reminiscent of Goldsworthy's snowballs as works of art, although it is not present on the Instagram stream.

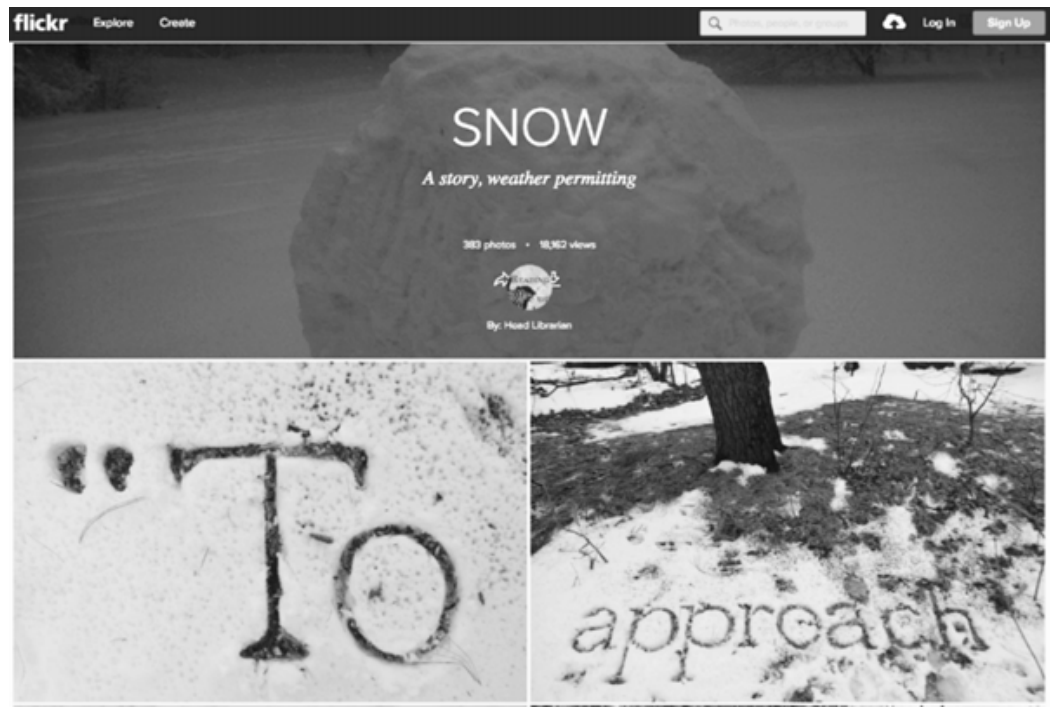

Fig. 3. Snow. A story, weather permitting.

It seems that such practices are a way to engender a whole variety of modes for the materialization of the actual artwork. This ranges from the most fragile and fugitive act (throwing the snow in the air) to the most tangible (holding the actual photograph), with the consecutive steps of the photographic process and the archiving of analogue negatives falling in between. This argument finds support in the description of the photographic process that is presented on the website of the Goldsworthy archive:

The resulting photographs have an indexical relationship to the sculpture(s) that they record, an aspect that is enhanced by Goldsworthy's preference for maximum depth of field in picture quality. Goldswor- 
thy also "brackets" his exposures, shooting a number of different exposures sequentially. This is necessitated by constant, and often imperceptible, fluctuations in atmospheric and lighting conditions, and the influence these have on the photographic rendering of the work. (Andy Goldsworthy Digital Catalogue)

The last sentence references the fact that the very materiality of the photographic works is a crucial element of Goldsworthy's outdoor practice. This explains why archiving the photographs is such an important part of Goldsworthy's artistic practice; indeed, Riedelsheimer's documentary devotes a separate section to the slide archive. Known as the "Slide Cabinet Index," and located at the artist's studio in Dumfriesshire, Scotland, the archive mostly consists of Kodakchrome slides and transparencies, organized according to a special system set up by Goldsworthy himself. In 2002, the part of the catalogue that covers the first ten years of Goldsworthy's career was digitized by the University of Glasgow and made available to researchers as the Andy Goldsworthy Digital Catalogue DVD (Volume 1: 1976-1986). Materialization and materialities are also key themes in Goldsworthy's practice more generally, and, in fact, his art is not so much about the passing of time as it is about the multifarious relations that exist between time and materiality. To put it another way, it is about the role that temporality plays in various processes affecting the material.

Such an exploration of different modes of materiality and the tension between the tangible and the ephemeral is also important for Shelley Jackson. This is the case with the previously discussed Snow (2014-) and also with her Ineradicable Stain: Skin Project (2003-), the latter being a story that is tattooed on the skin of volunteers, one word at a time, the full text of which is known only to participants. The tension is visible when both projects are compared to one another, but also within each respective project. This is especially the case with Snow, where-as mentioned above - the transient substance of the writing surface (snow) collides with the dynamics of the networked database, both existing in different states of tangibility.

The tangibility of digital photography is itself ambivalent, ${ }^{3}$ a fact that is exacerbated by both the logic of cloud computing and the popular streaming services where the content is hosted (this has been extensively analyzed by Søren Pold and Christian Ulrik Andersen). It is also necessary to remember that while Jackson's work could be perceived as a kind of installation, she assigns the major role to literary content. My observation follows the line of Roberto Simanowski's argument when he differentiates between digital literature and digital art (although in this context the notion of "digital" might not be obvious). While admitting that the borders between the two concepts can 
sometimes remain blurry, he nevertheless underlines a fundamental difference, something that is based on how the material used (i.e. text) functions in both genres: "If the text continues to be important as a linguistic phenomenon, then we may speak of digital literature. If the text becomes primarily a visual object of interaction, then we are dealing with digital art" (Simanowski 937). So, even if Jackson's works share with land art the intermedial strategy of the network, Snow is still meant as a story, where the semantic component is crucial. Nevertheless, judging from what is already available (considering the word count, this amounts to roughly half the story) the work is tightly interwoven with the more general question of the materiality of substances. As is clear from the opening sentences, the lines unveiled so far enumerate various sorts and kinds of snow, something which, at times, plays the role of an extended metaphor:

\begin{abstract}
"To approach snow too closely is to forget what it is," said the girl who cried snowflakes. Through a microscope one discovers that there are many kinds of snow: those made up of tiny paintings of shipwrecks in the style of Bonaventura Peeters, those made up of miniature bowls of wax fruit, very beautifully and realistically formed, except for the size; those made up of the fingernail clippings of babies; and those made up of the trimmed and tattooed scalps of shrews, used as money by certain native peoples of the Southern Urals. Jackson)
\end{abstract}

However, the snow functions here as much more than a surface-its materiality is also important structurally; in the age of climate change, snow is not only a robust semantic trope. That is why I would now like to ponder the second part of Jackson's title, "Weather permitting." To what extent can the weather and other natural elements be treated as the kind of literary agents that are capable of delivering meaning?

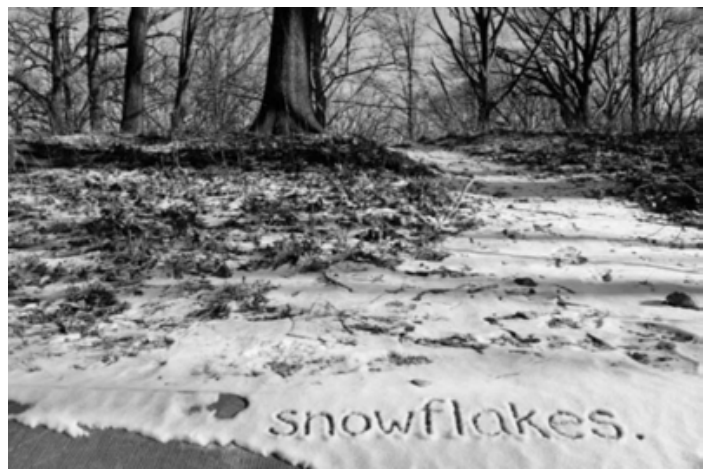

Fig. 4. Snowflakes. 


\section{Weather Permitting, or "Dance of Agency"}

To answer such questions, I will borrow from the domain of science and technology studies the metaphor of the "dance of agency," a concept that is notable in Andrew Pickering's The Mangle of Practice (Pickering 21-24). At first glance, such a choice might come as a surprise. Yet, upon closer inspection, quite significant similarities can be found between the aesthetic strategies of land art, Shelley Jackson's project, and scientific methods and procedures, understood here as the cultural practice of meaning production. The role of photography offers one obvious parallel, particularly in the way that it accounts for the intermedial strategy of the network. In scientific practice-as understood by adherents of action-network theory and science in its performative aspectthe material traces of research and any documentation (be it diaries, notes, lab reports or more formal texts) exert a significant role; these cannot be seen as mere "documentation," but rather they are "translations," important elements in forging the actor-network (Latour 121-141). In the case of both land art and Jackson's Snow, photography is also related to the temporality of the projects at hand. Such works develop according to a logic of experimentation, and such a logic lies at the heart of the scientific method, moving it closer to artistic culture than has traditionally been thought to be the case. ${ }^{4}$ The spirit of experimentation is clearly visible in Jackson's description of her creative process and the motivations behind it:

I hadn't worked out my technique, the snow was too deep that day, and you could barely even make out the words ... so I tried drizzling maple syrup in the shape of letters (my dog liked that) and then soy sauce, but they spattered and looped and sank into the snow, making spindly, uneven, handwritten-looking letters. (Then there was pee, which has a nice long tradition, but I didn't think my technique was up to the job). (Flood)

Jackson wanted her words to have a "printed" feel, so she eventually modelled the font after the Courier typeface. This proved to be difficult, and it slowed the process down: "I had hoped that I would be able to get the whole story done that winter, but it turned out to take much longer than I imaginedhours with freezing toes and fingers to finish half a sentence!" (Flood).

The subtitle "weather permitting" can, therefore, be read quite literally, and with this in mind, we must grant that non-human agents (i.e. the medium of snow and wider meteorological patterns) have a notable ability to shape the meanings of a literary text. Furthermore, interestingly enough, Snow consists of at least a few layers where media materiality really matters. In this case, the 
meaning of the category of "media" is understood in its double sense: it is both the medium of artistic expression and the media technology of popular photo sharing platforms. The two meanings are mutually interwoven, something that is underlined by Jackson's emphasis on the fact that she devised a special approach and technique for her undertaking. That's how the "material metaphor" comes into existence. It is a means of enabling "the traffic between words and physical artefacts" (Hayles 23), although the question of inscription technology is rather ambivalent in this particular case. After the snow has melted and all we are left with are images "stored" on platforms that are susceptible to all the illusions, deterritorializations and abstractions of "cloud computing" (Pold and Andersen 12-18), to what extent can Jackson's traces on the snow be thought of as "marks"? Or, on the contrary, is the seemingly illusory architecture of cloud computing the logical way to forge the actornetwork of a story that is constantly shifting between ephemerality and tangibility?

The idea of the "dance of agency" is, then, particularly useful when it comes to questions concerning the respective roles and agencies of various human and non-human actors and their contribution to the final outcome. The concept is not, however, employed to altogether do away with the notion of the author. Rather, the "dance of agency" helps to modify our concept of the author, just as N. Katherine Hayles's notion of "technotext” once did by implementing a category that was inclusive of technological agents. Pickering's idea-especially when combined with Jane Bennett's notions of "vibrant matter" and "vibrant materiality" — seems to be an interesting and fruitful point of departure if we hope to grasp the networked agency of any "material metaphor." This would encompass literary projects that involve organic and synthetic life and that make use of synthetic biology and genetics, such as Christian Bok's “living poetry” or Eduardo Kac’s “biopoetry” (Górska-Olesińska 173). Key to Pickering's proposition is the claim that, while material and human agents are closely intertwined and "intimately connected with one another" (Pickering 17), the material and the human cannot simply be mutually substituted. Pickering underlines the fact that acknowledging the contribution of material actors to the final outcome does not mean eradicating human intentionality. Instead, this helps to modify the ways in which we understand the category of intentionality. Pickering shows-when differentiating between the temporal emergence of the material agent and the goal-oriented, disciplined human actor-that, in scientific practice, human intentionality is in fact prone to temporal and unstable emergencies in the process of experimentation: "Goals are temporally emergent from culture (including machines and their material performativities) and can themselves be transformed in, and as inte- 
gral part of, real-time practice, which includes sensitive encounters with material agency" (Pickering 20).

Shelley Jackson's experiments with snow as writing-space can be framed as precisely this kind of "real-time practice," a "sensitive encounter with material agency" which has, to a great extent, influenced the way in which the project is carried out and how the meaning is produced and conveyed. Drawing upon a notion coined by the early philosopher and sociologist of science, Ludwig Fleck ("Practice and posthumanism" 163), Pickering has referred to the whole process - which involves consecutive, sensitive encounters with material agency, which recursively affects the scientific practice_-as "tuning." Accordingly, such "tuning" of human and non-human actors (including also scientific technical apparatus) is modelled as a "dance of agency," where human agents interchangeably take up active and passive roles. These roles include making passive, but careful, observations at moments when material agency has been enabled by the performance of a machine that has been constructed for the purposes of experimentation. Hence, an extended definition of the "dance of agency" is provided:

The dance of agency, seen asymmetrically from the human end, thus takes the form of a dialectic of resistance and accommodation, where resistance denotes the failure to achieve an intended capture of agency in practice, and accommodation of active human strategy of response to resistance, which can include revisions to goals and intentions as well as to the material form of the machine in question and to the human frame of gestures and social relations that surround it. (22)

Such a dialectic of accommodation and resistance is precisely what Pickering calls the Mangle of Practice (1995). Although the term has come to describe a process in scientific inquiry, it could also connote a significant part of artistic practice. In other words, the notion of the "dance of agency" here implies at least two important things. Firstly, there is the mutually supportive, reciprocal and recursive relation between emergence (associated sometimes with chaos, ephemerality and the instability of operations) and order (perceived as disciplined, organized and goal-oriented) or between contingency (ascribed to the culture of the arts and humanities) and a pattern (located usually on the side of scientific culture). Secondly, as "the material and social agency are mangled in practice" (Pickering 23), the meaning of the material shifts towards an active force rather than a passive object. According to Pickering, he seeks an idiom that will destabilize the binary opposition between human and non-human agents, offering instead "a posthumanist space" (Pickering 23). 
Indeed, such a posthumanist space is opened up by the material metaphors of such works as Shelley Jackson's Snow. And this has to include the fragile, inconsistent and risk-based world of climate change, where human agency alone is inadequate when it comes to capturing the scale of phenomena in the natural world, let alone properly addressing the problem. It is not a coincidence that, when explaining his metaphor, Pickering starts with a simple meteorological observation, noticing that material agency "comes at us from outside the human realm and that cannot be reduced to anything within that realm" (Pickering 6). Moreover, according to Jane Bennett (who follows Latour), it seems that the universal notion of agency requires further reconceptualization if it is to address "multiple modes and degrees of effectivity" (Bennett viii). Bennett calls for a more distributive concept of agency, one that would account for "vibrant matter" or "vitality in matter-energy." To her this means "the capacity of things ... not only to impede or block the will and designs of humans but also to act as quasi agents or forces with trajectories, propensities, or tendencies of their own" (Bennett x). Such a notion of distributed agency offers an extremely interesting starting point from which we can start to think again about authorial instances of creative practice in the posthumanist world (including writing with elements). Weather permitting, of course.

*I would like to thank Shelley Jackson for the permission to include the photographs in the publication.

\section{Notes}

1 Unpublished manuscript kindly provided by the authors before publication.

2 The last photograph to date was uploaded to Instagram on March $28^{\text {th }}$, 2017.

3 I have already analyzed such ambiguities elsewhere (cf. Nacher).

4 The subject was often discussed from the perspective of the chiasm between the so called "two cultures" - the sciences and the humanities-as outlined by C.P. Snow in his famous 1959 lecture. Snow proposed methods for closing the gap within the framework of a "third culture." The discussion currently continues with the fields of the arts, sciences and technology, where links between the three domains are being forged extensively and fruitfully, generating new ideas about possible collaborations between artists and scientists (the most obvious examples come from digital art, bioart and other artistic endeavors requiring sophisticated scientific 
apparatus). In fact, upon closer historical inspection, the "two cultures" might never have been that distant. According to Martha Blassnigg, "When looking into the intersections between Art and Science of individual case studies, however, many of the frequently discussed boundaries appear to dissolve in the acknowledgment of the productive tensions within contradictions, paradoxes and inconsistencies of day-to-day practices" (Blassnigg 69).

\section{Works Cited}

Bennett, Jane. Vibrant Matter: A Political Ecology of Things. Durham and London: Duke University Press, 2010.

Blassnigg, Martha. "Intuition and Imagination at the Convergence of Art and Science: Clues from the Past," edited by Ryszard W. Kluszczyński, $W$ strone trzeciej kultury. Koegsystencja satuki, nauki i technologii / Towards the Third Culture. The Co-Existence of Art, Science and Technology. Gdańsk: Laznia Centre for Contemporary Art, 2011.

Careri, Francesco. Walkscapes: El andrar comopractica estetica, Walking as an aesthetic practice. Barcelona: Editorial Gustavo Gil, 2002.

"Chaos at Italian Lake as Crowds Try to Walk on Water." The Local, 22 June (2016). 23 Jan. $2017<$ https://www.thelocal.it/20160622/chaos-at-italianlake-as-thousands-try-to-walk-on-water>.

Fiske, Tina et al. Andy Goldswortby Digital Catalogue DVD, Volume One: 19761986. 2001-2006, 17 Mar. 2017 <http://www.goldsworthy.cc.gla.ac.uk>.

Flood, Alison. "Shelley Jackson Writes on Snow for a New Type of Story." Guardian, 17 Jan. (2014). 15 Jan. 2017 <https://www.theguardian.com/books/2014/jan/17/shelley-jackson-writes-snow-story-tattoos >.

Goldsworthy, Andy, et. al. Portail du Land Art. 2008-2017, 14 Mar. $2017<$ htt$\mathrm{p}: / /$ www.landarts.fr $>$.

Górska-Olesińska, Monika. "Rozmowa z Eduardo Kacem.” Przeglad Kulturoznawcry, vol. 9, no. 1 (2011). 24 Apr. $2017<$ http://www.ejournals.eu/pliki/art/5552>.

Hayles, Katherine N. Writing Machines. Cambridge, MA: The MIT Press, 2002.

"Italy: Christo 'walk on water' project opens on Lake Iseo." BBC News, 18 June (2016). 23 Jan. $2017<$ http://www.bbc.com/news/world-europe-365678$71>$. 
Jackson, Shelley [HeadLibrarian]. Snow. A story, weather permitting, 26 Apr. 2017 <https://www.flickr.com/photos/25935290@N04/sets/7215763953949 $7175 />$.

Snow. A story in progress, weather permitting, 26 Apr. $2017<$ https://www.instagram.com/snowshelleyjackson>.

Kaiser, Peter, and Miwon Kwon. "Ends of the Earth and Back." Ends of the Earth_LLand Art to 1974, exhibition catalogue. New York and Munich: Prestel Publishing, 2012.

Kluszczyński, Ryszard W. "Strategies of Interactive Art." Journal of Aesthetics and Culture, vol. 2, no. 1 (2010). 18 Jan. 2017 <http://www.tandfonline.co$\mathrm{m} /$ doi/abs/10.3402/jac.v2i0.5525>.

Lailach, Michael, and Uta Grosenick, editors. Land Art. Hong Kong, Paris and Tokyo: Taschen, 2007.

Latour, Bruno. Reassembling the Social: Introduction to Actor-Network-Theory. New York and Oxford: Oxford University Press, 2005.

Morlin-Yron, Sophie. "Floating art lets people walk on water at Italy's Lake Iseo.” CNN, 27 June 2016. 23 Jan. 2017 <http://edition.cnn.com/2016/0$6 / 27 /$ travel/floating-piers-lake-iseo-italy>.

Nacher, Anna. "Online Photography-Media States of Matter." Pasja Fotografii. O mitośnikach $i$ mitosniczkach (The Passion of Photography: On Amateurs and Amateures), 8th Biennal of Photography, exhibition catalogue, Galeria Miejska Arsenał, Poznań, edited by Marianna Michałowska and Maciej Szymanowicz. 2013. 23 Mar. 2017 <https://www.academia.edu/5675522/Online_Photography_media_states_of_matter $>$.

Pickering, Andrew. The Mangle of Practice: Time, Agency, and Science. Chicago and London: University of Chicago Press, 1995.

"Practice and posthumanism. Social theory and history of agency." The Practice Turn in Contemporary Theory, edited by Theodore R. Schatzki, Karin Knorr Cetina and Eike von Savigny. New York and London: Routledge, 2001, pp. 163-174.

Pold, Søren, and Christian Ulrik Andersen. "MetaInterface: The Art of Platforms, Cities and Clouds." Chapter 4, unpublished manuscript.

Riedelsheimer, Thomas, dir. Rivers and Tides: Andy Goldswortby Working with Time. Roxie Releasing, 2001.

Shapiro, Gary. Earthwards: Robert Smithson and Art after Babel. Berkeley, CA: University of California Press, 1995. 
Smithson, Robert. "Spiral Jetty." Robert Smithson: The Collected Writings, edited by Jack Flam. Berkeley: University of California Press, 1996.

Simanowski, Roberto. Digital Art and Meaning: Reading Kinetic Poetry, Text Machines, Mapping Art, and Interactive Installations. Minneapolis, MN: University of Minnesota Press, 2011.

Tiberghien, Gilles A. Land Art. London: Art Data, 1995.

Walters, Joanna. "Why this new brand of fiction is a life sentence." Guardian, 16 Nov. 2003. 24 Apr. 2017 <https://www.theguardian.com/world/200$3 /$ nov/16/arts.usa $>$. 



\title{
María Teresa Vilariño Picos
}

\section{Narrative Across Media: Trans-Stories In-Betweeness}

\author{
Dedicated to Isabel Núñez, with heartfelt thanks.
}

\section{1 "Alone Together." The "Connected Multitude" Weaves the Net Paradigm}

In 1996, Sherry Turkle gave her first Ted Talk to express how moving it was to be connected in chatrooms and to belong to certain virtual communities. According to Turkle, what was important about those moments was not just the act of connecting, but also, and above all, that of disconnecting in order to lead our own lives and live our own identities. Years later, in 2012, in a new presentation called "Connected but Alone," Turkle claimed that technology is dragging us places we really do not want to go. Mobile devices have such psychological power that "they don't only change what we do, they change what we are." We are becoming accustomed to coexisting "alone together," to hiding from each other, even though we remain connected as a group. ${ }^{1}$

Along these lines, the philosopher Byung-Chul Han uses the term digital swarm to refer to the mass of isolated individuals that possesses neither soul nor spirit. These "individuals are melting into a new unit; its members no longer have a profile of their own" (Han 10) and "lack the interiority of assembly that would bring forth a we" (11). Han also employs the Japanese term bikikomori to refer to these people who live at the margins of society, seated in front of their computer screens. In the face of this isolation, Sherry Turkle, in her latest book, Reclaiming Conversation: The Power of Talk in a Digital Age (2015), strongly advocates face-to-face dialogue to regain the power of physical interaction, impaired by the advent of electronic media.

Digital networks and the current state of the entertainment media have favored the rise of personalized production and creation, à la carte, via streaming, as the tool of various distinct narrative forms. These recent cultural models adopt intermedial or transmedial methods, situating themselves in virtual spaces which have replaced physical ones and which require a great deal of interactivity. These are spaces of presence, given that their temporality is that of an "immediate present" (Han 15) in which representation becomes co-presentation (16).

I would now like to discuss those narratives that are ingrained between memory and the ephemeral, between conservation, reinvention, multiplication 
and manipulation or volatility; narratives that reflect on individual and collective identity, using polyphony as a tool. ${ }^{2}$ In short, they are literary and artistic narratives that, in their way, can be considered as multidisciplinary, multimedial and multicultural, that defend, for example, compromise and social activism but, nonetheless, derive from the commercialization and banalization of culture.

These narrative forms designed by cyberspace can be opaque to scholars who are not responsive to, or who are uncomfortable with, the change that has taken place in the field of Humanities. For one, they are narratives constructed for a select group of scholars and researchers and they also encourage a massive audience to use license-free or open source tools. They are, ultimately, narratives that play with the ability to give the impression that the reader or spectator is really interacting with them, and which, at the same time, please us because they allows us to believe that "no one is listening" (Turkle, "Connected"). The fact that we are able to edit the material that we share on the net also gives us the ability to delete and retouch texts, in a sort of narrative consumed in "little sips."

Communication technology, applied to art, film, or literature, creates environments that clearly affect the subjects that utilize it; the media, in the words of Carlos Scolari (29) create a type of ecosystem that surrounds individuals and molds their perception and cognition, establishing a discipline that we might call Media Ecology. This field of study would take as a guiding thread that no medium operates alone, but rather, affects all the rest (Nystrom 130), in an infinite, collaborative and enriching synergy. Scolari's words hearken back, of course, to Marshall McLuhan, when he spoke of the interaction of some media with others (43). Rajewsky describes the process of intermediality as follows:

"Intermedial" therefore designates those configurations which thereby can be differentiated from intramedial phenomena as well as from transmedial phenomena (i.e. the appearance of a certain motif, aesthetic, or discourse across a variety of different media). (Rajewsky 46)

Within the framework of the connected multitude, we could also mention the work of the Spanish visual artist Julián Pérez, which revolves around the uses of the internet and digital identity. Pérez researches the behaviors, processes and relationships we create as users of different web services, such as social networks, streaming channels or webchats, in which we question concepts such as anonymity, intimacy, self-monitoring or public vs. private. ${ }^{3}$ The digital medium not only offers windows for passive viewing, but also gateways to other windows, in which we show that we wish to produce and communicate in a totally active manner (Cf. Han 16). 
We might also ask ourselves how artisanal culture dialogues with digital practices today: ${ }^{4}$ an issue that has long interested the Raffaelo Sanzio Societies, ${ }^{5}$ where, in their works, Claudia Castellucci, Romeo Castelluccci and Chiara Guidi combine a theatrical craft with the most advanced technology or visual, audio or olfactory devices. The SRS Archive is noteworthy because it

holds rare documentary resources of major importance. The most unique and therefore most valuable material is that which concerns the primary creative process such as: dramaturgy (containing plays, scripts and notes), theory (early manifesti, theoretical texts), director's notebooks and notes, designs, drawings and visual materials. ${ }^{6}$

Between craft and digital technology, we find the piece Go Down, Moses (2016), which involves a radical transformation of the story of Moses, through art and its visceral language. Go Down, Moses "reinvents the world, presenting a blast of images that transport the audience from the most contemporary hyperrealism to an imaginary ancient world."' Through tableaux and fragments, Romeo Castellucci transforms various moments in Moses' life into a spectacle of fierce sounds and images.

Something similar has been occurring with the Catalan group La Fura dels Baus, ${ }^{8}$ from its creation in 1979 to the company's most current projects. One of them, M.U.R.S. (2014), ${ }^{9}$ employs mobile devices and GPS to reflect on the cities of the future: "The government, the economy, mobility. . . In the cities of the future, the so-called smart cities, it seems that all is controlled digitally." M.U.R.S. plays with five simultaneous spaces within Montjuïc Castle (Barcelona), through which the audience circulates, using mobile phones. To hear M.U.R.S.' narrative and to be part of the show, participants must have previously downloaded an application designed for this performance-installation. In the performance of the piece, there are machines, video installations, projections and augmented reality.

That is also the case in Mexican artist Carlos Amorales' production. His Dark Mirror (2004-2005), ${ }^{10}$ a collaboration with graphic designer André Pahl and pianist José María Serralde, uses a series of drawings as a background, from which he designs video animations, combining beasts and humans in a kind of apocalyptic nightmare. And he accomplishes all this while developing a "liquid archive" formed of digital drawings that he inserts into his personal memories.

The ecology of media comes to life in a public space and symbolizes the agora of exchange through networks (García Canclini). The internet reinforces the critical function of the community, the "connected multitude" (recall 
Pierre Lévy's collective intelligence, or Derrick de Kerckhove's connected intelligences), collaborating and participating in various digital assembly lines. ${ }^{11}$

\section{You Can See It and Experience It. Narrative Across Screens}

The net has had a big impact on the development of artistic creation, becoming a reservoir of images, in a constant flow of all kinds of visual, audio and multimedia material. We could speak of "a lyric of reveries," 12 in the words of Juan Martín Prada, whose defining characteristic is the existence of an artistuser who develops new work practices that become "appropriation" and "mélange." And to do so, they modify fragments and residuals of various characters and origins that recombine in the most successful, though not always aesthetically pleasing, works. Creation now involves the harnessing of heterogeneity within a whole that is far from being a finished work.

In the culture of remixing, it is no longer a priority to create original narrations which pose significant challenges, for example, to the legal issue of copyright. The people in front of the screen are not just spectators or readers, but also protagonists, collaborators of the art we consume, catching a glimpse of the lives, and private lives, of others. From there derives inevitably an interactivity, as we have already mentioned, between the user and the machine, which becomes synonymous with individual or collective participation.

Narrative is no stranger to the change that literature and culture have experienced in the digital age; it is disseminated in very different genres, from narrative using various devices (iPad, iPhone, computer, mobile devices) to narrative through social networks (Twitter, most of all) or YouTube, and a narrative that coexists with performativity and theatre. Antonio Gil González (53) ${ }^{13}$ is one of the many critics who have classified the various models of narrative that can develop through media. Let us take a moment to consider his classification:

1. The postnovel, still focused on the book and falling within the field of literature, which incorporates other languages.

2. Interactive narrative in an exclusively digital version, on the internet or in the form of a multimedia eBook or app.

3. Augmented reality narrative, in which print matter is projected on the screen through augmented reality codes, patterns and applications, which are getting further and further from traditional literature.

4. Transmedia narrative.

5. Ludonarrative. 
Above, we spoke of a performativity that extends to so-called online performances, a term that comes from certain projects developed during the first phase of net.art. Within the field, Rob Wittig'14 is a noteworthy performer of improvisational theatre on the internet called Netprov (networked improvised narrative). With his motto "play and go deep," Wittig works in what he defines as participatory fiction in networked media, "an emerging art form that creates written stories that are networked, collaborative and improvised in real time" (Wittig 2011).

Remix, which is not a new invention of social networks, involves a process of absorption, assimilation or digestion as a form of creation. The digital aesthetic, as Martín Prada claims, practices the intensification of artistic processes, based on the "plunder" and revision of preexisting material, with selection dominating over production. The plundered work is not distorted or displaced, but rather becomes participatory, changes its ground rules, or alternates certain procedural relationships.

Let us consider a practical case. Remix, recombination and recontextualization can be observed in Toxi $\bullet$ City: A Climate Change Narrative (2015), by Scott Rettberg (writer and producer) and Roderick Coover (director and producer). It is a hybrid narrative with six characters who inhabit a near future landscape, in the year 2020:

Toxi ${ }^{-C i t y}$ is a combinatory narrative film that uses computer code to draw fragments from a database in changing configurations every time it is shown. As some stories seem to resolve, others unravel. Just as with the conditions of ocean tides and tidal shores, the stories cycle and change without clear beginning or end. Rather, individuals grasp for meaning from fleeting conditions of a world in flux. As the characters paths intersect, story threads come together. These offer moments of resolution, contact and visions of the future, before the narratives are broken apart and a fresh cycle begins. ${ }^{15}$

The cast of characters is made up of a Fisherman, a Young Woman, a Fema Relief Worker, a Middle-Aged Woman, a Pig Farmer, and a Teenage Boy who live together in a piece that can play out over 130 minutes. Toxi $\cdot$ City is also a combinatory film that utilizes a database as a starting point, so that the story, the structure and the form change every time is shown to the active and awestruck spectator. In the narrative, the fictional lives of these six characters are interspersed with the true stories of a group of people who died during Hurricane Sandy, in a narrative whole that, as we have already mentioned, does not always have the same beginning nor offers closure at the end. Toxi $\bullet$ City advances toward constructive "chaos" to reflect the same chaos that results from 
natural disasters. To understand Toxi $\bullet$ City, it is necessary to watch a scene formed by three monitors and a Cinemascope screen.

Examples of narrative across media are of a very different nature. That is the case with the work of Canadian artist David Clark, ${ }^{16}$ whose "whole thing is all about bits and pieces, narrative vertigo, and informal conundrums. He has made interactive sculpture, experimental videos, a feature film, created a walkthrough periodic table-shaped science museum, and made public art pieces combining augmented reality and storytelling." 17

Clark rethinks the way stories can be told through the recombination of fragments. Hence, $A$ is for Apple (2002), 88 Constellations for Wittgenstein (2008), Sign After the X (2010), Meantime in Greenwich (2012), and The End: Death in Seven Colours (2015) turn narrative upside down from its very foundations. This last work is "a non-linear internet artwork, made in the interactive authoring environment Korsakow."18 The work is "made almost entirely of found material [and] constructs narratives through a densely woven series of associational connections and coincidences creating an almost holographic picture of death in our current technological society."19

Clark's artist statement likens The End: Death in Seven Colours (2015) to a "chose-your-own-adventure [sic] conspiracy theory" 20 and describes it as

an interactive mash-up of cinematic and internet materials centered on the deaths historical figures such as: Alan Turing, Sigmund Freud, Princess Diana, Jim Morrison, Roger Casement, Walter Benjamin, and Judy Garland. It is a work that explores themes such the unknown, concealment, secrecy, the boundary between animal and man, man and machine, and narrative closure. ${ }^{21}$

Another very interesting phenomenon is the "immersive cinema" of the group Spectacular!, which recreates for the audience the universe of various classic films. The concept of "immersive cinema" comes from the UK, where the "show" is a long-running tradition. The Spanish production company mixes different performing arts, like film, theatre and music, with the goal of "living" an immersive experience. Through the design of a meticulous mise-en-scène, the piece begins as follows: "the moment you click to purchase your ticket and submerge yourself in a unique and special environment." From that moment on, the company contacts the participants, us, to give us a series of instructions so that we can play our "role" and begin to take part in the film. ${ }^{22}$

In the fall of 2016, Spectacular! held its first performance, based on Brian de Palma's The Untouchables (1987). This new entertainment concept is a challenge for literature, theatre, and film, because it includes all of them at once, through improvisation, management of large spaces in which the only rule is that the 
protagonist is the audience, while keeping it surrounded by forty actors prepared to interact at anytime:

People are always looking for new forms of entertainment, they want to live different experiences, and formats that differ from the traditional are very appealing. Spectacular! responds to that demand, it is a new entertainment model that enriches leisure options in a completely novel way. ${ }^{23}$

Spectacular?s second show, which will take place in Madrid in June 2017, will engage with the film Dirty Dancing (1987) and is expected to last approximately six hours. Contrary to augmented reality, in immersive cinema narrative, a more physical reality can be seen, touched, smelled, and experienced firsthand.

Immersive cinema, therefore, is a show outside of a theatre, the reconstruction of a film, live and in real time. It is not a question of being an actor playing a role, but rather, of co-creating a story in which we must make our own decisions. The narrative and the physical spaces coexist with the screen. The city itself is a giant screen, any place can become a magnificent location for projection, thus recreating all the ambiance of a film. Hence, it is the setting and the interaction that make this narrative and screen unconventional.

\subsection{Intersections. Interzones. In-Betweeness. "I Share Therefore I Live."}

In her works, artist Alison Clifford plays with the notions of interstitial, interzones and in-betweeness in digital art. These terms refer to processes of translation and transposition between different media, taking note of the new possibilities that are engendered at the intersection of the former. Her prolific work includes formats like net.art, experimental film, certain interactive works and audiovisual installations.

One of her slightly older works is Palimpsest (2012), which is part of the Interstitial Articulations series and counts on the composer-performer Graeme Truslove as a collaborator to explore spaces halfway between sound and image: ${ }^{24}$

Each work reinterprets a photographic light painting taken during a drive at night. Considering the ethereal 'interstitial' light-forms in the photograph as source material, the artists imagine what it would be like to experience the light-forms in different contexts beyond the photographic image. How might they be reinterpreted and rewritten 
for another context? And how might audio be used to structure our visual experience of them? ${ }^{25}$

The title of the work, obviously, recalls Gérard Genette's book Palimpsestes: La littérature au second degrée (1982), in which the French author coined the concept of "transtextuality." However, Genette did not include transmediality—which we will discuss below-in his set of five models: transtextuality, intertextuality, paratextuality, metatextuality, architextuality and hypertextuality. These, in one way or another, were forerunners of the current transmedia universes.

Through social networks, we create fictional characters that generate a completely online personality and life, adopting some stereotypes culled from several platforms, first Facebook and now, to a larger extent, Instagram. Recall the work Excellences and Perfections (2014), by Amalia Ullman, which carries out a "scripted online performance via her Instagram and Facebook profiles."26

\section{Transmedia Narratives}

Approaching the topic of transmediality today requires a big effort to avoid repeating what has already been published and what is considered canonical, since this emerging topic has been the focus of national and international research projects, such as, in Spain, "Narrativas cruzadas. Hibridación, transmedialidad y performatividad en la era digital," 27 "Performa. El teatro fuera del teatro. Performatividades contemporáneas en la era digital,"28 "Narrativas transmediales: nuevos modos de ficción audiovisual, comunicación informativa y performance en la era digital,"29 "Intermedialidad, adaptación y transmedialidad en el cómic, el videojuego y los nuevos medios" or "Transescritura, transmedialidad, transficcionalidad: relaciones contemporáneas entre literatura, cine y nuevos medios II." 30

From the path laid by Henry Jenkins to current proclamations about transmedia, as Andrea Phillips suggests, what is certain is that the boom of transmedia narratives has not yet dried up. In fact, it is a very complex issue in itself, because academically, it is being approached in a multidisciplinary way, while its creators delve into it to create space for a mind that can no longer be contained by classical linearity. Transmedia, as Virginia Guarinos gathered back in 2007, involves

the hybridity that is achieved through the use of various systems, aesthetics and genres, products, taste cultures, arts, architectures and sciences. .. . This use of processes and signs from other media can no longer be understood as improper appropriation, nor as imitation, nor as a given medium's lack of its own resources. Today, trans is a collab- 
oration and mix of various modes in interaction, arriving at the erasure of belonging and achieving a corpus of its own universal elements which constitute postmodern subjects' special way of developing discourse, with no attention paid to where it comes from or where it is used in the search for global enrichment, in some cases as a source of global ignorance, while the use of elements from other media is not always pertinent, enhancing, or conscious and is more reminiscent of a culture of free chaos, with the emptiness of the use of symbols that are no longer symbols, which stop being symbols when removed from their context and paratext. (Guarinos 17-18)

The collective gaze and, as a consequence, collective creation, are thus defined as a constant flow that could explain the difficulty of focusing attention on a specific point, on a single story that is accessible in its entirety to be analyzed by narratology. Multiplatform creation, found in transmedia narratives, aspires to diversification and disperse images through works that reformulate their existence in real time.

There are two myths we can associate with discussions of transmedia. First, as Domingo Sánchez Mesa-Martínez claims, there is the myth that there is nothing different about transmedia stories or that transmedia is "a new and disruptive communicative paradigm" leading to the progressive "loss of relevance of the story-and of the -telling," in favor of world-building. The second myth is that the creation of characters and transmedial experiences results from the growing influence of the paradigm of videogames and the growing importance of collective or audience participation "in the various phases of transmedia production" (Mesa-Martínez et al. 2).

For Marie-Laure Ryan, transmedia narratives entail the breach of three different codes: that of fans, that of industry discourse, and that of narratology. Ryan explains that the term transmedia storytelling has gone viral in media studies and asks to what degree it can be considered a new phenomenon, different from more classical concepts of adaptation or transfictionality. An important question is what exactly means to tell a story through disparate media and how desirable this type of narrative production is. Ryan suggests the following models of transmedia narrative:

1. Transmedia journalism. "That contains a variety of documents: text, videos, photos and oral testimonies."

2. Installations. "That require the simultaneous use of multiple media, both in the sense of media as a means of expression and media as a delivery system." 
3. Alternate Reality Games (ARGs). "In these games, players reconstitute a story as though it were a jigsaw puzzle by following a trail of clues that comes to them through various delivery systems: mostly from websites on the internet, but also mobile phones, email, posters in the real world or even live actors."

4. Augmented books. "The main physical support of the work is a standard book filled with multimodal documents, for instance fake webpages and newspaper articles. This is multimodality, not transmediality. The transmedial dimension comes from an app that can be downloaded onto a tablet or smartphone with a camera."

5. Interactive TV. "Here I am thinking of projects that link a TV show to information available through other delivery channels." (3-4)

For Ryan, narratology should carry out something like a close reading through the study of concrete works taken from across an entire corpus, rather than using the approach of a "big data" study, as Franco Moretti proposed in Distant Reading (2013). Let us look at an example of a transmedia narrative, Lance Weiler and David Cronenberg's Body/Mind/Change (2013-2017), from a close reading perspective.

\subsection{Transmedia and Cyborg Ontology. On Lance Weiler and David Cronenberg's "Body/Mind/Change"}

The confluence between body and technology, the dissolution of the physical body in the virtual simulated world of the screen, resulting in a non-body, or an entity that differs from conventional parameters, occupies a prominent position in the oeuvre of David Cronenberg. Weiler and Cronenberg's Body/Mind/Change $(B / M / C)$ is categorized as an "Immersive Storytelling/Play Simulation." The experiment is configured as an innovative project that integrates the transmedia format with aspects of artificial intelligence. Lance Weiler, known for developing other transmedia universes like Pandemic 1.0, defines it as a play "on the quantified self and an experiment in data-generated objects." 31

If Cronenberg's work turns narrative around and reframes the issues of human hybridization with technology, implants and chips, along the lines of Stelarc, Orlan or Eduardo Kac, to name but three, Body/Mind/Change reflects a new ecology of human and nature. The work makes room for these Promethean creations, emerged from pixels and algorithms, bordering anti-nature. ${ }^{32}$

We must inevitably return to Donna Haraway or Chris Hables Gray, who in his Cyborg Citizen. Politics for the Posthuman Age (2002) announced that with the 
cyborg began the era of "posthumanity." 33 Recall that Mark Oehlert groups cyborgs "into three broad categories: simple controllers, bio-tech integrators and genetic cyborgs" (221). Citing Gray's unpublished research proposal, he explains the levels of integration of these three groups:

1) With informational interfaces including computer networks, human-computer communications, vaccinations and the technical manipulation of genetic information. 2) With simple mechanical-human relationships as with medical prosthesis, vehicle or weapon manmachine systems and more general human-tool integration. 3) With direct machine-human connections such as the military's state-of-theart attempts to hard-wire pilots to computers in DARPA's "pilot's associate" and the Los Alamos Lab's "pitman" exoskeleton. Plans to "download" human consciousness into a computer are part of this nexus as well. (221)

It has been said many times that David Cronenberg's vision of the cyborg is rather pessimistic compared to Haraway's, with its component of hope and optimism. ${ }^{34}$ "Cronenberg's cyborgization is a degenerative process in which the subject ultimately self-destructs physically or organically" (Aguilar García 17) into the already established concept of "new flesh." The transition to cyborg is a process in which the body imposes its own laws, though it is the mind that decides how to prolong or modify this body that will host the personal on-demand implants (POD Implants).

Because, as we have mentioned, Body/Mind/Change stems from a remediation of Videodrome (1983) or Existenz (1999), among others, it is unavoidable that Cronenberg's most pessimistic vision should also translate to transmedia, especially the part about how media devours. Cronenberg destabilizes borders between body and technology, creating an alienated technobody (Baudrillard).

The artists' statement describes the project in the following terms: Body/Mind/Change is the digital experience extension of the film exhibition David Cronenberg: Evolution and takes audiences through a Cronenbergian storyworld reimagined for the $21^{\text {st }}$ century and brought to life across three platforms: online, mobile and the real world. With plotlines and game mechanics involving biotechnology start-ups, body enhancements, and emotional learning systems, Body/Mind/Change presents the plausible science fiction found in Cronenberg's work as science fact. Through a multi-platform immersive narrative ride, players experience first-hand the emotional steps involved in merging with technology to transform and evolve oneself.

The work brings into play personalized requests and the purchase of POD Implants, which employ artificial intelligence to unleash the desires of every individual. Cronenberg lives the incorporation of the implant in his own body, 
thanks to the fictional company $B / M / C$ Labs: " $B / M / C$ is a digital experience designed to be the connective tissue between the elements of David Cronenberg: Evolution, a sprawling exhibit of artifacts and re-issued films from the filmmaker's career at the TIFF Bell Lightbox in Toronto." $B / M / C$ transforms science fiction into reality through these PODs, which are fabricated with a $3 \mathrm{D}$ printer: "POD wants to know you" and "life is not an adventure and POD is your partner," Cronenberg says in his presentation of the project. ${ }^{35}$

The transmedia experience, which is immersive, begins with a visit to $B / M / C$ Labs to receive a POD Implant. Once they are registered, the spectator-actor-readers delve into three different 20-minute simulations, through the web and on mobile phones, to collaborate in flesh and blood in the creation and education of an artificial intelligence prototype named Kay. Kay will acquire skills, and maybe she will pass the Turing test, observing the responses, reactions and interactions of each person with the simulations tailored by each participant's implants.

"Who do you trust?" That is the question the internet user is asked on a screen that introduces eight characters, whom you only get to know when you click to select one of them, in a format that recalls the hypertext of the 1980s. They are characters that you will want to stay away from: the rapist, the addict, the abuser, the thief, the murderer, the pedophile, the liar and the slut. The PODs respond to each person's desires, slipping in between fiction and reality, via the transmedia format.

To what extent is everything connected? This question is closely related to Transmedia Studies. Interaction between users (or between users and creators) has become an essential part of narrative across media nowadays. All these ideas are the engine of this story and most of them can be put in relation with our "networked culture."

\section{Notes}

1 Cf. also Sherry Turkle, 2011.

2 This text is part of the "Performa. El teatro fuera del teatro. Performatividades contemporáneas en la era digital," a project directed by Anxo Abuín González (Universidad de Santiago de Compostela). Reference number: Ministerio de Economía y Competitividad, FFI2015-63746-P (2016-2019).

3 Julián Pérez develops open source creative programming technology, through the Creative Coding Madrid group (formerly Processing Madrid). Since September 2015, he has been a part of Medialab-Prado's mediation 
team he coordinates the research on Stream and Creative Processes. Medialab-Prado's multimedia archive can be consulted at the following address: <http://medialab-prado.es/archive/video>.

4 Cf. Juan Martín Prada.

5 Cf. <http://www.societas.es/>.

6 Cf. <http://www.arch-srs.com/srs-archive>.

7 Cf. <http://www.teatroscanal.com/espectaculo/go-down-moses-romeocastellucci/ $>$.

8 Cf. <http://www.lafura.com/>.

9 Cf. <http://www.barcelonadot.com/m-u-r-s-de-la-fura-dels-baus-un-smartshow-que-genera-una-expectativa-tan-alta-como-su-decepcion/ $>$. This project is supported by academic institutions from the Massachusetts Institute of Technology (MIT) and the Futurelab of the Linz (Austria) Institut Ars Electronica to the Open Systems Department of the Universitat de Barcelona and the Universitat Rovira $i$ Virgili, and the TibreLab study and the Direcció de Creativitat i Innovació of the l'ICUB (Barcelona LAB). The trailer can be viewed at the following address: <https://www.youtube.com/watch?v=F1enDmTd9yA $>$.

10 Available at <https://www.youtube.com/watch?v=y101bpHTVwM>.

11 Cf. Juan Martín Prada's reference to the "multiplicity of active singularities" in "Poéticas de la conectividad," a special issue of Metrópolis, 2015: <http://www.rtve.es/alacarta/videos/metropolis/metropolis-poeticas-conectividad/3106671/>. See also El País' special "La multitud conectada" (Sunday, 31 January, 2016).

12 Juan Martín Prada. Metrópolis (TV program). RTVE2.

13 All translations were done by Marla Arbac.

14 Author's website < http://robwit.net/>.

15 Extracted from <http://www.crchange.net/toxicity/>.

16 Cf. <http://chemicalpictures.net/>.

17 Retrieved from <http://www.404festival.com/speaker/david-clark/?lang$=\mathrm{en}>$.

18 Cf. <http://theend7.net/?page_id=12>.

19 Cf. <http://david-clark-hrll.squarespace.com/\#/theend/>.

20 Cf. <http://www.404festival.com/speaker/david-clark/?lang=en>.

21 Cf. < http://david-clark-hrll.squarespace.com/\#/theend/>. 
22 This show has now been cancelled. Please see the project's official page $<$ https://spectacular.es./ $>$.

23 Cf. <http://www.traveler.es/viajes/tendencias/articulos/llega-spectacular-una-experiencia-de-cine-inmersivo-unica-en-espana/9687>.

24 Cf. <https://graemetruslove.com/>.

25 Cf. <http://alisonclifford.info/palimpsest/>.

26 Cf. <https://www.instagram.com/amaliaulman/> and <http://amaliaulman.eu/>

27 Dir. Anxo Abuín González < https://narrativascruzadas.wordpress.com/>. Completed.

28 Dir. Anxo Abuín González <https://grupoperforma.wordpress.com/tag/el-teatro-fuera-del-teatro/>. In progress.

29 Dir. Domingo Sánchez Mesa-Martínez < http://www.nar-trans.com/?locale $=$ es_ES $>$. In progress.

30 Both dir. Antonio Gil González and José Antonio Pérez Bowie, <http://doctes.usal.es/proyectos/transescritura-transmedialidad-transficcionalidad-relaciones-entre-literatura-cine-y-nuevos-medios-ii/>. The latter in progress (expected completion: 2019).

31 "When the quantified self gets creepy: Turning David Cronenberg's Science Fiction into Reality" < https://www.fastcompany.com/3021398/when-the-quantified-self-gets-creepy-turning-david-cronenbergs-science-fiction-into-reality $>$.

$32 \mathrm{~B} / \mathrm{M} / \mathrm{C}$ hearkens back to the whole Cronenberg universe, from Scanners (1981) to Videodrome (1983), The Naked Lunch (1991), Crash (1996), Existenz (1999) and Spider (2002).

33 Cf. Ihab Hassan, "Prometheus as Performer: Towards a Posthumanist Culture?” (1977).

34 Donna J. Haraway $(1989,1995,2000)$.

35 Cf. <http://lanceweiler.com/bodymindchange/>.

\section{Works Cited}

Aguilar García, Teresa. Ontología cíborg. El cuerpo en la nueva sociedad tecnológica. Barcelona: Gedisa, 2008.

Arch-Archival Research \& Cultural Heritage. The Theatre Archive of Societas Raffaello Sanzio. 2014. 17 May 2017 <http://www.arch-srs.com/srs-archive>. 
Baudrillard, Jean. "The Vanishing Point of Communication." The New Media and Technocultures Reader, edited by Seth Giddings and Martin Lister. London: Taylor and Francis, 2009.

Canclini, Néstor García. El mundo entero como lugar extraño. Barcelona: Gedisa, 2014.

Castellucci, Romeo. Go Down, Moses. 2016. 17 May $2017<$ http://www.teatroscanal.com/espectaculo/go-down-moses-romeo-castellucci/ $>$.

Clifford, Alison, and Graeme Truslove. Palimpsest. 2011. 17 May 2017 <http://alisonclifford.info/palimpsest/>.

Conde Nast Traveler. "Llega Spectacular!, una experiencia de cine inmersivo única en España.” 27 Oct. 2016. 17 May 2017 < http://www.traveler.es/viajes/tendencias/articulos/llega-spectacular-una-experiencia-de-cine-inmersivo-unica-en-espana/9687>.

Genette, Gérard. Palimpsestes: La littérature au second degré. Paris: Éditions du Seuil, 1982.

González, Antonio J. Gil. "Narrativa aumentada" [1616]. Anuario de Literatura Comparada, no. 5 (2015): pp. 45-74.

Gray, Chris Hables. Cyborg Citizen. Politics in the Posthuman Age. New York and London: Routledge, 2001.

—, editor. The Cyborg Handbook. New York and London: Routledge, 1995.

Guarinos, Virginia. “Transmedialidades: el signo de nuestro tiempo.” Comunicación, no. 5 (2007): pp. 17-22.

Han, Byung-Chul. In the Swarm: Digital Prospects. Translated by Erik Butler. Cambridge, MA: The MIT Press, 2017.

Haraway, Donna J. “A Manifesto for Cyborgs: Science, Technology, and Socialist Feminism in the 1980s." The Gendered Cyborg. A Reader, edited by Gill Kirkup, Linda Janes, Kath Woodward and Fiona Hovenden. London and New York: Routledge, 2000, pp. 50-57.

—. "Cyborgs and Symbionts: Living Together in the New World Order." The Cyborg Handbook, edited by Chris Hables Gray. New York and London: Routledge, 1995, pp. xi-xx.

- Primate Visions: Gender, Race and Nature in the World of Modern Science. New York: Routledge, 1989.

Hassan, Ihab. "Prometheus as Performer: Toward a Posthumanist Culture?." The Georgia Review, vol. 31, no. 4, Winter (1977): pp. 830-850. 
Kerckhove, Derrick de. Connected Intelligence: the arrival of the web society. Toronto: Somerville House, 1997.

Lévy, Pierre. L'Intelligence collective. Pour une anthropologie du cyberespace. Paris: La Découverte, 1994.

McLuhan, Marshall. Comprender los medios de comunicación: las extensiones del ser humano. Translated by Patrick Ducher. Barcelona: Paidós, 1996.

Mesa-Martínez Sánchez, Domingo et al. "Introduction. Transmedia narratives." ArtNodes. Journal on Art, Science and Technology, no. 18, Nov. 2016. 17 May 2017 <http://doi.org/10.7238/a.v0i18.3067>.

Moretti, Franco. Distant Reading. London: Verso, 2013.

Nystrom, Christine. Towards a Science of Media Ecology: The Formulation of Integrated Conceptual Paradigms for the Study of Human Communication Systems. New York: New York University, 1973.

Oehlert, Mark. "From Captain America to Wolverine." The Cyborg Handbook, edited by Chris Hables Gray. London and New York: Routledge, 1995, pp. 219-232.

Phillips, Andrea. "What's Happened to Transmedia?." deus ex machinatio. 28 Sept. 2016. 17 May 2017 <http://www.deusexmachinatio.com/blog/2016/9/28/whats-happened-to-transmedia $>$.

Prada, Juan Martin. Prácticas artísticas e Internet en la época de las redes sociales. Madrid: Akal, 2012.

. "Poéticas de la Conectividad.” Programa Metrópolis. 2015. 17 May 2017 <http://www.rtve.es/alacarta/videos/metropolis/metropolis-poeticasconectividad/3106671/>.

Prieto, Celia Fernández, translator. Palimpsestos: la literatura en segundo grado. By Gérard Genette, Taurus, 1989.

Rajewsky, Irina. "Intermediality, Intertextuality, and Remediation: A Literary Perspective on Intermediality.” Intermédialités, no. 6, Fall (2005): pp. 43-64.

Ryan, Marie-Laure. "Transmedia Narratology and Transmedia Storytelling." ArtNodes. Journal on Art, Science and Technology, no. 18, Sept. 2016. 17 May 2017 < http://doi.org/10.7238/a.v0i18.3049>.

Scolari, Carlos A., editor. Ecología de los medios: entornos, evoluciones e interpretaciones. Barcelona: Gedisa, 2015.

Turkle, Sherry. Alone Together. Why we Expect More from Technology and Less from Each Other?. New York: Basic Books, 2011. 
—. "Connected, but alone?." TED Talks. Feb. 2012. 17 May $2017<$ https://www.ted.com/talks/sherry_turkle_alone_together>.

- Reclaiming Conversation: The Power of Talk in a Digital Age. New York: Penguin, 2015.

Weiler, Lance. Body/Mind/Change. 2013-2017. 17 May $2017<$ http://lanceweiler.com/bodymindchange/ $>$.

Wittig, Robert. Networked Improv Narrative (Netprov) and the Story of Grace, Wit and Charm. 2011. The University of Bergen, Master dissertation. 17 May 2017 <http://hdl.handle.net/1956/6305master>. 



\section{Part Six:}

Tracking and Preserving Texts 



\section{Devon Schiller}

\section{Face, a Keyword Story}

\section{The Archiving Vocabulary for Facial Expression in the German Imaginary from Printed Text to Digital Image}

\section{Introduction}

There are many Geschichte [stories] about the human Gesicht [face] archived across the media imaginary of the German-speaking countries, between the art of physiognomy in the humorist medicine of the Age of Print, and the science of facial expression in the digital biometrics of today's Algorithmic Age. By "face story," I do not only describe the face by its phenotypical expressions, biologically specified and culturally universal, with their variability largely determined by display rules and social scripts. Rather, I define "face" as an explanatory concept, and in terms of what knowledge goes into how we experience our faces and the faces of others. The visible human surface, as an idea of self, is assembled through the world of face-to-face as well as mediated interactions, and plotted in agreement with societal attributes and social values (Goffman 5). In this sense, face is the product of scholarly discourse and socio-political discussion of "work." This face, that over-codes the proprioceptive body and even head, operates by an order of reasons as it is "deterritorialized" from the broader systems of the world, in a process of "facialization" from corporeal to calculus (Deleuze and Guattari 170-72).

I propose that across the most recent five centuries of what I define as "face studies," archival vocabularies - both inferential labels for making message-judgments, as well as keyword categories for storage, transmission and retrieval-play an essential role in the memory feedback of aesthetic-rhetorical artifacts into work practices and processes. Because of this, to semantically metasearch a seemingly-basic keyword as /facial expression/, and perform a cross-database or federated query that links word-organized archival content, can trace new and alternative histories for one of the most primordial resources for making meaning in the human experience. And not only may such a cross-cultural, intermedial, and trans-historical archival semantics demonstrate the extent to which "face concepts" stably fix or fluidly shift across the discursive conceptuality and localizing historicity of their mediation, but how the very "face question" itself is — and has always been-principally a textual way of thinking. 
To prospect these propositions, I probe a digital thesaurus, and two digitized objects there archived, as well as the very archiving systems that are intermedially referenced or combined in the original making of these "face artifacts." Towards this knowledge horizon, I adopt from the German-speaking countries that are here my focus, the vantages of MedienKunstHistory [MediaArtHistories], Bildwissenshaft [Image Science], and the Digitale Geisteswissenschaften [Digital Humanities]. I also use a new Media Art Research Thesaurus. This online tool was developed between 2014 and 2016 in Austria, by the Department für Bildwissenschaften at Donau-Universität Krems [Department of Image Science at Danube University Krems], and with the support of Die Fonds zur Förderung der wissenschaftlichen Forschung [Austrian Science Fund, or FWF] (Grau et al. 1). By utilizing the Thesaurus, I perform a keyword metasearch across two semantically "bridged" archival domains. These domains are also designed, and their resources digitized, by the Department for Image Science. The first domain is the online Graphische Sammlung Stift Göttweig [Graphic Art Collection of Göttweig Abbey], or GSSG. With acquisitions recorded since 1612 at this Benedictine monastery, the GSSG today preserves over thirty thousand Renaissance and Baroque prints, and is one of the most voluminous private holdings of graphic works in Austria. The second domain is the Archive of Digital Art (ADA). Established in 1999 as the pioneering encyclopedia in the field of digital art (also known as media art or "new" media), ADA today represents user-generated content from hundreds of community members out of over five thousand peer-reviewed applicants, through an open access social web 2.0 platform.

Interoperably traversing these media imaginaries both "traditional" and "avant-garde," the Media Art Research Thesaurus is a digital archival domain that supports a controlled semantic classification schema. With its computing platform, a TYPO3 content management system (CMS), Thesaurus keywording achieves metadata functionality. GSSG specialist archivists and ADA social archivers manually code this "data about data" onto information objects in graphical JPEG and MP4 as well as textual PDF formats. Thus, keyword metadata digitally annotate digitized artworks with a "shapeshifting text" (Maduro). By search query and social coding-through processual usage-these keywords newly-diagrammatize and re-narrativize the discursive interrelationships between those web-linked archival resources, and serve to expand accessibility, increase disseminability, and variegate contextuality (Ernst, Digital Memory and the Archive 27).

Within the technoarchive that is the Thesaurus, keywords are hierarchically organized as a "tree-like" taxonomy, whereby "branching" lexical units group from broad categorical generalities into narrow subcategorical specificities—-much like class $\rightarrow$ instance, genus $\rightarrow$ species, and type $\rightarrow$ token. No 
mere folksonomy with but a decentralized tagging assemblage, Thesaurus' keywords conform to a proprietary standardization. From a triadic "root" categorization that includes /Aesthetics/, /Subject/, and /Technology/, a select four hundred natural language keywords (and keyword phrases) codify art communities both old and new (Grau et al. 7).

To devise the Media Art Research Thesaurus, field experts qualitatively surveyed art historical indexes (such as the Getty Arts and Architecture Thesaurus, Iconclass, The Warburg Institute's Subject Index); as well as contemporary art glossaries (The Dictionnaire des Arts Médiatiques, GAMA, Daniel Langlois Foundation, Netzspannung); and even digital festivals as technologycatalytic forums (Ars Electronica, Inter-Society for the Electronic Arts, Transmediale).

For example, Iconclass, popular worldwide among cultural heritage institutions, began in the 1950s with Dutch art historian Henri van de Waal (1910-1972), and today is managed by the Rijksbureau voor Kunsthistorische Documentatie [Netherlands Institute for Art History], or RKD. Through a subject-specific alphanumeric notation (like the Dewey Decimal System), Iconclass classifies (3) /Human Being, Man in general/ $\rightarrow$ (32) / human types; peoples and nationalities / $\rightarrow(32 \mathrm{~A})$ /human types/ $\rightarrow$ (32A6) / physiognomy/. The Ars Electronica Festival, whose Prix Ars Electronica and Golden Nica is to digital art what the Academy Award and The Oscar are to film industry, premiered on the $18^{\text {th }}$ September 1979 in Linz, Austria, and today hosts thirty-five thousand visitors annually. Through its digital and print didactics, Ars Electronica increasingly catalogues artworks that incorporate / biometric/ technologies.

The Media Art Research Thesaurus, in order to "bridge" terminologies both historically established as well as contemporarily unstable (Grau et al. 2), encodes /Subject/ $\rightarrow$ /Body and Human/ $\rightarrow$ /physiognomy/, and /Techno$\operatorname{logy} / \rightarrow$ /Interface $\rightarrow$ /biometrics/. Etymologically-speaking, the word physiognomy (pronounced fIzI'p(g)nəmi) compounds a portmanteau from the

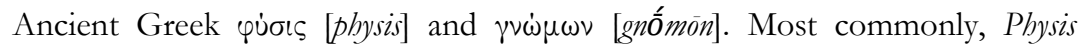
translates as "form" or "works of nature," but without a direct English correlate. And gnốmōn, which relates to both $\gamma$ $\gamma \nu \omega \dot{\omega} \omega \omega \mathrm{b}$ [gignốsōk] "knowing" and $\gamma \nu \tilde{\omega} \sigma \iota \varsigma$ [gnôsis] "knowledge," variously transcribes as "discern," "examine," "interpret," or "judge," simply a "mark," and most generally an "index." A gnómōn was also the instrument of a sundial by which a cast shadow is measured. Alliterated together, physis+gnốmōn mean, roughly, "form interpreter" or "nature

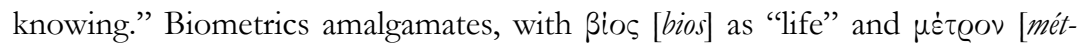
ron] as "measure," into "life-measuring." This turns another cheek among the many faces of what I define as "face studies," a moving science or supradiscipline guided not by formal disciplinization but by media change. But both ide- 
as about self, and the face (art)works by which they become conceptable to Homo significans, the Media Art Research Thesaurus semantically links with the keyword search /Subject/ $\rightarrow$ /Body and Human/ $\rightarrow$ /facial expression/. Through its metasearch function, the Thesaurus locates archival resources that are keywords tagged with / facial expression/ in narrative opposition to each other, and as items on a list that by their theoretical association can be relationally clustered (Manovich, The Language of New Media 212-232).
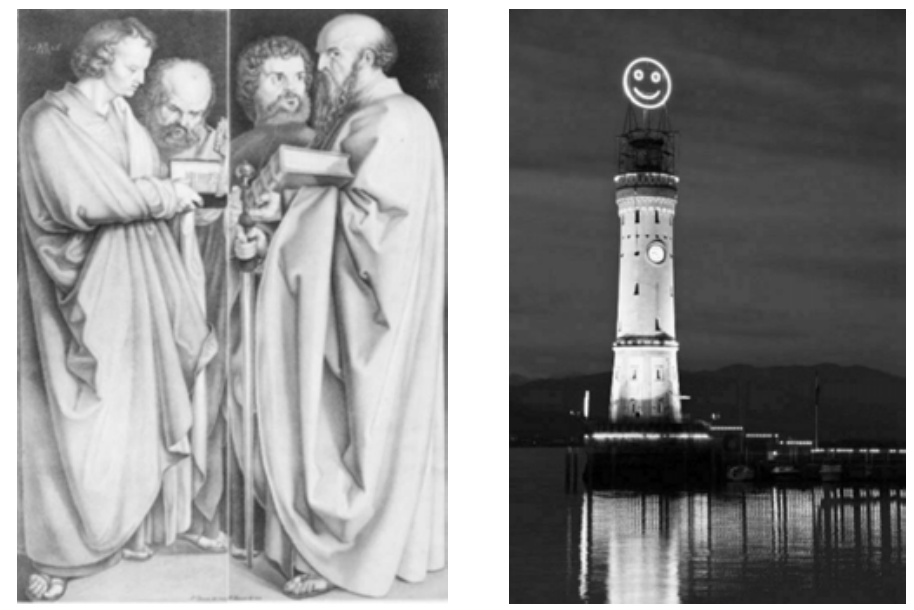

Fig. 1 (left). Johann Nepomuk Strixner. 1808-1815. "Master Study of Albrecht Dürer's The Four Apostles (1826)." 46.9×17 cm. Lithograph printed with tint stone and white highlights. Printed in: Johann Nepomuk Strixner and Ferdinand Polity. 1808-1815. Les Euvres Lithographiques choix de dessins d'après les grands maitres de toutes les Ecoles, tirées $d u$ Musée de S.M. Le roi de Bavière par Strixner, Piloty et Cie'. Munich: Johann Baptists Stunz. Archived in Göttweig Abbey Graphic Print Collection. Digitized by Department of Image Science, Danube University Krems, Inv. Nu. Je_002 and Je_003. Used with permission.

Fig. 2 (right). Julius von Bismarck, Benjamin Maus, and Richard Wilhelmer. 2010. Public Face (C) Felix Rundel, courtesy of the artists.

With the keyword phrase / facial expression/ as my point of departure, and the correspondences and conflictions between / physiognomy/ and /biometrics/ as my analytical space, I lexically link two privileged case studies: Johann $\mathrm{Ne}$ pomuk Strixner's 1808-1815 master study of Albrecht Dürer's Die vier Apostel [The Four Apostles]; and Julius von Bismarck, Benjamin Maus, and Richard Whelmer's 2008, 2010, and 2014 Fühlometer [Feel-O-Meter] or, as later titled, and as I refer to it, Public Face (fig. 1 and fig. 2). However, I do not archaeologically search for an origin in Strixner's Apostles to Bismarck's Public Face as having discrete affordances in an immobile history, but rather genealogically trace an 
intermedial space between these face artifacts as having diverse subjectivizations in many confrontational histories. That is, instead of excavating a "straight line" for media evolution from traditional lithographic print to avantgarde digital media, I expose the "broken circles" of media entanglement between these art forms.

\section{Archiving Face}

\subsection{In Search of Face}

As I proof here, keyword categories can be helpful in the semantic metaanalysis of ideas about face, as well as the discursive contextualities and localizing historicities for these face concepts over the many faces of face studies these past three millennia. But such metadata — or "face data about face data"-is also processually and methodologically necessary in the very archiving action whereby scholars of the visible human surface make the facial expressions of emotion both noticeable and knowable.

With the archival arché or act, data "about face" can be stored, transmitted and retrieved so that it can be used again as information through the ars memoriae or memory feedback into work process (Ernst, "Archive in Transition" 475). Most broadly defined, a "face archive" is any place where facts "about face" get made (from the view of a subject-oriented anthropology), or a space where facts perform their possibilities (to an object-oriented ontology). In other words, researchers into facial expression utilize archives as operationalizing systems for the formation and transformation of statements about what the face $i$ s. And through archival practices and processes, they cause this multiplicity about what the face could be here in this discursive contextuality, or might be then at that localized historicity, to emerge as regular events to be manipulated and modified (Foucault, The Archaeology of Knowledge 147). Facts, as suggested by the word's etymology — from the Medieval Latin factum, "an action or event, a thing done," and Classical Latin facere [to do] - are indeed artifacts (Daston 680).

By the making of artifacts in an archive, a researcher into facial expression searches for facts about face and its 1) schema, 2) image, and 3) affect as holistically encompassed on a trichotomic continuum. The 1) face schema is the phenomenological first-person subjective experience of one's own face or that of a close other, through its anatomical as well as neuroanatomical expression in motor neurons, cranial nerves, and facial muscles; perception in the fusiform face area of the visual system; and representation in the sensorimotor cortex of 
the brain. The 2) face image is the epistemological second-person objective conceptualization of a face, by the descriptive observation of its muscular contraction mechanisms and skin appearance movements, as well as their measurement and classification into discrete units upon which can be based truth claims and validity tests. And 3) face affect is the hermeneutic third-person intersubjective interpretation of the face, with a critical exegesis of the folk, popcultural, or scientific knowledge (and its mediations) that, while perhaps beyond conscious awareness, effect attitudes, beliefs, or dispositions toward face (cf. Gallagher). Or, to put it naively, the central questions of face study remain: What is our sensorimotor experience of face? How do we consciously attend this experience? And to what extent is this experience mediated through sociopolitical languages?

\subsection{The Face Collector}

All scholars who research facial expression are also archivists - whether they are from the place where Gutenberg first innovated the printing press, or of this time, when technocrats invent automated frameworks. Most even personally testify to the processual essentiality of cultivating an archival practice. And they do so self-witness explicitly, in methodological exposé of their pictures, and the intellectual provenance of their writings (cf. Darwin 13-35; Ekman and Friesen 240-243). Some scholars of face are even characterized by their colleagues or companions as "born collectors" (Colombo 36; Gibson and Rafter 21-3), "gifted face readers" who spend many an hour immersed with mediations of facial expression (Tomkins xi; Gladwell), or experiencing some kind of some such "archival impulse" (cf. Foster 3).

In the search for face over the last half millennia, these face collectors have archived: the great masters of the visual arts remediated as etching, photograph, or today's digitized image; aristocratic portraiture and emblemata; spontaneous candid photos found in a print shop or bookstore; mug shots and wanted posters; celebrities and politicians recorded off televised news or mass media; selfies web-scrapped from the Internet; and scene extractions made with distributed smart camera. Such found objects are the "raw stuff' - the very artifacts and material of thought - in that which I call face studies. Of course, the archivization of materialities and imagings has long been held as a necessitated condition of knowledge production in both the "two cultures" of the sciences and humanities. But to the face collector, the archiving of such artifacts is more than an experiment result, proof instrument, argument narrativization, popular dissemination, or institutionalizing strategy. Further, artifacts of face constitute a singular immanence in both media-expression and image-content, 
becoming how the face subject is transmitted in an object, as well as what the research work is about. Respectively, face archives may be purpose-built and pre-existent archives can be so temporarily purposed, either in history, or to historian_ as I do here with the Media Art Research Thesaurus, and its semantic link between the Göttweig Graphic Collection and Archive of Digital Art.

Many face collectors, who for much of their lives search the folds, lines, and wrinkles of brow, cheek, and jaw, also spend years-sometimes decades - in the discovery, development, and dissemination of archival technologies. That is, beyond archiving some found objects about face, through the archive they also make their own face artifacts. For this, an archive, so named af-

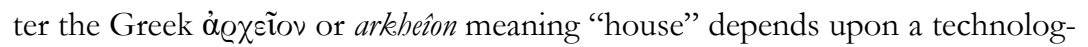
ical apparatus—cabinet or collection, library or museum, anthology or index, exhibition or workshop, laboratory or studio, database or dataset, or an online platform for the digital or digitized.

Indeed, each and every face collector, whether they are a self-professed artist or scientist, or partitioned so by society, also personally testifies to an artbased research, training in the arts, or that they themselves are artists. Never in Western media culture — at least not since around 500 BCE when the physiognomist Zopyros diagnosed from a portrait that the philosopher Socrates be possessed "of many vices" - has there been a face archive not theoretically as well as practically located at the very intersection of art and science.

Really, when it comes down to a question about face, most analytic judgments of archivization are likewise an aesthetic judgment of intermediation. This term-intermedia-has wide articulation in German image science and art histories since the 1990s. After the Latin prefix inter for "among, between, or during," its first usage by romantic poet Samuel Taylor Coleridge in 1818, further popularization came from Fluxus "anti-art" artist Dick Higgins in 1966, with its framework beholden to the intertextuality of literary semiotician Julia Kristeva from the $1960 \mathrm{~s}-70 \mathrm{~s}$. And the intermedial relation per se has been acknowledged since antiquity.

By retrospectively applying this media philosophy, I suggest that the face archive is not solely a space in which are housed mixed- or multi-media, and where the materials of various established art forms are "brought together" and merely juxtaposed (Clüver 14, 43); the remediated, where pre-existing media are appropriated, refashioned, or simulated (Bolter and Grusin); or the transmedial, where certain motifs appear across all the various media specificities of its artifacts, and so in turn emanate a "trans-archival aesthetic" (Ernst, "Archive in Transition" 475). Rather, the face archive is intermedial, and ontologically a betweenness. Almost "as if" or "as like" a performative stage (Krtilová 37-45), here an assemblage or network of media and all their affordances, specificities, and technologies exist in process of becoming. Towards an empir- 
ical horizon of "Medienerkenntnis" [media recognition] (Krämer 82), face collectors search for the face in the media by understanding these media in relation to other media with their respective processes of socio-cultural production.

\subsection{Evidencing Face}

The face collector, harnessing the new or newest media for its past perfect promise to re-determine present knowledge (Gates 8-10), probes the totality of extant material cultures: historical diachronic or contemporary synchronic, found objects and made artifacts. To make facts about face is dependent upon the indexing of observed facial expression data, from which hypothesized facial content information can be retrieved. This is achieved, principally, using artifacts made within archives — whether lab or studio, dataset or exhibition. Here, a "proofing of thingyness" or "trial of things" takes place. That is, to carry such metaphor, the archive becomes like a courtroom in which a judiciary of artist-scientists examine and cross-examine the artifacts through a scientific methodology. And it is an apt metaphor, because for the face researcher-whatever their discipline-there is usually a perceptual bias or methodological empathy: all facial signs are presumed to be meaningful until proven otherwise.

Faces most afford evidence as "something becoming apparent as something" (Siegmund qtd. in Krüger 14) when somebody fixes them into something plastic. Through such artifaction, and in Classical rhetoric called a demonstratio ad oculos [demonstration by the eye] (Russell VI.ii.32), past formings of the face are transcribed into present formations of faceness. In the search for face, those scholars who research facial expression have, for instance, pictorially and textually diarized the facial behaviors of their own children during maturation from infancy to adolescence; they have used mirrors both analogue and digital to train facial expressiveness on their own faces through voluntarily muscle. In these ways, making faces within the archival space, experiential occurrences of this or that "living" facial event-both artificially staged and naturally spontaneous, both static and in real-time—are translated into so many "plastic" face artifacts to be qualified or quantified.

When studying facial expressions as so-called averbal or nonverbal components of communication that paralinguistically coordinate within social interaction and spoken language, the procedural reason for needing artifacts is simple: in order to objectivize the face, more than one face must already be observable. This instance of comparison could be the face in the mirror, or the faces in an "electronic mugbook." But, to perform such artifaction, the new or newest media is most commonly used, be it a drawn sketch, woodcut print, 
written manuscript, printed book, photographic plate, motion picture, videotape, data matrix, digital image, digital text, or algorithmic and automated framework. Media such as painting or sculpture may also be harnessed in face research, but are so less frequently. Although media specificities fluctuate over the two millennia of the face project, media affordances fixate as consistency, economy, legibility, portability, reproducibility, and usability. But only when an artifact of face is archived into a constellation, whether assemblage or series, does it become the $\dot{\varepsilon} v \dot{\alpha} \varrho \gamma \varepsilon \iota \alpha$ [enargeia] of evidence or an illustration. Then, artifacts might evoke an immediate witness to facts, and with such immersive vividness that the spectator has the impression of looking "at the very thing itself” in all its circumstance and consequence (Clark IV.liv.68).

As considered from the view of German-speaking Bildwissenschaft [Image Science], a vantage cultivated in the rhetoric of Antiquity, this evidenz involves a "pictorial-performative procedure" (Krüger 16) between the artifact that shows, its content that is seeable, and the experience of seeing, in trilateral reciprocity (Halbfass 830). As this evidence becomes cognizable (or, more accurately, recognizable) through the production of an artifact, facts can then be made via aesthetic judgments. That is, "the media is the method" — to frame this evidentiary procedure in the language of visual studies, the Anglo-American counterpart to the German Bildwissenshaft (cf. McLuhan and Fiore). As the face collector through their face archive makes some face artifacts, it is by the physical signifiers or sign vehicles of these objects - their material or materiality, their medium - that information about face is conveyed. But such mediation does not only instantiate statements about what the face is, can or may be, and structurally formalize these truth claims, but also methodizes the creative hypothesizing and visual thinking of work processes.

\subsection{Naming Faces}

This "physiognomic genre," as I call it, can be classified by a picture plane that isolates face from head and body, balanced lighting with even illumination and contrast emphasis, chronological and typological sequencing of multiple images, and alphanumeric code as image metadata - among other stylistic elements. And these aesthetic characteristics are relatively constant between corporeal, graphic, and textual informative mediations, as well as kinesthetic, ocular, and auditory sensory modalities. Of course, there is no a priori diagrammatic logic behind why verbal linguistic phonemes should make transparent averbal morphologic corpemes. Yet, "words about face" have since the physiognomists of old been used in face studies to make facts about face. 
Within the causal conditional that if there is this physiological form /smile/, then there must also be that psychological function /happiness/, the letters $/ \mathrm{s} /, / \mathrm{m} /, / \mathrm{i} /, / \mathrm{l} /$, and $/ \mathrm{e} /$ do not simply correspond to forming "features into a pleased, kind, or amused expression" (OED). The $/-/$ of the $/ 1 /$ and the /./ of the /i/ are not morphologically equivalent to the sygomatic major pulling upwards the /lip corners/ and orbicularis oculi gathering laterally the /eye folds/. Only by conventional law does such a "real" facial expression connect with the visual pattern of the word /smile/ rather than, say, the word / frown/. The size or style of the typography in which / smile/ is written do not necessary decrease or increase with changes in the intensity of a facial expression. And the keyword category /happiness/ could still convey the same meaning about face if called by any other name (/Supercalifragilisticexpialidocious/ might work pretty much just as well). Even languages themselves differ in their labeling of emotions or temperaments. In German, for example, /gemutlich/ [cozy], /schadenfreude/ [happy about the pain of another], / mitgefuibl/ [empathy with the feeling of another], /trauring/ [funerary grief], and /glïcklick/ [happy and lucky] have no exact correlate in English.

Which keyword terms or phrases are used to describe a certain facial expression of emotion - whether the humorist temperament /sanguine/ or the basic emotion / happiness/—are contingent upon a kind of paradigmatic "face of the age"; that is, the leading explanatory system for measuring facial sign-vehicles, as well as for evidentiary interpretation of the face's message-judgments. With face studies, the interest has always been more in valuating inferential labels than typologizing inferential units. A particular face story at its time of narration is assimilated into such interpreting encyclopedias as those about atavism, criminality, deception, emotion, ethnicity, gender, intelligence, or leadership. And the facial expressions of emotion distinguished and defined by keyword categories are ontologically neither actual nor possible, but rather linked to such socio-cultural codes about facial sign meaning.

\section{A Tale of Two Archivings: The Göttweig Abbey Graphic Art Collection}

\subsection{The Face Story by Johann Nepomuk Strixner}

To problematize how keyword vocabularies feed artifacts of face back into the practices and processes of face work, as well as the extent to which an archival semantics presents a given face concept to be fixedly stable or fluidly shifting across the many faces of what I define as face studies, I probe the Media Art 
Research Thesaurus developed by the Department of Image Science at Danube University. By performing the keyword search from the category /Subject/ $\rightarrow$ to subcategory /Body and Human/ $\rightarrow$ and its sub-subcategory / facial expression/, I semantically retrieve from both the Graphische Sammlung Stift Göttweig (GSSG) and the Archive of Digital Art (ADA) numerous artifactions in which facial expressions that have been plasticized in pigment, print, or pixel appear- either in history, or to historian — to wear the mask of a scientific calculus about face. These include a face story by engraver and lithographer Johann Nepomuk Strixner (1782-1855), stored within the Graphische Sammlung Stift Göttweig [the German for what in English is known as the Graphic Art Collection of Göttweig Abbey] in Niederösterreich [Lower Austria], an UNESCO World Heritage Site since 2001, and digitized into their online archive. Strixner is little remembered by art history, save for the odd institutional record or reference entry. Even at Stift Göttweig, directing curator of the Graphische Kabinett [Graphical Cabinet] Gregor Martin Lechner, a theological art historian and indoctrinated priest, catalogues no biography for this $19^{\text {th }}$ century stecher [engraver]. The keyword-based metasearch, however, that locates Strixner's work in narrative opposition to today's art, can well illuminate histories alternately and newly contextualize.

Because Strixner's life is but a footnote to art history, some biographic information is necessary to contextualize his history with the artifaction of face. Strixner began studying the arts at fifteen, before apprenticing to Hermann Joseph Mitterer in Munich at his Feiertagsschule München [Holiday School] for applied vocational training. At the time, Munich was growing as a centrum of technological modernization in printing methods, as well as for venturous enterprise in lithographic mediations. Like many draftsmen, Strixner found employment with Johann Alois Senefelder, the former lawyer and sometime poet

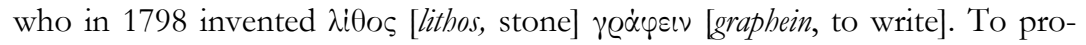
mote lithography, and its market for art reproduction, Senefelder and Strixner collaborated in 1508 to intermedially transpose Albrecht Dürer's ChristlichMythologische Handzeichnungen [Christian Mythological Drawings]. As Senefelder himself later accounted, this memorial to Dürer "fixed the reputation of our establishment" (62)_ as it did that of Strixner as well, and brought the young artist one etching-stylus closer to make an archive of his very own face.

In 1808, Strixner matriculated to the Akademie der Bildenden Künst München [Munich Academy of Fine Arts]. After graduation, he received a consignment to intermediate the Alte Meister [Old Masters] exhibited at the Bayerische Staatsgemäldesammlungen [Bavarian State Painting Collection]. Among its many homages to all thingynesses Germanic, the 423 print series included Johann Strixner's lithographic master study of Albrecht Dürer's oil painted artwork Die vier Apostel (the authentic German title for what the English-speaking world 
knows as The Four Apostles). That Strixner had witnessed the original proves his first contact with the face concept of the four humors.

The Göttweig Abbey Collection acquired Strixner and Polity's Lithographiques, and within it Strixner's The Four Apostles, not long after its publication in the early $19^{\text {th }}$ century. One hundred years earlier, art conservationist, diplomat, and patron Abbot (1714-1719) Johann Franz (Gottfried) Bessel had sponsored the protocols that systematically augmented the Collection. In a project developed between 2002 and 2012, Danube University digitized the lithographic master study along with more than 6000 other graphic works. In the Department's Digitization Center, a Digit Repro Master, which combined an English Linhof M679cc digital camera, German Anagramm scanback, and flicker-free fluorescent bulbs, afforded $8000 \times 9700$ pixel resolution, 16-bit color depth per channel, and uniform lighting. With this new such digital materiality, Strixner's Apostles could be "virtually" exhibitable and online indexed (Grau and Coones iv). Within the GSSG online database, with an ImageFinder/DocuMax content management system as Internet platform, the two panels of The Four Apostles from Strixner's Les CEures Lithographiques are code-named "Je_002" and "Je_003." Keyword metadata encodes data fields about this face artifact, such as stecher [engraver] /Strixner/, inventor [inventor] /Dürer/, [genre] /Heiligendarstellung/ [Holy Representation], Ikonographie [iconography] /Neues Testament/ [New Testament], and Technik [technique] /Lithographie/ [lithography]. "Metadata teams" - the "unsung heroes of digitization," according to The Getty Museum's first-ever digital media architect, Chris Edwards — create this digital surrogacy of original artifacts, for which a record without image is more highly evaluated than image without record (Stephan 2). Yet, among this metadata for The Four Apostles by Strixner there is no textual cipher to / facial expression/ for this saintly tetrad.

\subsection{Humorous Faces}

As an archival resource worthy of the keywording / facial expression/, Strixner in his lithographic master study of 1808-1815, succeeding Dürer in his painting Four Apostles of 1526, intermedially referenced the art of /physiognomy/, as theory behind-and method within - the medicine of the humors (or humors).

Of course, in the Media Art Research Thesaurus, such a paradigmatic dimension is implicitly imagined within the image grid of its metadata visualization (Manovich, The Language of New Media 212-232). That is, because when using the Thesaurus, a keyword search /Subject/ $\rightarrow$ /Body and Human/ $\rightarrow$ /facial expression/ retrieves Strixner's apostles from its Web storage, and digi- 
tally transmits it to the user's device, this work seems to be authoritatively connected with such meaning. Certainly though, I would not (and did not) take the keyword's word for it—or, more correctly, the keyword coder's. Instead, from the archival record's primary endodata within itself (such as, on the GSSG, front matter, image annotations, printing institution, etc.), I web-linked down the Internet "rabbit hole" to this archival record's secondary epidata framing it—artist biographies, critical reviews or library catalogues (cf. Genette 344-351). A single keyword as metadata, transcribed between porous zones of private backend datafication and public frontend discursivity can make present many keyword textualities (and some "link deaths") by which users may navigate through algorithmic thresholds of interpretation ad infinitum.

Johann Neudörffer (1497-1563), a professional Nurembergian calligrapher, was the first to notice a "physiognomy-saint connection." Himself working on Apostles, Neudörffer inscribed the Lutheran epistles at the base of the oil on linden wood panels $(215 \times 76 \mathrm{~cm})$. And in the mid- $16^{\text {th }}$ century, memorializing Dürer in a series of short biographies on Nuremberg artists, Neudörffer vouched how the "pictures in oils" represented "properly speaking, a sanguine, a choleric, a phlegmatic, and a melancholic" humorist prototype (qtd. in Panofsky 234-235). To eponymous Dürerian biographer Erwin Panofsky (1892-1968), "it is impossible to discard this statement of a man" who conversed and collaborated with Dürer in the master artist's own workshop. With other art historians (Pfeiffer 390), however, this primary source ego-document contains no conclusive evidence that Neudörfer credibly witnessed Dürer "say" and not only "show" it.

Regarding Albrecht Dürer's The Four Apostles (1526), Erwin Panofsky's The Life and Art of Albrecht Dürer, first published in 1943, recognized: 1) iconographical motifs (iconic), where the "indexes of age and complexion" and "hierarchy of [color] values" of the saintly faces, have a likeness or community in some quality with already more than one face of their humorist type; 2) iconography themes (indexical), where the "maxima, or optima" apostolic visages with most "dominant" scale and foreground arrangement, correspond in fact to literatures on humorist pathology and physiognomic deduction regarding the "noblest humours [sic]"; and 3) iconology intrinsic meanings (symbolic), where the four apostles gain imputed qualities from “Dürer's period and by Dürer himself" when related to the socio-cultural conventions, habits or laws of the early modern period (235).

This humorist pathology, while a "theory of everything" (Kemp 15), is also a face concept in which the human visage is comprehended to be a microcosm of the natural world, and the very embodiment of all the universe's physics and forces in equilibrium or imbalance. Humorism persevered extant from the dietetic principles of classical antiquity, and texts by Empodocles of Acra- 
gas (c. 495-425 BCE), Hippocrates of Cos (c. 460-370 BCE), and Galen of Pergamum (c. 130-210 CE); to the diagnostic practices of the medieval and early modern periods, through Dürer's time, beyond Strixner's; and well into the $20^{\text {th }}$ century with its technosocial accelerationism of psychometric taxonomies.

With this holistic model for face in humorist medicine, the physician, as well as the physiognomist, described the kraseis [Latin for mixtures] of matter- the material, or even the media (cf. Belting)_ or for the human temperare [temperament]. In so doing, they identified well-mixed or poor-balanced functions, and evaluated these as the first cause of either good or bad health and character (Leunissen 22). Through this "four roots of all" numerological philosophy, physician and physiognomist alike diagrammed personhood into informational categories (fluid, organ, element, season, entity, celestial, life cycle, astrological aspect, quality) within a tetradic taxonomy of human types: sanguine (blood, liver, air, spring, sky, morning, youth, Jupiter, hot-moist), choleric (yellow bile, spleen, fire, summer, sun, midday, maturity, Mars, hot-dry), melancholic (black bile, gall bladder, earth, autumn, earth, evening, later middle age, Saturn, cold-dry), or phlegmatic (phlegm, lungs, water, winter, night, old age, Venus, cold-moist).

But physicians diagnosed from the external symptomata [symptoms] of the body, to the internal diseases of a patient, so as to provide a prognosis and prescribe a treatment. Physiognomists, however, deduced from the outside physiological behavior or semeia [signs] of the face to the psychological phenomena inside of an individual, so as to operationalize the self inside out into these universal or utilitarian attributes.

\subsection{See Your Face in this Painting as in a Text}

To Dürer, however, the techne (Latin from the Greek $\tau \dot{\varepsilon} \chi \nu \eta$, or art) of technitai (practitioners of this art) in physiognomy was no mere particulate amidst a generalized early modern and Northern Renaissance "atmosphere of face" or "facial ethos"—as even Panofsky only traced (260-275). Rather, Dürer navigated the German media landscape that he inhabited in such a way as to intermedially reference particular face archives, and feedback through the ars memoriae the facts about face therein plasticized into his work process.

At the very space and time Dürer painted The Four Apostles, printers were beginning to publish material about physiognomy in anthologies, books, encyclopedia, and pamphlets (Porter 108). As with Strixner's Munich at the turn of the $19^{\text {th }}$ century, because of Senefelder's lithography, Dürer's Nuremberg at 
the turn of the $16^{\text {th }}$ century, because of Gutenberg's innovation, sustained rapid economic growth to its print industry (Pettegree 36, 40, 93-94).

It can be stated with enough probability as to perhaps be a fact, that Dürer's Four Apostles intermedially referenced Desiderius Erasmus' face artifacts. Erasmus of Rotterdam (c.1466-1546), a Dutch Catholic priest and sobriquetical "Crowning Glory of the Christian Humanists," was a longtime acquaintance of the master artist. In 1520, six years before Apostles, Erasmus sat twice with Dürer for a portrait. And when Dürer passed on the $6^{\text {th }}$ of April 1528, Erasmus praised him as an artist who "even depicts what cannot be depicted ... characters and emotions; in fine, the whole mind of man as it reflects itself in the behavior of the body" (qtd. in Panofsky 44). Much of this accolade, Erasmus appropriated from Naturalis Historia (c. $77 \mathrm{CE}$ ), in which Pliny the Elder praised Apelles of Kos for painting "such perfect likenesses that ... a physiognomist, or metoposkopos as [the Romans] call them, was able to tell from the portraits alone how long the sitter had to live or had already lived" (qtd. in Elsner 203). That is, by using the keyword / physiognomist/, and keyword phrases for the logical inference from/physical behavior/ to /psychological phenomena/, the author Erasmus explicitly extolled the artist Dürer to be a scientist of face.

Actually, Erasmus authored ideas about face throughout his ample oeuvre. In 1511, Erasmus first published in Latin his Moriae Encomium (or In Praise of Folie), translated into German just a few years before Dürer began Four Apostles. There, Erasmus satirized the civil stratosphere of statesmen who "haue two faces muche vnlyke and dissemblable," aristocrats with "faces lyke visers," and churchmen who "did but ones loke [wisedome] in [hir] face" (Knight). Through his protagonist-narrator, Folly, "distributrix and dealer of all felicitee," Erasmus parodied: "if any man, mistaking [Folie] for Wisedome, could not at first sight convince himself by my face, the true index of my mind?" . . " $[\mathrm{N}]$ or do I carry one thing in my looks and another in my breast," his Folly said, for "I am no Counterfeit." This German keyword, Kontrafactur [counterfeit] even came to categorize a poetic genre of mimetic imitation purposed to parodiable inspection. Proclaiming the human visage first among "parts of the body are named honest, that endengre gods, and men," Erasmus stated-and Folly narrated - that the signs of face are "no liyng myrrour of the minds disposicion."

Along with the textual representation of Erasmus' Folly, German portraitist Hans Holbein the Younger (c.1497-1543) graphically represented Folly as a "fool" mirror-gazing upon a theatrical prop cast in her own likeness, a "true index" of self-transparency, reflection, and knowledge (fig. 3 and fig. 4).

Holbein only illustrated one first edition of Erasmus' Folly with these pen and ink sketches, a copy owned by Protestant theologian Oswald Myconius. 
But other image-makers over the centuries remediated this physiognomic protocol across innumerable text editions, inspiring the symbolic topos of "the fool and the mirror" as an onto-cartographic blueprint.
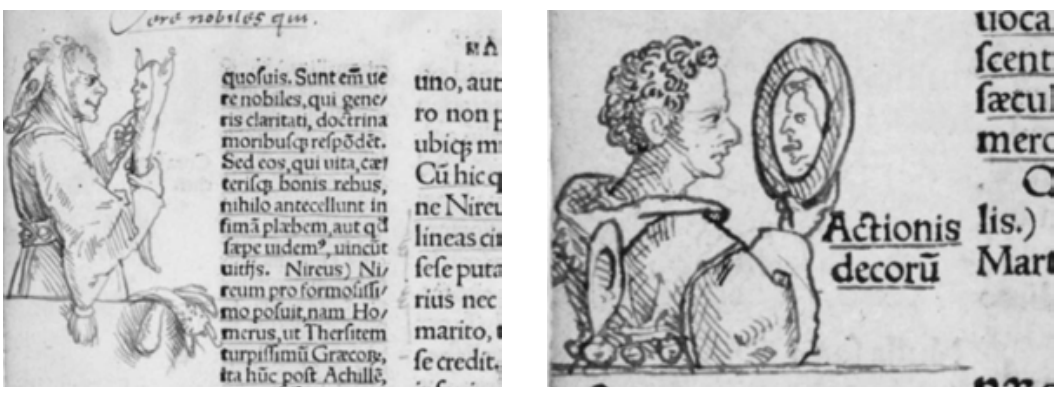

Fig. 3. and Fig. 4. Hans Holbein. 1515. "A fool considers himself in a mirror." Feather pen with brown ink, $22.3 \times 16 \mathrm{~cm}$. In: Erasmus of Rotterdam, Encomium Moriae. Copy belonging to Johann Froben, Basel, Switzerland, Inv. No. 1622.166.29 1662.166.13 fol. E 2 verso and fol. K 4 verso and. Photo (C) Kunstmuseum Basel/ Martin P. Bühler. Used with permission.

Of course, Folly's most stereotypical formulae or topos (Huhtamo 34), "the face and the mirror," can be seen in ontological cartographies that have endured since classical antiquity in physiognomic thought and material culture, as with maps for being like Narcissus, Prudence, and Venus. By Dürer's day, many books about face even called for personal or communal reading with the aid of a looking glass, as did popular physiognomic games and prayers (Porter 280) — a kind of "choose your own [face] adventure" or "do it [the facial expression] yourself” combinatorial narrativization. And prefaces to physiognomic texts, such as "Of this said booke make oft a looking glas" (Manzalaoui 275), often served to restate the Augustinian rule "that you may see yourself in this little book as in a mirror" (Bradley 100-105).

\subsection{Textualizing Face}

But Dürer intermedially referenced other face archives and the artifacts therein housed as well. On the $7^{\text {th }}$ of May 1522, one year before Dürer composed preparatory drawings for his Apostles (Panofsky 230-231), and four years before he completed the painting, Strasburg printer Johann Schott published in Latin the first-ever printed treatise with an entire chapter "periaxiomatibus de faciebus signorum" [about the value of facial signs] to be illustrated with a face archive of individual case studies (Porter 157). German reformist priest and consulting astrologer Johannes de Indagine (1456-1537) authored an introduc- 
tion to physiognomy. Hans “Grien” Baldung (c. 1484-1545), Dürer's very own apprentice, carved the woodcut prints to interlay the "modern" humanistic type (fig. 5 and fig. 6).
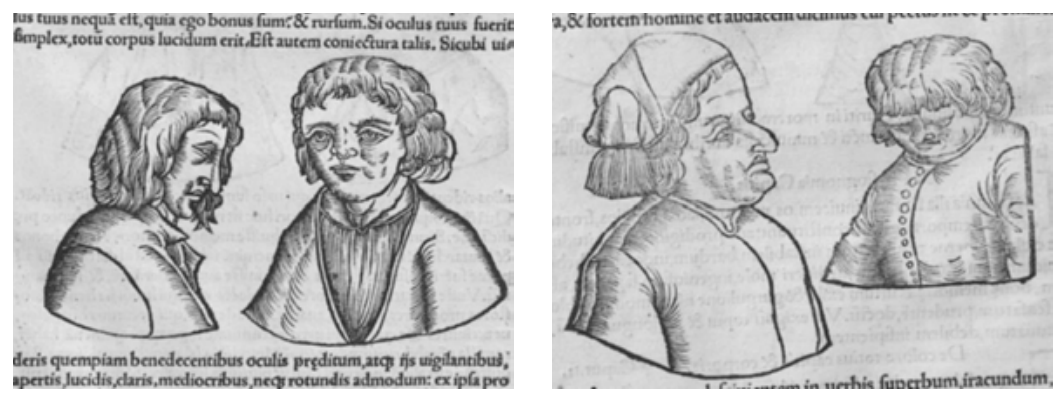

Fig. 5. and Fig. 6. Hans Baldung. 1522. Woodcut. In Johannes de Indagine, Introductiones apotelesmaticae elegantes in Chyromantiam, Physiognomiam, Astrologiam maturalem, Complexiones bominum, Naturas planetarum. Universitätsbibliothek Basel, DA III 21. Used with permission.

With his introduction to physiognomy, Indagine pursued the paramount objective of the face project: to "beholde the whole bodye, with the lyneamentes, and proporcion of the same, whiche is called his Phisiognomie," and by so doing make visible "the inward motion and affections of the mide and heart" (Withers 1575). As with most Renaissance face scholars, Indagine translated accepted truths into astute observations, justifying this with the classical writings of ancient Greece and Rome (Porter 199). Indagine even claimed that one physiognomic aphorism "confirms the Old Proverb, Animi mores corporis temperamentum sequuntur; the disposition of the soul follows the temperament of the body" (1557).

Indagine's "Physiognomiam" sections co-localized both spatially and temporally with Baldung's twenty-two faces in eleven woodcuts. Both textual subject and graphical predicate, adjacent each other on the printed page, communicated information about the same referent object: a facial aliquid [something] that stat pro [stands for] the psyquic aliquo [something] that emanates it-much like how smoke stood for the fire that produced it in the third century BCE Hel-

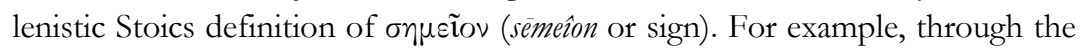
face archive of Introductiones Apotelesmaticae, Indagine composed statements of fact such as "the face of them that be very cleane, is meane in the cheeks, and temples \& somewhat fat. And that face is a true face, louing and not disdaineful. The mery face commeth of a mery heart, and so the contrary" (qtd. in Porter 199). This semantic network intermedially referenced Galen's in De Locis Affectis, that sanguine "heat" makes "a man tall ... soft, fair and fat", as Dürer's 
oil pigments in Vier Apostel, that St. Paul by his physiognomic visage is of sanguine temperament.

As Indagine and Baldung's book about face met with wide acclaim across Europe, the number of woodcut physiognomies increased from eleven woodcuts with twenty-two faces in the Latin folio of 1522, to an unprecedented forty-five faces for the Dutch translation of 1536. Some faces added are identical as regards their physiognomic signs (fig. 7 and fig. 8) to those in Dürer's The Four Apostles (Panofsky 230-231). This may suggest that Baldung and his physiognomic treatise informed Dürer's painting. Or perhaps the master's painting became a face artifact in the face archive of Introductiones, which would be standard curricula in the study of face for nearly two centuries.
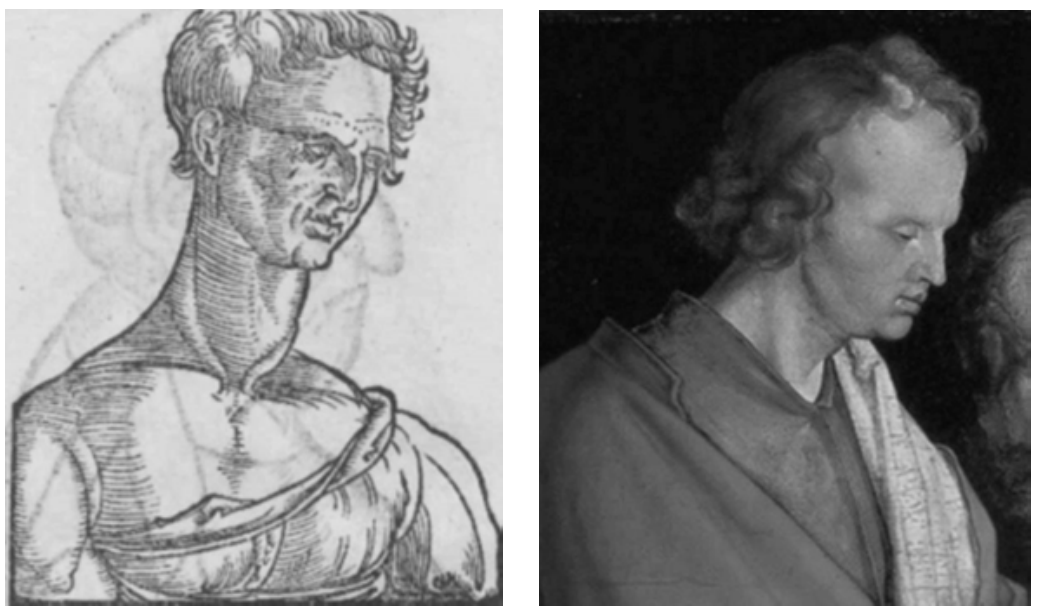

Fig. 7 (left). Joannis Indaginis. 1536, 10 February. Introductiones apotelesmaticae elegantes in chyromantiam, physiognomiam, astrologiam naturalem, complexiones hominum, naturas planetarum (detail). Etchings by Hans Baldung. Printed by Jan Berntsz in Dutch. Utrecht. Universiteitsbibliotheek Utrecht, R fol 456 (Rariora).

Fig. 8 (right). Albrecht Dürer. 1526. Die vier Apostel (detail). Each panel 215×76 cm. Oil on lindenwood. Munich: Alte Pinakothek. Open source.

\subsection{In the Name of the Face}

In addition to a master study of The Four Apostles (1526), Johann Nepomuk Strixner and Ferdinand Polity's Les Oeuvres Lithographiques (1808-1815) also contained Polity's intermedial transposition of Dürer's Self-Portrait (1500) (fig. 9, left). Almost certainly, Strixner proposed the inclusion. While still a student, he had similarly_ if less skillfully_imitated (fig. 10, center) the Great Master's 
visage in Christlich-Mythologische (1808). The positive reviews for Strixner and Polity's Lithographiques were, at least in part, by virtue of the prevailing nostalgia for Dürerian prestige in the German-speaking socio-cultural imaginary. Three centuries later, a printing of this stone lithograph with white highlights is stored in a file drawer of the Göttweig Abbey Graphic Print Collection (GSSG). It is retrievable as a digitized image from the GSSG online. And it is transmitted to users of the Media Art Research Thesaurus via the keyword search /Subject/ $\rightarrow$ /Body and Human/ $\rightarrow$ /facial expression/ (among other possible search paths). As such, on the Thesaurus, Polity's lithographic masterstudy of Dürer's painted self-portrait also semantically links to my privileged case studies: Strixner's Four Apostles as well as Bismarck's Public Face.
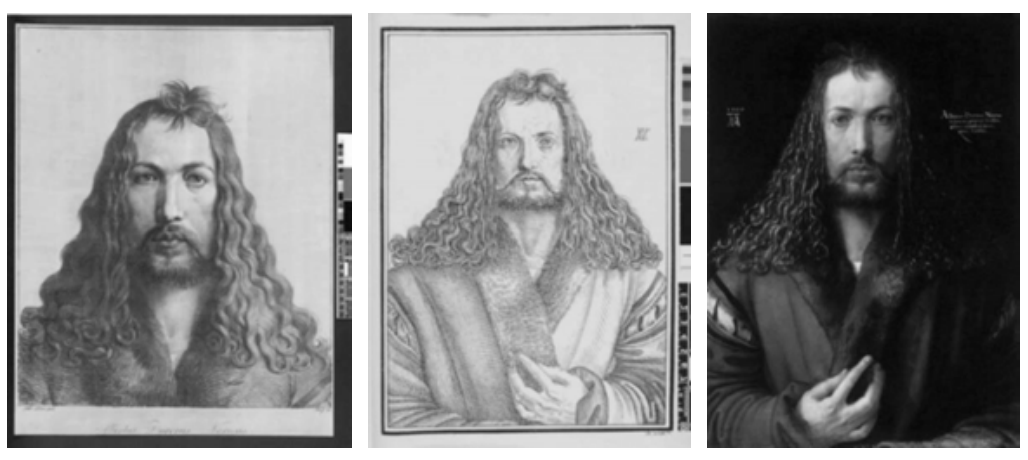

Fig. 9. (left) Ferdinand Polity I. 1810-1816. Albertus Durerus Noricus. Lithograph printed with tint stone and with white highlights. $46 \times 38 \mathrm{~cm}$. In Johann Nepomuk Strixner and Ferdinand Polity. 1810-1816. Les oewres lithographiques. The British Museum. CC BYNC-SA 4.0.

Fig. 10. (center) Johann Nepomuk Strixner. 1808. Albrecbt Dürer. Lithographic print. In Johann Alois Senefelder. 1808. Albrecht Dürer's Christlich-Mythologische Handzeichnungen. London: The British Museum, U.1171. CC BY-NC-SA 4.0.

Fig. 11. (right) Albrecht Dürer. 1500. Self-Portrait. Oil on wood panel. $66.3 \times 49$ cm. Munich: Alte Pinakothek. Public domain.

The face artifaction of Dürer's visage (fig. 11, right), as in Strixner and Polity's Les Oeuvres Lithographiques, even appeared within the physiognomic literary tradition. Ludwig Tieck (1773-1853), for example, Sturm und Drang novelist and Strixner's contemporary, textualized physiognomics in his 1798 Franz Sternbalds Wanderungen: Eine Altdeutsche Geschichte [Franz Sternbalds Hiking: An Old German History]. In the novel, the fictional protagonist, twenty-two year old apprentice Franz, one sunny day turned his physiognomic gaze upon his master Dürer's visage. And Franz bemerkte deutlich, wie die Umrisse von Alberts Gesichte 
denen auffallend glichen, mit denen man oft den Erlöser der Welt zu malen pfegt [Franz could distinctly see how the contours of Albrecht's face were strikingly similar to those with which painters usually depict our Saviour] (qtd. in Tytler 160). Of course, in his self-portrait, Dürer styled his face deliberately like a Christ the Anointed. And Tieck, as a virtual reader narrativizing for the real readers, described the face of Dürer from its facial sign-vehicles to his own moral message-judgments, as in: the terminology "edlen Stirn hervor" [fine forehead]; the qualified adjectival phrase about eyes looking "feurig aber sanft" [piercingly, yet gently]; and the "Umrisse" [contours] of Dürer's face that he is "den Erlöser der Welt' [the Redeemer of the World] (Tytler 160).

Tieck published this textual portrait of an artist as a young man comingof-age while navigating Enlightenment and proto-Romantic themes of affect, individualism, and nature, a decade before Strixner and Polity realized their own Dürer portraits. The emergent artists were ages sixteen and twelve respectively, no doubt aspired to paint like the Master, and most likely read the historical fiction. Thus Franz Sternbalds $W$ anderungen, which popularized face science, motivated the use of Dürer's face in Les Oeuvres Lithographiques. So inspired, Strixner's encyclopedic archive thereby enclosed an idea of Dürer's individual physiology as an ideal of Germany's collective psychology.

But Dürerian face artifaction was made famous just thirty years before Strixner and Polity's Lithographiques, when Swiss Pietist minister Johann Kaspar Lavater (1741-1801) published the Physiognomisches Fragmente zur Beförderung dere Menschenkenntniß und Menschenlibe [Physiognomic Fragments: For the Promotion of Human Understanding and Human Love] (1775-1778). These fourvolumes, themselves a "living" or participatory archive, set off a till then unparalleled-if not unprecedented-Raseri der Physiognomik [physiognomic frenzy] (Lichtenberg). Subscribing readers' submitted portraits, which Lavater intermedially combined into lithographic emblemata, inscribed with his own personalized hand-written "face readings," and included within a future edition (Rauchensteiner and Swoboda 112). These silhouetted profiles became highly regarded in German civil society, as they offered prominent aristocrats a valuable celebrity based on facial recognition or recognizability (Gray xxxii).

For this printed treatise, the first in Germany to be disseminated by subscription, Lavater made the face artifact of "a boldly sketched portrait of Albert Dürer" into a factual statement for "the universality of physiognomical sensation" (Lavater 47). After Dürer, Lavater claimed that the "original language of Nature, written on the face of Man" would one day "certainly become a science definable in mathematical terms" (Lavater qtd. in Gray 5). And today, the website header for the Die Pinakotheken homepage is none other than Dürer's portrait of his own face. 


\subsection{Keywording the Face by Dürer}

Yet, in the over two centuries since Lavater's Physiognomisches Fragmente, the keyword descriptions for Dürer's The Four Apostles are still dominated by a traditional art historical vocabulary. These keywords have lead to a lastingly impact on its face artifacts' metadata coding as an information object, and informed both platform domain indexing and user community retrieval of its many digitized iterations_ — even of Strixner's lithographic study.

At the Google Search level of entry into the information ecosystem of the Internet, a brief survey of results links the lexical units most frequently annotated, coded, or tagged to /Albrecht Dürer The Four Apostles/. Reading between electronic commerce and personal blogs of the first 30,500 hits, an English Wikipedia article connects Hex \#0645AD blue hyperlinks to pages about the artwork's medium / panel painting/ on wood with oil paint; the German /Renaissance/ mastered by Dürer; Bavarian /Elector Maximilian I/ who acquired the painting for /Munich/ in 1627; /Nuremberg/ where Dürer was born and practiced his art; as well as the /Four Temperaments/ of humorist medicine.

And on the German page of Die freie Enzyklopädie article, linked contributions include those about /diptychon/ and the /Lutherbibel/; the particularized four apostles /Johannes/, /Petrus/, /Markus/, and /Paulus/; and their associated /sanguiniker/, /phlegmatikier/, /choleriker/, and /Melancholiker/ humors. WikiArt tags the artwork with the style /Northern Renaissance/, genre /religious painting/, as well as with /Christianity/ and /Saints-and-Apostles/ themes. And a search result for Gardner's Art Through the Ages, an American textbook first published in 1926 , now in its $15^{\text {th }}$ edition, and standard curriculum to many art history 101 courses, links to a digitized edition on Google Books, where the user is directed to a thematic inset /Luther and the Reformation/ (Kleiner 630).

With a reading of a less generalist and more specialized direction, like keywords also code the Die Pinakotheken [Picture Galleries] of the Bavarian State Picture Collection in Munich, where Dürer's original Vier Apostel [Four Apostles] (Inv. Nr. 545) today is displayed for past remembrance or future erudition, and is digitized for online visitors. The website frontend enables no keyword search engine functionality. And the website backend inspects navigational coding rather than keyword metadata. Yet, programmed keywords within a word layout descriptive paragraph, highlight for virtual readers "sich eine schmale Inschriftenleiste, die Bestandteil des Bildes ist" [the narrow inscription strip, which is part of the picture], and the Lutherian "Warnung" [warning] Dürer-with Neudörffer's calligraphy — there addressed to the Nuremberg City Council, that the "weltlichen regenten" [secular regents] ought respect the "word" 
of the Bible and beware of religious "falschen Propheten" [false prophets]. These keywords are, word for word, after Panofsky (233).

Such a challenge to classification is even apparent in the keyword categories of archive catalogues. Since the $13^{\text {th }}$ century, European libraries collected physiognomic treatises, and by the late Middle Ages university curricula educated physiognomic thought. For instance, in the mid- $15^{\text {th }}$ century, statutes of the Albert-Ludwigs-Universität Freiburg [University of Freiburg] in Breisgau, Germany, prescribed the reading of physiognomy (Porter 75). Yet, the early modern librarian might well catalogue "books about face" under such keyworded categories as / astrology/, /Chiromancy and Geomancy/, /Logic and Dialectic/, /Medicine/, /Metaphysique/, /Morale /, /moral treatises on the Virtues and vices/, /Oracles, dreams and hermetic philosophy and magic/, /philosophy/, /Physics and Natural History/, or /Sciences and Arts (Astronomy and Cosmos)/ (Porter 115-116).

By the early $21^{\text {st }}$ century, there have been many faces to what I define as "face studies" as a documented field of inquiry: anthropometry, biometrics, characterology, craniology, humorist medicine, non-verbal communication, pathognomy, phrenology, physiognomy, and the science of facial expression. Even so, there is a continuing absence of a comprehensive presence in disciplinary identity for the diverse researches into knowledge by the visage. In fact, only I here have introduced the keyword phrase / face studies/ with a first usage. Such a lack of coherence causes both an intradisciplinary problem, whereby face scholars have difficulty integrating their idea(s) of face within the rhizomatic network of information communities, as well as an intendisciplinary problem, wherein face concepts and methods become difficult to exchange across academic arenas.

Indeed, since classical antiquity, individual "authors of face" invent largely ex novo their own idiosyncratic face concept and method, in a perpetual "reinvention of the wheel" - or "reinvention of how to best describe the mouth corners and eyebrows, and determine their meaning." Altogether, the presence of an absence in shared keywords about face both within and across disciplines, significantly constrains artistic, scientific, and technologic creatives in making a robust and sustainable knowledge on the visible human surface one of the most primordial resources for meaning-making within Homo significans (Latin for signifying man, a contemporary play on the binomial nomenclature Homo sapiens, or wise man, for our human species). Thus, a meta-analysis of the many faces of face studies is called for. With research tools for digital humanities such as the Media Art Research Thesaurus, the archival resources that are Dürer's original painting (1526) and Strixner's copied lithograph (1808-1815) of The Four Apostles can both be newly diagrammatized and re-narrativized among the histories of the face. 


\section{A Tale of Two Archivings: The Archive of Digital Art}

\subsection{The Face Story by Julius von Bismarck}

Using the Media Art Research Thesaurus, I perform the keyword search that is for my Thesis the privileged case study, from the category /Subject/ $\rightarrow$ to subcategory /Body and Human/ $\rightarrow$ and its sub-subcategory / facial expression/. This keyword phrase / facial expression/ semantically links Strixner's The Four Apostles (1808-1815), from the Graphische Sammlung Stift Göttweig (GSSG), as well as German principal artist Julius von Bismarck (1983-), digital designer Benjamin Maus, and Austrian filmmaker Richard Wilhelmer's Public Face (2008, 2010, and 2014), from the Archive of Digital Art (ADA). As keyword tagged by specialist metadata coders and socially tagged by ADA community members, respectively, both The Four Apostles and Public Face correspond in the keyword /Subject/ $\rightarrow$ /Body and Human/ $\rightarrow$ /facial expression/. But once retrieved from web storage and transmitted to user interface, and graphically displayed adjacent each other within a justified and responsive image grid, the lithographic print and digital artwork also conflict between /Subject/ $\rightarrow$ /Body and Human/ $\rightarrow$ /Physiognomy/ and /Technology/ $\rightarrow$ /Interface $/ \rightarrow$ /biometrics/. This confliction points to the primary "broken circle" of media entanglement between these face artifacts from which my semantic probing departs.

In contrast to the early $19^{\text {th }}$ century Johann Nepomuk Strixner, whose Four Apostles is housed within the past archivization at Göttweig Abbey, the early $21^{\text {st }}$ century Julius von Bismarck's Public Face is housed on the present archiving that is the Archive of Digital Art. Strixner is a "dead artist," the primary sources or ego documents he left behind radically open to methodological empathy and evidentiary interpretation. Bismarck, however, is a "living artist"- some thirty-five years of age at the time of this writing. As such, that his portrait of face is also an artifaction for face can be stated with enough certainty as to be considered a fact. Indeed, Bismarck "says so" himself, explicitly self-witnessing and personally testifying within his methodological exposé to having used the science and technology of face studies as both subject-image and medium-vehicle for his one-and-a-half ton, eight-meter circumference, neon and steel, Automated Facial Expression Analysis-based "smiley."

As he self-described on the Archive of Digital Art, Bismarck—a "wannabe physicist" (Hinrichsen)—uses his digital art-based research to conduct experiments with the physics and forces of the material universe. Much as with the early modern physiognomist, who inferred from facial signs to humorist temperament, thereby deducing the mixtures of matter in a man, Bismarck 
somaticizes from bodily symptoms to natural forces such as gravity, light, and pressure (Bismarck). In the German artistic tradition called for by Dürer to be based on the right foundations of science and mathematics, Bismarck explains his intent as an artist as being like "that of a scientist," although he "wouldn't have the patience" for the discipline's validity testing, preferring to more loosely hypothesize facts that, while probable, may be undoubtedly false. By augmenting physical spaces with "an other-dimension" via ocularcentric technologies such as cameras, lenses, and mirrors, Bismarck "wants to find out what there is out in the world and how I can contribute to our understanding of it" (Hinrichsen).

Bismarck's ideas about face are contingent upon the "facial atmosphere" or "face ethos" at this the beginning of our Algorithmic Age, when Automated Facial Expression Analysis largely conjures in the German cultural imaginary the foreboding vision of a grand technocratic "eye in the sky." These electronic machines are mythologized by the mass and news media as omniscient observers with omnipresent visual access. As goes this face story, AFEAframeworks gaze into the digital cave of human-computer interaction and computer-mediated communication, social networks and selfie culture, spectacle and surveillance societies. A computer state, through an Orwellian phantasm of institutionalized control, monitoring, and watchfulness, is conceptualized as the very embodiment of the utopian transparency latent in the panopticon, and dystopian technocracy of panopticonism. This global change to the media climate, so feared by faciaphobic and fetishized by faciaphilic, stimulates technosocial accelerationism in psychometric taxonomies-or, as in the late $18^{\text {th }}$ century physicist Lichtenberg satirized with physiognomist Lavater, an ever increasing "physiognomic frenzy."

At least, that is the myth. And while this is a story told across $21^{\text {st }}$ century information landscape, digital artists narrativize today's 'face of the age'-its paradigmatic explanations and pedagogical norms - with critical dataveillance and tactical mediation. Working at the intersection of art, science, and technology, an increasing number of digital artists, including Julius von Bismarck, base their face (art)work on Automated Facial Expression Analysis, and its functionality achieved via the face artifacts stored, transmitted, and retrieved from face archives. Such digital artworks—on the Archive of Digital Art, and semantically linked into the Media Art Research Thesaurus-are keywordcoded by the digital artists themselves as a socio-culturally recognizable kind of action that extends across diverse genrefications.

For example, with Selfiecity (2014) Lev Manovich's Software Studies Initiative web scrape from Instagram self-portrait "poses and expressions" a psychographic "mood analysis," media visualizing "lots of smiling faces" in Bangkok (0.68) and São Paulo (0.64), and so greater "Happiness," and in Moscow the 
least "on the smile score scale" (0.53) of five cities subjectivated, and so with the most "Anger" (Manovich, Selfiecity). Yet Manovich confesses "enough difficulty collecting selfies," that he "doesn't know" how "state-of-the-art face analysis software" uses "scientific research in emotion" (Manovich, "Skype Interview").

With Face-to-Facebook (2011), third in The Hacking Monopolism Trilogy, Paolo Cirio and Alessandro Ludovico sort one million Facebook profile pictures by facial gestures popularly used "to define a person at a distance" into / climber/, /easy going/, / funny/, /mild/, /sly/, and / smug/ groups on a dating website "Lovely-Faces.com." Cirio and Ludovico "selected forty samples for each category in an 'arbitrary' way based on how they looked," so as to "customize" a neural network from the MatLab Library (Cirio and Ludovico), which they "randomly bought from one of the weird Italian coders that happened to have one of the few automated face recognition algorithms" available at that time (Cirio).

And with Mood Meter (2012), Javier Hernandez and Ehsan Hoque install a computer vision system to count smiles on The Massachusetts Institute of Technology campus, "a time-changing location-based emotional footprint," or "live portrait," of interactors faces' overlaid with a "green happy smile" if greater than 50\% intensity, and yellow "smiley blob" if less (301). Hernandez and Hoque, who self-identify not as artists but as scientists, commit method to reviewed journal, though not spatiotemporally contiguous with the interactive graphs and map displays of their project website, or the work itself.

The social tagging of such information assemblages as / facial recognition/ and /biometrics/ is little clarified and much confused by Archive of Digital Art community member artists and scholars as they naïvely keyword their own digital artworks. In fact, / facial recognition/ preludes process, and /biometrics/ postludes production in the /Automated Facial Expression Analysis (AFEA)/ software frameworks upon which they base their /Database Art/, /Digital Activism/, /Installation (interactive or performance)/, /Net Art/, and /Robotics/.

\subsection{See Your Face in This Smiley as Through the Digital}

In order to make factual statements about what facial expressions are, can, or may be in the Algorithmic Age, face collectors pro tempore Bismarck, Maus, and Wilhelmer through Public Face intermedially combine fluorescent neon tubes and steel buttressing sculpture with an Automated Facial Expression Analysis (AFEA) hard/software interface. These differentiable media, ontologically between some more conventional mediations and most contemporary technolo- 
gies, "wear down" and "constitute newly" into a "plurimedial constellation" in which each is "simultaneously and oscillatingly present" (Hansen-Löve 325). Within Public Face, the AFEA-system constitutes a singular immanence in both how media expresses "the changing, average emotions of city inhabitants" through an object, as well as what image content this object makes visible "to everyone in a public space" (Bismarck). In other words, Automated Facial Expression Analysis is how the artwork is made, as well as what the artwork is about.

Spectating passersby see Bismarck's Public Face as a colossal "smiley," that weighs one-and-a-half tons, and has an eight-meter circumference. As with most digital artworks composed among technologies that disperse functionality and rapidly obsolesce, Public Face is characterized by its ephemerality, interactivity, processuality, and both site and context specificity (Grau 4). To exhibit Public Face in each of its several iterations (2008, 2010, 2014), Bismarck, Maus, and Wilhelmer had to install in situ surveillance cameras, computer servers, and software frameworks (fig. 12 and fig. 13.).
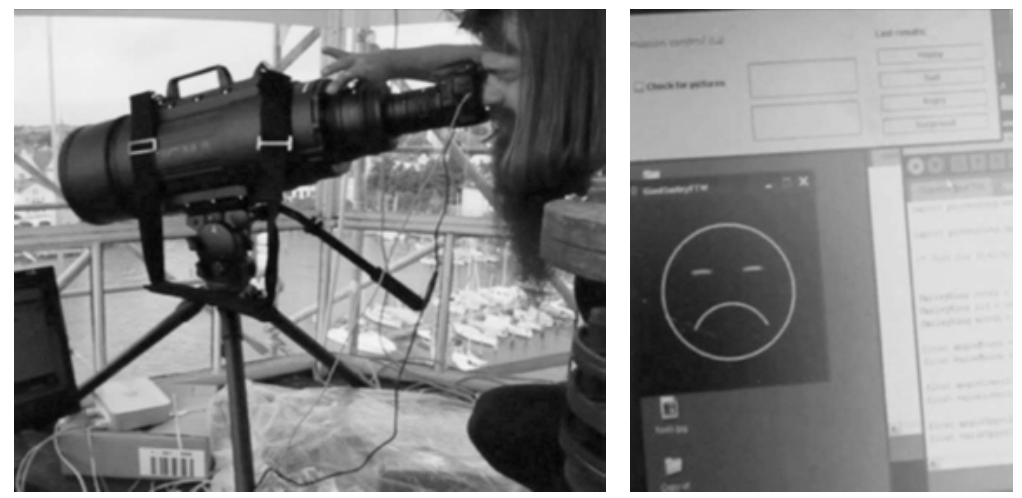

Fig. 12 and Fig. 13. Arnie Fehmel and Raasso Hilber. "Public Face II - MakingOf." Vimeo, Studio of Julius Von Bismarck, 7 July 2010, vimeo.com/26688450. Used with kind permission of the artists.

The face artifact has been displayed at Berlin's 7th District TemplehofSchöneberg in 2008; in 2010 as part of the PROVINZ exhibition at Malzfabrik Gallery. Space light-tower on the Island of Lindau at the eastern end of Bodensee [Lake Constance]; in 2014 on top of the former Phillips Administration Building (built 1962-1964) high rise at Triester Straße 64 in Vienna. These places make it possible for the Automated Facial Expression Analysis system to detect faces up to considerable range and down to $8 \times 8$ pixels, as well as extract data from the census features of numerous interactants. But there the

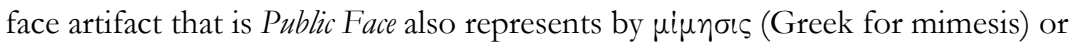


imitatio the very facial plane and position in the human phenotype itself with its actual bilateral symmetry. This artwork of the digital achieves such representativeness both literally and figuratively. The emoticon "face" in fluorescent tubes and steel sculpture is located spatially forward of an architectural structure, as if a human face ventrally in front on the coronal plane. And its "eyes in the sky" surveillance cameras are related hierarchically above those individuals passing-by, as like the ocular organs superiorly on top a vertical position. That Bismarck, Maus, and Wilhelmer's Public Face preserves some face schema and image in its actuality, stimulates in the spectator a mostly non-conscious face affect, as well as pre-linguistic level of emergent meaning that is based on the recurrent patterns of their own "daily" sensorimotor interactions. That is, they perceive this artifact as if or as like our own face.

But passersby's interaction with Public Face is also a carto-ontogenesis of selfhood. The first instance of self-cognition (before there can be self recognition) in a catoptric prosthesis, as in gazing at one's own double image reflected in a mirror, marks a symbolic encounter that involves the very mirroring between a first-person subjective "I" and a second-person objective "you." Similarly, expressing interactors as well as installation expression-audience and artwork—gaze back through a biofeedback loop into each others' faces, as the media that is muscular mechanisms and skin movements is representationally reflected in the media that is buttressing sculpture and fluorescent tubes. Metaphorically, at least, if not scientifically, Public Face is like a "window to the soul."

In the traditional lithographic printing of the early $19^{\text {th }}$ century, Strixner's Four Apostles immersed spectators within an illusory $360^{\circ}$ image space, wherein each apostolic figure referenced one of four humorist temperaments. And the face of a melancholic Saint Paul gazed back at the viewer across the fourth wall of the lithographic print, so as to encompass them in the center of this "physiognomy in the round." In the avant-garde digital mediations of the early $21^{\text {st }}$ century, Bismarck's Public Face immerses passersby within a $360^{\circ}$ archival space, wherein "everyone feels a potential victim of emotional control" (Mittendorfer) because each of their facial expressions are keyword coded with one of four basic emotions.

To evidence with immediacy such a concept about face, principal digital artist Julius von Bismarck and his collaborators mounted 200-500mm f/2.8 APO EX DG Ultra-Telephoto zoom lenses (fig. 12), produced by the Sigma Corporation of America, onto digital single-lens reflex cameras (DLSR). These, in turn, are connected to a Sophisticated High-speed Object Recognition Engine (SHORETM) Framework, created at the Fraunhofer Institute for Integrated Circuits (IIS) in Germany (fig. 13). From real-time facial event input, to aggregate emotion lexicon output, Bismarck's Public Face plasticizes visible hu- 
man surfaces into face artifactions that compute the movement commands for the "smiley" installation. As Public Face's "mouth," a semi-circular curve of neon and steel, and separate half-circle upper as well as lower "eyelids," rotate on their vertical axis, the face artifact displays expressions related to four Basic Emotions categories: $>_{-}<$as wut [anger]; :) as freude [happiness], :(as kummer [sadness], and 0_0 as wundern [surprise]. These so-called emoticons, the word itself a portmanteau of emotion+icon, trace across intermedial genealogies from salient averbal gestalts and anthropomorphic pictograms; through unfixed typographic convention and typographical art; to the yellow smiley (;) designed by graphic artist Harvey Ball in 1963 for State Mutual Life Assurance; and the ASCII :-) character sequence first proposed by computer scientist Scott Fahlman, on a 1982 "joke markers" thread of the Carnegie Mellon online bulletin board (bboard). And today, emoticon faces are digitally archived within almost every communicational device. So, as Bismarck stated "[p]eople see the smiley face, and find it funny." Then, they discover that Public Face "can read emotions, and that's funny as well. But in this instance, the laughter sticks in the throat because they consider: what if this software got into the wrong hands?" (Kaczor).

Shinning a light both neon and Diogenean, Public Face's media specificities — neon and steel, cameras and AFEA-intermedially reference the emoticon, emoticon-based, and emoticon-like signs. Beyond the formalized grammar and syntax of written oral language, vertical ASCII or Unicode :-) or horizontal emoji $(;)$ correspond to facial expression, its co-speech gestures, and gross body language as a kind of electronic paralanguage. The "semiotic machine" (Nadin) of the computer, whether laptop, touchpad, or smartphone, and their standardized graphical user interface (GUI), predominantly advances verbal signs over the averbal signs of face-to-face (F2F) communication. Consequently, computer-mediated communication (CMC), short messaging service (SMS), and social network service (SNS) all enclose a "semiotic vacuum" (Bülow 306) devoid of behavioral codes. The media etiquette—or "netiquette" (Reid 166)_of the emoticon may not yet be keyword searchable on Google. And Oxford Dictionaries only first recognized an emoji as word of the year in 2015 (the "Face with Tears of Joy," or Unicode Character U+1F602). But (:) or $: 0$ are today as much emotions vocabulary as are / happy/ or /sad/.

\subsection{Digital Face Archivization}

But beneath its aesthetic surface, Public Face achieves its actual functionality - much in the sense of Janus, the two-faced Roman god of transition who cast his two-faced gaze both towards future and past-by locating visually 
within comparative opposition two "lists" of faces: the "living" facial actions of passersby, in real time made into plastic artifacts when captured with digital cameras; and the "dead" face artifacts from photograph databases, fed newly into work process through the memory retrieval (Belting 198-199).

The essential procedure of the Sophisticated High-speed Object Recognition Engine (SHORETM) Framework (fig. 14) used by Bismarck, Maus, and Wilhelmer in Public Face, as with most Automated Facial Expression Analysis (AFEA), is to 1) detect 'real' views of human faces in photographic artifacts; from these 2) extract face data by determining facial points or landmarks such as the eye, mouth, and nose corners; and 3) classify these facial expressions of emotion under metadata keyword categorizations based on their visual comparison to prototypical face models housed in digital archives. In order to expound this facial "mask" applied by Public Face onto spectating passersby, it is critical to examine how socio-political languages—such as that for Basic Emotions from today's face studies-ineludibly become stored within SHORETM into an a priori knowledge system from which AFEA is performed (Schuller 232-233).

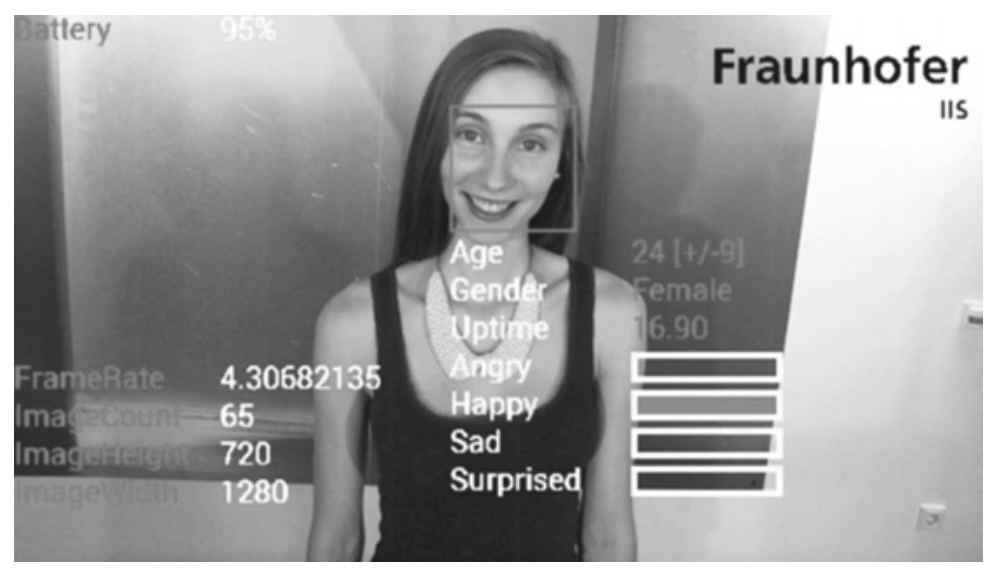

Fig. 14. Fraunhofer Institute for Integrated Circuits. SHORETM. Photograph (C Fraunhofer IIS/Kurt Fuchs. Used with permission.

Jens-Uwe Garbas and the Institute for Integrated Circuits (IIS), innovated SHORE $^{\text {TM }}$ at the Fraunhofer-Gesellschaft zur Förderung der angewandten Forschung $e$. $V$. [Fraunhofer Society for the Advancement of Applied Research] in Erlangen, Germany, with the support of a European Commission grant (\#FP62005-IST-5) for Information Society Technologies (IST). SHORETM Framework is algorithmically trained using face archives. These are also termed "electronic mugbooks," after the English slang mug [face], and the late nineteenth "signaletic notice" proceduralized by Parisian policeman Alphonse Bertillon. 
And just as in the late $19^{\text {th }}$ century, when face collectors intermedially combined photograph cabinets with photographic cameras within the archival space, in the early $21^{\text {st }}$ century the archival technology is as pivotal as the archived media when making facts about face (Sekula 16). With Bertillon's portrait-parlé, a "speaking likeness' or verbal portrait" (Sekula 55) turned "real lives into writing" (Foucault, Discipline and Punish 185). With this face concept for "l'bomme moyen" ["the average man"], the aim "had been not only to go once more through the task of Albert [sic] Dürer, but to execute it also on an extended scale" (Knox v) through a social and moral statistics. And some five centuries after Dürer, and his The Four Apostles, face archives continue to store, transmit, and retrieve indexical artifactions that are manually annotated with physiological landmarks that correspond specifically to psychological lexicons.

But the archival technology of the digital technosphere also significantly contrasts with the archival catalogue of the file cabinet as used in "Bertillonage" for identifying criminals through anthropometric measurements. In the Automated Facial Expression Analysis frameworks of today, digital and digitized face artifacts - sometimes more than 10,000 in number-present multimodally as visual graphic annotated with verbal texts to a face algorithm as its probe sets and evaluation protocol. By so training the algorithm, an operationalized face model can be computed for "universal" application to "similar faces in yet unseen images" (Ruf 238). At first sight, or even on $\mathrm{n}^{\text {th }}$ look, this archival ghost in the machine of Bismarck's Public Face may not be visible to the artwork's spectating interactors. And to the naked eye, even by the end of exhibition days, these training photographs per se are not materially present. The Fraunhofer team trained SHORETM's face detection and extraction functionalities using the CMU+MIT dataset, BioID, and Facial Recognition Technology (FERET) Database, which house face artifacts photographed from mass media, corporate culture, and defense department, respectively. And to train facial classification, the Japanese Female Facial Expression (JAFFE) database supplied faces staged in a university laboratory. All of these face artifacts intermedially combine into Public Face as the very "sources" that determine the Automated Facial Expression Analysis systemreferenz [system reference] by which its newly formed media-specificity comes into being (Rajewsky 53).

Used to train SHORE ${ }^{\text {TM's }}$ facial detection, for the CMU+MIT Dataset the face collectors digitized from video signal and scanned photo 130 images with 507 total facial expressors. These face artifacts include found objects such as great masterpieces of visual art, as well as celebrity musician "head shots," stock photography of infants and adolescents, news media stills, face gestaults in academy lecture, and television cast press releases.

Within the CMU+MIT Dataset, each graphical face is notated with textual code, one line that provides a ground truth facial location as $\mathrm{x}$ and $\mathrm{y}$ coordi- 
nates for left-eye, right-eye, nose, left-corner mouth, center-mouth, and rightcorner mouth (Wang). These verbal linguistic phonemes (a, b, c, 1, 2, 3, etc.) compose digital signs with an arbitrarily conventional symbol reference to facial formations, while averbal morphologic corpemes constitute analogue signs with a directly qualitative iconic reference to a facial formings. Correspondingly, this digitizing artifaction transposes literally the physiognomic textualism-largely consistent across face studies in the five centuries since the advent of the printing press — wherein meaning about the face is interpreted not from the sign-vehicles of the face itself, but from the signs for the face as marked in a text.

After learning how to detect human faces in photographic artifacts, SHORETM's algorithmical functionality for the extraction of face data is trained by the Fraunhofer team on the BioID digital face archive. Their opensource face archive stores 1521 digital photographs with 23 different expressors. With photographs taken at corporate headquarters with desktop computer mounted web-cameras, "real world" conditions lead to variations in illumination, background, and scale (fig. 15 and fig. 16). For high interoperability across platforms, each image is formatted as a text in American Standard Code for Information Exchange (ASCII) binary.
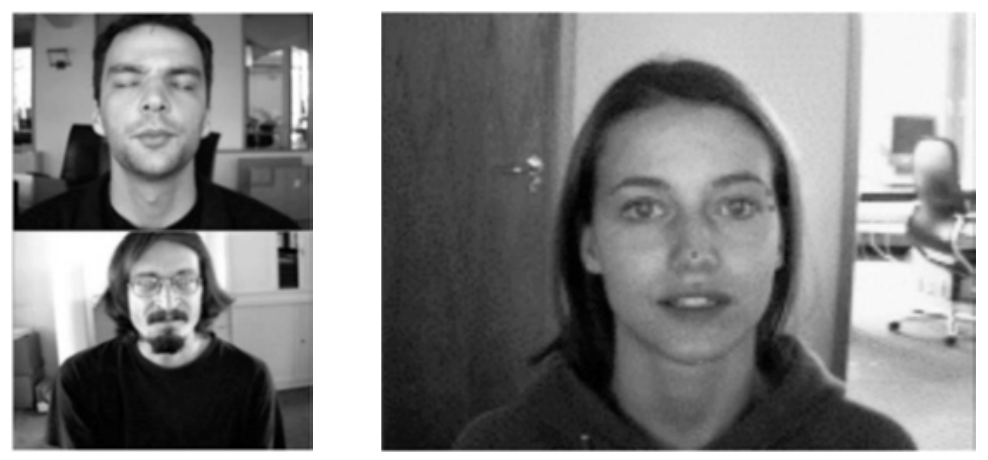

Fig. 15. and Fig. 16. BioID GmbH. "BioID Face Database-FaceDB." BioID Face Recognition. Used with permission.

The Facial Recognition Technology (FERET) program, operated from August 1993 to July 1997, is funded by the US Department of Defense's CounterDrug Technology Development Program Office (CDTDPO) run through the Defense Advanced Research Projects Agency (DARPA). This face archive aims to "support government monitored testing and evaluation" in automated face recognition with applications towards "security, intelligence, and law enforcement” (Philips et al.). The FERET “image corpus” archives 14,126 total faces, in evidentia or series of 1564 image sets, which include 1199 individuals. The 
face artifacts employ the very same cognitive style that is relatively stable in the rhetorical artifactions used throughout face studies, since Indagine's "Physiognomiam" spatio-temporally co-localized with Baldung's woodcuts.

For training face analysis, SHORE ${ }^{\mathrm{TM}}$ 's "happiness analyzer" is "benchmarked at a recognition rate is 95.3\%" (Ruf 244) on the Japanese Female Facial Expression (JAFFE) database. Ten Japanese female models have posed 213 facial expressions. Frontality and visibility, as picture plane isolates face from body, and forward-facing models tie away hair "to expose all expressive zones of the face" (Lyons et al.). Alphanumeric code spatially co-located adjacent, as 60 Japanese undergraduate subjects code nominal semantic categories of /anger/, /disgust/, /fear/, /happiness/, /sadness/, and /surprise/ for image metadata.

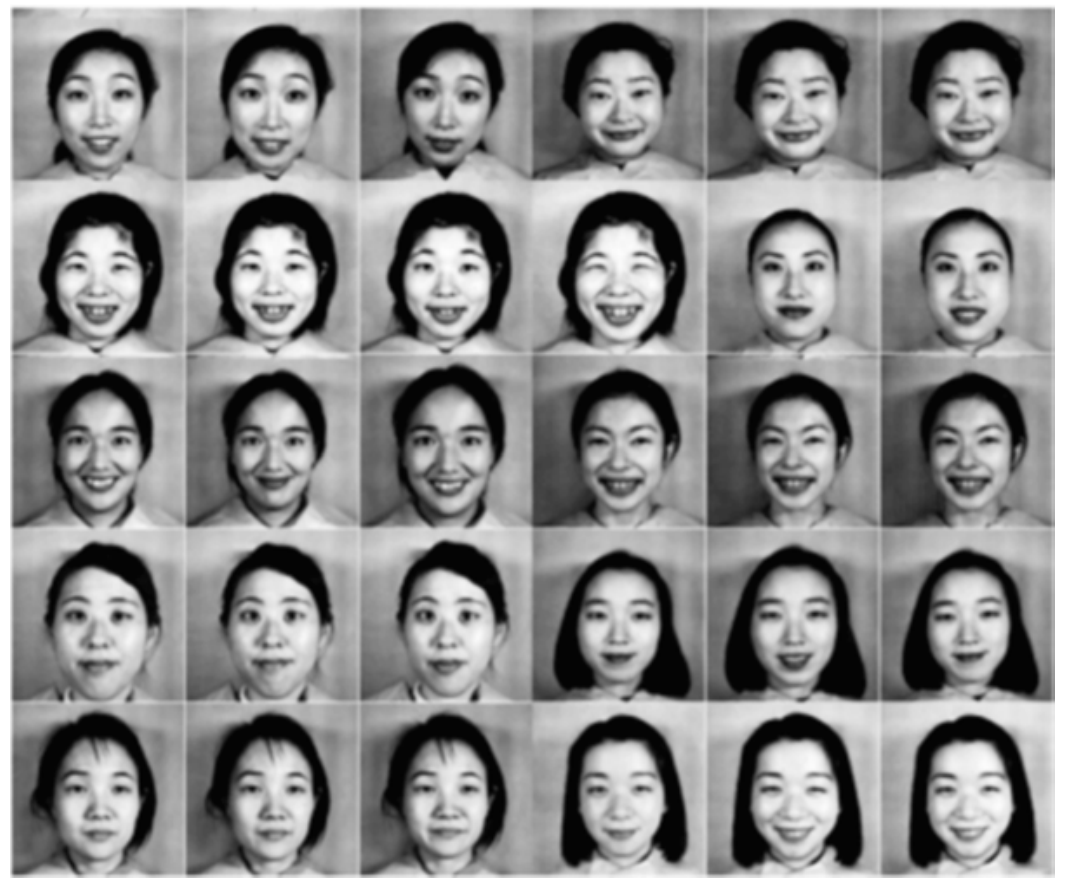

Fig. 17. Thirty-one face images annotated with emotion category "Happy" from the JAFFE database (KA.HA3.31 not shown), Lyons 1998. Used with permission.

Conflicting, however, with physiognomic texts, which afforded for a face competency that was relatively proportionate to the reader's literacy in the socio-political codes of face meaning, most Automated Facial Expression Analysis systems are "black box" frameworks. Introduced by technological industry and scientific experts, these proprietary closed source algorithms veil the ma- 
jority of program functionality input from available data output. To configure such a framework so that resulting content from detection and analysis of a photographic image can be annotated with face marker points and emotion class attributes, a "user or client" — such as the digital artists Bismarck, Maus, and Wilhelmer-needs only to "know how to configure it and integrate it into a larger scale application" (Ruf 237-238). As such, Public Face itself becomes an in-visible and un-knowable face archive, a "shadow archive" (Sekula), hidden from the immediate observation of the artists as well as by spectators. But intermedially concealed on the verso of the images in JAFFE, these FACS photographs rhizomatically fuse in the deep subface of the media combined into Public Face.

\subsection{Doing the Facial Foursome}

Johann Nepomuk Strixner's The Four Apostles lithographically represented from the age and complexion of facial formations, to the four humorist temperaments/choleric/, /melancholic/, /phlegmatic/, and /sanguine/. Whereas, Julius von Bismarck, Benjamin Maus, and Richard Wilhelmer's Public Face digitally represents from the mouth-corners and eyebrows of facial formings, to the prototypical expressions of the emotions /anger/, /happiness/, /sadness/, and /surprise/ (fig. 18 and fig. 19). But in each tetrad-saintly face and emoji smiley is represented how, as Hippocrates early described in his De natura hominis [The Nature of Man], the "constituents of a man are, according to both convention [i.e., nurture] and nature, always alike and the same" (Jones II.31). In other words, a form of the flesh must correspond to a function of the mind, and will do so across all ethnicities, genders, individuals, and peoples-whether the mental phenomena are typologized by keywords humorist or biometric. Such a "universality hypothesis," in the $19^{\text {th }}$ century Charles Darwin made into an argument in The Expression of the Emotion in Man and Animals, and in the $20^{\text {th }}$ century Paul Ekman made into an algorithm with the Facial Action Coding System (or FACS). Today, Automated Facial Expression Analysis (AFEA) frameworks — such as that intermedially combined by Bismarck in Public Face (2008, 2010, and 2014)-are functionally contingent upon this "Universality Theory." 

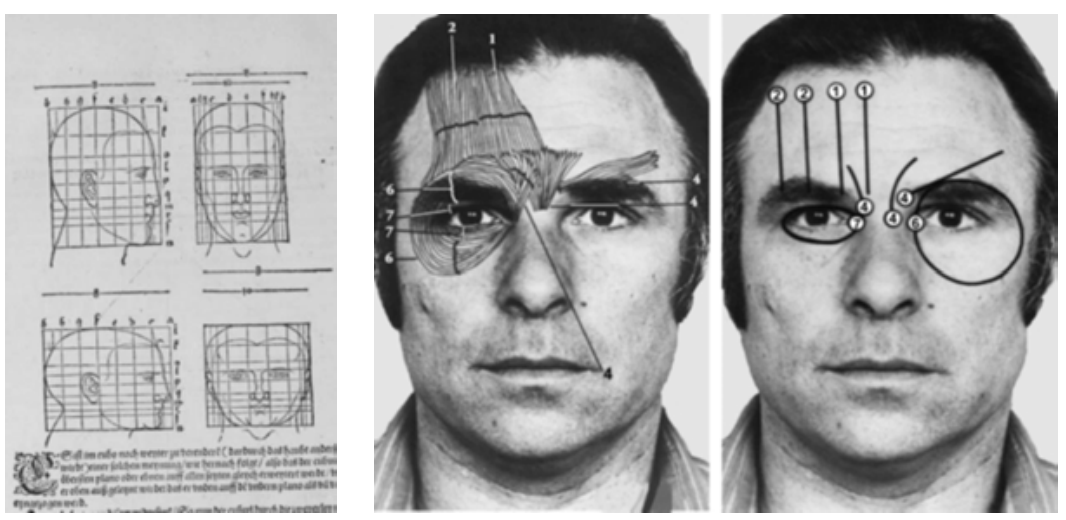

Fig. 18. (left): Albrecht Dürer. Hierinn sind begriffen vier Bucher von menschlicher Proportion durch Albrechten Durer von Nurerberg [sic.] erfunden und beschuben zu nutz, allen denen so zu diser kunst lieb tragen [Four Books on Human Proportion]. 1528. Hieronymus Andreae Formschneider, 1528. Glasgow School of Art. CC BY-NC-SA 2.5 SCOTLAND.

Fig. 19. (right): Paul Ekman, Wallace V. Friesen, and Joseph C. Hager. FACS Manual on CD-ROM. Network Information Research Corporation, 2002, 15.

The procedural reason for needing universality is simple: solely on the basis of a stable binary (or one-to-one) correspondence between a physiological behavior and a psychological phenomena (Boys-Stones 40), can the theoretical belief in the facial expressions of emotion as being discrete biological prototypes be crafted into a practical approach for informating self and instrumenting life. This "law about face," that its expressions are universal, is beneficial to affective computing, or computing that "relates to, arises from, or influences the emotions" (Picard 1), because Automated Facial Expression Analysis becomes quantifiably operationalizable through syllogistic logic.

From the so-called Universal Emotion View or Basic Emotions Theory (BET), emotions are seen to be phylogenetically stable and functionally discrete neuro-humor dispositions that activate with the appraisal of stimuli, and trigger patterns of response such as the anatomical mechanics that produce facial behaviors. While a diversity of thinkers in the twentieth and twenty-first centuries have determined between two and twenty such Basic Emotions, in the $19^{\text {th }}$ century naturalist pioneer Charles Darwin first identified universally recognizable facial expressions of emotion across cultures and, from these, investigated whether there are prototypical emotions specified by biology. In The Expression of the Emotions in Man and Animals, translated into German the very year of its first publication in 1872, Darwin hypothesized that every "true or inherited expression seems to have had some natural and independent origin," and "once existed in a much lower and animal-like condition" (130). 
This treatise began (page-one, line-one) by reviewing the state of the art in physiognomic thought. Darwin critiqued that "many works have been written on expression," but these "older treatises"—-such as those by Indagine, Erasmus, Dürer, and Lavater — had "been of little or no service" (Darwin 13). In contrast, Darwin based his face concept not on surface forms in skin appearance but subface formings in muscular anatomy. He observed facial signs sémeia [signs] not as humorist symptomata [symptoms] but ethogrammatical sima [signals]. Though just another marked sign type, the signa— unlike the symptom- had a sign-function directed upon triggering receiver action. With Expression, Darwin codified for "the several passions in some of the commoner animals" what today's animal communication scientists call ethograms. Darwin detailed these behavioral dossiers_ or "palettes of the face" — to be of "paramount importance" because they afforded "the safest basis for generalization on the causes, or origin, of the various movements of Expression" (28). Open to all demonstratio ad oculos by which to make facial expressions apparent as emotions signals, Darwin hoped "to derive much aid from the great masters in painting and sculpture, who are such close observers," and looked to "engravings of many well-known works" to retrieve information about face (25). But as he probed both historical found objects and contemporary made artifacts, the evolutionist extraordinaire determined photography "made by the most instantaneous process the best means for observation, as allowing more deliberation" (155). With some, Darwin even annotated psycho-emotional keyword classifications, as with his own archived copy of Schultz's The Actor Portraying Various Character Types from 1867: /(avaricious) miser/, /cocky fellow dandy/, /good nature/, /happy simpleton/, /hypocrite/, /lazy man/, /learned man scholar/, /morose grumbler/, / silly (weak head)/. That these face artifacts might evoke an immediate witness to his ideas about face, Darwin cropped and montaged them into the constellation or series of evidence.

For a hundred years, Darwin's Expression lay fallow under the abrupt climate change of the Behaviorist zeitgeist (Ekman and Rosenberg 11), but by the mid-20 ${ }^{\text {th }}$ century, Darwin's dangerous idea (well, one of them) - that facial expressions of emotion are phenotypic prototypes, biologically specified and culturally universal, with variability largely determined by volitional display rules and social scripts - again proved scientifically fertile and ripe for harvest. However, a century after Charles Darwin, differing scholars both devised and discarded many a system for coding the facial expressions of emotion. In order to design a facial coding system that measured and classified what the face can do, rather than what it should do (Ekman, Friesen and Hager 103, 110; Ekman and Rosenberg 14), a digital archive of face artifacts was needed.

Psychologists Paul Ekman and Wallace Friesen at the University of California San Francisco would develop the first-ever digital face archive. They 
called it The Visual Information Display and Retrieval System (or VID-R). Ekman himself had long cultivated a proficiency in photography, and even attended the University of Chicago with photographic theorist Susan Sontag. He discovered the science behind the method using still photograph and motion picture documentation of peoples such as the Fore of Papua New Guinea, whom had not yet had visual contact with mass media, and so could not have learned or simulated the facial expressions of Western culture. Ekman and Friesen's pioneering interface between electronic computer and video equipment "came about as a by-product" of the need to store, transmit, and retrieve this "overwhelming amount of film" (Ekman and Friesen 240). At the time, in the late 1960s, Ekman and Friesen within their archival space intermedially combined Sony PV 120 U video tape recorders, an MVR video disc recorder, high-resolution television monitors, ASR 33 teletype keyboard printer with paper tape punch and reader, and the Digital Equipment Corporation's PDP-S computer. This technological apparatus and its media specificities- though obsolescent when compared with the Fraunhofer's SHORETM framework - then afforded for film-to-video transfer, real time and slow motion viewing, video fields search and frame retrieval, and "dubbing" new visual events without information loss in tape originals, as well as the writing of data matrixes by which to keyword-code facial signs (Ekman and Friesen 242-243).

Out from this digital archive for ethnographic artifacts, and over the subsequent ten years, Ekman, Friesen, and their Emotions Lab at the University of California San Francisco, developed the Facial Action Coding System by modeling their own visible skin movements in a mirror, self-firing ever more discrete muscular contractions, and transcribing these facial expressions into photo- and videographic media. The face archive that would eventually become the FACS Manual, housing face artifacts that include photographic GIF, video MOV, and textual PDF-formatted files, fielded into interpretation appearance changes in the folds, lines, and wrinkles of the Upper and Lower Face; how to code both spatial analysis as well as specific measurement of these signs and their Intensity into visual classes or Action Units; and transcribe the combination of these AUs into facial expressions as linear notation of alphanumeric code (e.g. $6 c+12$ d, or the Duchenne Smile). Applying FACS, expert raters measure the visible signs of the human surface, describe its muscular contraction mechanisms and skin appearance movements, and code these into visual classes termed Action Units.

Julius von Bismarck's Public Face specifically references the medium qua system of FACS in the movement commands of its fluorescent neon tubes and steel buttressing sculpture into emoticon representations of the keyword categories /anger/, /happiness/, /sadness/, and /surprise/. These FACS-supported Basic Emotions, the SHORE ${ }^{\mathrm{TM}}$ algorithm learned to detect, extract, 
and classify through the Japanese Female Facial Expression (JAFFE) database. Rhizomatically fused into the deep histories of the intermedia combined within Public Face, all of the above face archives and face artifacts signal passersby to apply text-bound schemata when interacting with the digital artwork.

\section{Conclusion: The Face by Any Other Name}

These two face stories, those of Johann Nepomuk Strixner's (1810-1815) lithographic treatise The Four Apostles, and Julius von Bismarck's digital artwork Public Face (2008, 2010, 2014), alike in intermediation, and in the German media imaginary where they are most often shown and told, both describe a certain level of what I call "facial literacy."

But by such "facial expression competence," I do not illustrate the mediaspecific metaphorizing that has endured since Classical Antiquity, wherein the / face/ target domain is lexically substituted "as if" or "as like" a / text/ source domain, with its muscular contraction mechanisms and skin appearance movements diagrammed in a relation of similarity to a grammar with a "syntax" or a book to be "read." Nor do I intend a "calculating science of the unseen" (Stafford 118), whereby naïve, expert, or even automated face raters deductively infer (or "read") from the outside physiological behavior of the face, to the psychological phenomena inside of an individual. Whether Public Face is — or is not — with robust validity "able to read the emotions on a person's face" (Bismarck; emphasis added), as Bismarck makes his statement of fact, this digital face artifact does indeed transcribe literally a figurative textualism: the "turning of real lives into writing" (Foucault, Discipline and Punish 185), and facial expressions into so many marks or signs to be systematized or measured. So, by facial literacy, I illumine somebody's degree of knowledge in the face schema, image, and affect of the day, and the paradigmatic explanations and pedagogical norms that compose a face concept or concepts.

Such an idea about face is not simply a generalized "given" within any facial atmosphere or ethos, some discursive contextuality or localizing historicity, but rather is specifically made through the "face work" (Goffman 5) of face collectors - those artists and scientists like Strixner and Bismarck, Indagine and Garbas, Lavater and Darwin, Dürer and Ekman. And this "work," this forming and transforming of statements about what the face is, can, or may be, principally takes place through memory feedback into work process, through archivization.

The face archive may vary greatly cross-culturally and trans-historically in the media specificity of its technological apparatus, and be it Strixner's The Four Apostles or Bismarck's Public Face, Indagine's Introductiones Apotelesmaticae or the 
Fraunhofer's SHORE ${ }^{\text {TM }}$ framework. However, all of these face archives are there and then themselves an intermedial betweeness, rhizomatically located at a performative intersection among or during: 1) The "language" of scientific inquiry that as a discursive calculus prescribes a modelling system for stating possible meanings about face. And 2) the "corpus" of scientific communication with its artifacts proscribes through media imaginary the evidentiary interpretation of these meanings (cf. Foucault, The Archaeology of Knowledge 130). That is, to identify a "face archive" is to 1) name a space into which statements about face ontologically commence through the content indexing of face artifacts, according to the biological nature of the face, as well as the socio-political history of its (inter)mediations. But it also 2) names a space from which these statements nomologically command through the content retrieval of face artifacts, in an exercise by face collectors of their objectivizing gaze through societal actions (cf. Derrida).

This archive of face affords not only for the storage, retrieval, and transmission of face artifacts, and for the making of facts about face by aesthetic judgements. But face artifacts also intermedially combine, reference, and transpose face archives, and the face concepts thereof. Although, of course, this intermediality might be just a "shadow archive," perhaps beyond conscious awareness, but that still effects attitudes, beliefs, or dispositions towards one's own face or that of another.

By keyword-problematizing my privileged case studies, two German face artifactions, one / facial expression/ historical from the Age of Print, and one contemporary from today's Algorithmic Age, I probed their respective archival contextualities: Johann Nepomuk Strixner as through his The Four Apostles (1810-1815) making intermedial references to the textual structures of Dürer, Indagine and Baldung, Erasmus, and some citations removed to the Classical authors as well. This systemreferenz to the textual medium qua facialization system of /physiognomy/, in cognitivist terms, signals a spectator to apply textuality-bound schemata when gazing upon the lithographic image, as too with its oil-painted origin point (1526). While contributing signification to the artwork, this intermedial reference affords for a face competency the transparency of which is relatively proportionate to a spectator's literacy in socio-political codes of face meaning, as in the humorist temperament prototypes lexicalized as /sanguine/, /choleric/, /phlegmatic/, and /melancholic/.

In contradistinction to such a "clear box" face concept, however, Julius von Bismarck with his Public Face (2008, 2010, 2014) makes intermedial combination not only of sculptural elements, surveillance cameras, and computer server, but the Automated Facial Expression Analysis software framework SHORETM, "living" face artifacts of passersby, and those of the CMU+MIT, BioID, FERET, and JAFFE archives. This plurimedial constellation "wears 
down" and "constitutes newly" the imagistic media qua facialization system of /biometrics/, with all these face artifacts becoming inextricably merged in Public Face as simultaneously and oscillatingly co-present (Hansen-Löve 325). While contributing signification to the artwork, this intermedial combination affords for a face competency the teleological opacity of which is determined by scientific experts and technological industry, a "black box" that hides how exactly basic emotion prototypes /anger/, /happiness/, /sadness/, and /surprise/ are retrieved, stored, and transmitted. Consequently, Bismarck's artist interviews, exhibition statements, and online reviews that frame Public Face, illuminates the algorithm only as that "developed by the Fraunhofer Institute" (Bismarck), with no evaluation of face artifacts made or further archived (Hernandez et al. 301).

From reader engagement with the physiognomic aphorisms of the Age of Print (Porter 217), to media reception with the computable face of the Algorithmic Age, face collectors artist and scientist alike tend to be interested less in the phenomenological experience or even epistemological description for the schema and image of the face, than in the hermeneutic interpretation-and indeed, (e-)valuation - of its affect. That is, face artifaction and archivization is typically motivated not by what the face $i$, can, or may be, but by what the face should do, rather than what it can do. Physiognomists, scientists of facial expression, and even Automated Facial Expression Analysis systems all use the "auxiliary organs" of media prostheses to extend their perceptual faculties, and overcome the limitations of naked opthalmoception set by the eye's retinal structure to become a "kind of prosthetic God" (Strackey 37-39). But most of their face questions are at least to some degree theory-biased, the gaze cast towards making message-judgments more than measuring sign-vehicles, and typologizing inferential labels more than inferential units (Ekman, Friesen and Hager 103, 110). Within face archives, these inferential labels indicate a psychological content for a physiological expression, and act as a cipher or key to a practical facial coding system, as well as the theoretical ideas about face upon which it is based. As a kind of physiognomic metadata—or "face data about face data" — such keywords operate by the textualization of "actual" corporeal facial expressions into the $\sum \tau$ ¿ $\chi \varepsilon \tilde{\alpha} \alpha$ (stoichea or elementa) of a facial expression calculus, and from an analogue continuum perceived with graded layers on an implicit dimension, into digital units within a limited infinity of discrete possibilities on the explicit.

So would a facial form, formation, or forming that is labeled by certain inference, such as the humorist temperament / sanguine/ or the basic emotion /happiness/, /melancholic/ or /sadness/, if called by any other name still convey the same meaning about face? Certainly, yes, the forty-four bilaterally symmetrical striated facial muscles, and their selective and sexual evolution in- 
to a communication system, are biologically specified. But it is only because of the media imaginary that signifiers — such as "ruddy complexion," and "tall ... soft, fair and fat," or the zygomatic major pulling upwards the lip corners, and orbicularis oculi laterally gathering the eye folds_are recognized as having a sociopolitically inherited, specific meaning. And if such a / facial expression / were to be called by any other facial keyword, it might well retain its conventional entanglement with / physiognomic/ or /biometric/ tradition. But it could not if it were nameless, and unable to be recurrently identified through intermediations both image and text, physiognomic treatise or digital artwork.

The face concept that conditions this keywording is also the obstacle to its analysis, as only by a paradigm shift in explanatory models can such / facial expression/ be complicated or contextualized. But, the semantic cross-database search through face archive vocabularies — a digital face literacy - makes visible a face story about face stories, or a human meta-face that can indeed, as hoped Aby Warbug (1866-1929), "father" to Bildwissenschaft, "cast light on great and universal evolutionary processes in all their interconnectedness" (Gombrich 271-275).

\section{Works Cited}

Belting, Hans. Face and Mask: A Double History. Translated by Thomas S. Hansen and Abby J. Hansen. Princeton, NJ: Princeton University Press, 2017.

Bismarck, Julius von, Benjamin Maus, and Richard Wilhelmer. 2008. "Stimmungsgasometer/ Fühlometer; or, Public Face.” 1 Feb. $2016<$ https://www.digitalartarchive.at/database/general/work/stimmungsgasometerfuehl ometer.html>.

Bolter, Jay David, and Richard Grusin. Remediation: Understanding New Media. Cambridge, MA: The MIT Press, 2000.

Boys-Stones, George. "Physiognomy and Ancient Psychological Theory." Seeing the Face, Seeing the Soul: Polemon's Physiognomy from Classical Antiquity to Medieval Islam, edited by Simon Swain. New York and Oxford: Oxford University Press, 2007, pp. 19-124.

Bradley, Sister R.M. "Backgrounds of the Title Speculum in Medieval Literature." Speculum: A Journal of Medieval Studies, 29, 1954, pp. 100-115. JSTOR, 28 Jan. $2017<$ http://www.jstor.org/stable/2853870?seq=1\#page_scan_tab_contents $>$. 
Bülow, Edeltraud. "Sprechakt und Textsorte in der Telekommunikation." Telefon und Gesellschaft Band 2, edited by Forschungsgruppe Telefonkommunikation. Berlin: Spiess, 1990, pp. 300-312.

Cirio, Paolo. Email Interview with Devon Schiller. 18 January 2017.

Cirio, Paolo, and Alessandro Ludovico. "Face-to-Facebook: How We Did It." 28 Jan. 2017 <http://www.face-to-facebook.net/how.php>.

Coleridge, Samuel Taylor. "Coleridge on Spenser." Literary Remains of Samuel Taylor Coleridge, vol. 1, edited by Henry Nelson Coleridge. London: William Pickering, 1836-1839.

Colombo, Giorgio. La scienza infelice: Il museo di antropologia criminale di Cesare Lombroso [1975]. Turin: Bollati Boringhieri, 2000.

Darwin, Charles. The Expression of the Emotions in Man and Animals [1872]. New York: Penguin Books, 2009.

Daston, Lorraine. "Hard Facts." Making Things Public: Atmospheres of Democracy, edited by Bruno Latour and Peter Weibel. Cambridge, MA: The MIT Press, 2005, pp. 680-685.

Deleuze, Gilles, and Félix Guattari. A Thousand Plateaus: Capitalism and Schizophrenia. Translated by Brian Massumi. Minneapolis, MN: University of Minnesota Press, 1988.

Derrida, Jacques. “Archive Fever: A Freudian Impression.” Diacritics, vol. 25, no. 2 (1995): pp. 9-63.

Ekman, Paul, and Erika L. Rosenberg, editors. What the Face Reveals: Basic and Applied Studies of Spontaneous Expression using the Facial Action Coding System (FACS), 2nd ed. Oxford: Oxford University Press, 2005.

Ekman, Paul, and Wallace Friesen. "A tool for the analysis of motion picture film or videotape." American Psychologist, vol. 24 (1969): pp. 240-243.

Ekman, Paul, Wallace Friesen, and Joseph C. Hager. FACS Manual on CDROM. Network Information Research Corporation, 2002.

Elsner, Jaś. 2007. "Physiognomics: Art and Text." Seeing the Face, Seeing the Soul: Polemon's Physiognomy from Classical Antiquity to Medieval Islam, edited by Simon Swain. Oxford: Oxford University Press, pp. 203-224.

Ernst, Wolfgang. "Archive in Transition." Interarchive, Perspektiven/Perspectives 137, translated by Alexis Theodorou. Hannover: Niedersäshsischen Lottostiftung, 2002, pp. 475-483.

Digital Memory and the Archive. Minneapolis, MI: University of Minnesota Press, 2013. 
Foster, Hal. “An Archival Impulse.” MIT Press Journals, Fall 2004, pp. 3-22.

Foucault, Michel. The Archaeology of Knowledge and the Discourse on Language. Translated by Alan Sheridan. London and New York: Routledge, 2002.

Discipline and Punish: The Birth of the Prison. Translated by Alan Sheridan. New York: Vintage Books, 2012.

Gallagher, Shaun. How the Body Shapes the Mind. New York and Oxford: Oxford University Press, 2011.

Gates, Kelly A. Our Biometric Future: Facial Recognition Technology and the Culture of Surveillance. New York: New York University Press, 2011.

Genette, Gérard. Paratexts: Thresholds of Interpretation. Cambridge: Cambridge University Press, 1997.

Gibson, Mary, and Nicole Hahn Rafter. "Introduction.” Cesare Lombroso: Criminal Man, edited and translated by Mary Gibson and Nicole Hahn Rafte. Durham, NC: Duke University Press, 2006.

Gladwell, Malcolm. "The Naked Face." The New Yorker Magazine, Annals of Psychology, 5 Aug. 2002. 3 June 2017 <https://www.newyorker.com/magazine/2002/08/05/the-naked-face $>$.

Goffman, Erving. "On Face-Work: An Analysis of Ritual Elements in Social Interaction." Interaction Ritual: Essays in Face-to-Face Behavior [1967]. New York: Doubleday, 2005, pp. 5-45.

Gombrich, E.H. "Aby Warburg: His Aims and Methods: An Anniversary Lecture." Journal of the Warburg and Courtaultd Institutes, vol. 62 (1999): pp. $268-282$.

Grau, Oliver, Sebastian Haller, Janina Hoth, Viola Rühse, Devon Schiller, and Michaela Seiser. "Documenting Media Art: A WEB 2.0-Archive and Bridging Thesaurus for MediaArtHistories." Leonardo. June 23. 2017. 4 Sept. 2017 <doi:10.1162/LEON_a_01482>.

Grau, Oliver and Wendy Coones. "The Digitized Assets of the Graphic Collection of the Göttweig Abbey." MediaArtHistories Archive. 2012. 4 Sept. 2017 < http://hdl.handle.net/10002/592>.

Grau, Oliver. "The Database of Virtual Art: For An Expanded Concept of Documentation." ICHIM 03, Art Access \& Visual Education / Éducation visuelle \&o Accès à l'art, 2003.

Gray, Richard T. About Face: German Physiognomic Thought from Lavater to Auschwitz: Detroit: Wayne State University Press, 2004. 
Halbfass, Wilhelm and Klaus Held. "Evidenz (evidentia, evidence, self-evidence)." Historisches Wörterbuch der Philosophie, vol. 2, edited by Joachim Ritter and Karlfried Gründer. Basel: Schwabe, 1972, pp. 829-834.

Hansen-Löve, Aage A. "Intermedialität and Intertextualität: Probleme der Korrelation von Wort-und Bildkunst-Am Beispiel der russischen Moderne." Dialog der Texte: Hamburger Kolloquium zur Intertextualität, edited by Wolf Schmid and Wolf-Dieter Stempel. Vienna: Wiener Slawistischer Alamanach, 1983.

Hernandez, Javier, Mohammed Ehsan Hoque, Will Drevo, and Rosalind Picard. "Mood Meter: Counting Smiles in the Wild." Proceedings of International Conference on Ubiquitous Computing (Ubicomp). 2012. pp. 301-310.

Hett, W. S., translator. Minor Works: On Colours. On Things Heard. Physiognomics. On Plants. On Marvellous Things Heard. Mechanical Problems. On Indivisible Lines. The Situations and Names of Winds. On Melissus, Xenophanes, Gorgias. By Aristotle. Cambridge, MA: Harvard University Press, 1936.

Higgins, Dick. Horizons: The Poetics and Theory of the Intermedia. Carnbondale, IL: Southern Illinois University Press, 1984.

Huhtamo, Erkki. "Dismantling the Fairy Engine: Media Archaeology as Topos Study." Media Archaeology: Approaches, Applications, and Implications, edited by Erkki Huhtamo and Jussi Parikka. Berkeley, CA: University of California Press, 2011, pp. 27-47.

Hutchison, Jane Campbell. Albrecht Dürer: A Biography. Princeton, NJ: Princeton University Press, 1990.

Jones, W.H.S., translator. The Nature of Man. Hippocrates, Vol. IV. By Hippocrates. Loeb Classical Library 150. Cambridge, MA: Harvard University Press, 1931.

Kaczor, Eva. "Julius von Bismarck and the Smiley in Berlin." Art Berlin/Kunstszene Berlin. 2012. 1 Feb. 2016 <http://www.artberlin.de/kuenstler/julius-von-bismarck-smiley/>.

Kemp, Martin. The Human Animal in Western Art and Science. Chicago: University of Chicago Press, 2007.

Kleiner, Fred S. Gardner's Art Through the Ages: A Global History, 15 $5^{\text {th }}$ edition, vol. 1, 2016. Boston: Cengage Learning.

Knight, Thomas Chaloner, translator. The praise of folie: Moriae Encomivm a booke made in latine by that great clerke Erasmus Roterodame [1549]. Early English Books Online. Text Creation Partnership. 2003. 1 Feb. 2016 <http://name.umdl.umich.edu/A00384.0001.001>. 
Knox, R., translator. A Treatise on Man and the Development of His Faculties [1842]. Internet Archive. Internet Archive, 1 Feb. 2016 <https://archive.org/details/treatiseonmandev00quet $>$.

Krtilová, Kateřina. "Intermediality in Media Philosophy." Travels in Intermedia[lity]: ReBlurring the Boundaries, edited by Bernd Herzogenrath. Lebanon, NH: Dartmouth College Press, 2012, pp. 37-45.

Krüger, Klaus et al. "Double Vision-Manifold Evidenz." Double Vision: Albrecht Dürer and William Kentridge, edited by Klaus Krüger, Andreas Schalhorn, and Elke Anna Werner. Munich: Sieveking Veerlag, 2016, pp. 12-18.

Lavater, Johann Caspar. Physiognomy: Or, the Corresponding Analogy Between the Conformation of the Features and the Ruling Passions of the Mind [1826]. Internet Archive, 1 Feb. 2017 <https://archive.org/details/physiognomyorcor001ava>.

Leunissen, Mariska. "Physiognomy in Ancient Science and Medicine." Oxford Handbook of Science and Medicine in the Classical World, edited by Paul Keyser and John Scarborough. Oxford: Oxford University Press, 2016.

Lichtenberg, Georg Christoph. "Über Physiognomik; wider die Physiognomen: Zu Beförderung der Menschenliebe und Menschenkenntnis." Schriften und Briefe, vol. 2, edited by Wolfgang Promies. Munich: Carl Hanser Verlag, 1968-1971.

Lyons, Michael J. JAFFE Database. 1998. 28 Jan. 2017 <http://www.kasrl.org/jaffe_info.html>.

Lyons, Michael J., Julien Budynek, and Shigeru Akamatsu. "Automatic Classification of Single Facial Images." IEEE Transactions on Pattern Analysis and Machine Intelligence, vol. 21, no. 12, Dec. (1999): pp. 1357-1362.

Maduro, Daniela Côrtes. Shapeshifting Texts: Keeping Track of Electronic Literature. 2017. 28 Jan. 2017 <https://shapeshiftingtexts.wordpress.com/>.

Manoff, Marlene. "Theories of the Archive from Across the Disciplines." Libraries and the Academy, vol. 4, no. 1, 2004, pp. 9-25. Project Muse, 28 Jan. 2017 <https://muse.jhu.edu/article/51302>.

Manovich, Lev. The Language of New Media. Cambridge, MA: MIT Press, 2001. Selfiecity. 2011-2014. 28 Jan. 2017 <http://selficity.net/>.

Skype Interview by Devon Schiller. 2 December 2015.

McLuhan, Marshal, and Quentin Fiore. The Medium is the Massage: An Inventory of Effects. Berkeley, CA: Ginko Press, 1967. 
Mittendorfer, Elisabeth. "Riesen-Smiley misst Stimmung der Wiener." derStandard.at, 10 Feb. 2014 <http://derstandard.at/1389859858081/RiesenSmiley-misst-die-Stimmung-der-Wiener $>$.

Nadin, Mihai. "Semiotics for the HCI Community." Code. 2001. 20 Jan. 2017 <http://www.code.uni-wuppertal.de/uk/hci/>.

Panofsky, Erwin. The Life and Art of Albrecht Dürer [1943]. Princeton, NJ: Princeton University Press, 1955.

Pettegree, Andrew. The Book in the Renaissance. New Haven, CT: Yale University Press, 2010.

Pfeiffer, Gerhard. "Albrecht Dürer und Lazarus Spengler.” Festschrift für Max Spindler zum 75, edited by Dieter Albrecht von Geburtstag, Andreas Kraus, and Kurt Reindel. Munich: CH.Bech'sche Verlagsbuchhandlung, 1969, pp. 370-400.

Phillips, P. J., P. J. Rauss, and S. Z. Der. "FERET (Face Recognition Technology) Recognition Algorithm Development and Test Results." Army Research Lab Technical Report 995, October, 1996.

Picard, Rosalind W. "Affective computing." Tech. Report: 321, MIT Media Lab, Tech. Rep., 1995.

Porter, Martin. Windows of the Soul: The Art of Physiognomy in European Culture 1470-1780. New York: Oxford University Press, 2005.

Rajewsky, Irana O. Intermedialität. Tübingen: Francke, 2002.

Rauchensteiner, Meinhard, and Gudrun Swoboda. "Physiognomische Rhetorik I." Das Kunstkabinett des Johann Caspar Lavater, edited by Greda Mraz and Uwe Schögl. Wien: Böhlau, 1999, pp. 110-17.

Reid, Elizabeth. "Virtual Worlds: Culture and Imagination." CyberSociety: Computer-mediated Communication and Community, edited by Steven Jones. Thousand Oaks, CA: SAGE Publishing, 1995, pp. 164-183.

Ruf, Tobias, Andreas Ernst, and Christian Küblbeck. "Face Detection with the Sophisticated High-speed Object Recognition Engine (SHORE)." Microelectronic Systems: Circuits, Systems and Applications, edited by Albert Heuberger, Günter Elst and Randolf Hanke. Berlin: Springer-Verlag, 2011, pp. 243-252.

Rummel, Erika, editor. "On the Education of Children." The Erasmus Reader. By Desiderius Erasmus. Toronto: University of Toronto Press, 1990.

Russell, Donald A., translator and editor. The Orator's Education, vol. III. By Marcus Fabius Quintilianus [Quintillian]. Cambridge, MA: Harvard University Press, 2001. 
Schuller, Björn W. "Multimodal Affect Databases: Collection, Challenges, and Chances." Oxford Handbook of Affective Computing, edited by Rafael A. Calvo, Sidney K. D’Mello, Jonathan Gratch, and Arvid Kappas. New York: Oxford University Press, 2015, pp. 323-333.

Sekula, Allan. "The Body and the Archive.” October, vol. 39 (1986): pp. 3-64.

Senefelder, Johann Alois. Senefelder on Lithography: The Classic 1819 Treatise. Mineola, NY: Dover Publications, 2005.

Stafford, Barbara Maria. Body Criticism: Imaging the Unseen in Enlightenment Art and Medicine. Cambridge, MA: The MIT Press, 1993.

Stephan, Annelisa. 2017. "A Conversation with the Getty's Imaging and Digital Media Architect: Chris Edwards will spearhead digitization projects, imaging R\&D, and a deep dive into 3D.” 27 Apr. 2017. 5 June $2017<$ http://blogs.getty.edu/iris/a-conversation-with-the-gettys-new-imaging-anddigital-media-architect $/>$.

Strackey, James, translator. Civilization and its Discontents. By Sigmund Freud. New York: W.W. Norton, 1962.

Tomkins, Silvan S. Affect Imagery Consciousness: The Complete Edition, Volumes $I-I V$. Berlin: Springer, 2008.

Tytler, Graeme. Physiognomy in the European Novel: Faces and Fortunes. Princeton, NJ: Princeton University Press, 2014.

Vegetti, Mario. "Galen on Body, Temperaments and Personalities." Greek Science in the Long Run: Essays on the Greek Scientific Tradition (4 $4^{\text {th }} \mathrm{c} . \mathrm{BCE}-17^{\text {th }} \mathrm{c}$. CE), edited by Paula Olmos. Cambridge: Cambridge Scholars Publishing, 2012, pp. 265-280.

Withers, Fabian, translator. Briefe introductions, both naturall, pleasaunt, and also delectable unto the art of chiromancy, or manuel divination, and physiognomy [1557]. By Johannes de Indagine. Early English Books Online. Text Creation Partnership. 2003. 1 Feb. 2016 <https://quod.lib.umich.edu/e/eebo2/A03968.0001 .001 ? view $=$ toc $>$. 


\section{Daniela Côrtes Maduro}

\section{Curating "Shapeshifting Texts"}

\section{Setting and Concept}

Between the $3^{\text {rd }}$ and the $5^{\text {th }}$ of November 2016, I was the curator of the exhibition "Shapeshifting Texts: An Exhibition About Electronic and Experimental Literature." Together with the "International Conference on Digital Media and Textuality" (ICDMT) and an Evening of Performances entitled "Electronic Literature Authors Perform Their Work," this event was supported by the University of Bremen (Excellence Initiative). The present text is an account of the curation process, from the creation of the exhibition's materials, to the assemblage of an online gallery.

The exhibition "Shapeshifting Texts" took place at the University of Bremen library (Staats- und Universitätsbibliothek Bremen) and the evening of performances was hosted by the city library ${ }^{1}$ (Stadtbibliothek Bremen). As for the conference, it took place at the university campus and in the city center. While these were events mostly dedicated to the academic community participating in the conference, the exhibition and the evening of performances were open to the general public. The evening of performances was included in the "globale - -Festival für grenzüberschreitende Literatur"2 [Transnational Literature Festival] which welcomes poets and artists from countries all around Europe. Literaturhaus Bremen, ${ }^{3}$ a lively and flourishing platform and forum based in Bremen, sponsored this Evening of Performances.

Several members of the Consortium on Electronic Literature (CELL) made precious contributions to the exhibition: entries published in several archives and directories were used to introduce the works displayed. All these events were supported by the Electronic Literature Organization (ELO). The exhibition "Shapeshifting Texts" also benefited from a collaboration with the Deutsche Forschungszentrum für Künstliche Intelligenz GmbH [German Research Center for Artificial Intelligence] (DFKI), as well as the Bremer Institut für transmediale Textualitätsforschung [The Bremen Institute for Transmedial Textuality Research] (BITT). These events were organized under the project "Shapeshifting Texts: Keeping Track of Electronic Literature" funded by the University of Bremen and the Marie Skłodowska-Curie Actions. The aim of this project was twofold: besides addressing changes in the field of electronic literature, it was also focused on the study of individual texts. The following is a summary of the project: 
How do we read a dynamic and shapeshifting surface that demands rapid shifts of attention and multiple reading strategies? Meaning, even when considered as arbitrarily related to form, has been studied as if it was inscribed in a stable and neutral surface. However, digital texts are, from the computer processor to the screen, ever-changing artifacts. Besides that, a digital text can assume the contours of a movie, a game or the pages of a book. Shapeshifting is the ability of a creature to change its form. While reading a mutating text, the reader's attention and approach also shifts. In order to address these texts, one needs to take into account digital materiality, multimodality and the cognitive and physical tasks performed by the reader. The way meaning emerges is a key element in this research project. The term "shapeshifting" will be applied to the production and reception of meaning, which is constantly being deferred or delayed in digital transient texts. Likewise, electronic literature can be described as a rapidly changing field. Digital media invite experimentation, and thus allow the creation of new types of texts. However, because they often emerge in response to new technology, digital works are being permanently subjected to obsolescence or dispersal across the web. There are several institutions, as for example ELO (Electronic Literature Organization) and ELMCIP (Electronic Literature as a Model of Creativity and Innovation in Practice), working to find new ways to deal with electronic literature's constant metamorphosis. By using the concept of "shapeshifting," I will track several turning points in the history of electronic literature and propose a general perspective from which to view such field. ${ }^{4}$

Exhibitions can be considered as a way to preserve and keep track of electronic literature, as well as to promote the reading of this literary form. The exhibition "Shapeshifting Texts" allowed visitors to experience some works which, at some point in time, became inaccessible due to technology obsolescence. Some of these works have been rescued from oblivion. Such is the case of Shelley Jackson's Patchwork Girl (1995) which was first released on floppy disk, distributed in CD and, in 2014, became available on USB pen drive. ${ }^{5}$ However, some of the works displayed in the exhibition (namely, those published in Flash or CD) remain at risk of disappearing. Furthermore, several works need a specific configuration to be accessed. For instance, Caitlin Fisher's 200 Castles (2014), 6 an augmented reality work, and Søren Pold's Ink After Print (2012), ${ }^{7}$ a digital installation, need specific software and devices in order to be experienced. Therefore, exhibitions can also afford readers an unique opportunity to experience a vast array of works.

As I will explain later on, the exhibition benefited from the participation of some of the authors. It also welcomed representatives of several archives 
and directories of electronic and experimental literature. Thus, in addition to reading and experiencing a wide diversity of works, visitors had the opportunity to meet some of the authors and, since this exhibition was part of ICDMT, to participate in discussions or to share their questions and ideas with a community involved in the study of digital media.

Because I intended to introduce electronic literature to students and departments of the University of Bremen, this exhibition had a strong pedagogical component. As it becomes clear from the way it was structured (works were distributed along alphanumeric, rhizomatic, hybrid and recombinant groups), the exhibition aimed to present several types of works to a public not familiar with electronic literature. The exhibition also aimed to demonstrate that electronic literature is part of an open-ended dialogue between art forms and, as such, belongs to a long tradition of experimentation with surfaces of inscription. Since the exhibition was put together at the university library, I decided to emphasize this link by including book editions owned by the Staatsund Universitätsbibliothek Bremen (SuUB). Works written by the following authors were displayed together with computers and other devices: Jacob Grimm, Wilhelm Grimm, Georges Perec, Guillaume Apollinaire, Italo Calvino, Johann Wolfgang von Goethe, Jorge Luis Borges, Lewis Carroll, Mary Shelley, Raymond Queneau, Walter Benjamin, William Burroughs and Brion Gysin. One Thousand and One Nights and I Ching were also part of this exhibition.

\subsection{Shapeshifting Texts: The Concept}

I believe that the selection of the setting and the concept behind an exhibition are of the utmost importance because these help curators to convey their message effectively. Similar to the "Shapeshifting Texts: Keeping Track of Electronic Literature" project, the concept behind the exhibition is based on the notion that all sorts of texts can change during a reading session. The concept of "shapeshifting" can be applied to different changes suffered by texts. These can take place at the:
a) computer processor level;
b) surface level;
c) meaning level.

As hinted before, texts can also shapeshift across time. For this reason, we need to take into account not only the way works change during a reading session, but also how they change, or might change, while stored in a specific platform. Dene Grigar suggests three methods for preserving electronic litera- 
ture: "software emulation; migration to newer media and the creation of collections." "As mentioned above, Patchwork Girl has "migrated" to new platforms in order to survive and has shapeshifted from a floppy disk into a CD, and lastly, a pen drive. Storyspace itself has also been updated, as stated in Eastgate Systems Inc.'s webpage: “Storyspace 3 works with existing Storyspace files and creates new Storyspace documents in a robust, state-of-the-art XML format. Legacy Storyspace work immediately takes advantage of Storyspace 3's outstanding new typography." Words such as "transformation," "transiency" or "mutation" are normally used to describe the process of change undergone by digital texts. However, the concept of "shapeshifting" places a particular focus on form and (contrary to "metamorphosis," which seems to refer to a long and slow change, often irreversible) allows us to describe texts that suffer a sudden or swift change, with or without the influence of the reader, during a reading session. Due to its mythical background (the myth of "shapeshifting" is shared by different cultures); the scientific application of the term (for instance, "Shape-Shifting nanoparticles") or its presence in the world of gaming and science fiction, the term "shapeshifting" also enables us to emphasize the link with several fields of research, such as science fiction, oral tradition, game studies, cognitive sciences and computer science.

Electronic literature cannot be analyzed without resourcing to a vast array of knowledge gathered within several interconnecting disciplines. The importance of taking into account antecedents and neighboring fields in the study of electronic literature has been sufficiently highlighted by several authors. However, the term "shapeshifting" allows us to describe the textual behavior (Aarseth) and, simultaneously, the context in which electronic literature emerged and developed. Because of the sudden shapeshifting moments suffered by electronic literature, I have described it elsewhere as a shapeshifter. ${ }^{10}$ Even though electronic literature shares several features with experiences performed by, for instance, Oulipo, I am specifically concerned with the use of computers and other devices as a central feature of this literary form: as we know, several types of software have allowed the creation of further texts (and deemed others unreadable), thus producing swift changes in the field.

Exhibitions contribute towards the preservation of literary works, and thus, they help scholars and institutions to deal with the shapeshifting ability displayed by electronic literature. Besides taking into account media affordances and materiality, the concept of "shapeshifting" also views the emergence (or shapeshifting) of meaning as an object of analysis. In this sense, the concept of "shapeshifting" can refer to individual texts, but also to an entire field such as literature.

This exhibition was focused on the second level of shapeshifting: the surface level. In the case of the works displayed in this exhibition, even though 
some of them could be easily inserted in more than one strand, I wanted to underline some features of these works, which strongly contribute to a shapeshifting process. In these works, this process was catalyzed by shapeshifting numbers and letters (Alphanumeric Surfaces), by randomness and selfgenerativity (Recombinant Surfaces), by multilinearity and bifurcation (Rhizomatic Surfaces) and, finally, by multimodality (Hybrid Surfaces).

\subsection{The Materials}

Several exhibitions, as for example No Legacy ${ }^{11}$ (2016), or Affiliations, Communities and Translations (2017), ${ }^{12}$ have demonstrated that design plays a decisive role in conveying the curator's message. For instance, these exhibitions have selected materials such as cardboard or wood to reflect upon issues of inscription and materiality. For the exhibition "Shapeshifting Texts," I departed from concepts such as randomness and change. When I thought of an object that could represent playfulness, interactivity, impermanence and experimentalism (features usually displayed by electronic literature works), a cootie catcher came to mind. ${ }^{13}$ This object also allowed me to represent the ability of digital media to turn texts into customizable or configurable objects. João Rui ${ }^{14}$ and I created all the materials from scratch.
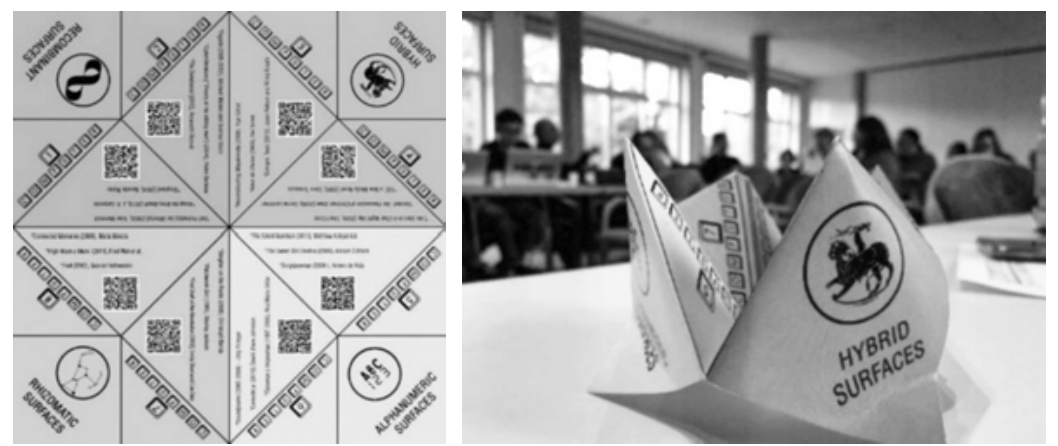

Fig. 1. and Fig. 2. The cootie catcher.

The cootie catcher represented the four strands of the exhibition and included QR Codes which offered further information about the works. Besides drawing a visible link between ICDMT and the exhibition "Shapeshifting Texts," this object was used to suggest an alternative perspective over the exhibition.

For those who did not own a device with a QR Code reader, we included a stand with information about each work. Nevertheless, some details were exclusively available at a "hidden exhibition" which remained accessible through 
the cootie catcher. Visitors were invited to use their cootie catchers in order to access this "hidden exhibition." Here, they would find the following challenge:

If you arrived here, that's because you are holding a cootie catcher in your hands. You have probably used a cootie catcher before. Yes, a cootie catcher is a children's game to predict the future. Like the multiple-sided cootie catcher you are now manipulating, electronic and experimental literature invite you to play with language and to explore this surface of inscription in an unconventional way. However, just because you are holding this object in your hands, it does not mean that you have everything under control, or that you will get to see the whole. There are several paths ahead. Besides that, you will have to discover how each artefact works and solve several riddles in order to keep going. This cootie catcher will work as an oracle to predict the future. As such, it will help you deal with uncertainty and randomness. You can explore the exhibition sequentially (computers 1, 2, 3, 4, 5, 6, $7,8)$. However, we challenge you to use your cootie catcher and face the unknown. Move your fingers in order to know what comes next. There are shapeshifting texts waiting for you. ${ }^{15}$
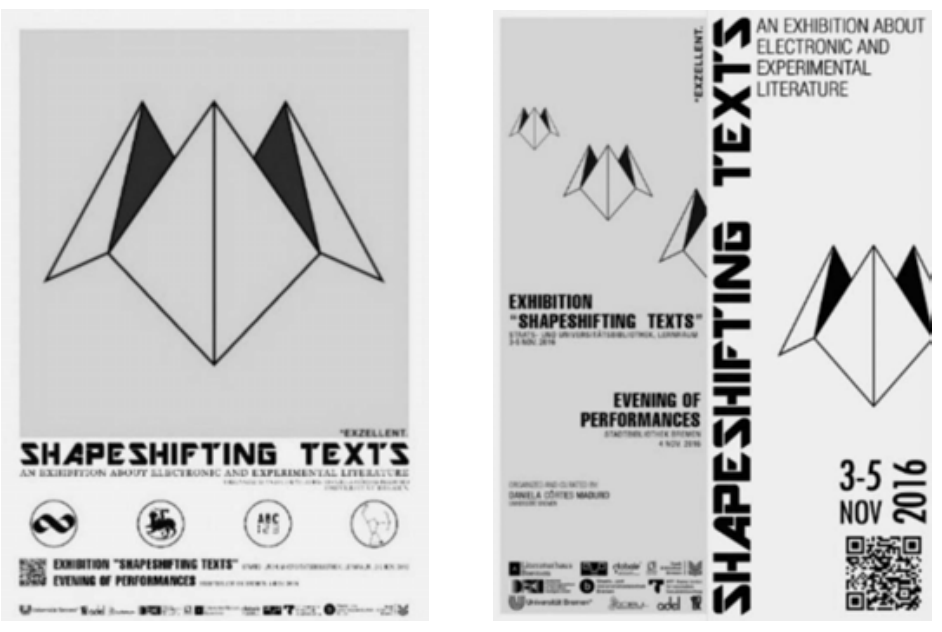

Fig. 3. Poster. Fig. 4. Flyer.

\subsection{The Room}

The exhibition took place at a room inside the University of Bremen's library. This room is prepared to welcome study groups and is divided into four sections separated by walls. These sections are originally equipped with a TV 
screen and a media hub and each of them hosted one of the four exhibition strands. Strands were comprised of two computers with three works each. Besides that, MP3 players, mobile phones and tablets were used to display works. A fifth section (In the Making) was created in order to provide a space where software developers and artists, as well as scholars, could inform visitors about ongoing projects, call for papers, newly released works or tools designed for the creation of electronic literature works.
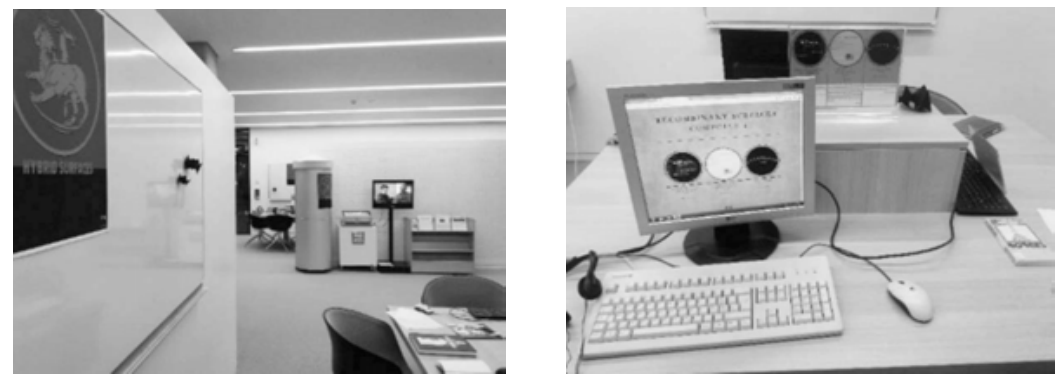

Fig. 5. (left) Hybrid, In the Making and Rhizomatic Surfaces stations.

Fig. 6. (right) Recombinant Surfaces, Computer 1.
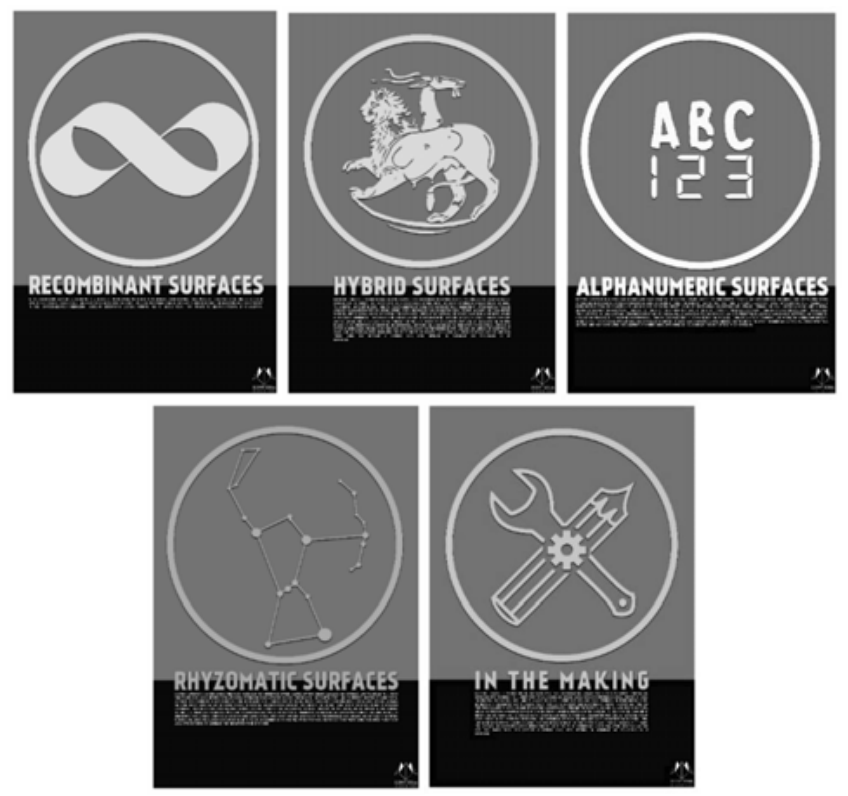

Fig. 7. Station logos. 


\section{$1.4 \quad$ Artist Talks}

The exhibition opening took place on the first day of the conference. Jörgen Schäfer (a member of the ongoing project "Archiv der deutschsprachigen elektronischen Literatur" [Archive of German Electronic Literature]) and Rui Torres (director of the Po-ex.net: Arquivo Digital da Literatura Experimental Portuguesa [Digital Archive of Portuguese Experimental Literature]) spoke about their projects.

I consider exhibitions as unique places where artists, researchers and the general public can meet and exchange ideas. With this in mind, I gathered artists, the directors of archives dedicated to electronic and experimental literature, as well as researchers from different fields. Rui Torres and Søren Pold, two authors featured at the exhibition, were invited to give an artist talk and share their work with visitors. María Mencía, who created a work about the harbor of Bremen (Gateway to the World: Data Visualisation Poetics), ${ }^{16}$ specifically for this exhibition, was one of the six keynote speakers. John Barber, author of the work Tunnel to Another World (2014-2016), ${ }^{17}$ also attended the exhibition and participated in the conference.

The Evening of Performances took place on the second day of the conference. During this event, Scott Rettberg presented a screening of Toxi $\bullet$ City (Scott Rettberg and Roderick Coover), "a combinatory film in which narrative segments and a chorus of historical anecdotes chronicling deaths from Hurricane Sandy are drawn from a data-base of materials." 18 AIMISOLA a performance based on the research developed by Álvaro Seiça and Sindre Sørensen "on immigration, Spanish immigration policies, cultural, social and political issues in Spain" was presented by Álvaro Seiça. In PoeticUnConversationS, Rui Torres presented (and performed) his work.

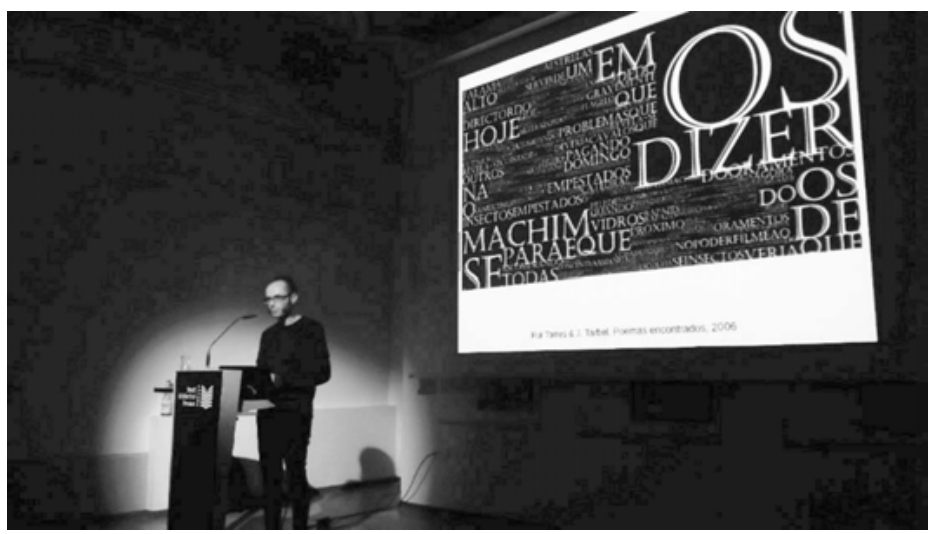

Fig. 8. PoeticUnConversationS, Rui Torres. 


\subsection{Directories and Archives}

Besides Rui Torres and Jörgen Schäfer, Scott Rettberg, director of the ELMCIP (Electronic Literature as a Model of Creativity and Innovation in Practice) Knowledge Base, and Joseph Tabbi (editor in chief of the Electronic Literature Directory and the Electronic Book review) were also invited to speak about their projects. Both the conference and the exhibition opening benefited from the presence of the Electronic Literature Organization's (ELO) president and director of the Electronic Literature Lab (ELL), Dene Grigar.

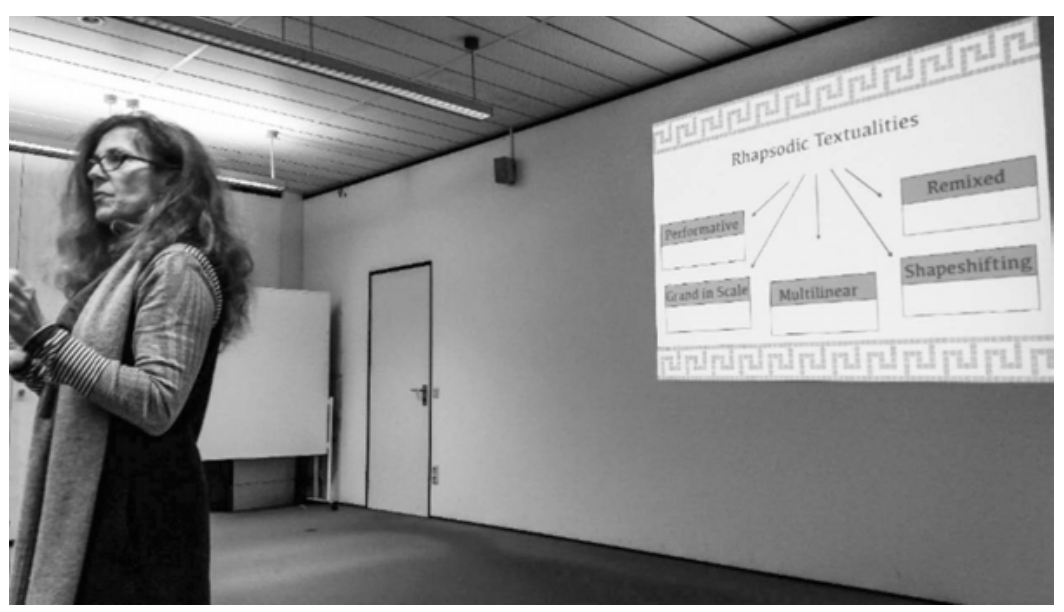

Fig. 9. "Rhapsodic Textualities," Dene Grigar.

Carlos Reis (director of the Center for Portuguese Literature and coordinator of the Dictionary of the Portuguese Figures of Fiction), as well as Manuel Portela (performer, translator, director of the Materialities of Literature Programme and coordinator of Fernando Pessoa's Book of Disquiet digital archive) were also present. As stated in the exhibition's manifesto, I sought to:

... present the collaborative work done by institutions and archives focused on the preservation of electronic and experimental literature and, simultaneously, to demonstrate that electronic literature is part of an ever-evolving process which might have been catalyzed by the first experiences with language and surfaces of inscription. ${ }^{19}$

The work of several archives, collections and directories played an important role in this exhibition. Pieces included in this exhibition were introduced to visitors through entries published in the Digital Archive of Portuguese Experimental Literature (Po-ex.net), Electronic Literature as a Model of Creativity 
and Innovation in Practice (ELMCIP), Electronic Literature Lab (ELL), Electronic Literature Directory (ELD), NT2 (Le Laboratoire de recherche sur les oeuvres bypermédiatiques), and I Love E-Poetry. Entries written by the editors of volumes I, II and III of the Electronic Literature Collection were also cited in order to introduce some of the works.

As Dene Grigar and Stuart Moulthrop have claimed in the introductory note to Traversals: The Use of Preservation for Early Electronic Writing (2017), "many pioneering works of electronic literature are now largely inaccessible because of changes in hardware, software, and platforms." 20 Several institutions, such as Lori Emerson's Media Archaeology Lab ${ }^{21}$ and Dene Grigar's Electronic Literature $\mathrm{Lab}^{22}$ are (re)creating environments where these works can survive. The project Pathfinders, developed by Dene Grigar and Stuart Moulthrop, aims "to make documentary video recordings of readers as they engage with works of early computational literature involving multi-path reading strategies, dating from the crucial period of invention that preceded popularization of the Internet (roughly 1985-99)." 23 The fact that authors are often invited to participate and to read/perform their own works, turn traversals into interesting exercises which can shed new light on both creative and reading processes. In the "Shapeshifting Texts" exhibition, a traversal (video recording as envisaged by the Pathfinders project) of Patchwork Girl was displayed with the purpose to demonstrate how digital works can fall into oblivion as they become unreadable or inaccessible.

\section{The Online Gallery}

\subsection{The Structure}

The exhibition online is comprised of five strands, a section dedicated to the cootie catcher; a section where videos and photos were published; acknowledgments, and a section where visitors are invited to take a survey. This page was disclosed on the last day of the conference, as we were approaching final remarks. Until then, the works displayed remained accessible in the exhibition room, or by using the cootie catcher.

EXHBITION SHAPESHIFTING TEXTS

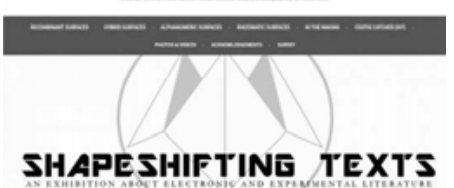

Fig. 10 Gallery homepage 
The "Cootie Catcher" section was created so that people who did not have the chance to attend ICDMT could get a glimpse of the exhibition. The strands of the exhibition are now available online. However, even though a great number of works can be read online, not all of them can be accessed by the reader. As explained before, some of the works need a specific configuration in order to be read and experienced.

\begin{tabular}{|c|c|c|c|}
\hline $\begin{array}{l}\text { Recombinant } \\
\text { Surfaces }\end{array}$ & $\begin{array}{l}\text { Hybrid } \\
\text { Surfaces }\end{array}$ & $\begin{array}{l}\text { Alphanumeric } \\
\text { Surfaces }\end{array}$ & $\begin{array}{l}\text { Rhizomatic Sur- } \\
\text { faces }\end{array}$ \\
\hline $\begin{array}{l}\text { Self Portrait(s) [as } \\
\text { Other(s)] (2003), } \\
\text { Talan Memmott } \\
\text { Along the Briny } \\
\text { Beach (2012), J. R. } \\
\text { Carpenter } \\
\text { Storyland (2004), } \\
\text { Nanette Wylde } \\
\text { Facade } \\
\text { (2005-2012), Mi- } \\
\text { chael Mateas and } \\
\text { Andrew Stern } \\
\text { Cyberlitera- } \\
\text { ture,"Theory of } \\
\text { the sitting man" } \\
\text { (2014), Pedro } \\
\text { Barbosa } \\
\text { The Deletionist } \\
\text { (2013), Amaranth } \\
\text { Borsuk, Jesper } \\
\text { Juul and Nick } \\
\text { Montfort. } \\
\text { Looppool (1998), } \\
\text { Bas Boettcher } \\
\text { Stochastische Texte } \\
\text { (2010), Johannes } \\
\text { Auer }\end{array}$ & $\begin{array}{l}\text { Entropic Texts } \\
\text { (2015), Jason Nel- } \\
\text { son and Alinta } \\
\text { Krauth } \\
\text { Like Stars In A } \\
\text { Clear Night Sky } \\
\text { (2006), Sharif Ez- } \\
\text { zat } \\
\text { Deviant: The Posses- } \\
\text { sion of Christian } \\
\text { Shaw (2004), } \\
\text { Donna Leishman } \\
\text { TOC: a New Media } \\
\text { Novel (2009), Steve } \\
\text { Tomasula } \\
\text { Ink After Print } \\
\text { (2012-), Søren } \\
\text { Pold } \\
\text { Breathing Wall } \\
\text { (2004), Kate Pull- } \\
\text { inger } \\
\text { 200 Castles } \\
\text { (2014-), Caitlin } \\
\text { Fisher }\end{array}$ & $\begin{array}{l}\text { The Silent Numbers } \\
\text { (2013), Matthew } \\
\text { Kirkpatrick } \\
\text { The Sweet Old Etcet- } \\
\text { era (2006), Allison } \\
\text { Clifford } \\
\text { Scriptpoemas } \\
\text { (2008-), Antero } \\
\text { de Alda } \\
\text { Soundpoems } \\
\text { (2002-2008), Jörg } \\
\text { Piringer } \\
\text { Concrete p. (2010), } \\
\text { David Jhave John- } \\
\text { ston } \\
\text { Tipoemas y Anipoe- } \\
\text { mas (1997-2003), } \\
\text { Ana Maria Uribe } \\
\text { Signagens } \\
\text { (1985-1989), E. } \\
\text { M. de Melo e Cas- } \\
\text { tro } \\
\text { Prosthesis (2011) } \\
\text { Ian Hatcher } \\
\text { Tunnel To Another } \\
\text { World } \\
\text { (2014-2016), John } \\
\text { F. Barber }\end{array}$ & $\begin{array}{l}\text { Senghor on the Rocks } \\
\text { (2008) Christoph } \\
\text { Benda } \\
\text { Patchwork Girl } \\
\text { (1995) Shelley } \\
\text { Jackson } \\
\text { First Draft of the } \\
\text { Revolution (2012), } \\
\text { Emily Short and } \\
\text { Liza Daly } \\
\text { Connected Memories } \\
\text { (2009), María } \\
\text { Mencía } \\
\text { High Muck a Muck } \\
\text { (2014), Fred Wah, } \\
\text { Nicola Harwood, } \\
\text { Jin Zhang, Bessie } \\
\text { Wapp, Thomas } \\
\text { Loh, Tomoyo } \\
\text { Ihaya, Hiromoto } \\
\text { Ida, Phillip Djwa, } \\
\text { and Patrice Leung } \\
\text { Fest (2012), Gabri- } \\
\text { el Helfenstein } \\
\text { Shelley Jackson's } \\
\text { Traversal of Patch- } \\
\text { work Girl (2013) } \\
\text { Gateway to the } \\
\text { World: Data Visu- } \\
\text { alisation Poetics } \\
\text { (2016), María } \\
\text { Mencía }\end{array}$ \\
\hline
\end{tabular}

Table 1. Exhibition strands and works displayed. 


\subsection{The Abstracts}

Each strand is introduced by an abstract comprised of words or sentences extracted from the entries published in different directories, archives or collections. A citation is used at the beginning of every abstract to introduce visitors to the literary debate depicted in the strand.

\section{Recombinant Surfaces}

"After the novel, and subsequently cinema privileged narrative as the key form of cultural expression of the modern age, the computer age introduces its correlate: database." Lev Manovich, in The Language of New Media (2001)

Electronic literature can shapeshift randomly by resourcing to a database of images, sounds or words. The present works were "subjected to the knife of the cut-up." Some of them could be described as a "generated text cascading down the screen." In this strand, you will have the opportunity to read "computer-generated combinatorial" stories as if you were conducting an "experiment in electronic narrative." Furthermore, you will be invited to "uncover poems" that "promote the generative potential of an algorithm."

\section{Hybrid Surfaces}

"When we have business with language, we are possessed by its dreams and demons, we grow intimate with monsters. We become hybrids, chimeras, centaurs ourselves: steaming flanks and solid redoubtable hoofs galloping under a vaporous machinery." Shelley Jackson, in Patchwork Girl (1995)

The works here presented can shapeshift between several semiotic modes and art forms. In this strand, you will visit a "website gone amok" or poems that have "succumbed to entropy." You will be invited to click "blue stars in the night sky," and explore fictional worlds populated by "terrible creatures." If you follow this path, you will engage in a multisensory experience and activate "night-dreams" that respond to your rate of breathing, as if you were facing a "magic looking glass."

\section{Alphanumeric Surfaces}

"A sense of fascination and adventure told me that the letters and the signs standing still on the page could gain actual movement of their own. The words and the letters could at last be free, creating their own space." E. M. de Melo e Castro, in Media Poetry: An International Anthology (2007), edited by Eduardo Kac.

This strand is comprised of works that suggest "graphic and kinetic possibilities." Here, letters and numbers are defamiliarized and display a "verbicovisual energy." The manipulation of their graphical properties often results in a "re- 
mediatization of concrete poetry." Letters and numbers become "enigmatic shapes," or sounds vocalized by a robotic voice whose "traces" you need to follow. These works shapeshift between the ideogrammatic and the alphanumeric, presenting words and numbers as encrypted, and persistently exploring the transition from absence to emergence of meaning.

\section{Rhizomatic Surfaces}

"[C]ontrary to a deeply rooted belief, the book is not an image of the world. It forms a rhizome with the world, there is an aparallel evolution of the book and the world." Gilles Deleuze and Felix Guattari, in A Thousand Plateaus (1987).

The works included in this strand invite the reader to enroll in a "journey on the map" and to stitch body/hypertext parts together. You will engage in a "letter-writing" session, activate a "decisional process" or participate in an "exploration of oral histories." Memories that connect people will surface along the way.

\subsection{The Survey}

Visitors of the exhibition were invited to take a survey which will enable me to understand how electronic literature reaches a public not familiar with this literary form and to evaluate the impact of events such as the "Shapeshifting Texts" exhibition. This survey is now available online and the data collected will allow me to know visitors' reaction to the exhibition or the online gallery, as well as to electronic literature. The survey will also grant me the opportunity to know, for instance, the place and context where visitors familiar with electronic literature were introduced to this literary and artistic form.

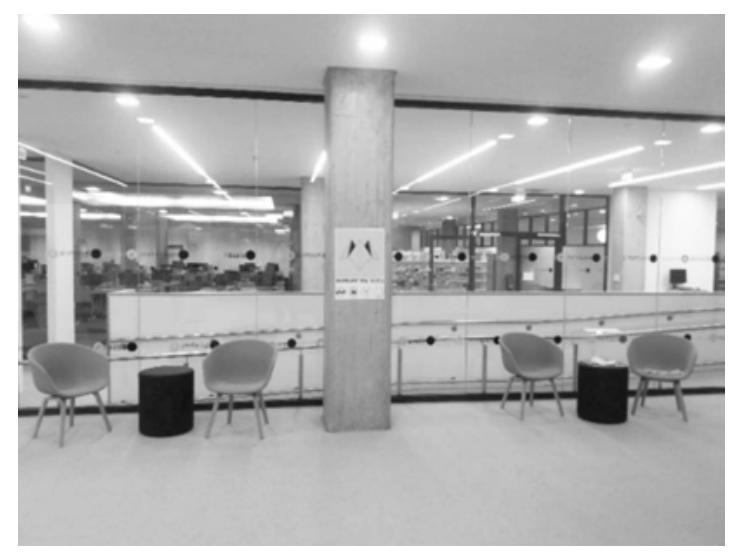

Fig. 11. Exhibition room and survey box. 


\section{Survey Questions}

1. What is your job and academic degree?

2. What is your field of research/study?

3. How old are you?

4. Genre.

5. Were you at the exhibition "Shapeshifting Texts" in Bremen? Before visiting the exhibition in Bremen/online:

5.1 had you ever visited an exhibition about electronic literature? Which one?

5.2 had you ever read electronic literature? If yes, how did you come across electronic literature?

6. Did you know any of the works displayed? / Are there any works you did not know? Which ones?

7. How would you describe electronic literature? Please use adjectives separated by commas.

8. Did you find any connection with works you have read before? Could you offer some examples?

9. If you were given the chance, would you attend a course about electronic literature? Which topics would you prefer to address? Electronic literature and: experimental literature, game studies, narrative, literary theory, feminism, multimodality, media studies, film studies, programming or other.

9.1 If you replied "Other," please let us know your suggestions.

\section{To Be Continued...}

The exhibition "Shapeshifting Texts" was recently presented at ELO 2017 in a round table entitled "Exposé!! The Global Practice of Curating Electronic Literature," together with exhibitions curated by the following scholars: Élika Ortega (Northeastern University, USA), Alexandra Saum-Pascual (University California Berkeley, USA), Dene Grigar (Washington State University Vancouver, USA), Scott Rettberg (University of Bergen, Norway), James Brown (Rutgers University, USA), Robert Emmons (Rutgers University, USA) and Giovanna di Rosario (Catholic University Louvain, Belgium). This roundtable has shown the importance of exhibitions for the promotion, study and preservation of electronic literature. It also made clear that a growing number of researchers are interested in using exhibitions as a way to study and preserve electronic literature.

When I first started planning the exhibition "Shapeshifting Texts," I was thinking about scholars who wish to implement the study of electronic litera- 
ture in their universities. The titles of the exhibition's strands are linked with antecedents represented by, for instance, concrete poetry (Alphanumeric Surfaces); Oulipo (Recombinant Surfaces); novels written by Jorge Luis Borges or Italo Calvino (Rhizomatic Surfaces), and works such as Alice in Wonderland (1946) written and illustrated by Lewis Carroll (Hybrid Surfaces). Without overly circumscribing, I wished to offer four points of departure based on antecedents and literary debates ignited before the adoption of personal computers as tools for literary and artistic creation. Currently, materials are being prepared so that visitors can use this gallery inside classrooms. As a result, the exhibition here introduced will continue shapeshifting in order to keep track of electronic literature.

\section{Notes}

1 Bremen's city library website <http://www.stabi-hb.de/ $>$.

2 globale ${ }^{\circ}$ Festival für grenzü̈berschreitende Literatur <http://globale-literaturfestival.de/ueber-uns $/>$.

3 Literaturhaus Bremen <http://www.literaturhaus-bremen.de/uber-uns/>.

4 Project summary available at <https://wordpress.com/post/shapeshiftingtexts.wordpress.com/684>.

5 Patchwork Girl available for purchase at <http://www.eastgate.com/catalog/PatchworkGirl.html>.

6200 Castles <https://exhibitionshapeshiftingtexts.wordpress.com/shapeshiftingtexts/hybrid-surfaces/200-castles/>.

7 Ink After Print <https://exhibitionshapeshiftingtexts.wordpress.com/shapeshiftingtexts/hybrid-surfaces/ink-after-print/ $>$.

8 Review of the seminar taught by Dene Grigar at the University of Coimbra, Portugal. Available at <https://matlit.wordpress.com/2014/12/07/caring-for-electronic-literature $/>$.

9 Storyspace 3 <http://www.eastgate.com/storyspace/index.html>.

10 More information about the project "Shapeshifting Texts: Keeping Track of Electronic Literature" (2015-2017) available at < https://shapeshiftingtexts.wordpress.com $/>$.

11 Exhibition No Legacy < http://nolegacy.berkeley.edu/>.

12 ELO 2017 exhibits <https://conference.eliterature.org/2017/exhibits>. 
13 The cootie catcher <https://exhibitionshapeshiftingtexts.wordpress.com/about/cootie-print/>.

14 João Rui is a Portuguese musician and songwriter. He is the lead singer of the Portuguese band a Jigsaw <http://www.ajigsaw.net/about.html>. João Rui designed the exhibition materials and assembled the online gallery.

15 This citation can be found in the cootie catcher's "About" page < https://cootiecatchershapeshiftingtexts.wordpress.com/>. Please download the cootie catcher here: <https://exhibitionshapeshiftingtexts.wordpress.co$\mathrm{m} /$ about/cootie-print $>$. Some details are not available in the online gallery.

16 Gateway to the World: Data Visualisation Poetics available at <https://exhibitionshapeshiftingtexts.wordpress.com/shapeshiftingtexts/rhizomatic-surfaces/gateway-to-the-world-data-visualisation-poetics $/>$.

17 This work is available at <https://exhibitionshapeshiftingtexts.wordpress.com/shapeshiftingtexts/alphanumeric-surfaces/tunnel-to-another-worl$\mathrm{d} />$.

18 Toxi $\cdot$ City available at $<$ http://crchange.net/toxicity $>$.

19 Online exhibition is available at <https://exhibitionshapeshiftingtexts.wordpress.com $/>$.

20 Traversals' overview available at $<$ https://mitpress.mit.edu/books/traversals $>$.

21 Media Archaeology Lab < https://loriemerson.net/media-archaeology-la$\mathrm{b} />$.

22 Electronic Literature Lab < http://dtc-wsuv.org/wp/ell/author/denegrigar $/>$.

23 The Pathfinders project < http://dtc-wsuv.org/wp/pathfinders/description $/>$.

\section{Works Cited}

Aarseth, Espen. Cybertext: Perspectives on Ergodic Literature. Baltimore, MD: The Johns Hopkins University Press, 1997.

Jackson, Shelley. Patchwork Girl. Watertown, MA: Eastgate Systems, Inc. 1995.

Maduro, Daniela Côrtes. Shapeshifting Texts: Keeping Track of Electronic Literature. 2017. 28 Jan. 2017 <https://shapeshiftingtexts.wordpress.com/>. 
_. "Caring for Electronic Literature." Doctoral Programmme in Materialities Literature. 8 Aug. 2017 <https://matlit.wordpress.com/2014/12/07/caring-for-electronic-literature $/>$.

Manovich, Lev. The Language of New Media. Cambridge, MA: MIT Press,

Melo e Castro, E. M. “Videopoetry." Media Poetry: An International Anthology, edited by Eduardo Kac. Bristol and Chicago: Intellect, 2007, pp. 175-184.

Moulthrop, Stuart, and Dene Grigar. Pathfinders. 8 Aug. 2017 <http://dtc-wsuv.org/wp/pathfinders/description/>.

- Traversals: The Use of Preservation for Early Electronic Writing. Cambridge, MA: The MIT Press, 2017. 



\section{Frieder Nake}

\section{Postscript}

\section{Loosely Connected Only to What it's Coming After}

\section{First}

As humans, we are always already interpreting: we are the interpreting animal. Semiotic animals we are, as the mathematician Felix Hausdorff would say. ${ }^{1}$ In this note at the end of an exciting volume full of thrilling articles, I invite the reader to lean back for a short moment of reflection.

The sign is the stuff of semiotics. It is not a thing. Nobody has ever seen a sign out there in the world. We do not encounter signs; we make them. Anything we may encounter in world, we may make to be a sign. That is happening then and there and, first of all, to us. Our making of a sign out of a thing is by acts of interpretation.

But even worse! Not the sign itself is of utmost importance for the human being. Processes really are what we must pay attention to, processes of signs the dynamics, not the statics - are what make us humans. Semiosis is the term Charles Sanders Peirce prefers to use, and the sign itself is nothing but the analytical construct he needed to write about the sign's transformations, one into another. Everything is flow and fluid, nothing ever stable. And the interpretation of the sign creates as its result another sign again. The concept of the Peircean sign is in itself recursive, and that is the most fantastic of its features! Peirce did not rest in thinking and writing about the sign because in it he tried to capture all of our understanding anything. More than seventy versions of his describing the sign exist ${ }^{2}$ (cf. Peirce 1998).

Today, we live with machines that we may call semiotic engines, based on recursive functions. Isn't this a marvelous cultural development and event? I believe it is. Therefore, I take the opportunity of this epilogue to remind a friendly reader of such circumstances even though she (and also he) is heavily occupied with her (and his) very specific detailed article on something I don't have the faintest clue of.

Semiotic animals are meeting semiotic engines and thus the animals come to believe their engines were somehow similar to themselves. Communication of humans with machines (ridiculous to think of in a strong sense of the word) here finds its reason and appeal. If they are to be characterized by semioses just like us, they must be similar to us in such a way that we communicate with 
them. However, it appears to us, and that is all, as if there was communication of the kind we call communication. There is exchange, indeed, of signs from us to software and back to us. And wonderful it is to see how smoothly and with little friction we do exchange and do it quite successfully much of the time. This is because the sign on our side quickly takes on the form of nothing but a signal when it gets ready for treatment by some software. The wonder is that permanent reduction of signs into signals and back into signs and then in signals and so on is going on so smoothly and so effortlessly. It is wonderful and so full of wonder that a believer must say: look, this is intelligence. But no machine will ever become human unless the human likes to be machinic. As-if characterizes the semiotic engine. The great machine of permanent as-if, that's the computer. And whenever we say "computer" we must better say "computer-and-software." For it is always only software that is responsible for what we witness as fantastic, unbelievable, and absolutely just the way we could not do better, in fact, we cannot do at all.

All semioses are as-ifs. Each sign is nothing but a something behaving as if it were another. The virtual is heavily upon us. But has it not been with us long before? Each drama far away in ancient Athens or Epidavros, each poem hanging in the air that makes us sad and full of love foregone, each novel, even in realistic times, dealt with acts of revolution and upheaval. Black matter in the form of letters, spread out on paper with seductive smell, my eyes perceiving this and wandering about, my tears start running in despair and sympathy for what is happening. Nothing is happening, dear friend, nothing is happening at all. The virtual mode of what we call reality, that's all, and it has all been with us for centuries. My tears are actual but in response to something virtual.

Such is human existence. It is always already against horizons of our death which we are consciously aware of, permanently. And no machine will ever be unless... The only difference is that now the virtual has become machinic. Great deal.

\section{Second}

Hypertext and multimedia became bypermedia. And all of this was local, nothing global. And the internet did not play its role yet that now appears as if it drove us crazy. At conferences and workshops, young philosophers and sociologists sang the song of a future without the printed book. And the book, in their mind, was horrible because it forced its readers to start and end where the author wanted them to start and end. They elegantly ignored the fact that no reader had ever obeyed this dream of the author, and our friends young thinkers published at least two books per year as stepping stones for their careers. 
But this is long ago and of no interest now to anybody. What may, however, be interesting is the link. Without the link none of those enormous structures could exist that we now take for granted. The link constitutes the information system as the ubiquitous medium the same way that the cut constituted the film. Seemingly moving pictures became the medium film when the cut was invented that cannot be filmed but must be introduced into a moving image after filming. It is a not-film element that is needed to take film out of its McLuhan phase ${ }^{3}$ into the essential phase.

The link is called pointer in programming languages. There, a variable must be of pointer type if its values are to be addresses of some location in the computer's storage space. On the lowest level of programming, those addresses are readily available. On higher levels of programming, the machine must be protected against humans (in their roles of programmer or user). The link is the protective means. A fantastic invention connecting abstract algorithmic descriptions with locations in storage whose contents algorithms may manipulate.

As media consumers we usually do not pay much attention to the cuts in film and their choreography. As media consumers we are also only occasionally becoming aware of the links that make themselves known as light on screen that can be clicked. It can be clicked, as we have come to say, because it looks like that. We know it fairly well. But we do not often know what such an utterance is standing for. What it is standing for is hidden far away from us in the mythology of the postmodern. There it has become so easy to intelligently speculate about intelligence of machines whose functioning we do not have a clue of, and we don't need a clue, for it is smoothly functioning, is it not?

Everybody, of course, knows that the footnote mechanism is the archaic form of the link. What has happened to the footnote in all its childish innocence is the machinisation ${ }^{4}$ of the footnote mechanism. The reader of a book had to perform the mental act of interpreting a small number, lifted up a bit, next to the end of some word on a page of text as an invitation to him to look out for a text component down by the page bottom or, perhaps, on the next page, or even, quite inconvenient for the human, but easy for the computer program, at the end of the main text. An action of the mind was needed to cleverly design and interpret footnotes. Maybe, this action of the mind was the reason why engineers did not like footnotes. Now they have become links and thus machinic. 


\section{Third}

Nothing exists in computable form that we, the humans, would not before have done in a kind of routine fashion. And at this point, I cannot help it, an anecdote pops up into my mind that I must interrupt and tell you, my dear reader, as your reward for having stayed with me up to here. The anecdote is a true encounter, and it is probably the best I ever had in my life.

It is the $5^{\text {th }}$ of February, 1965. We are assembling in the seminar rooms of the Institute of Philosophy and Theory of Knowledge at University of Stuttgart, West-Germany. Max Bense's institute whose rooms he uses for seminars like the Ästhetisches Kolloquium, but also for exhibitions of art. Experimental art that is, concrete art and concrete poetry. As an intellectual in Stuttgart in the 1960s you go there whenever an occasion comes up. You are there with others of your kind. The Weltgeist of rationality is with us. We feel it and we know it.

The invitation for the opening of the show this late afternoon had announced "Computergrafik." The artist is Georg Nees. In 1965, nobody has a clue what that could be. Something with computers, okay. But nobody knows what a computer is. In 1965, there is no such thing as a scientific discipline of Informatik on the European continent.

A small number of not very large drawings on the walls, geometric, in parts rather complex. Interesting structures. Some indications of tension between micro- and macro-aesthetics. Bense speaks. A new brochure is for sale, Bense and Nees': Computergrafik. A short essay by Bense, Projekte generativer Ästhetik. A manifesto of computer art. After Bense, Nees explains how he makes a program do line-drawings. Polite applause.

A group of artists and designers is present from the local school of art. One of them addresses Georg Nees: "Quite interesting, young man, what you say about drawing using a computer. But tell me, can you make your machine draw as I do it"? Nees thinks for a moment. Then: "Oh yes, of course I can-if you tell me how you do it." The artists are shocked and leave in disgust. They are shocked by the answer's frivolity. They don't understand how ingenious the answer is. How could they?

Nees' answer was ingenious because, in a nutshell, he gave the answer to all questions concerning computing and the rest of the world, Artificial Intelligence in particular. Only that, we learn. And really, at most, that can become a program which we can make explicit, that we can describe precisely, and even more: for which we can develop an algorithm, i.e. a computable function. In all likelihood, we must adjust, reduce, and approximate the task from its familiar human form when we intend to model it for computer, i.e. algorithmic treat- 
ment. First step is always to make it explicit. A painter does not know how she paints. She does it.

These are the three reductions from intuitively doing something to having a program do something different but close to the first or, at least, similar: reduce the activity to a description (the semiotic reduction); reduce the semiotic activity to its syntactics, i.e. get rid of all context; reduce the syntactic activity to a computable one (the algorithmic reduction).

\section{Fourth}

Digital media appear for the first time in the spring of 1963. To say this is, of course, wrong. Nevertheless, I do so because I want to point out an activity that must, in hindsight, be interpreted, as "Oh, look, that's digital media." What happened in early 1963 ?

At the Spring Joint Computer Conference 1963 in Detroit, a young man of age twenty-five presented his Ph.D. thesis, submitted to MIT earlier that year. The young man was Ivan E. Sutherland and the title of his talk and thesis was: "Sketchpad. A man-machine graphical communication system." The thesis begins: "Heretofore, most interaction between man and computer has been slowed down by the need to reduce all communications to written statements that can be typed; in the past, we have been writing letters to rather than conferring with our computers" (17). Sutherland's work consists of a number of great algorithms and of enormously expanding data structures. For the state of technology, those structures were too large to be of great practical influence. But the conceptual inventions were so fantastic, that even twenty years later not all of them had become everyday knowledge.

From our perspective, it is obvious that Sutherland sees a graphic work on a computer monitor as a piece of machine manipulation and its display for human perception. He uses the surface and subface existence of computer things, as I call it. Things on a computer must appear perceivably (e.g., visible) for the human; they must also exist hidden but capable to be manipulated by the machine. Their ontological status is of double existence. Surface and subface that cannot be separated. This is what has come anew into the world, and the aesthetics of those new things happen between their two forms of existence: we prepare subfaces that the machine is using for its computations so that an audience can perceive what is happening as they watch.

All algorithmic art is about algorithmic signs, and algorithmic signs are surface and subface. This is simple but essential for all of computing, i.e. also for any literature and language research and art. To write a program for generating a single piece is crazy. Programs should always stand for infinite sets. They want 
to run forever in order to demonstrate to us all their potentials. The existence of surfaces should thus be of a dynamic kind, whatever this would turn out to be in an actual case. Early algorithmic art came in pieces to be put up on a wall, and people could buy them. That was McLuhanesk: "Look, I am not more than you could expect; however, I am made by a computer!"

But now we are more than fifty years later. Keep this in mind.

\section{Notes}

1 He said so, using his pseudonym of Paul Mongré (Mongré 7). He was afraid his fellow mathematicians would no longer take him seriously if he wrote about a semiotic animal and other such things. He did so after reading Nietzsche.

2 A remark seems in place here to justify why I use Charles S. Peirce as my source, and not Ferdinand de Saussure. Very briefly, Saussurean semiotics is based on a dyadic concept of the sign, Peircean semiotics is based on a triadic one. Saussure studies language signs, Peirce more generally every kind of sign. In the triad of the sign, conventional and situational (or cultural and individual) interpretations can be distinguished. Finally, the recursive character of Peircean signs makes them the stuff of postmodern thinking.

3 The "McLuhan phase" I call when a medium is still its own and main message.

4 The word machinisation is used here, and not mechanisation, because from a historic perspective, the second is wrong, and the first is correct. "Mechanisation" is one form only of machinisation. It is the historic form (in times of manufactoring) of transferring (parts of a human operation or activity onto a machine or tool or other instrument. Computers and mechanics belong to different historic periods.

\section{Works Cited}

Bense, Max, and Georg Nees. "computergrafik." rot 19. Elisabeth Walther, 1965. 4 Sept. 2017 <http://dada.compart-bremen.de/item/publication/$362>$.

Mongré, Paul. Sant'Illario. Gedanken aus der Landschaft Zarathustras. Leipzig: C.G. Naumann, 1897. 
Peirce, Charles S. The Essential Peirce: Selected Philosophical Writings, Vol. 2. Edited by the Peirce Edition Project. Indianapolis: Indiana University Press, 1998.

Saussure, Ferdinand de. Course in General Linguistics. New York: McGraw-Hill, 1966.

Sutherland, Ivan E. "Sketchpad. A man-machine graphical communication system.” AFIPS Conference Proceedings, vol. 23 (1963): pp. 232-238. 



\section{Contributors}

Sandy Baldwin is an Associate Professor of English and Program Director of Digital Humanities and Social Sciences at the Rochester Institute of Technology. He is the author or editor of more than ten books. His monograph The Internet Unconscious (Bloomsbury) won the 2015 N. Katherine Hayles prize for the best work of criticism in the field of electronic literature. He is managing editor of electronic book review, one of the oldest all online peer reviewed journals, and editor of two academic book series on electronic literature: Computing Literature (WVU) and Electronic Literature (Bloomsbury). He has extensive involvement with the Electronic Literature Organization. His current artwork is exhibited widely and explores performative agit-prop theater interventions in multiplayer video games.

Dene Grigar is Professor and Director of The Creative Media \& Digital Culture Program at Washington State University Vancouver whose research focuses on the creation, curation, preservation, and criticism of electronic literature, specifically building multimedial environments and experiences for live performance, installations, and curated spaces; desktop computers; and mobile media devices. She has authored 14 media works such as "Curlew" (2014), "A Villager's Tale" (2011), the "24-Hour Micro E-Lit Project" (2009), "When Ghosts Will Die" (2008), and "Fallow Field: A Story in Two Parts" (2005), as well as 53 scholarly articles. She also curates electronic literature and media art, mounting shows at the Library of Congress and for the Symposium on Electronic Art (ISEA) and the Modern Language Association (MLA), among other venues. With Stuart Moulthrop (University of Wisconsin Milwaukee), she is the recipient of a 2013 NEH Start Up grant to support the digital preservation of early electronic literature, a project that culminated in an open-source, multimedia book entitled Pathfinders (2015) and a book of media art criticism, entitled Traversals: The Use of Preservation for Early Electronic Writing (2017) for The MIT Press. She is President of the Electronic Literature Organization and Associate Editor of Leonardo Reviews and Literary Studies in the Digital Age. In 2017, she was awarded the Louis E. and Stella G. Buchanan Distinguished Professorship by Washington State University.

Otso Huopaniemi is a performance-maker, artistic researcher, and teacher who has shown work internationally including PS122 (NYC); 3LD Art \& Technology Center (NYC); Kiasma Theater (Helsinki); ZKM Center for Art and Media (Karlsruhe); Theaterdiscounter (Berlin). Currently, Otso is completing a doctor of arts degree (DA) at the University of Helsinki, Theatre Academy. His practice-based research looks into how the so-called digital revolution has altered 
performative writing and reading practices. In particular, Otso's research examines and proposes methods of writing with, alongside and through algorithmic (machine) translation. Otso has received numerous grants for artistic projects and academic studies in Finland, the US, and in Germany. He has collaborated with various artists and companies in all three countries and taught writing and dramaturgy at Uniarts Helsinki on a part-time basis since 2006. Also, Otso has given workshops in live writing at the ELO2015 Conference in Bergen and at ZKM Karlsruhe.

María Goicoechea de Jorge teaches English and US-American literature at the Complutense University of Madrid. She has studied at the University of East Anglia (UEA), UK, and at the University of Maryland Baltimore County (UMBC), USA, where she obtained a Master's Degree in Intercultural Communication. Her doctoral dissertation is entitled The Reader in Cyberspace: A Literary Ethnography of Cyberculture (2004). Her research interests include literary theory, ethnography, and cyberculture. Goicoechea's publications include the edited volume Alicia a través de la pantalla. Lecturas literarias en el siglo XXI (2013), the book chapters "In Search of a Female Technological Identity in Electronic Literature: Dancing with the Spanish Domestic Cyborg," in \#WomenTechLit (with Laura Sánchez, 2017); “The Reader in Cyberspace: In Search of Digital Literature in Spain" and "Teaching Digital Literature in Spain: Reading Strategies for the Digital Text," in Reading Moving Letters: Digital Literature in Research and Teaching (2010), and the articles "The Mechanic Ear: North American Sound Poetry in the Digital Age," Complutense Journal of English Studies (with Víctor Salceda, 2015), "Literary Reading Rituals and Practices on New Interfaces," Literary and Linguistic Computing (with Amelia Sanz, 2012). Currently, she is a teacher of the English Department at the University Complutense of Madrid (UCM) and Principal Investigator of the project eLITE-CM in Electronic Literary Edition. Prof. Goicoechea is a member of LEETHI Research Group (UCM), and of HERMENEIA (Universitat de Barcelona), two interdisciplinary research groups dedicated to the study of literature and computers.

Daniela Côrtes Maduro is a post-doctoral researcher, teacher, editor and curator. After writing a master thesis titled A Creature Made of Bits: Illusion and Materiality in the Hyperfiction Patchwork Girl by Shelley Jackson, Daniela Côrtes Maduro was awarded an individual doctoral grant by the Portuguese Foundation for Science and Technology (FCT) to complete her PhD in Materialities of Literature at the University Coimbra, Portugal. Her research interests lie in the study of science fiction; storytelling and oral tradition; experimental and electronic literature; narratology; literary analysis; archive and curation of literature. She is an associate researcher of the Consortium on Electronic Literature and works at 
the Universität Bremen (Germany), where her project, "Shapeshifting Texts: Keeping Track of Electronic Literature," is being developed with the support of the University of Bremen and the Marie Skłodowska-Curie Actions Research Fellowship Programme.

María Mencía is a multimedia artist, practice-based researcher and lectures at Kingston University, London, UK. She is an executive member of the Electronic Literature Organization. Her artistic research explores hybrid textualities at the intersection of poetics, art and digital technologies with an interest in social and political issues. It has been exhibited worldwide, presented at numerous conferences and published in the Electronic Literature Collection, Volume 1 and the ELMCIP Anthology of European Electronic Literature. She has also curated and edited e-literature shows and journals. She is interested in collaboration and has been the recipient of various fellowship grants to conduct research at the RMIT in Melbourne, NYU and at the University of Sydney. Her current publications include Gateway to the World: Data Visualisation Poetics in GRAMMA: Journal of Theory and Criticism, Digital Literary Production and the Humanities and she is the editor of \# WomenTechLit, published by West Virginia UP which was awarded second prize for the N. Katherine Hayles Award for Criticism by the ELO 2017.

Anna Nacher has been working, since 2006, at the Institute of Audiovisual Arts, Jagiellonian University, Kraków, Poland. Her research interests include new media art, cyberculture, sound studies, digital textuality and e-literature. She currently pursues a 3-year long research project on the post-digital imagery ("The aesthetics of post-digital imagery: between new materialism and objectoriented philosophy," 2017-2019, grant from the Polish National Science Centre). The author of three books in Polish, the newest one published in 2016 focuses on the locative media. A reworked version of one chapter has been published as "Internet of things and automation of imaging: beyond representationalism" in "communication+1," vol. 5 (2016). Other articles include: Mashup as paratextual practice: beyond digital objects (in the age of networked media) in N. Desrochers, D. Apollon (eds.), Examining Paratextual Theory and its Application in Digital Culture, Information Science Reference, IGI Global 2014; Stelarc and His Experiential Machinarium [in:] R. W. Kluszczyński (ed.), STELARC: Meat, Metal \& Code / Contestable Chimeras, Gdańsk 2014. She has participated in several international conferences, including "Other Codes" The First Galway Digital Cultures Initiative Conference (National University of Ireland in Galway 2017), "Transimage—The Transdisciplinary Imagining Conference" (Plymouth University 2016), International Conference on Digital Media and Textuality (University of Bremen 2016), Electronic Literature Organization's 
Conferences (in 2013, 2015 and 2017) and NECS Conference (2015). More information in: <http:// nytuan.wordpress.com>.

Frieder Nake belongs to the founding fathers of (algorithmic) computer art. He produced his first works in 1963. He first exhibited his drawings at Galerie Wendelin Niedlich in Stuttgart in November 1965. His early work was influenced by Max Bense's Information Aesthetics. Until 1969, he went through a succession of increasingly complex programs, using in succession machine language, Algol, FORTRAN, and PL/I. His main work phases are identified by the collection of programs, compArt ER56 (1963-65), Walk-through-raster (1966), Matrix multiplication (1967-1968), Generative aesthetics I (1968-1969). He declared not to continue producing computer art in 1971 when he published the note, There should be no computer art in page, the Bulletin of the Computer Arts Society. His reasons were mainly of political origin: He did not see how he could actively contribute to computer art and, at the same time, be a political activist against capitalism. He resumed publishing on computer art in the mid 1980s with the breakdown of the radical left. With the start in 1999 of project "compArt: a space for computer art," Nake returned to his roots as a theoretician, writer, creator, and teacher in the domain of digital art and beyond. He is head of "compArt: Center of Excellence Digital Art." After three years in Toronto and Vancouver, Frieder Nake has been a full professor of computer science at the University of Bremen, Germany, since 1972. Since 2005, he has also been teaching at the University of the Arts, Bremen. His teaching and research activities are in computer graphics, digital media, computer art, design of interactive systems, computational semiotics, and general theory of computing. Nake was represented at all important international exhibitions on computer art. He has published in all the areas mentioned above, with a preference for computer-generated images. "The drawings were not very exciting. But the 'principle' was!” (Nake 2004/2005).

María Teresa Vilariño Picos is Associate Professor at the University of Santiago de Compostela. She holds a PhD in Literary Theory and Comparative Literature from the University of Santiago de Compostela. She has taught courses on cyberliterature and digital culture, and on film and literature. She was a visiting professor at several universities, including Queens (Canada), Amsterdam, Kiel, Toulouse, and Trento. She is the author of several books, including Literatura e Cinema (2002) and Teoría del hipertexto: La literatura en la era electrónica (2006). Since 2003, her research has focused on the relationship between literature and new technologies, including the poetics of video games and the relations between the literary system and digital culture. She is a member of the project "proxecto le.es: literatura electrónica en españa." 
Carlos Reis is a professor at the University of Coimbra whose areas of specialization are $19^{\text {th }}$ and $20^{\text {th }}$ century Portuguese literature, with an emphasis on the Realist writer, Eça de Queirós (1845-1900). He is the author of over twenty monographs and has taught at several universities outside of Portugal throughout Europe and in Brazil and the United States. He was awarded a doctorate bonoris causa by the Catholic University PUC-Rio Grande do Sul in 2000. He is the director of the Critical Edition of the Works of Eça de Queirós (sixteen volumes published to-date) and the Critical History of Portuguese Literature (nine volumes). He was the director of the Portuguese National Library (1998-2002), Chancellor of the Universidade Aberta (2006-2011), and president of the International Association of Lusitanists (2010-2011) and the European Association of Distance Teaching Universities (1998-2000). He is a corresponding member of the Spanish Royal Academy and the Scientific Academy of Lisbon. Currently, he coordinates the Center of Portuguese Literature at the University of Coimbra, Portugal.

Jörgen Schäfer is an assistant professor in German and Comparative Literature at the University of Siegen (Germany). He is currently working on a monograph on electronic literature. He also is one of the project leaders of the research group Literature in Electronic Media (LEM) and of the Archive of German Electronic Literature (ADEL) and also a member of the research initiative Transformations of the Popular. He is the co-editor of Handbuch Medien der Literatur (de Gruyter, 2013), Beyond the Screen: Transformations of Literary Structures, Genres and Interfaces (Transcript, 2010), Reading Moving Letters: Digital Literature in Research and Teaching (Transcript, 2010), The Aesthetics of Net Literature: Writing, Reading and Playing in Programmable Media (Transcript, 2007), Wissensprozesse in der Netzwerkgesellschaft (Transcript, 2004) and Pop-Literatur (Text + Kritik, 2003) as well as the author of Pop-Literatur: Rolf Dieter Brinkmann und das Verbälnis zur Populärkultur in der Literatur der sechziger Jahre (Metzler, 1998) and Exquisite Dada: A Comprehensive Bibliography (G.K. Hall, 2005). He also is the Series Editor of International Texts in Critical Media Aesthetics (Bloomsbury Academic) and a founding member of both the Consortium on Electronic Literature (CELL) and the European Network of Digital Literature (DDDL).

Devon Schiller is a Member of the Academic Staff in the Department of Image Science at Danube University Krems, Austria. Originally from Cambridge, Massachusetts, and today living in Vienna, Austria, Schiller holds a BFA in art history and studio painting from the Kansas City Art Institute, as well as an MA in MediaArtHistories from Danube University, and is an alumnus of the Studio Arts College International in Florence, Italy. Currently, he pursues his doctorate in semiotics. From a theoretical framework of cognitive semiotics, 
emotions histories, and image science, Schiller's scholarship problematizes the intermedial and multimodal genealogies between physiognomy, the science of facial expression, and digital biometrics. He probes how artists, scientists, and technologists use media prosthetics to interpret from the outside physiological behavior of the face to the psychological phenomena inside of an individual; the diagrammatology of such methodologies; and how these rhetorical artifacts can inform the display rules, social scripting, and truth claims about emotions experience in society. Schiller is also an internationally exhibited digital artist.

Gabriel Tremblay-Gaudette is a scholar in the fields of digital literature, semiotics, comics studies and video games. From 2016 to 2017, he completed a postdoctoral research grant at West Virginia University and Rochester Institute of Technology, and will be a post-doctoral researcher at LABEX H2H Arts in Paris 8 for the year 2018. Head editor of the Pop en Stock series at Éditions de Ta mère, he was formerly the Media Coordination Assistant at the Laboratoire NT2. He is also a member of the editorial board of bleuOrange, the only French electronic literature journal, and is the editor for the "Image + Narrative" thread of Electronic Book Review.

Mia Zamora is an Associate Professor of English, Director of the MA in Writing Studies, Director of the Kean University Writing Project, and former Coordinator of the World Literature Program at Kean University in Union, NJ. Zamora is a scholar of Electronic Literature (literary works that originate in a digital environment and require digital computation to read). She is a digital humanist and she writes about how digital technologies are transforming education in the $21^{\text {st }}$ century. Mia Zamora has won the Kean University Presidential Excellence Award for Teaching, she is a Fulbright scholar, and she is a past President of the New Jersey College English Association. Her research interests in Comparative Literature, Postcolonial Literature, nationalism, and cultural studies are reflected in her book entitled Nation, Race, History in Asian American Literature: Remembering the Body (2008) and her Postcolonial Studies Book Series. Dr. Zamora completed her M.A. and Ph.D. in Comparative Literature at the University of Wisconsin-Madison, where she was a fellow of the Center for Southeast Asian Studies. 


\section{Medienwissenschaft}

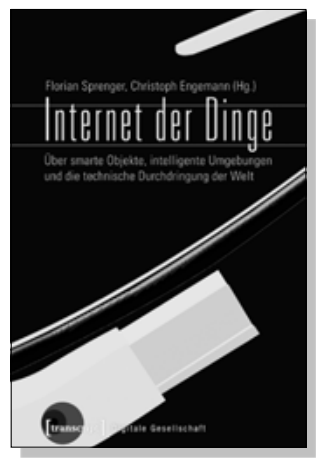

Florian Sprenger, Christoph Engemann (Hg.)

\section{Internet der Dinge}

Über smarte Objekte, intelligente Umgebungen und die technische Durchdringung der Welt

2015, 400 S., kart., zahlr. Abb.

29,99€ (DE), 978-3-8376-3046-6

E-Book

PDF: $26,99 €(D E)$, ISBN 978-3-8394-3046-0

EPUB: $26,99 €$ (DE), ISBN 978-3-7328-3046-6

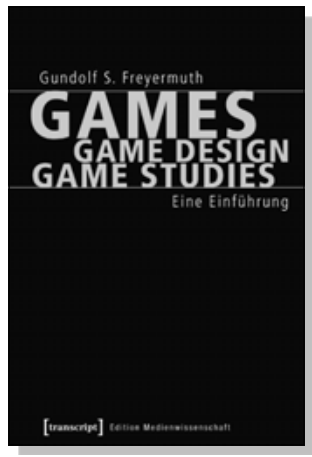

Gundolf S. Freyermuth

Games | Game Design | Game Studies

Eine Einführung

2015, 280 S., kart.

$17,99 €(D E), 978-3-8376-2982-8$

E-Book

PDF: $15,99 €(D E)$, ISBN 978-3-8394-2982-2

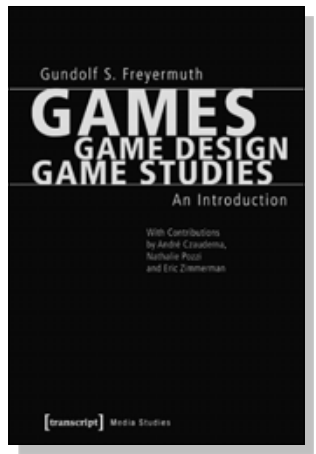

Gundolf S. Freyermuth

Games I Game Design | Game Studies

An Introduction

(With Contributions by André Czauderna, Nathalie Pozzi and Eric Zimmerman)

2015, 296 p., pb.

$19,99 €(D E), 978-3-8376-2983-5$

E-Book

PDF: 17,99 € (DE), ISBN 978-3-8394-2983-9 


\section{Medienwissenschaft}

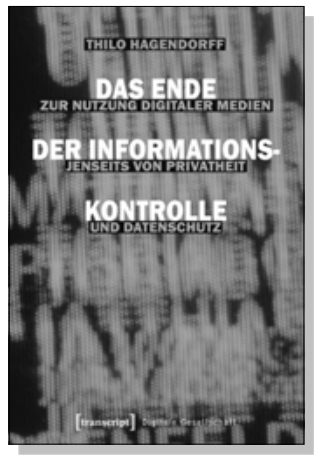

Thilo Hagendorff

Das Ende der Informationskontrolle

Zur Nutzung digitaler Medien jenseits

von Privatheit und Datenschutz

Januar 2017, 264 S., kart.

$29,99 €(D E), 978-3-8376-3777-9$

E-Book

PDF: $26,99 €(D E)$, ISBN 978-3-8394-3777-3

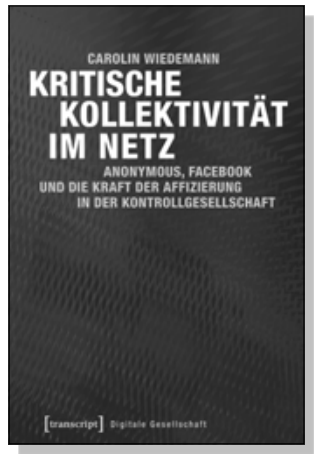

Carolin Wiedemann

\section{Kritische Kollektivität im Netz}

Anonymous, Facebook und die Kraft der Affizierung in der Kontrollgesellschaft

2016, 280 S., kart.

29,99€ (DE), 978-3-8376-3403-7

E-Book

PDF: $26,99 €(D E)$, ISBN 978-3-8394-3403-1

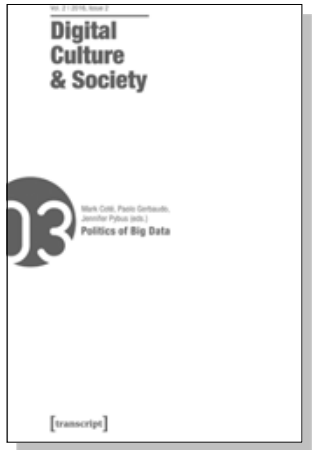

Ramón Reichert, Annika Richterich,

Pablo Abend, Mathias Fuchs, Karin Wenz (eds.)

Digital Culture \& Society (DCS)

Vol. 2, Issue 2/2016 - Politics of Big Data

2016, 154 p., pb.

29,99€ (DE), 978-3-8376-3211-8

E-Book

PDF: $29,99 €$ (DE), ISBN 978-3-8394-3211-2 